\title{
Predição de mudanças conjuntas de artefatos de software com base em informações contextuais
}

\author{
Igor Scaliante Wiese \\ TEXTO SUBMETIDO \\ PARA O
}

Instituto DE MATEMÁTiCA E ESTATÍSTICA DA

UNIVERSIDADE DE SÃO PAULO

PARA

GRAU DE DOUTOR EM CIÊNCIA

\section{Programa: Ciência da Computação \\ Orientador: Professor Dr. Marco Aurélio Gerosa}

Esta pesquisa foi apoiada pela Fundação Araucária (projeto DINTER UTFPR/IMEUSP), CAPES (processo BEX 2039-13-3), NAWEB, NAPSoL-PRP-USP, FAPESP e CNPq (Universal 461101/2014-9) 


\section{Predição de mudanças conjuntas de artefatos de software com base em informações contextuais}

Esta versão da tese contém as alterações sugeridas pelos membros do comitê durante a defesa pública da versão original deste trabalho, que ocorreu em 18 de março de 2016. Uma cópia da versão original está disponível no Instituto de Matemática e Estatística (IME) - Universidade de São Paulo (USP)

Membros do Comitê:

- Prof. Dr. Marco Aurélio Gerosa (orientador) - IME-USP

- Prof. Dr. Auri Marcelo Rizzo Vincenzi - UFSCAR

- Prof. Dr. Carlos Denner Santos Junior - UnB

- Prof. Dr. Marco Túlio de Oliveira Valente - UFMG

- Prof. Dr. Roberto Hirata Júnior - IME-USP 


\section{Agradecimentos}

Inicio meus agradecimentos pelo meu orientador Marco Aurélio Gerosa: os conselhos dados, as experiências compartilhadas, a paciência, as cobranças, a sua presença e acima de tudo a confiança em acreditar que eu seria capaz, foram fundamentais durante esse percurso, me ensinando a ser um pesquisador. Você me deu muitas oportunidades de aprendizado. A convivência contigo, a nossa amizade, não me tornou somente um professor/pesquisador melhor, mas tenho certeza que me transformou em uma pessoa melhor (na essência, não será esse é o papel de um grande pesquisador - "transformar pessoas"?). Em você eu me espelharei para continuar os meus próximos passos.

Agradeço aos vários pesquisadores que se tornaram amigos, na sequência anunciados, que muito contribuíram durante a realização deste doutorado. A David F. Redmiles, que me recebeu e acolheu na Universidade da Califórnia: foram seis meses indescritíveis para mim e minha família, nos quais pude aprender muito com suas orientações e sugestões. A Christoph Treude que dividiu comigo seus inúmeros conhecimentos.

Sou grato a todos os membros do comitê de qualificação e do comitê examinador final desta tese. Foi um prazer receber orientação e comentários de um grupo de pesquisadores de destaque: Carlos Denner, Marco Túlio Valente, Auri Vincenzi e Roberto Hirata. Estendo esse reconhecimento a todos os revisores anônimos da comunidade científica que deram um feedback importante para os artigos científicos submetidos nas diversas conferências.

Este doutorado não seria possível sem o projeto interinstitucional de Doutorado (DINTER), financiado pela Fundação Araucária, e por isso, lembro aqui dos professores do IME/USP Fabio Kon e Carlos Eduardo Ferreira que não mediram esforços para que isto se efetivasse. Nesse mesmo contexto, reconheço e aplaudo os trabalhos de Reginaldo Ré, que ajudou e coordenou a implantação do DINTER como membro da UTFPR e, em especial, por colaborar com a minha pesquisa. Amplio esta saudação a todos os professores do IME que apoiaram e participaram desse projeto, bem como, a Lucileide R. G. Tadei, secretária de CCP/CC que foi sempre muito prestativa. Incluo ainda neste tópico todos os integrantes do Departamento de Computação, que de uma forma ou de outra, apoiaram a realização do DINTER.

Obrigado a todos os colegas do nosso grupo de pesquisa LAPESSC e do CCSL, principalmente Igor Steinmacher, Gustavo Ansaldi e Maurício Aniche pelo apoio, ajuda e coautoria em diversos trabalhos que realizei ao longo dos últimos 5 anos. Somo à minha caminhada, todos os colegas moradores do apartamento 141 (SP): André Kawamoto, André Schwerz, Frank Helbert, Igor Steinmacher, Ivanilton Polato, Lucio Valentin, Luiz Arthur Feitosa, Marcos Silvano, Rafael Liberato, Rodrigo Campiolo, Rogério Gonçalves e Wellington Previero. Aos amigos, Rodrigo Kuroda e Reginaldo Ré, pelo apoio, amizade e por acreditarem nesta pesquisa, estando dispostos a dar prosseguimento ao trabalho realizado nesta tese. Evidencio ainda, os desenvolvedores da Fundação Apache que interagiram conosco e deram sugestões valiosas.

Durante a realização desta tese, recebi apoio financeiro de diferentes órgãos de fomento: Fundação Araucária (DINTER UTFPR / IME-USP), a CAPES pela bolsa no CsF (BEX 2039-133), NAWEB, NAPSoL-PRP-USP, FAPESP e CNPq (Universal 461101/2014-9). A todas elas, o nosso reconhecimento pelo investimento na produção do conhecimento tão necessário aos avanços que se busca constantemente.

Finalmente, lembro e agradeço imensamente, os esforços da minha família que se juntaram aos meus: a minha esposa, Andreia Faxina Wiese, incentivadora, anjo da guarda, porto seguro, que adiou sonhos para a realização dos meus; a minha linda e amada filha Maria Clara Faxina Wiese, que nasceu entre a vontade de realizar o doutorado, scripts de $\mathrm{R}$ e o ponto final desta tese e que nem sempre entendia minhas ausências, embora não duvidasse do meu imenso amor por ela; aos meus pais Alceu Wiese e Cleusa Fatima Scaliante Wiese, que desde o meu nascimento se fazem presente em minha vida de todas as maneiras, por vezes renunciando a si mesmos, em favor da união familiar, do amor incondicional. Vocês são a razão da minha vida, o amor maior. Para vocês 
dedico esta tese, em nome da minha gratidão e do meu amor. A Deus, pela força motivadora que não me abandou ao longo desses anos de intenso estudo. 


\section{Abstract}

WIESE, I. S. Predicting co-changes of software artifacts based on contextual information. 2016. 112 f. Tese (Doutorado) - Instituto de Matemática e Estatística, Universidade de São Paulo, São Paulo, 2016.

Co-change prediction aims to make developers aware of which artifacts may change together with the artifact they are working on. In the past, researchers relied on structural analysis to build prediction models. More recently, hybrid approaches relying on historical information and textual analysis have been proposed. Despite the advances in the area, software developers still do not use these approaches widely, presumably because of the number of false recommendations. The hypothesis of this thesis is that contextual information of software changes collected from issues, developers' communication, and commit metadata describe the circumstances and conditions under which a co-change occurs and this is useful to predict co-changes. The aim of this thesis is to use contextual information to build co-change prediction models improving the overall accuracy, especially decreasing the amount of false recommendations. We built predictive models specific for each pair of files using contextual information and the Random Forest machine learning algorithm. The approach was evaluated in 129 versions of 10 open source projects from the Apache Software Foundation. We compared our approach to a baseline model based on association rules, which is often used in the literature. We evaluated the performance of the prediction models, investigating the influence of data aggregation to build training and test sets, as well as the identification of the most relevant contextual information. The results indicate that models based on contextual information can correctly predict $88 \%$ of co-change instances, against $19 \%$ achieved by the association rules model. This indicates that models based on contextual information can be 3 times more accurate. Models created with contextual information collected in each software version were more accurate than models built from an arbitrary amount of contextual information collected from more than one version. The most important pieces of contextual information to build the prediction models were: number of lines of code added or modified, number of lines of code removed, code churn, number of words in the discussion and description of a task, number of comments, and role of developers in the discussion (measured by the closeness value obtained from the communication social network). We asked project developers about the relevance of the results obtained by the prediction models based on contextual information. According to them, the results can help new developers to the project, since these developers have no knowledge about the architecture and are usually not familiar with the artifacts' history. Thus, our results indicate that prediction models based on the contextual information are useful to support developers during the maintenance and evolution activities.

Keywords: co-changes, logical coupling, contextual information, mining software repository, software metrics, prediction models., change propagation, change impact analysis. 


\section{Resumo}

WIESE, I. S. Predição de mudanças conjuntas de artefatos de software com base em informações contextuais. 2016. 112 f. Tese (Doutorado) - Instituto de Matemática e Estatística, Universidade de São Paulo, São Paulo, 2016.

O uso de abordagens de predição de mudanças conjuntas auxilia os desenvolvedores a encontrar artefatos que mudam conjuntamente em uma tarefa. No passado, pesquisadores utilizaram análise estrutural para construir modelos de predição. Mais recentemente, têm sido propostas abordagens que utilizam informações históricas e análise textual do código fonte. Apesar dos avanços obtidos, os desenvolvedores de software ainda não usam essas abordagens amplamente, presumidamente por conta do número de falsos positivos. A hipótese desta tese é que informações contextuais obtidas das tarefas, da comunicação dos desenvolvedores e das mudanças dos artefatos descrevem as circunstâncias e condições em que as mudanças conjuntas ocorrem e podem ser utilizadas para realizar a predição de mudanças conjuntas. O objetivo desta tese consiste em avaliar se o uso de informações contextuais melhora a predição de mudanças conjuntas entre dois arquivos em relação às regras de associação, que é uma estratégia frequentemente usada na literatura. Foram construídos modelos de predição específicos para cada par de arquivos, utilizando as informações contextuais em conjunto com o algoritmo de aprendizagem de máquina random forest. Os modelos de predição foram avaliados em 129 versões de 10 projetos de código aberto da Apache Software Foundation. Os resultados obtidos foram comparados com um modelo baseado em regras de associação. Além de avaliar o desempenho dos modelos de predição também foram investigadas a influência do modo de agrupamento dos dados para construção dos conjuntos de treinamento e teste e a relevância das informações contextuais. Os resultados indicam que os modelos baseados em informações contextuais predizem $88 \%$ das mudanças corretamente, contra $19 \%$ do modelo de regras de associação, indicando uma precisão 3 vezes maior. Os modelos criados com informações contextuais coletadas em cada versão do software apresentaram maior precisão que modelos construídos a partir de um conjunto arbitrário de tarefas. As informações contextuais mais relevantes foram: o número de linhas adicionadas ou modificadas, número de linhas removidas, code churn, que representa a soma das linhas adicionadas, modificadas e removidas durante um commit, número de palavras na descrição da tarefa, número de comentários e papel dos desenvolvedores na discussão, medido pelo valor do índice de intermediação (betweenness) da rede social de comunicação. Os desenvolvedores dos projetos foram consultados para avaliar a importância dos modelos de predição baseados em informações contextuais. Segundo esses desenvolvedores, os resultados obtidos ajudam desenvolvedores novatos no projeto, pois não têm conhecimento da arquitetura e normalmente não estão familiarizados com as mudanças dos artefatos durante a evolução do projeto. Modelos de predição baseados em informações contextuais a partir de mudanças de software são relativamente precisos e, consequentemente, podem ser usados para apoiar os desenvolvedores durante a realização de atividades de manutenção e evolução de software.

Palavras chave: mudanças conjuntas, propagação de mudanças, acoplamento lógico, acoplamento de mudança, contexto, informação contextual, informações sóciotécnicas, mineração de repositórios de software, métricas de software, modelos de predição, impacto de mudanças. 


\section{Sumário}

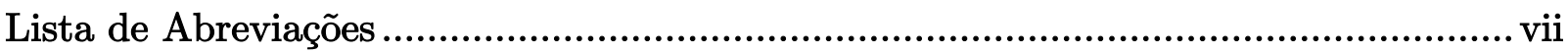

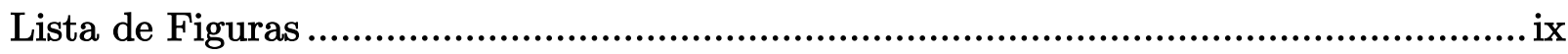

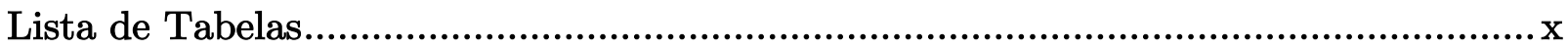

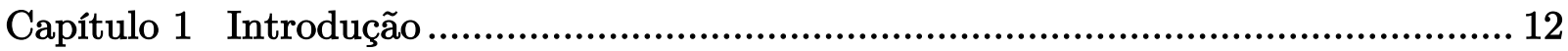

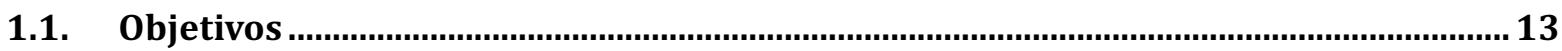

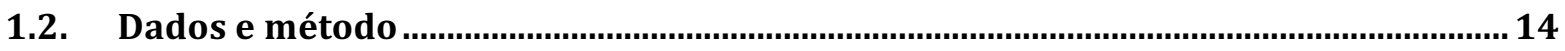

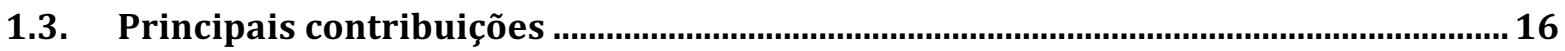

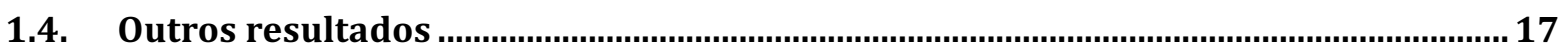

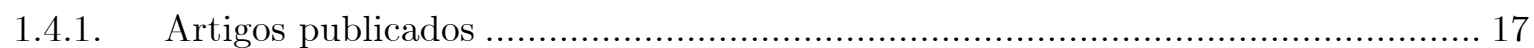

1.4.2. Orientações de trabalho de conclusão de curso ............................................... 18

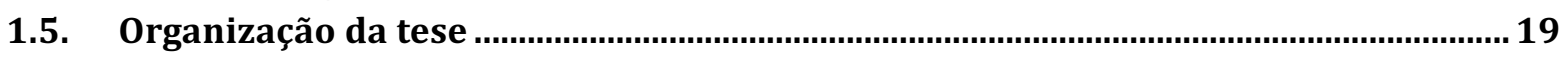

Capítulo 2 Fundamentação teórica e trabalhos relacionados ................................. 20

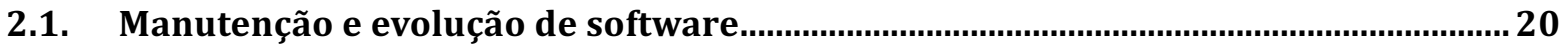

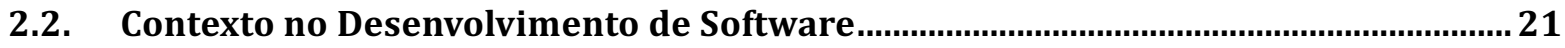

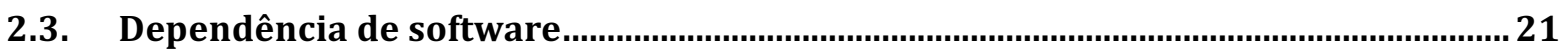

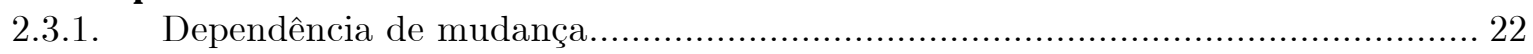

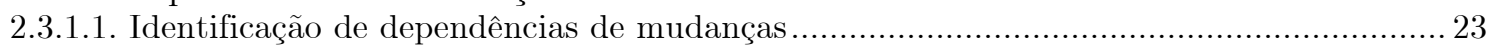

2.3.1.2. Técnicas para determinar dependências de mudança relevantes ...................................... 24

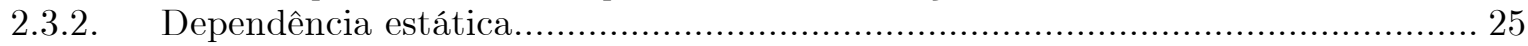

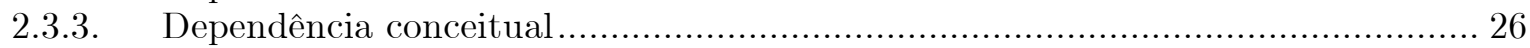

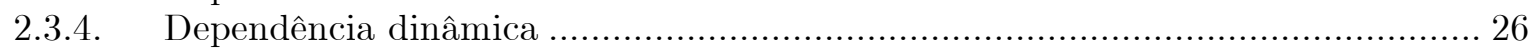

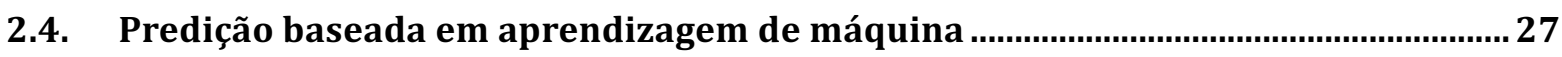

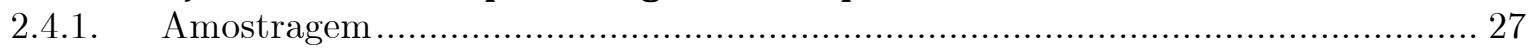

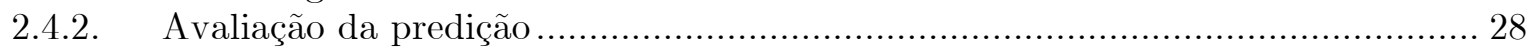

2.5. Trabalhos relacionados de predição de mudanças conjuntas ………........................... 29

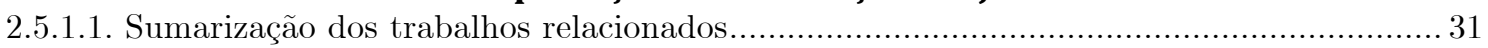

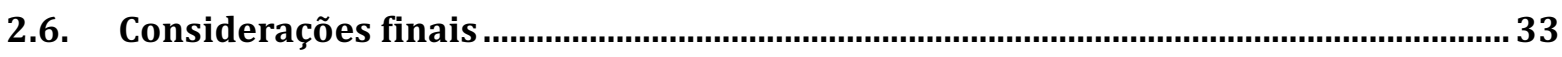

Capítulo 3 Informações contextuais do desenvolvimento de software ....................... 34

3.1. Mapeamento sistemático sobre métricas sociais usadas em modelos de predição

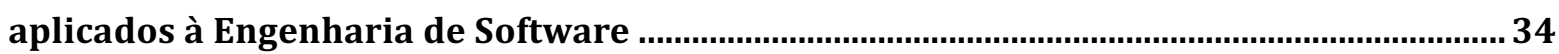

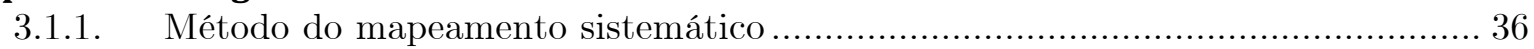

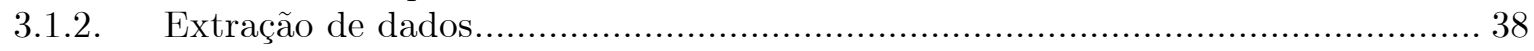

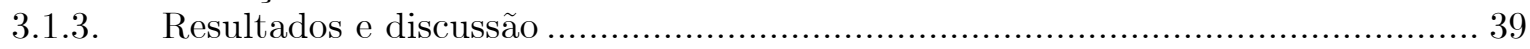

3.1.3.1. Quais as métricas sociais foram usadas em modelos de predição? ................................... 39

3.1.3.2. Classificação das métricas sociais usadas em modelos de predição em Engenharia de

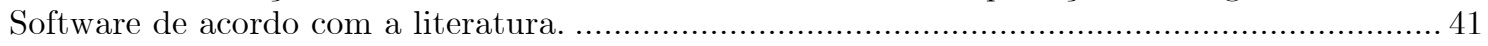

3.1.3.3. Proposta de classificação das métricas sociais ................................................................... 42

3.1.3.4. Implicações das métricas sociais nos modelos de predição de Engenharia de Software ... 43

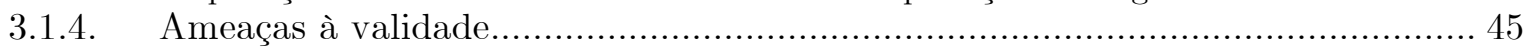

3.2. Informações contextuais para predição de mudanças conjuntas entre arquivos de

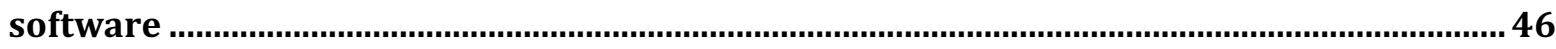

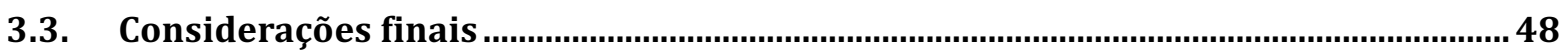

Capítulo 4 Modelos de predição de mudanças conjuntas baseados em informações contextuais 


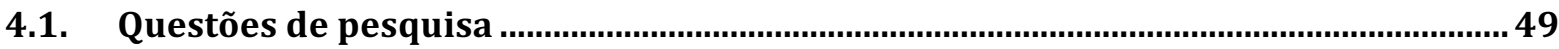

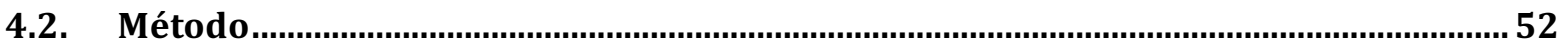

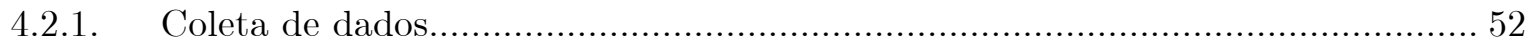

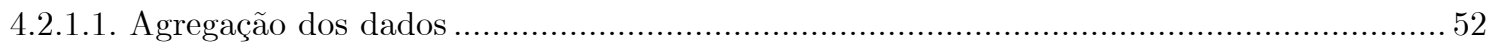

4.2.2. Construção do modelo de predição …….......................................................... 53

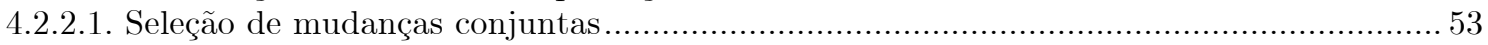

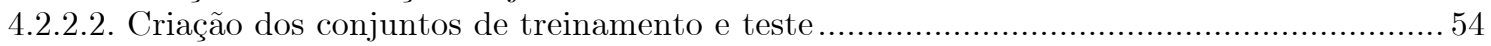

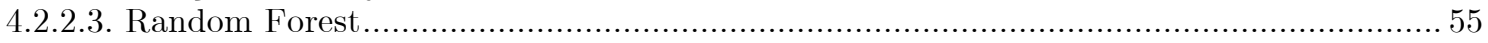

4.2.3. Avaliação dos modelos de predição ……......................................................... 56

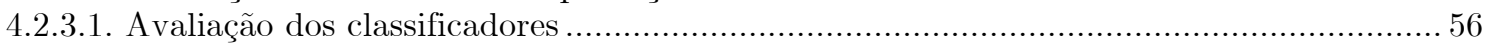

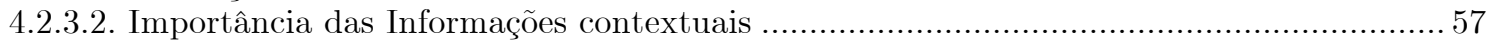

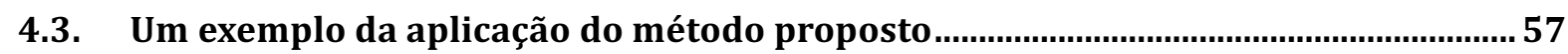

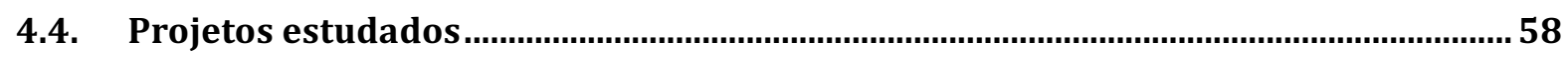

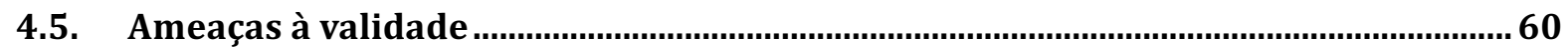

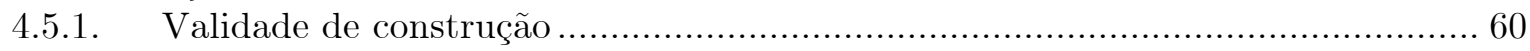

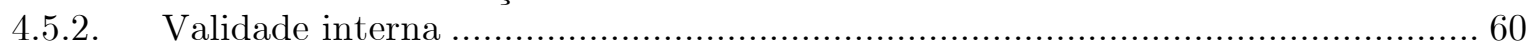

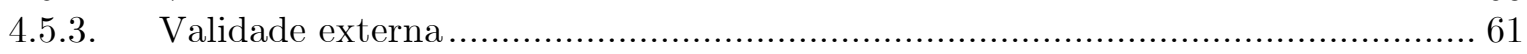

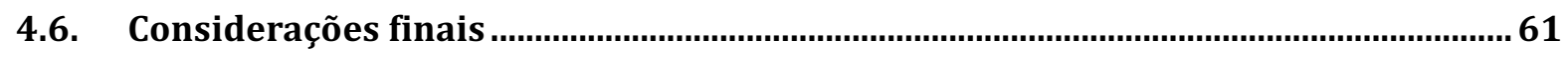

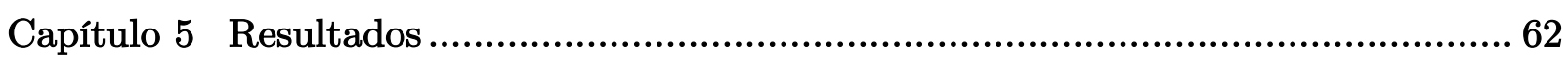

5.1. Questão de pesquisa 1: As informações contextuais possibilitam predizer as

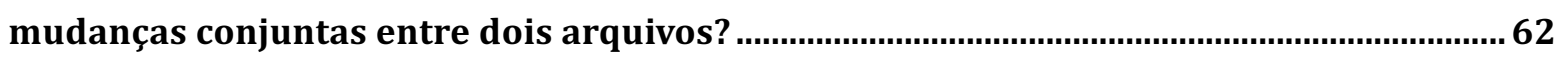

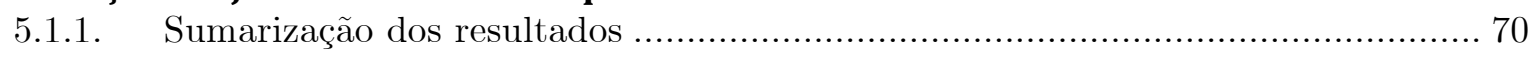

5.2. Questão de pesquisa 2: Qual o desempenho da predição de mudanças conjuntas dos modelos de predição baseados em informações contextuais comparado com as

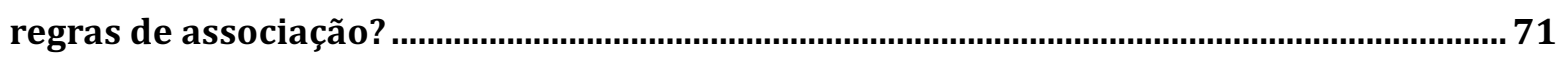

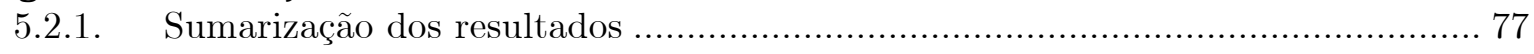

5.3. Questão de pesquisa 3: Qual a influência dos conjuntos de dados usados para

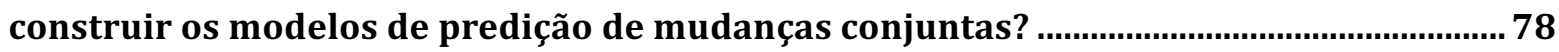

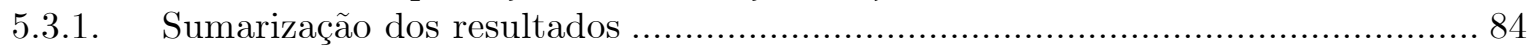

5.4. Questão de pesquisa 4: Qual o desempenho da predição de mudanças conjuntas para os arquivos que mais mudaram nas últimas 500 tarefas do projeto? ......................... 84

5.5. Questão de pesquisa 5: Quais informações contextuais são mais relevantes para

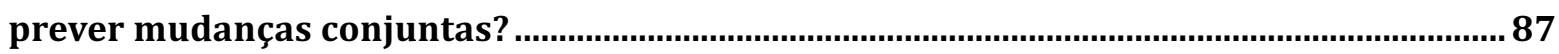

5.5.1. Comparando as melhores métricas sociais e de mudanças .................................. 90

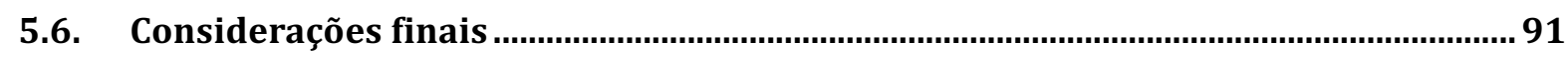

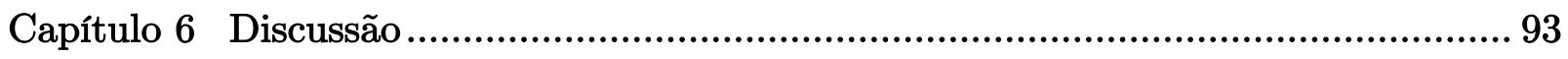

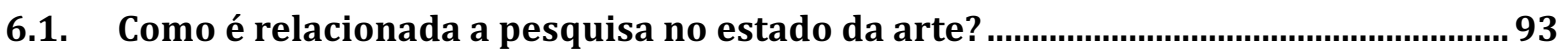

6.1.1. Importância das informações contextuais ...................................................... 95

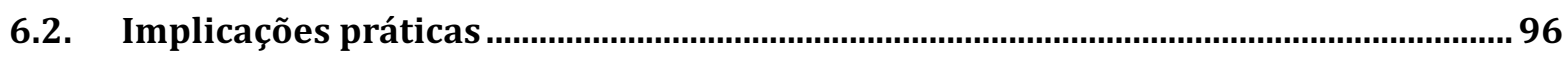

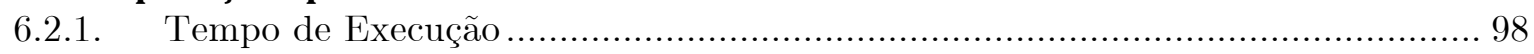

6.3. Interação com os desenvolvedores dos projetos avaliados ............................................98

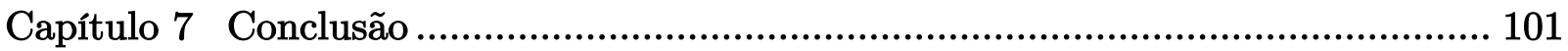

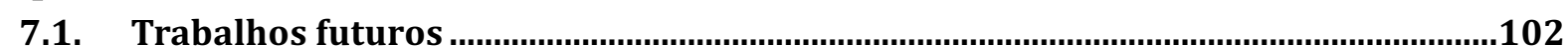

Referências Bibliográficas ......................................................................... 104 


\section{Lista de Abreviações}

ACM Association for Computing Machinery

ASF Apache Software Foundation

AUC Area Under the Curve

CCBC Conceptual Coupling Between Classes

CCSL Centro de Competência em Software Livre

CRIWG International Conference on Collaboration and Technology

CSCW Computer-Supported Cooperative Work and Social Computing

CSD Context in Software Development

DBLP Digital Bibliography \& Library Project

ESEM Empirical Software Engineering and Measurement

FN Falso Negativo

FP Falso Positivo

FSE Foundations of Software Engineering

ICCD Import Coupling Class Dynamic

ICP Information-Flow-Based Coupling

ICSE International Conference on Software Engineering

IEEE Institute of Electrical and Electronics Engineers

IST Information and Software Technologies Journal

JPDA Java ${ }^{\text {M }}$ Platform Debugger Architecture

LAPESSC Laboratório de Pesquisa em Engenharia de Software e Sistemas Colaborativos

LHS Left-Hand-Side

LNCS Lecture Notes in Computer Science

LOC Lines of Code

MCC Matthew's Correlation Coefficient

MSR Mining software repository

OSS Open Source Software

RFE Recursive Feature Selection

RHS Right-Hand-Side

SBES Simpósio Brasileiro de Engenharia de Software

SCV Sistema de Controle de Versão

SNA Social Network Analysis

TDD Test Driven Development

UML Unified Modeling Language 
Verdadeiro Negativo

VP

Verdadeiro Positivo 


\section{Lista de Figuras}

Figura 1-1 Visão geral da pesquisa e publicações

Figura 2-1 Modelo conceitual UML para dependências de mudanças em sistemas orientados a objetos (Oliva 2011)......

Figura 2-2 Exemplo da aplicação da regra de associação para identificar dependências de mudanças .....

Figura 3-1 Método de Bola de Neve usado para o mapeamento sistemático.......................... 36

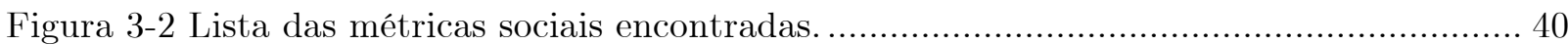

Figura 4-1 Sumarização do método de construção do modelo de predição baseado em

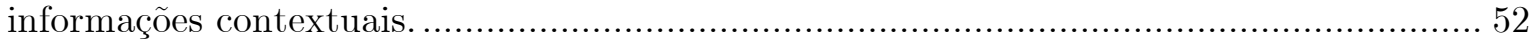

Figura 4-2 Exemplo de agregação de commits e tarefas. .................................................... 53

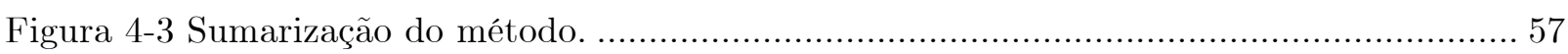

Figura 5-1 Distribuição do percentual de acertos dos modelos testados................................ 64

Figura 5-2 Distribuição do percentual de verdadeiro positivos (acertos) somente para as mudanças conjuntas

Figura 5-3 Distribuição dos valores de Medida F dos modelos para prever mudança conjunta.

Figura 5-4 Distribuição dos valores de AUC para os modelos construídos com todas as métricas e somente as métricas numéricas.

Figura 5-5 Boxplot com os valores das predições corretas por projeto.

Figura 5-6 Boxplot com os valores da medida $\mathrm{F}$ da predição das mudanças conjuntas por projeto.

Figura 5-7 Comparação dos valores de Precisão, Sensibilidade e Medida F entre os modelos construídos com informações contextuais numéricas e regras de associação.

Figura 5-8 Comparação dos valores de Precisão, Sensibilidade e Medida F entre os modelos construídos com todas as informações contextuais e regras de associação.

Figura 5-9 Valor da Medida F dos modelos construídos com informações contextuais (métricas numéricas e todas as métricas) comparado com o modelo baseado em regras de associação

Figura 5-10 Comparação do valor da Medida F dos modelos construídos com cada agrupamento de dados por projeto.

Figura 5-11 Comparação da quantidade de mudanças conjuntas por limiar de suporte e confiança em cada agrupamento de dados

Figura 5-12 Comparação do valor da Medida F dos modelos construídos com cada agrupamento de dados por limiar de suporte e confiança. 


\section{Lista de Tabelas}

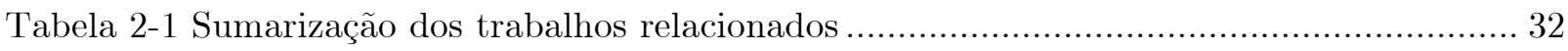

Tabela 3-1 Revisões sistemáticas de predição em Engenharia de Software ............................. 35

Tabela 3-2 Critério de qualidade para inclusão de artigo no mapeamento sistemático ............ 37

Tabela 3-3 Sumarização dos estudos primários incluídos e rejeitados .................................... 38

Tabela 3-4 Efeito do uso das métricas sociais em modelos de predição ..................................... 44

Tabela 3-5 Informações contextuais usadas como preditores de presença ou ausência de

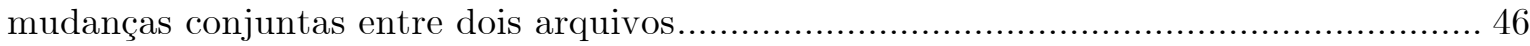

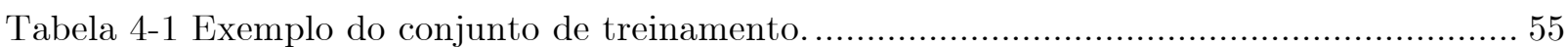

Tabela 4-2. Como é objetivo da tese, comparar o desempenho dos modelos baseados em informação contextual com as regras de associação, as tarefas e commits selecionados para o conjunto de teste são escolhidos a partir das regras de associação encontradas no

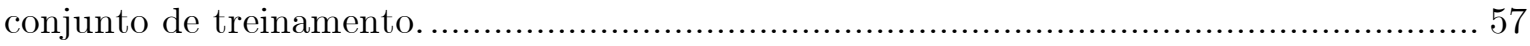

Tabela 4-3 Sumarização dos projetos de acordo com OpenHub.net ..................................... 58

Tabela 4-4 Sumarização dos dados coletados no gerenciador de tarefa e no controle de versão

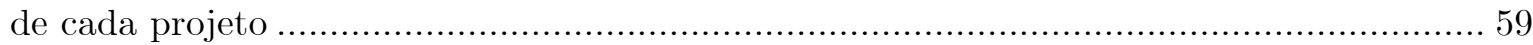

Tabela 5-1 Visão geral da técnica de predição realizada com informações contextuais ............. 63

Tabela 5-2 Medidas de Avaliação da predição de mudanças conjuntas................................... 63

Tabela 5-3 Comparação da Precisão, Sensibilidade e Medida F para a predição de mudanças

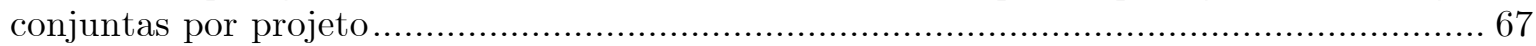

Tabela 5-4 Quantidade de versões com Medida F igual ou maior que 0,75.......................... 69

Tabela 5-5 Quantidade de pares de arquivos por limiar de suporte e confiança....................... 72

Tabela 5-6 Visão geral dos modelos de predição baseados em informações contextuais comparados com os modelos de regras de associação...................................................... 72

Tabela 5-7 Medidas de Avaliação da predição de mudanças conjuntas ..................................... 73

Tabela 5-8 Sumarização dos intervalos de dados usados para construir conjuntos de

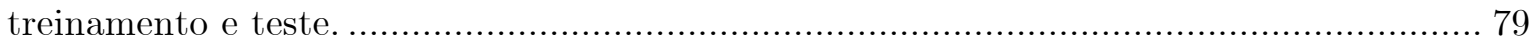

Tabela 5-9 Visão geral da predição realizada em cada intervalo de dados. ............................. 79

Tabela 5-10 Visão geral da técnica de predição realizada com informações contextuais em cada

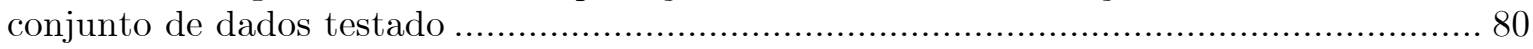

Tabela 5-11 Comparação da Precisão, Sensibilidade e Medida F para a predição de mudanças

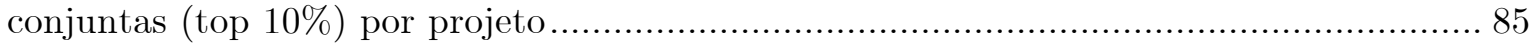

Tabela 5-12 Comparação da Precisão, Sensibilidade e Medida F para a predição de mudanças

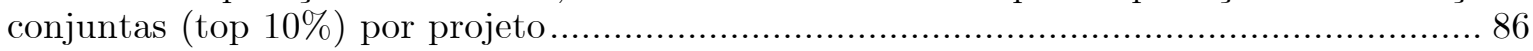

Tabela 5-13 Comparação da quantidade de amostras no conjunto de treinamento em cada

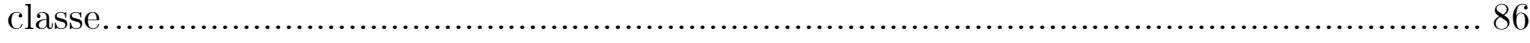

Tabela 5-14 Importância de cada informação contextual para prever mudanças conjuntas em cada projeto. 
Tabela 5-15 Importância de cada informação contextual para prever mudanças conjuntas em

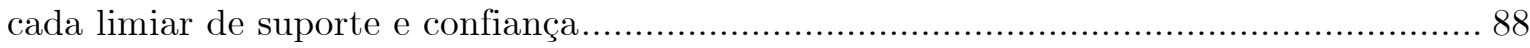

Tabela 5-16 Quantidade e Média de informações contextuais selecionadas por projeto ........... 89

Tabela 5-17 Percentual de seleção de cada informação contextual em cada projeto ................ 90

Tabela 5-18 Comparação da Precisão, Sensibilidade, Medida F, MCC e \% de Predições corretas para o subconjunto de métricas sociais e de mudança para a predição de

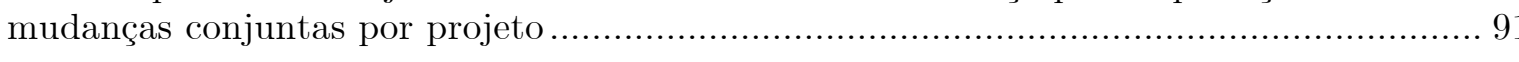

Tabela 6-1 Comparação dos trabalhos relacionados com os resultados obtidos na questão de

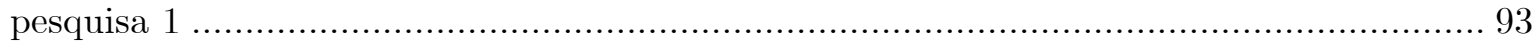

Tabela 6-2 Comparação do tempo de execução dos modelos baseados em regras de associação e

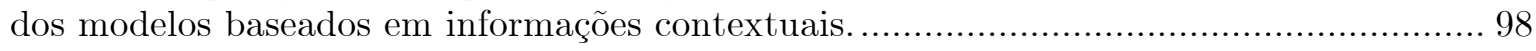

Tabela 6-3 Comparação dos trabalhos relacionados com os resultados obtidos na questão de

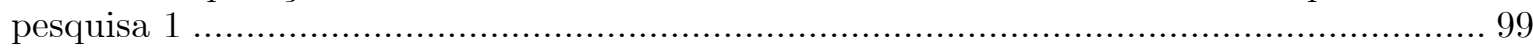




\section{Capítulo 1 Introdução}

Sistemas de software são compostos por arquivos que dependem uns dos outros (Stevens et al. 1974) e, como resultado, arquivos são modificados conjuntamente durante a manutenção e evolução de software (Canfora et al., 2014). Durante a modificação de um software, a falta de informação dos desenvolvedores sobre interdependências, a falta de experiência dos desenvolvedores e a existência de dependências inesperadas levam à incompreensão e mudanças incompletas (Brooks, 1975; Parnas, 1994).

Para evitar a ocorrência de mudanças incompletas, a predição de mudanças conjuntas (cochanges, do inglês) tem sido utilizada para recomendar artefatos propensos a mudar conjuntamente (Bohner e Arnold, 1996; Zimmermann et al. 2005). Dentre os benefícios da predição de mudanças conjuntas destacam-se a diminuição do esforço necessário para completar uma mudança e a diminuição de defeitos gerados por conta de mudanças incompletas (D'Ambros et al. 2006; Hassan e Holt, 2004; Kagdi et al. 2013; Shihab et al. 2013). Uma vez que os desenvolvedores necessitam modificar arquivos conjuntamente para evoluir e manter o software de modo consistente, pesquisadores passaram a estudar alternativas para auxiliar os desenvolvedores durante a realização das mudanças, recomendando artefatos propensos a mudar conjuntamente em um commit $^{1}$ (Bohner e Arnold, 1996; Zimmermann et al. 2005).

Meilir Page-Jones, no início dos anos 90, introduziu o conceito de conascença (do inglês, connascence) (Page-Jones, 2000, 1992). A conascença ocorre quando dois elementos de software necessitam ser modificados conjuntamente em alguma circunstância para manter o software funcional, atendendo às necessidades dos usuários e clientes do software. Ball et al. (1997) introduziu o conceito de acoplamento de mudança (do inglês, change coupling), que captura a ideia de que alguns arquivos frequentemente mudam conjuntamente durante o desenvolvimento de software. Isso indica que quanto mais dois arquivos são modificados conjuntamente, mais acoplados por mudança os artefatos se tornam, logo, maior é a probabilidade de que os artefatos continuem mudando conjuntamente nas versões subsequentes do software.

Abordagens têm sido propostas para predizer mudanças conjuntas utilizando, por exemplo, análise estática (Briand et al. 1999) ou dinâmica do código fonte (Orso et al. 2004), frequência de mudanças passadas e análise de dependências de mudanças (Canfora et al. 2010; Gall et al. 1998; Ying et al. 2004; Zimmermann et al. 2005) e análise semântica/conceitual do código fonte (Kagdi et al. 2010; Revelle et al. 2011). Essas abordagens são baseadas na relação de dependência entre os arquivos para prever a ocorrência de uma mudança conjunta. Como premissa, essas abordagens consideram que se existe uma dependência (de qualquer tipo) entre dois arquivos, eles são mais propensos a mudar conjuntamente.

Apesar do amplo progresso que tem sido feito, essas abordagens ainda emitem recomendações falsas aos desenvolvedores. Isso acontece porque a maioria dos resultados indicam alta precisão e baixa sensibilidade (recall) ou vice-versa (Li et al. 2012; Sun et al. 2015).

Melhorar a acurácia das predições, evitando recomendações falsas aos desenvolvedores ainda é um desafio. A hipótese desta tese é que informações contextuais obtidas das tarefas, da

\footnotetext{
1 Ato de enviar as modificações realizadas localmente nos arquivos para o Sistema de Controle de Versão.
} 
comunicação dos desenvolvedores e das mudanças dos artefatos são capazes de descrever as circunstâncias e condições em que as mudanças conjuntas ocorrem e podem ser utilizadas para predição de mudanças conjuntas. A motivação para usar as informações contextuais advém do fato de as mudanças de software acontecerem por diversas razões e não somente porque existem dependências de software (Canfora et al. 2014; Oliva e Gerosa, 2015a; Oliva et al. 2013).

A abordagem de predição proposta nesta tese considera que as mudanças conjuntas são melhores preditas por informações contextuais sócio-técnicas em vez de usar somente diferentes tipos de dependências entre os arquivos, uma vez que os desenvolvedores precisam interpretar o relato da tarefa e comunicar e cooperar com outros desenvolvedores para realizar as mudanças necessárias para completar uma tarefa (De Souza et al. 2007; Schröter et al. 2012; Tsay et al. 2014; Wolf et al. 2009; Zanetti, 2012). Consequentemente, os elementos centrais da abordagem proposta compreendem aspectos humanos e de processo do software (por exemplo, comentários dos desenvolvedores, métricas extraídas de redes sociais da comunicação entre desenvolvedores, metadados históricos das mudanças dos arquivos e meta-dados das tarefas) em vez de informações centradas em algum tipo de dependência de software (por exemplo, dependências estáticas, conceituais e dinâmicas, tais como grafos de dependências).

\subsection{Objetivos}

O objetivo desta tese é, portanto, avaliar se o uso de informações contextuais melhora a predição de mudanças conjuntas entre dois arquivos em relação às regras de associação, que é uma estratégia frequentemente usada na literatura (Ball et al. 1997; Dit et al. 2014; Kagdi et al. 2013, 2010; Li et al. 2012; Sun et al. 2015; Ying et al. 2004; Zimmermann et al. 2005). A inovação baseiase no uso de novas fontes de informação que melhoram a acurácia da predição de mudanças conjuntas combinadas com algoritmos de aprendizagem de máquina para construir modelos de predição para cada par de arquivos em vez de um modelo de aprendizado global para o projeto, reduzindo a quantidade de recomendações falsas que confundem os desenvolvedores durante a realização das mudanças. Deste modo, o conjunto de dados usados para treinamento é coletado em um período (por exemplo, uma versão do software) com o teste ocorrendo no período consecutivo (por exemplo, a próxima versão do software). A questão de pesquisa principal investigada nesta tese é: "Informações contextuais podem embasar a predição de mudanças conjuntas de pares de arquivos de código fonte de software?".

Esta tese visa melhorar a acurácia da predição de mudanças conjuntas entre dois arquivos de software utilizando informações contextuais das tarefas, da comunicação e de metadados dos commits, diminuindo a quantidade de recomendações falsas e usando modelos que não necessitam de configuração de limiares. Para esse propósito, usamos modelos de predição baseados em um algoritmo de aprendizagem de máquina para prever a ocorrência de mudanças conjuntas entre pares de arquivos.

Os objetivos específicos são:

- Identificar um conjunto de informações contextuais das mudanças de software coletáveis dos repositórios de tarefas e de código fonte com o intuito de melhorar a acurácia dos modelos de predição de mudanças conjuntas (Capítulo 3).

- Propor modelos de predição de mudanças conjuntas baseados em informações contextuais. Os modelos de predição propostos capturam informações contextuais das tarefas, da comunicação e de metadados dos commits para construir modelos de predição de mudanças conjuntas específicos para cada par de arquivos (Capítulo 4).

- Avaliar a acurácia dos modelos de predição de mudanças conjuntas baseados em informações contextuais obtidas das tarefas, da comunicação entre os desenvolvedores e da mudança dos arquivos. Os modelos propostos na literatura atual são baseados em diferentes tipos de dependências de software (estática, conceitual e dinâmica) ou baseados 
na frequência de mudanças conjuntas existentes no passado (dependência de mudança). O uso de fontes de informações inexploradas pode aumentar acurácia da predição, evitando recomendações falsas por meio da redução de falsos positivos (Capítulo 5, Questão de Pesquisa 1: as informações contextuais possibilitam predizer as mudanças conjuntas entre dois arquivos?).

- Comparar o uso do modelo de predição proposto com um modelo que utiliza regras de associação. As regras de associação são mineradas a partir da frequência de mudanças conjuntas dos arquivos identificados no histórico das mudanças. O modelo de regra de associação foi escolhido com base no estado da arte relacionado à predição de mudanças conjuntas. Com a comparação é possível posicionar os resultados em relação ao estado da arte (Capítulo 5, Questão de Pesquisa 2: qual o desempenho da predição de mudanças conjuntas dos modelos de predição baseados em informações contextuais comparado com as regras de associação?).

- Avaliar o desempenho do modelo de predição comparando o agrupamento de dados por versão e por quantidade de tarefas. O modo de construção dos conjuntos de dados influencia o esforço de construção e execução dos modelos. Em particular, é necessário avaliar o impacto do agrupamento de dados na construção dos conjuntos de treinamento, verificando qual forma de agrupamento de dados leva a melhores resultados de predição, utilizando uma menor quantidade de informação contextual (Capítulo 5, Questão de Pesquisa 3: qual a influência dos conjuntos de dados usados para construir os modelos de predição de mudanças conjuntas?).

- Avaliar o desempenho da predição para os arquivos mais modificados recentemente em cada projeto. O resultado da predição para os arquivos mais modificados recentemente indica a viabilidade de uso do modelo de predição proposto para os dados correntes de cada projeto (Capítulo 5, Questão de Pesquisa 4: qual o desempenho da predição de mudanças conjuntas para os arquivos que mais mudaram nas últimas 500 tarefas do projeto).

- Identificar quais informações contextuais utilizadas no modelo proposto são mais relevantes para a realização da predição de mudanças conjuntas. Dado que o modelo de predição proposto utiliza diferentes informações contextuais, descobrir quais informações são mais relevantes tornam o esforço de construção e execução do modelo de predição menor. Essas informações oferecem insights para as organizações e gerentes de projeto sobre quais informações contextuais são mais relacionadas às mudanças conjuntas de cada projeto (Capítulo 5, Questão de Pesquisa 5: quais informações contextuais são mais relevantes para prever mudanças conjuntas?).

\subsection{Dados e método}

Os dados coletados foram obtidos de projetos da Fundação Apache por três razões. Primeiro, os projetos são amplamente adotados por diversas organizações e frequentemente usados em estudos empíricos relacionados à engenharia de software. Segundo, os projetos hospedados na Fundação Apache utilizam ferramentas que armazenam dados relacionadas à evolução e manutenção do código fonte, o que possibilita a coleta de informações sobre as tarefas realizadas, os arquivos modificados e interações sociais que ocorreram durante a realização das tarefas. Em terceiro lugar, os projetos possuem domínios de aplicação diferentes e apresentam diversidade nas características (quantidade de desenvolvedores, forma de organização do trabalho, frequência de mudanças etc.) das comunidades de software que mantêm a evolução desses projetos.

Para realizar cada um dos objetivos descritos anteriormente foram coletados dados de dez projetos do repositório da Fundação Apache: Camel, Cassandra, Cloudstack, CXF, Derby, Hadoop, Hbase, Hive, Lucene e Solr. Os projetos têm características diferentes, tais como: 
participantes/comunidade, domínio de aplicação e quantidade de tarefas, arquivos e mudanças conjuntas (Capítulo 4. Seção 4.4).

Os dados recolhidos compreendem dois tipos de fontes de informação diferentes: o repositório de código fonte (Sistema de Controle de Versão - SCV) e o gerenciador de tarefas (JIRA). Dos commits, foram coletadas as modificações realizadas em cada arquivo para resolver uma tarefa, como por exemplo, o número de linhas adicionadas e removidas e o nome do autor do commit. Das tarefas foram obtidas as informações que descrevem cada tarefa, tais como, quem reportou a tarefa, quem foi associado à tarefa para completá-la, a descrição e o tipo da tarefa, versões afetadas, entre outros. Além disso, foram registrados dados da comunicação referente a cada tarefa. Essas informações constituem o conjunto de informações contextuais proposto.

Após o pré-processamento dos dados, foi construído um modelo de predição para cada par de arquivos, levando em consideração as informações obtidas em cada tarefa e em cada commit realizado para esses arquivos. Os modelos foram construídos com o algoritmo de aprendizagem de máquina random forest, que aprende com os conjuntos de dados coletados do passado, denominados conjuntos de treinamento. Esses dados são rotulados para gerar a base de conhecimento do modelo preditivo. Os modelos são usados para prever novas mudanças conjuntas com base no padrão aprendido. Essas novas instâncias são denominadas conjunto de testes. Os rótulos representam a ocorrência ou a não ocorrência de uma mudança conjunta

A avaliação do modelo preditivo foi feita com base em medidas de avaliação usadas em modelos de aprendizagem de máquina. Testes estatísticos foram usados para comparar o desempenho entre os modelos construídos, entre a nossa abordagem e as regras de associação e entre a construção dos conjuntos de treinamento usando versões ou divisão por quantidade de tarefas.

Estudos preliminares avaliaram o uso de modelos baseados em algoritmo de aprendizagem de máquina em conjunto com informações contextuais do desenvolvimento de software. Dentre os estudos publicados, dois deles avaliaram se um par de arquivos era propenso de mudar conjuntamente na versão seguinte (Wiese et al. 2014a; Wiese et al. 2014b). Nesses estudos, foi utilizado um único modelo de predição para todos os pares de arquivos. A entrada de dados para construção dos modelos de predição considerava um período de tempo (6 meses) para coletar as métricas sociais e de processo das mudanças usadas para indicar a propensão de mudança conjunta entre dois arquivos na versão seguinte. Nesse cenário, o modelo de predição criado era global, porque as mudanças conjuntas de todos os pares de arquivos eram usadas para prever se um par de arquivo específico era propenso a mudar conjuntamente. A diferença dos estudos preliminares para esta tese, é que os modelos construídos são específicos para cada par de arquivos e são usados para prever mudanças conjuntas em um commit específico feito em uma tarefa.

Para estender os estudos iniciais, também foi construído um modelo de predição para prever se arquivos que eram classificados como mais propensos a mudar na versão seguinte também eram propensos a propagar defeitos nessas modificações. Sabendo quais pares de arquivos eram mais propensos a mudar em uma versão e quais desses arquivos eram mais prováveis de estarem envolvidos em mudanças relacionadas à correção de defeitos, os gerentes de projetos poderiam usar os modelos para priorizar arquivos para revisão de código (Wiese et al. 2015). Os trabalhos preliminares apresentados serviram como base para a definição dos modelos de predição propostos, bem como, testar formas de coleta de dados e obtenção de informações contextuais.

Para identificar métricas sociais usadas em modelos de predição aplicados à Engenharia de Software (Wiese et al. 2014a) foi realizado um mapeamento sistemático da literatura. A partir desse mapeamento, foram selecionadas as informações contextuais utilizadas nos modelos de predição construídos.

A Figura 1-1 apresenta a visão geral da pesquisa e as publicações obtidas em cada etapa do trabalho. 


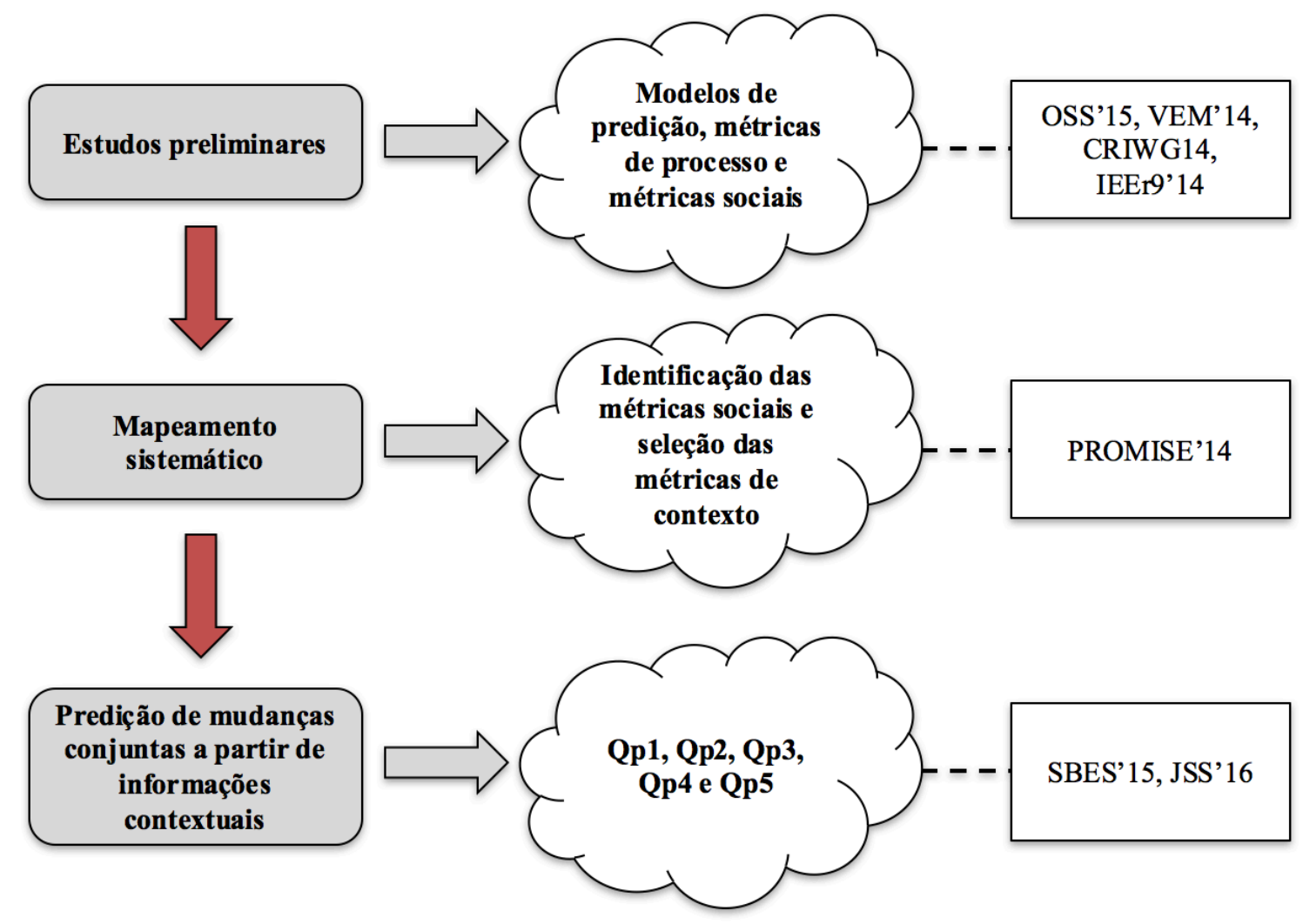

Figura 1-1. Visão geral da pesquisa e publicações

\subsection{Principais contribuições}

Esta tese contém as seguintes contribuições principais:

Mapeamento sistemático dos modelos de predição e métricas sociais: Um mapeamento sistemático foi realizado para identificar métricas sociais usadas na literatura. As métricas identificadas foram classificadas em três grupos: métricas sociais relacionadas à comunicação, à organização do projeto e às mudanças dos artefatos. Esses grupos refletem as perspectivas do modelo 3C de colaboração (comunicação, coordenação e cooperação) (Fuks et al. 2005). As métricas para o modelo de predição de mudanças conjuntas foram selecionadas a partir do mapeamento sistemático.

Método para construção de modelos de predição específicos para cada par de arquivos, baseado em informações contextuais das mudanças para prever a ocorrência de mudanças conjuntas: $O$ estado da arte atual baseia em tipos diferentes de dependência de software para realizar a recomendação da mudança conjunta. Os resultados indicaram que o uso de informações contextuais e algoritmos de aprendizagem de máquina realizaram $88 \%$ das predições corretamente, contra $19 \%$ do estado da arte (regras de associação). Especificamente, nos casos da ocorrência de mudanças conjuntas, $75 \%$ (aproximadamente 20 mil das 26 mil mudanças conjuntas testadas) foram preditas corretamente. A precisão para prever mudanças conjuntas é 3 vezes maior que o estado da arte, consequentemente, o método proposto reduz a quantidade de recomendações falsas. A abordagem proposta não requer configuração de limiares para ser utilizada, simplificando seu uso em relação às abordagens do estado da arte baseados em dependências de software. Os resultados foram obtidos em 129 diferentes versões dos 10 projetos citados anteriormente.

Estudos empíricos do desempenho dos modelos de predição propostos em diferentes cenários: (i) Os resultados indicaram que há diferença estatística no desempenho entre os modelos baseados 
em informação contextual e regras de associação. A melhoria da precisão dos modelos ocorre porque é possível reduzir o número de falsos positivos com a predição de quando uma mudança conjunta específica não ocorre, o que não é detectado pelos modelos de regra de associação. (ii) Em relação ao modo de agrupamento dos dados para a construção dos conjuntos de treinamento e teste, os resultados indicam que a predição de mudanças conjuntas é melhor quando se utiliza dados obtidos de cada versão, em vez de usar as informações contextuais de um número arbitrário de tarefas. (iii) Em relação aos arquivos que mudaram nas últimas 500 tarefas de cada projeto, a qualidade da predição das mudanças conjuntas é maior que na validação de todo o histórico do projeto, indicando que a abordagem proposta nesta tese é viável em cenários práticos. As mudanças conjuntas foram preditas com pelo menos $85 \%$ de acerto.

A identificação das principais informações contextuais selecionadas para a construção do modelo: Dentre as métricas com maior importância para os modelos de predição de mudanças conjuntas destacam-se: o número de linhas adicionadas ou modificadas, número de linhas removidas, code churn que representa a soma das linhas adicionadas, modificadas e removidas durante um commit, número de palavras na discussão e na descrição da tarefa, número de comentários e papel dos desenvolvedores na discussão, medido pelo valor do índice de intermediação dos desenvolvedores (betweenness) na rede social de comunicação. Essas métricas representam o subconjunto com os cinco maiores valores de importância. Em projetos novos, essas métricas seriam recomendadas como prioritárias para construir os modelos de predição de mudanças conjuntas baseados em informações contextuais.

\subsection{Outros resultados}

Esta tese resultou em um conjunto de publicações, orientação de trabalhos de conclusão de curso na graduação e projetos financiados por agências de fomento nacionais e estaduais. Nas subseções a seguir, são apresentados esses resultados.

\subsubsection{Artigos publicados}

Durante a realização desta tese, um conjunto de artigos que tratam diversos aspectos relacionados ao tópico de pesquisa foram publicados no CRIWG 2014, PROMISE 2014, ESEM 2014 (Simpósio de Doutorado), OSS 2015 e SBES 2015, JSS - Journal of Software and Systems 2016.

As referências sumarizadas para os artigos originados desta pesquisa são:

WIESE, Igor Scaliante; GEROSA, Marco Aurelio; OLIVA, G. A.; STEINMACHER, Igor; KURODA, R. T.; RÉ, R, TREUDE, Christoph. Using contextual information to predict cochanges. Using contextual information to predict co-changes, Journal of Systems and Software, Available online 12 July 2016, ISSN 0164-1212, http://dx.doi.org/10.1016/j.jss.2016.07.016.

WIESE, Igor Scaliante; GEROSA, Marco Aurelio; OLIVA, G. A.; KURODA, R. T.; RÉ, R. Informações contextuais do desenvolvimento de software na predição de propagação de mudanças. In: 29th Brazilian Symposium on Software Engineering (SBES 2015). Belo Horizonte. p. 100-109, 2015.

WIESE, Igor Scaliante; KURODA, R. T.; RÉ, Reginaldo; OLIVA, G. A.; GEROSA, M. A. An Empirical Study of the Relation Between Strong Change Coupling and Defects Using History and Social Metrics in the Apache Aries Project. In: 11th Intl. Conf. on Open Source Systems, 2015, Florença. Lecture and Notes in Computer Science (LNCS), p. 3-12, 2015.

WIESE, Igor Scaliante; COGO, F. R.; RÉ, Reginaldo; STEINMACHER, I. F.; GEROSA, Marco Aurelio. Social Metrics included in Prediction Models on Software Engineering: A Mapping 
Study. In: PROMISE - The 10th International Conference on Predictive Models in Software Engineering, Turin, p. 72-81, 2014.

WIESE, Igor Scaliante; KURODA, R. T.; NASSIF JUNIOR, D.; RÉ, Reginaldo; OLIVA, G. A.; GEROSA, Marco Aurelio. Using structural holes metrics from communication networks to predict change dependencies. In: International Conference on Collaboration and Technology (CRIWG 2014), 2014, Santiago. Proceedings of the 20th International Conference on Collaboration and Technology - LNCS, 2014. v. 8658. p. 302-318

WIESE, Igor Scaliante; KURODA, R. T.; Ré, R.; OLIVA, G. A; GEROSA, Marco Aurelio. Um estudo empírico do uso da comunicação para caracterizar a ocorrência de dependências de mudanças no projeto Rails. In: 2nd Workshop on Software Visualization, Evolution, and Maintenance VEM, 2014, Maceio.

WIESE, Igor Scaliante; NASSIF JUNIOR, D.; RÉ, R.; STEINMACHER, I. F.; GEROSA, M. A. Comparing communication and development networks for predicting file change proneness: An exploratory study considering process and social metrics. Electronic Communications of the EASST, v. 65, p. 1-15, 2014.

FALESSI, Davide; CODABUX, Zadia; RONG, Guoping; STAMELOS, Ioannis, FERREIRA, Waldemar; WIESE, Igor Scaliante; BARREIROS, Emanoel; QUESADA-LOPEZ, Christian; TSIRAKIDIS, Periklis. Trends in empirical research: the report on the 2014 Doctoral Symposium on Empirical Software Engineering. ACM SIGSOFT Software Engineering Notes. Volume 40 Issue 5, p. 30-35, 2015. (doctoral Symposium)

\section{Principais publicações relacionadas publicadas em coautoria:}

STEINMACHER, Igor Fábio; GEROSA, Marco Aurelio; CONTE, Tayana U.; WIESE, IGOR S. Increasing the self-efficacy of newcomers to Open Source Software projects. In: 29th Brazilian Symposium on Software Engineering (SBES 2015). Belo Horizonte, p. 160-169 2015.

STEINMACHER, Igor Fábio; WIESE, Igor Scaliante; SCHWERZ, André Luís; ROBERTO, Rafael Liberato; FERREIRA, João Eduardo; GEROSA, Marco Aurélio. Historical Analysis of Message Contents to Recommend Issues to Open Source Software Contributors. RESI: Revista Eletrônica de Sistemas de Informação, v. 13, p. 1-19, 2014.

OLIVA, G. A.; STEINMACHER, I.; WIESE, Igor Scaliante; GEROSA, Marco Aurelio. What Can Commit Metadata Tell Us About Design Degradation? In: IWPSE-EVOL, 2013, Saint Petersburg, Russia. 13th International Workshop on Principles on Software Evolution (IWPSEEVOL 2013). ACM: Saint Petersburg, Rússia, p. 18 - 27, 2013.

GEROSA, Marco Aurélio; WIESE, Igor Scaliante; OLIVA, Gustavo Ansaldi; ANICHE, Maurício Finavaro. Mineração de Repositórios de Software Livre. Revista Computação Brasil. Sociedade Brasileira de Computação. Edição 02/2015, pag. 19-24, 2015.

WIESE, Igor S.; KURODA, Rodrigo T.; RÉ, Reginaldo; BULHÕES, Rodrigo S.; OLIVA, Gustavo A.; GEROSA, Marco A. "Do historical metrics and developers communication aid to predict change couplings?," in Latin America Transactions, IEEE (Revista IEEE America Latina), vol.13, no.6, pp.1979-1988, June 2015. - doi: 10.1109/TLA.2015.7164225.

\subsubsection{Orientações de trabalho de conclusão de curso}

Vidal Daniel da Fontoura. Predição de falhas em projetos de software livre baseada em métricas de redes sociais. 2011. Trabalho de Conclusão de Curso - Universidade Tecnológica Federal do Paraná. Orientador: Igor Scaliante Wiese. 
Douglas Nassif Roma Junior. Uma ferramenta para mineração de dados de projetos de software livre e criação de redes sócio-técnicas. 2012. Trabalho de Conclusão de Curso Universidade Tecnológica Federal do Paraná. Orientador: Igor Scaliante Wiese

Willian Schultz Dworak. Uma perspectiva social para recomendação de Experts em Projetos de Software livre. 2015. Trabalho de Conclusão de Curso - Universidade Tecnológica Federal do Paraná Orientador: Filipe Roseiro Cogo, Co-orientador: Igor Scaliante Wiese.

Eduardo Roberto Greco. Agrupamento de Projetos Similares utilizando métricas de software e algoritmo BSAS. 2015. Trabalho de Conclusão de Curso - Universidade Tecnológica Federal do Paraná Orientador: Reginaldo Ré, Co-orientador: Igor Scaliante Wiese.

\subsection{Organização da tese}

Esta tese está organizada da seguinte maneira. O Capítulo 2 apresenta a fundamentação teórica e trabalhos relacionados. Dentre os tópicos, são apresentados os conceitos de manutenção e evolução de software, contexto na engenharia de software, os tipos de dependências de software, em especial a dependência de mudança, que é frequentemente usada para prever mudanças conjuntas, o referencial teórico sobre modelos de predição baseados em aprendizagem de máquina e os trabalhos relacionados que inspiraram e serviram como base para a abordagem descrita nesta tese.

No Capítulo 3 é apresentado o mapeamento sistemático realizado para identificar métricas sociais em modelos de predição aplicados em engenharia de software. Esse mapeamento deu origem e embasou a escolha das métricas, que representam a nossa noção para o contexto da mudança conjunta entre artefatos de software.

O método e os dados utilizados são apresentados no Capítulo 4. O método compreende a criação dos modelos de predição que compreendem a forma de seleção dos pares de arquivos, o cálculo das métricas e a construção do conjunto de treinamento necessário para realizar as predições. As informações de cada um dos projetos coletados também são apresentadas no Capítulo 4.

O Capítulo 5 apresenta os resultados das cinco questões de pesquisa investigadas. Cada um dos objetivos específicos foi mapeado em uma questão de pesquisa. São apresentados os resultados gerais da predição realizada com as informações contextuais, comparados com o modelo aleatório (questão de pesquisa 1), a comparação com as regras de associação (questão de pesquisa 2), a comparação do modo de agrupamento de dados: por versão e por divisão de tarefas (questão de pesquisa 3), os resultados da predição para os arquivos que mais mudaram recentemente (últimas 500 tarefas) no projeto (questão de pesquisa 4), e as informações contextuais mais relevantes (questão de pesquisa 5).

O Capítulo 6 discute os resultados com relação às implicações de aspectos práticos e o posicionamento desta pesquisa em relação ao estado da arte. Por fim, no Capítulo 7, são apresentadas as conclusões e trabalhos futuros. 


\section{Capítulo 2 \\ Fundamentação teórica e trabalhos relacionados}

Este capítulo apresenta a fundamentação teórica desta tese e as informações contextuais coletadas para realizar a predição de mudanças conjuntas. São apresentados os conceitos de manutenção e evolução de software, a definição de contexto e os tipos de dependência de software. São mencionados também os trabalhos relacionados à predição de mudanças conjuntas e o conceitual teórico sobre os modelos de predição baseados em algoritmos de aprendizagem de máquina.

\subsection{Manutenção e evolução de software}

A manutenção do software é uma importante fase de qualquer processo de desenvolvimento e parte fundamental na evolução do software. A IEEE indica que a fase de manutenção compreende as tarefas de modificação do software depois da sua entrega (Mamone, 1998). Já o termo evolução é usado para se referir ao processo pelo qual o software é modificado, do qual à fase de manutenção é parte (Bennett e Rajlich, 2000).

De acordo com Lehman, mudanças no software são fundamentais para a manutenção e a evolução, uma vez que é necessário adaptar o software para atender as mudanças de requisitos. Nesse sentido, Lehman propôs importantes leis que caracterizam a dinâmica da evolução do software, das quais a primeira lei descreve a propriedade de "mudança contínua" do software (Lehman, 1985). Diversos pesquisadores (Canfora et al. 2014; Hassan, 2009) têm estudado mudanças contínuas no desenvolvimento de software e descobriram que essas mudanças têm um impacto direto na qualidade do produto gerado.

Para realizar as modificações no software, diferentes tarefas são realizadas, dentre elas, a correção de defeitos e a melhoraria da qualidade do código fonte existente. Durante a realização das tarefas, pedidos de modificação do software são armazenados e monitorados e o impacto das alterações no software é avaliado. Por conta do conjunto de atividades necessário para realizar essas tarefas, a manutenção de software é uma fase do processo de software com grande intensidade de trabalho, custo e dificuldade (Schneidewind, 1987).

Normalmente, o fluxo de uma atividade de manutenção e evolução do software é descrito da seguinte forma (Bennett e Rajlich, 2000). Primeiro, um envolvido (stakeholder) demanda uma solicitação de mudança no software e um requisito é criado ou modificado. Segundo, os desenvolvedores interpretam o relato da solicitação de mudança e alteram o código fonte. Nessa fase, é importante que os desenvolvedores conheçam e compreendam o funcionamento do sistema e a sua arquitetura. Terceiro, após a conclusão das mudanças, o software é testado e implantado.

Percebe-se, que as mudanças têm relação com as atividades de manutenção e evolução do software. Logo, é importante auxiliar os desenvolvedores durante a realização das mudanças e a das tarefas de manutenção e evolução. 


\subsection{Contexto no Desenvolvimento de Software}

A noção de contexto é explorada por pesquisadores da área de CSCW - Computer-Supported Cooperative Work. De acordo com Dey et al. (2001), contexto é "qualquer informação que pode ser usada para caracterizar a situação de entidades". Para Brézillon et al. (2004) contexto representa "uma descrição complexa do conhecimento compartilhado sobre algo físico, social, histórico ou qualquer outra circunstância com os quais uma ação ou evento ocorre".

Na Engenharia de Software, o termo "contexto" não é frequentemente utilizado. Recentemente, o estudo do contexto aplicado à Engenharia de Software deu origem ao workshop CSD - Context for Software Developers, que ocorreu em conjunto com a principal conferência de Engenharia de Software (ICSE - International Conference on Software Engineering).

Em projetos de software, os desenvolvedores devem gerenciar uma grande quantidade de informações de contexto para concluir suas tarefas, incluindo os arquivos relevantes de software e seu histórico de mudanças, requisitos, especificações de projeto, tarefas dependentes, trabalho concorrente, discussões e trocas de conhecimento sobre as tarefas e arquivos.

Nesse sentido, é possível observar que o contexto no desenvolvimento de software é multidimensional. Há diversas informações relevantes que configuram o contexto para um desenvolvedor trabalhando em uma determinada tarefa. Consequentemente, no dia-a-dia os desenvolvedores fazem uso do conhecimento adquirido do contexto para tomar decisões, coordenar seu trabalho e entender como as suas tarefas se encaixam no projeto.

Adaptando a definição de Dey et al. (Dey et al. 2001), é possível afirmar que o contexto de uma mudança conjunta é caracterizado pelo conjunto de informações que são obtidas da ocorrência das mudanças dos artefatos. A partir dos repositórios de dados disponíveis e do próprio código fonte, diferentes métricas são calculadas para representar o contexto em que dois arquivos são mais propensos a mudar conjuntamente. Para Lanza et al. (Lanza et al. 2006), métricas auxiliam gerentes, arquitetos e desenvolvedores a entender, guiar e controlar o desenvolvimento de software, bem como obter uma visão geral da aplicação e identificar potenciais problemas no projeto do software.

Dentre os repositórios de dados utilizados para cálculo das métricas, estão os gerenciadores de tarefas, que armazenam relatos de defeitos ou novos requisitos, e o log do controle de versão, que armazena informações dos meta-dados dos commits realizados e o código fonte. Cada uma das fontes de informações representa uma perspectiva distinta utilizada para capturar o contexto do desenvolvimento de software e possui informações implícitas que representam o conhecimento tácito sobre a evolução, manutenção e decisões de projeto tomadas durante o desenvolvimento de software e modificações dos arquivos.

Nesta tese, as métricas representam informações contextuais da ocorrência ou da não ocorrência de uma mudança conjunta. No Capítulo 3, são descritas as informações contextuais e como cada métrica é calculada, bem como detalhes da revisão sistemática realizada para identificação das métricas de contexto social aplicadas em modelos de predição de engenharia de software.

\subsection{Dependência de software}

Na literatura há diversas definições para dependência de software. David Parnas (1979) foi um dos primeiros autores a definir esse conceito. Para Parnas, um programa A depende de um programa B se a execução correta de $\mathrm{B}$ é necessária para completar a tarefa descrita nas especificações do programa A. Algumas décadas depois, Lakos (1996) descreve o conceito de dependência de software adicionando a ideia do relacionamento entre dois componentes de software. Lakos afirmou que o componente A depende do componente B "fisicamente" se o 
componente A não é compilável sem o componente B. Essa definição tornou-se conhecida como a definição de dependência estrutural sintática.

Na UML - Unified Modeling Language, a definição de dependência de software é dada de uma forma mais geral, na qual a relação de dependência indica que a semântica do elemento "cliente" é semântica ou estruturalmente dependente da definição do elemento "fornecedor". Para Larman (2004), dependência significa que um arquivo de software "cliente" tem conhecimento do arquivo "fornecedor" e que, portanto, uma mudança no "fornecedor" pode afetar o arquivo "cliente".

Ball et al. (1997) foram os primeiros a definir o conceito de dependências de software a partir da observação do repositório do sistema de controle de versão (SCV). Esses autores identificaram um tipo de dependência, chamada de dependências de mudanças, que não necessariamente advêm das dependências estruturais. Nesse tipo de dependência, os arquivos são conectados a partir das modificações realizadas, portanto, remetendo a um ponto de vista evolucionário relacionado a alguma necessidade de modificação nos arquivos.

Enquanto as dependências estruturais capturam a relação em tempo de compilação ou de ligação por meio de relações de agregação, associação, realização e generalização, as dependências de mudanças capturam aspectos de relacionamento lógico e implícito que ocorrem na modificação dos arquivos durante a evolução do software e muitas vezes não são planejados.

Nas subseções a seguir, são descritos quatro tipos de dependências (de mudança, estática, conceitual e dinâmica) que são usados para prever a propensão de mudanças conjuntas.

\subsubsection{Dependência de mudança}

Quando os arquivos são frequentemente modificados conjuntamente, infere-se um relacionamento de dependência de mudança entre eles. Na literatura esse tipo de dependência é chamada de dependência lógica (do inglês, logical dependency) (Gall et al. 1998, Robbes et al. 2008, Pirklbauer 2010), dependências de mudança (change dependencies) (Fluri et al. 2005, Fluri e Gall 2006, D'Ambros et al. 2008, Mens e Demeyer 2008, Zhou et al. 2008), dependências evolucionárias (evolutionary dependencies) (Zimmermann et al. 2005, Bantelay et al. 2013) e mudanças conjuntas históricas (historical co-changes) (Aversano et al. 2007, Ali et al. 2013).

Dependências de mudanças são inferidas a partir da análise da evolução histórica das mudanças dos arquivos quando arquivos de software são modificados, independentemente da razão dessas mudanças. Diferentemente da dependência estrutural, as dependências de mudanças não são definidas baseadas no código fonte, mas sim no histórico da mudança dos arquivos. Com base na frequência de mudanças encontradas no histórico é possível inferir que quanto mais mudanças conjuntas dois arquivos têm, mais acoplados os arquivos estão (Ball et al. 1997; Ying et al. 2004).

Esse tipo de dependência tem despertado atenção de vários pesquisadores, cujos estudos abordaram sua correlação com a ocorrência de defeitos (Cataldo et al. 2009, D'Ambros et al. 2009b), análise de impacto de mudança (Zimmermann et al. 2005, Zhou et al. 2008, Hassan 2009), qualidade de software (Cataldo e Nambiar 2012), mineração de aspectos (Adams et al. 2010), descoberta de falhas na arquitetura e oportunidades de refatoração (D'Ambros et al. 2009a), avaliação da arquitetura de software (Zimmermann et al. 2003), rastreamento de requisitos (Ali et al. 2013) e avaliação da modularidade do sistema (Silva et al. 2014).

As dependências de mudanças são frequentemente detectadas por meio da análise e interpretação dos dados obtidos de sistemas de controle de versão, tais como CVS, SVN, Git e Mercurial e, portanto, as técnicas de detecção de dependências de mudanças são afetadas pela forma com que o histórico das mudanças dos arquivos é armazenado.

A fim de apoiar a identificação e compreensão das entidades significativas no domínio de dependências de mudanças, a Figura 2-1 apresenta o modelo conceitual UML proposto por Oliva 
(2011) para descrever as dependências de mudanças. Note que o autor utiliza o termo "dependência lógica" para referenciar o que neste trabalho está sendo chamado de dependência de mudanças.

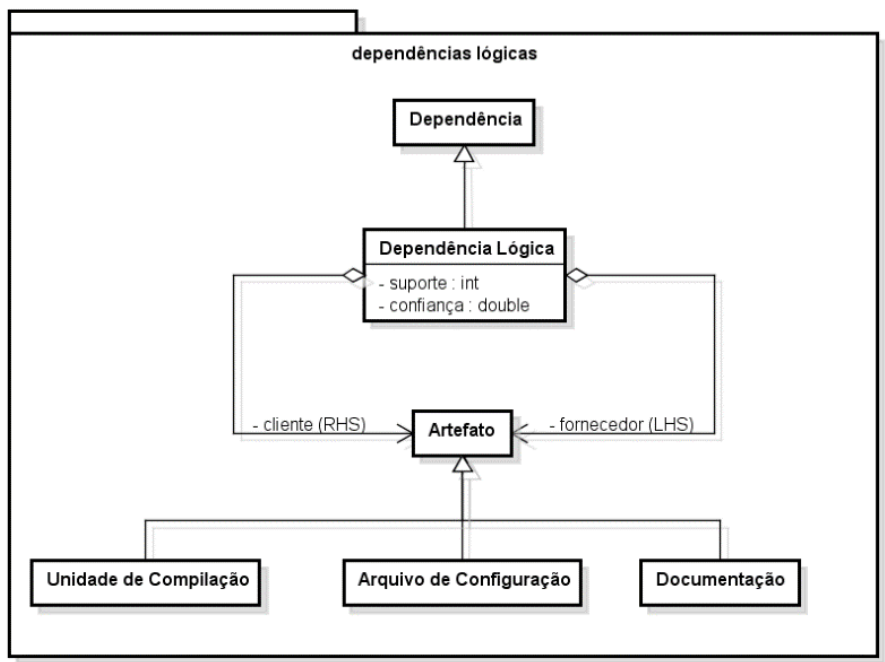

Figura 2-1. Modelo conceitual UML para dependências de mudanças em sistemas orientados a objetos (Oliva 2011).

O modelo conceitual revela que as dependências de mudanças são estabelecidas entre quaisquer arquivos armazenados no sistema de controle de versão, tais como unidades de compilação (como classes e interfaces), arquivos de configuração e documentação. Os detalhes sobre como utilizar algoritmos de regra de associação para encontrar as dependências de mudanças relevantes são descritos na seção a seguir.

\subsubsection{Identificação de dependências de mudanças}

A identificação de dependências de mudanças é feita por meio do uso de técnicas de mineração de repositórios de software e revela acoplamentos "ocultos" entre arquivos de código que estejam sob um sistema de controle de versão.

Diferentes pesquisas foram realizadas para identificar dependências de mudanças (Ying et al. 2004, Zimmermann et al. 2005, Canfora et al. 2010), das quais destacam-se a abordagem de Zimmermann et al. (2005). Essas abordagens são baseadas em identificar a ocorrência de "dependências de mudanças frequentes" utilizando o histórico de modificações dos arquivos. No contexto da identificação das dependências de mudanças, a abordagem proposta por Zimmermann et al. (2005) utiliza algoritmos de regras de associação para identificar as dependências de mudanças e usa essas dependências para recomendar arquivos que são mais propensos a mudar conjuntamente. Tais algoritmos são empregados com diferentes propósitos na área de mineração de dados, como por exemplo, a mineração de itens comprados conjuntamente em um supermercado ou livraria.

Para a identificação de dependências de mudanças, uma regra de associação indica uma relação entre dois artefatos, na forma $A_{1} \Rightarrow A_{2}$, que diz que quando um arquivo $a_{1}$ muda, o arquivo $\mathrm{a}_{2}$ também deveria mudar. $\mathrm{A}_{1}$ e $\mathrm{A}_{2}$ são dois conjuntos disjuntos de itens, que no nosso contexto é representado por arquivos modificados durante o desenvolvimento de software. $\mathrm{O}$ arquivo $\mathrm{a}_{1}$ é chamado de antecedente (também conhecido como left-hand-side e LHS) e o arquivo $\mathrm{a}_{2}$ é chamado de consequente (também conhecido como right-hand-side e RHS). Para este trabalho, uma dependência de mudança de um arquivo cliente para outro arquivo fornecedor é denotado pela regra $A_{1} \Rightarrow A_{2}$, na qual o antecedente e o consequente são conjuntos unitários que contêm os arquivos $\mathrm{a}_{1}$ e $\mathrm{a}_{2}$. 
Regras de associação utilizam medidas de interesse e significância que, usualmente, são dadas por limiares (thresholds) de suporte (support) e confiança (confidence). A medida de suporte denota o número de vezes que dois arquivos foram modificados conjuntamente. A medida de confiança define o grau em que arquivos estão logicamente conectados, caracterizando a força da relação. Cada medida é calculada da seguinte forma (Oliva 2011):

- Frequência de um conjunto de arquivos A em um conjunto de commits C:

$\operatorname{frq}(\mathrm{C}, \mathrm{A})=\mid\{\mathrm{c} \mid \mathrm{c} \in \mathrm{C}$ e $\mathrm{c}$ inclui todos os arquivos em $\mathrm{A}\} \mid$

- $\quad$ Suporte de uma dependência de mudança $A_{1} \Rightarrow A_{2}$ :

$\sup \left(C, A_{1} \Rightarrow A_{2}\right)=\operatorname{frq}\left(C, A_{1} \cup A_{2}\right)=$ número de commits que contêm ambos $a_{1}$ e $a_{2}$

- Confiança de uma dependência de mudança $A_{1} \Rightarrow A_{2}$ :

$\operatorname{conf}\left(\mathrm{C}, \mathrm{A}_{1} \Rightarrow \mathrm{A}_{2}\right)=\sup \left(\mathrm{C}, \mathrm{A}_{1} \Rightarrow \mathrm{A}_{2}\right) / \operatorname{frq}\left(\mathrm{C}, \mathrm{A}_{1}\right)$ = valor de suporte dividido pelo número de commits que contêm $\mathrm{a}_{1}$

É importante observar que os valores de confiança para $A_{1} \Rightarrow A_{2}$ e $A_{2} \Rightarrow A_{1}$ podem ser diferentes. No primeiro caso, o valor de confiança determina o grau em que o arquivo $a_{2}$ é cliente de outro arquivo $a_{1}$. Analogamente, no segundo caso, a confiança determina o grau em que o arquivo $a_{1}$ é cliente de $\mathrm{a}_{2}$. Para ilustrar essa sutil diferença, considere o exemplo mostrado na Figura 2-2.

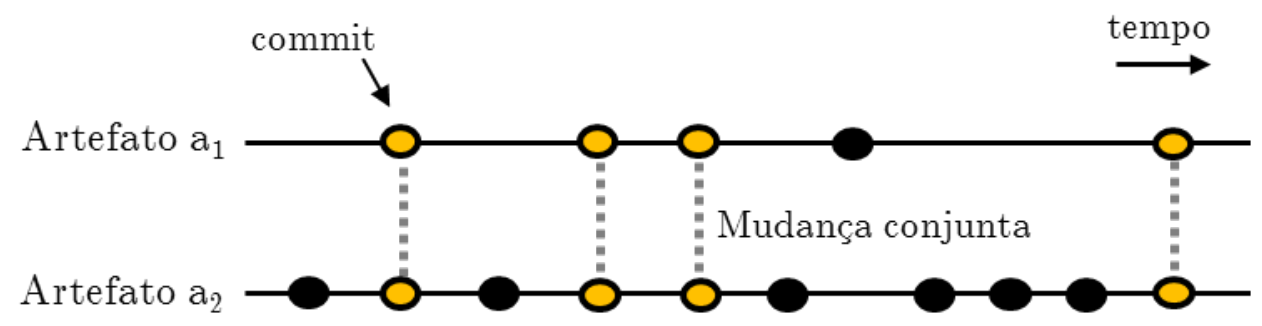

Figura 2-2. Exemplo da aplicação da regra de associação para identificar dependências de mudanças

Na maior parte das vezes, quando o arquivo $\mathrm{a}_{1}$ é incluído em um commit, o arquivo $\mathrm{a}_{2}$ também é. Portanto, a regra $A_{1} \Rightarrow A_{2}$ (que diz que $a_{2}$ depende de $a_{1}$ ) tem uma confiança alta: $\operatorname{conf}\left(C, A_{1} \Rightarrow A_{2}\right)=$ número de commits que contêm $\mathrm{a}_{1}$ e $\mathrm{a}_{2} /$ número de commits que contêm $\mathrm{a}_{1}=4 / 5=80 \%$. Por outro lado, a regra $\mathrm{A}_{2} \Rightarrow \mathrm{A}_{1}$ (que diz que $\mathrm{a}_{1}$ depende de $\mathrm{a}_{2}$ ) tem metade da confiança da regra anterior: $\operatorname{conf}\left(\mathrm{C}, \mathrm{A}_{2} \Rightarrow \mathrm{A}_{1}\right)=$ número de commits que contêm ambos $\mathrm{a}_{1}$ e $\mathrm{a}_{2} /$ número de commits que contêm $\mathrm{a}_{2}=4 / 10=40 \%$ (Oliva 2011).

Além do suporte e confiança, o lift pode ser usado para indicar o grau de interesse de uma regra de associação. Essa medida pode ser obtida dividindo-se o valor da confiança de uma regra de associação pelo valor do consequente. Entretanto, diferentemente do valor da confiança, o Lift é uma medida unidirecional, que implica que o valor do lift da regra $A_{1} \Rightarrow A_{2}$ é igual a $A_{2} \Rightarrow A_{1}$ (Alali, 2014).

\subsubsection{Técnicas para determinar dependências de mudança relevantes}

O uso de algoritmos de regras de associação possui dois indicadores sobre as associações identificadas a partir das modificações dos arquivos. Enquanto um valor maior de suporte indica uma probabilidade maior de uma relação existir entre dois arquivos alterados conjuntamente, a confiança determina qual arquivo tem a maior probabilidade de provocar mudanças em outro arquivo (Zimmermann et al. 2005). Nesse sentido, suporte significa evidência, ou seja, quão evidente aquela dependência de mudança é para o projeto. Confiança remete à ideia de intensidade/força da dependência (Zimmermann et al. 2005). 
Para determinar se uma dependência de mudança é relevante, as medidas de suporte e confiança devem apresentar valores acima de um limiar determinado. Pesquisas anteriores alertam que a escolha dos limiares impactam no resultado das pesquisas que utilizam regra de associação para identificar as dependências de mudança (Zimmermann et al. 2005, Beck e Diehl 2013). Elas também indicam que a escolha do limiar não é trivial e, normalmente, é muito dependente de cada projeto.

Zimmermann et al. (2005) utilizaram valores de suporte maiores que 1 e confiança superiores a 0,5 para determinar dependências de mudança relevantes, porém recomendam valores de confiança superiores a 8 e confiança de pelo menos 90\%. Por sua vez, Bavota et al. (2013) utilizaram uma taxa para o valor de suporte que corresponda a pelo menos $2 \%$ dos commits (suporte / número de commits) e valores de confiança iguais ou maiores que 0,8 (80\%). Esse valor, por exemplo, é muito mais restritivo do que o de Zimmermann et al. Em pesquisas recentes (Wiese et al. 2014b; Wiese et al. 2015), utilizamos valores de suporte maiores ou iguais a 2 e valores de confiança maiores que 0,5 .

Um limite de suporte é muitas vezes o primeiro parâmetro a ser determinado. Como descrito na seção anterior, o limiar de suporte é obtido por meio de uma análise da distribuição dos valores de suporte das dependências identificadas. Depois de ter determinado as dependências que são suficientemente evidentes, um limiar de confiança é aplicado para filtrar aquelas que também são suficientemente fortes.

Quanto às escolhas dos limiares de suporte e confiança, algumas alternativas são recomendadas. A primeira alternativa sugere determinar o limiar de suporte das dependências de mudança que são suficientemente evidentes e, posteriormente, apontar um limiar de confiança para filtrar aquelas dependências que também são suficientemente fortes. Por exemplo, Zimmermann et al. (2005) sugerem testar iterativamente diferentes valores de suporte e confiança, analisando o impacto da escolha desses limiares. Oliva et al. (2011) propôs estabelecer três intervalos adjacentes para os valores de confiança, que correspondem às dependências de mudança fraca, regulares e fortes. Os intervalos de confiança definidos foram [0,00, 0,33[ para dependências de mudanças fracas, $[0,33,0,66[$ para dependências de mudanças regulares e $[0,66,1,00]$ para dependências fortes.

Uma alternativa é utilizar a análise de quartil para determinar os valores de suporte e confiança de acordo com a distribuição dessas medidas no projeto. Nesse caso, uma sugestão é utilizar o terceiro quartil para verificar as dependências mais relevantes. O terceiro quartil (Q3) corresponde ao valor a partir do qual se encontram $25 \%$ dos valores mais elevados de uma medida. Usando o terceiro quartil é possível separar os dados em dois conjuntos, um com $25 \%$ dos maiores elementos (valores acima ou iguais ao valor do terceiro quartil) e um segundo conjunto com $75 \%$ dos dados que correspondem aos menores valores (valores inferiores ao terceiro quartil). Por fim, outra alternativa para determinar a relevância de uma regra de associação consiste na combinação dos valores de suporte e confiança com o valor do Lift (Alali, 2014).

\subsubsection{Dependência estática}

No contexto das linguagens de programação orientadas a objetos, como $\mathrm{C}++, \mathrm{C} \#$ e Java, as dependências estruturais ocorrem quando uma unidade de compilação depende de outra qualquer em tempo de compilação ou de ligação. A análise estrutural estática extrai dependências dos elementos estruturais de um programa, tais como classes, métodos e atributos, ou por meio da construção de um grafo de dependência (Briand et al. 1999; Horwitz et al. 2004).

Dentre as métricas mais utilizadas, destacam-se o acoplamento baseado em fluxo de informação (do inglês, information-flow-based coupling - ICP), que é obtido estaticamente a partir da análise do código fonte. O ICP mede a quantidade de fluxos de informação que entram e saem de uma classe por meio de parâmetros invocados em um método (Bavota et al. 2013). 
$\mathrm{Na}$ predição de mudanças conjuntas, a análise estrutural estática é usada para recomendar artefatos estruturalmente conectados. Por exemplo, quando uma classe muda, o ICP é calculado entre essa classe e as demais classes do sistema. As classes com maior valor de ICP são recomendadas para mudar conjuntamente (Briand et al. 2006, 1999).

\subsubsection{Dependência conceitual}

Algumas partes expressam a semântica de um determinado código fonte, como, por exemplo, os identificadores para nomes de classes, métodos ou atributos e comentários. Os identificadores contêm informação importante e muitas vezes são usados como ponto de partida para tarefas de compreensão de código (Abebe et al. 2009; Arnaoudova et al. 2010). A análise textual dos identificadores tem sido utilizada para medir a similaridade entre dois arquivos de software e inferir a dependência conceitual entre eles, como uma alternativa aos demais tipos de dependência para a predição de mudanças conjuntas (Kagdi et al. 2013, 2010; Poshyvanyk e Marcus, 2006).

Diferentes métricas foram propostas para calcular a similaridade entre as classes. Uma dessas métricas é o Acoplamento Conceitual entre Classes $(C C B C$ - Conceptual Coupling Between Classes). O CCBC é baseado na informação léxica das classes derivadas de comentários e identificadores. A média da similaridade textual entre todos os pares de métodos não ordenados de duas classes indica o valor de CCBC. Da mesma forma que as medidas de similaridade usadas em mineração de dados, como por exemplo, a distância de cosseno, o CCBC varia entre 0 e 1 , onde 1 indica que duas classes são completamente semelhantes. Outros autores propuseram métricas semelhantes a CCBC (Kagdi et al. 2013).

Na predição de mudanças conjuntas, classes que têm alto valor de dependência conceitual com o arquivo que está mudando são recomendadas para os desenvolvedores. A ideia por trás dessa recomendação é que se duas classes contêm termos similares em seus identificadores e/ou comentários, então é provável que os desenvolvedores utilizem as classes para responsabilidades do sistema que também são similares (Poshyvanyk e Marcus, 2006).

\subsubsection{Dependência dinâmica}

A análise dinâmica do código fonte considera entradas específicas e baseia-se na análise das informações coletadas durante a execução do programa (por exemplo, rastros de execução, informações de cobertura, etc.) e utiliza essas informações para inferir a existência de dependência entre dois arquivos (Apiwattanapong et al. 2005; Orso et al. 2004).

Pesquisadores têm proposto diferentes métricas para realizar a análise dinâmica e a identificação desse tipo de dependência. Arisholm (2002) propôs um conjunto de métricas para calcular a dependência dinâmica e verificou que existe forte relação entre a dependência dinâmica e a propensão de mudança entre os arquivos. A métrica ICCD (Import Coupling Class Dynamic Message) conta o número de mensagens distintas, por exemplo, o número de chamadas de métodos enviados de uma classe C para todas as outras classes do sistema.

Para a predição de mudanças conjuntas, além dessa métrica, ferramentas como o Java ${ }^{\mathrm{TM}}$ Platform Debugger Architecture (JPDA) da Oracle foram usadas para inferir dependência dinâmica (Gethers et al. 2012) e recomendar quais arquivos são mais propensos a mudar conjuntamente. 


\subsection{Predição baseada em aprendizagem de máquina}

Modelos de predição baseados em classificação utilizam algoritmos de aprendizagem de máquina que aprendem com conjuntos de treinamento compostos de vetores de características (features). Nesta tese, as características são representadas pelas métricas obtidas das informações contextuais de cada mudança, descritas no Capítulo 3. Os algoritmos de classificação leem um conjunto de treinamento e constroem um modelo de aprendizado a partir das métricas que são mais úteis para diferenciar cada uma das classes. As classes são representadas pela presença ou ausência de uma mudança conjunta entre dois arquivos em um commit.

Considerando os diferentes algoritmos e modelos de aprendizagem existentes, optou-se por utilizar um algoritmo chamado de random forest. Essa escolha foi baseada no recente uso desse algoritmo em modelos de predição aplicados em engenharia de software e especialmente pelo fato do random forest conseguir lidar com classes não balanceadas (McIntosh et al. 2014; Menzies et al. 2015). No conjunto de dados utilizado nesta tese, existe uma proporção de desbalanceamento entre as amostras da classe que indicam a ocorrência de mudança conjunta ( $20 \%$ das amostras) e a classe que agrupa as amostras nas quais uma mudança conjunta não ocorre ( $80 \%$ das amostras). Essa proporção é apresentada e discutida no Capítulo 5.

O algoritmo random forest cria uma grande quantidade de árvores de decisão em tempo de treinamento usando um subconjunto das métricas coletadas para prever as mudanças conjuntas. A escolha das métricas é feita de modo aleatório, entretanto todas as árvores devem possuir uma correlação fraca entre elas (Breiman, 2001). Usando uma agregação dos votos de todas as árvores, o algoritmo decide se a pontuação final é maior do que um limiar pré-determinado para decidir qual será o resultado da predição. Nesta tese, o algoritmo é utilizado com sua configuração padrão, o que significa dizer que o limiar utilizado foi de 0,5. Logo, o algoritmo irá predizer a ocorrência e a não ocorrência de mudança conjunta se o valor da classe for superior a 0,5 .

\subsubsection{Amostragem}

Além da escolha dos algoritmos de aprendizagem, é importante selecionar o método de amostragem. O método de amostragem é responsável pela escolha das instâncias que farão parte do conjunto de treinamento e teste. Três formas de seleção de amostragem são frequentemente usadas: Holdout, Bootstrap e validação cruzada estratificada.

Na técnica Holdout, o conjunto de dados é dividido com base em uma proporção determinada no momento da execução do algoritmo de aprendizagem. Normalmente, utiliza-se a proporção de dois terços do conjunto de dados para criar o conjunto de treinamento e um terço para criar o conjunto de testes (Michie et al. 1994).

No método Booststrap, $k$ subconjuntos de treinamento são gerados a partir do conjunto de dados original. As amostras são selecionadas aleatoriamente combinada com reposição. Isso significa que uma amostra pode estar presente no conjunto de treinamento mais de uma vez, entretanto, uma vez selecionada para o conjunto de treinamento, essa amostra não é incluída no conjunto de teste. Cada amostra tem $63,2 \%$ de chance de ser selecionada pelo menos uma vez para o conjunto de treinamento. É importante mencionar que o método Bootstrap é custoso computacionalmente e é recomendado quando a quantidade de amostras é pequena (Jain et al. 1987; Kuhn, 2008).

A validação cruzada estratificada possibilita gerar aleatoriamente $k$ subconjuntos mantendo a quantidade de amostras e a proporção das duas classes encontradas no conjunto de dados. Os $k$ subconjuntos avaliados são utilizados como conjuntos de treinamento e testes. As métricas de avaliação dos modelos são obtidas a partir da média da execução de cada subconjunto (Faceli et al. 2011). 
O uso de métodos de amostragem controla os efeitos de superajuste dos dados (overfitting) e o subajustamento do modelo (underfitting). O superajuste indica a baixa capacidade do modelo em aplicar o aprendizado obtido a novas instâncias, ou seja, o modelo é somente útil para explicar o conjunto de treinamento, mas não as novas instâncias de um conjunto de teste. O subajustamento indica que existe baixa taxa de acerto no conjunto de treinamento (Faceli et al. 2011).

\subsubsection{Avaliação da predição}

Tipicamente, estudos de classificação avaliam a qualidade do modelo utilizando medidas de sensibilidade (recall), precisão (precision), medida F (F-measure) e área sob a curva (AUC - Area Under the ROC Curve). Essas medidas são amplamente utilizadas na literatura (Faceli et al. 2011; Hall et al. 2011; Powers, 2011). Entretanto, seguindo as orientações de Powers (2007), que comparou o desempenho das métricas, optou-se por adicionar o coeficiente de correlação de Matthews (MCC), por se tratar de uma medida de correlação da qualidade da modelagem.

Para calcular essas medidas, matrizes de confusão são usadas. Os valores nessa matriz são: Verdadeiro Positivo (VP), Verdadeiro Negativo (VN), Falso Negativo (FN) e Falso Positivo (FP). A sensibilidade (recall) é calculada para identificar a proporção das instâncias de uma determinada classe que o modelo pode recuperar com sucesso. A precisão mede a porcentagem correta de identificação de uma classe. Um bom modelo tem os valores de sensibilidade e precisão altos, entretanto, aumentar um valor frequentemente reduz o outro.

Os valores dessas três medidas variam de 0 até 1 , onde 1 representa os melhores valores para cada uma das métricas. A medida F indica a média harmônica dessas duas medidas (Powers, 2011). Abaixo são apresentadas as fórmulas para cada uma das medidas de avaliação de desempenho dos modelos.

$$
\begin{aligned}
& \text { precisão }=\frac{V P}{V P+F P} \\
& \text { sensibilidade }=\frac{V P}{V P+F N} \\
& \text { medida } F=2 * \frac{\text { precisão } * \text { sensibilidade }}{\text { precisão }+ \text { sensibilidade }}
\end{aligned}
$$

Segundo Powers (2007), essas medidas devem ser utilizadas com cuidado, uma vez que elas apresentam viés na sua interpretação pois não consideram valores negativos. Além disto, os valores de precisão, sensibilidade e medida $\mathrm{F}$ são calculados para cada uma das classes, que no nosso caso é representado por grupos de dependências de mudanças fortes e fracas. Como visto anteriormente, um bom modelo deve apresentar valores altos dessas três medidas para as duas classes estudadas.

Por esse motivo, reportamos também o coeficiente de correlação de Matthews (MCC) para mostrar a qualidade da explicação obtida levando em consideração as duas classes. O MCC corresponde à correlação entre o valor observado e o predito de cada dependência de mudança. Essa medida leva em conta os valores da matriz de confusão (VP, VP, TN e FN) e corresponde a uma medida balanceada, levando em consideração os valores de falso positivo e negativo das duas classes.

Diferentemente dos valores de sensibilidade, precisão e Medida F, o MCC é uma medida para a qualidade do modelo e é utilizado sempre que existem problemas relacionados ao desbalanceamento de classes (Powers 2007). Essa medida devolve um valor entre -1 e +1 . O MCC de +1 representa a modelagem perfeita, 0 significa uma modelagem aleatória e -1 indica uma total falta de concordância entre os valores do conjunto de treinamento e teste. Idealmente, esperamos próximos a +1 . 
O MCC é calculado de acordo com a expressão (Powers 2007):

$$
M C C=\frac{(V P * V N)-(F P * F N)}{\sqrt{(V P+F P) *(V P+F N) *(V N+F P) *(V N+F N)}}
$$

Para comparação entre os modelos de classificação, a medida da área sob a curva é usualmente empregada para comparar o desempenho de diferentes modelos, seja porque os mesmos foram utilizados com diferentes características (métricas) ou porque utilizam diferentes estratégias de aprendizado (diferentes algoritmos de classificação) (Fawcett 2006). A curva ROC é um gráfico que apresenta a relação entre a medida de sensibilidade no eixo y e a taxa de alarme falso (taxa de falso positivos) no eixo x. Uma das vantagens da curva ROC sobre a precisão e a sensibilidade é que ela não é sensível aos limiares utilizados como parâmetros de corte para definir cada uma das classes.

A diagonal da curva ROC representa um classificador aleatório e a posição $(0,1)$ representa a perfeita modelagem da relação entre as classes que indicam a presença ou ausência de mudança conjunta entre um par de arquivos.

Dado que a curva ROC é um instrumento de avaliação visual do desempenho do modelo, a AUC representa uma medida abrangente que facilita a comparação entre diferentes modelos, visto que o AUC é medido como um único valor: uma área de 1 representa um classificador perfeito, enquanto para um classificador aleatório uma área de 0,5 é esperada. O valor 1 representa a perfeita modelagem e diz respeito ao poder discriminante que as métricas têm em relação aos dois grupos de dependências de mudanças. Modelos com valores de AUC inferiores a 0,5 deveriam ser descartados por serem considerados aleatórios, sendo desejável que os valores estejam acima de 0,75 $(75 \%)$.

A discriminação no nosso caso é relativa à capacidade que o modelo tem de utilizar um conjunto de métricas e relacioná-las a cada um dos grupos. Para ilustrar esse cenário, suponha que existem dois grupos já classificados de pares de arquivos que mudaram conjuntamente e pares de arquivos que não mudaram conjuntamente. Agora escolhe-se aleatoriamente um par de arquivos de cada grupo. Suponha que o valor do modelo da AUC é 0,85 (85\%). Isso significa que o modelo consegue discriminar com $85 \%$ de certeza se o par aleatoriamente selecionado mudou conjuntamente. Essa probabilidade é uma propriedade estatística importante, por ser não paramétrica e equivalente ao teste de Wilcoxon test of ranks (Fawcett 2006). Outra propriedade estatística importante da AUC está relacionada com o coeficiente de Gini, uma vez que esse coeficiente é obtido calculando o dobro da área entre a diagonal da curva ROC (Gini $+1=2$ * AUC).

\subsection{Trabalhos relacionados à predição de mudanças conjuntas}

Segundo Li et al. (2012), as técnicas de análise de impacto de mudança (do inglês, change impact analysis) são aplicadas para prever mudanças conjuntas entre artefatos ou verificar os efeitos de uma mudança no sistema. Impacto de mudança é definido como "um processo para identificar potenciais consequências de uma mudança ou estimar o que precisa ser modificado para completar uma mudança" (Arnold e Bohner, 1993). Adicionalmente, também é possível aplicar as técnicas de análise de impacto de mudança para gerar informações que possibilitem compreender as mudanças ou auxiliar nas tarefas de priorização de testes, modularização, depuração de código ou cálculo do custo ou esforço necessário para realizar manutenções (Li et al. 2012) .

Dentre os trabalhos de predição de mudanças conjuntas, a pesquisa realizada por Zimmermann et al. (2005) merece destaque. Esse trabalho recebeu, recentemente, um prêmio na Conferência Internacional de Engenharia de Software (ICSE) por sua importante contribuição. Os autores construíram um componente chamado ROSE para o ambiente de desenvolvimento Eclipse para 
coletar informação sobre as mudanças dos códigos fontes do repositório e alertar os desenvolvedores sobre prováveis mudanças conjuntas entre os arquivos. Regras de associação foram utilizadas para recomendar mudanças conjuntas entre arquivos ou métodos, baseado nos valores de suporte e confiança obtidos do histórico das mudanças dos arquivos. Zimmermann et al. (2005) relataram valores de sensibilidade e precisão em torno de $30 \%$ e recomendam que, para projetos com evolução contínua, a melhor precisão é obtida no nível de arquivo. Os autores indicam que o uso de regras de associação possibilita melhores predições para as mudanças conjuntas quando os valores de suporte e confiança são iguais a 8 mudanças conjuntas e que os arquivos tenham mudado pelo menos em $90 \%$ das vezes conjuntamente no histórico de mudanças do projeto.

Canfora et al. (2010) também utilizaram regras de associação para prever mudanças conjuntas entre os arquivos. Os autores sugerem que a combinação das regras de associação com séries temporais de Granger melhoram a acurácia da predição de mudanças conjuntas, indicando que a medida $\mathrm{F}$ pode alcançar valores de $30 \%$ no melhor caso, enquanto as regras de associação sozinhas podem alcançar em torno de $25 \%$. Similarmente ao trabalho de Zimmermann et al. (2005), Canfora et al. (2010) recomendaram o uso de suporte com valores de pelo menos $2 \%$ das mudanças realizadas e confiança igual ou superior a $80 \%$, também como uma forma de filtrar e usar somente as regras de associação mais importantes para diminuir a quantidade de recomendações falsas para os desenvolvedores.

Outros autores também utilizaram as regras de associação combinadas com outros tipos de acoplamentos, como por exemplo, acoplamento semântico/conceitual ou dinâmico para prever mudanças conjuntas. Gethers et al. (2012) e Kagdi et al. (2013, 2010) propuseram um modelo híbrido que combina, além do acoplamento evolucionário e conceitual, as informações da análise dinâmica do código. Nesse trabalho, primeiramente, foram recuperadas as informações da versão atual de cada projeto para estimar o impacto da mudança utilizando o acoplamento conceitual. Após a verificação do acoplamento conceitual entre os artefatos, os acoplamentos evolucionário e dinâmico foram utilizados para melhorar as recomendações de mudanças conjuntas. Os resultados apresentados pelos autores indicam que a precisão pode obter uma melhoria de até $17 \%$ e a sensibilidade de até 41\%. Essa abordagem difere dos trabalhos de Zimmermann et al. (2005) e Canfora et al. (2010) que partem da análise do histórico das mudanças para inferir as mudanças conjuntas. Entretanto, Gethers et al. (2012) ressaltam que nem sempre o acoplamento evolucionário ou dinâmico está disponível para ser calculado, e, por essa razão, o acoplamento conceitual foi utilizado para realizar as primeiras recomendações, já que o acoplamento conceitual é calculado utilizando o código fonte, que normalmente é acessível.

Gethers et al. (2012) avaliaram vinte e quatro versões de projetos diferentes (KOffice, iBatis, ArgoUML, Apache Http e jEdit). Os resultados indicam que os valores da medida $\mathrm{F}$ variam de $7 \%$ a $23 \%$ e que foi possível prever corretamente de $40 \%$ a $71 \%$ de mudanças conjuntas. Os resultados obtidos indicam que as combinações de dois tipos de acoplamento melhoram a recomendação das mudanças conjuntas. Recentemente, Dit et al. (2014) propuseram uma ferramenta chamada ImpactMiner para ajudar os desenvolvedores a extrair as mudanças conjuntas do controle de versão no nível de métodos. A ferramenta implementa a combinação das técnicas propostas por Kagdi et al. $(2013,2010)$ e Gethers et al. (2012).

Diferentemente dos trabalhos anteriores, Hassan e Holt (2004) propuseram um conjunto de heurísticas que usam o autor do commit, similaridade do nome das classes, o histórico das mudanças conjuntas e a estrutura do código para prever a propagação de mudanças conjuntas. Os autores concluíram que o histórico das mudanças conjuntas é um melhor preditor do que as dependências estruturais do código. Também indicaram que as heurísticas usadas de modo individual produziam altos valores de sensibilidade (até $86 \%$ ), mas valores de precisão bem baixas (6\%). Para melhorar a qualidade das predições, os autores combinaram heurísticas que produziram melhores predições com taxas de precisão de até $49 \%$ e sensibilidade de até $51 \%$.

Zhou et al. (2008) testou o uso de redes bayesianas para construir modelos de predição de mudanças conjuntas. Os autores extraíram informações sobre a dependência estática do código, a frequência passada das mudanças conjuntas, o período da mudança e quem realizou a mudança. Um modelo genérico com todas as mudanças foi construído para prever as mudanças conjuntas 
entre artefatos. Hassan e Holt (2004) realizaram testes em dois projetos de software livre: Azureus e ArgoUML reportando precisão e sensibilidade em torno de $60 \%$ e $40 \%$, respectivamente.

Poshyvanyk et al. (2009) desenvolveram uma técnica para identificar acoplamentos baseados em uma medida do grau de similaridades dos identificadores e comentários. A ferramenta desenvolvida chama-se IRC2M. Durante a pesquisa, os autores identificaram que a similaridade dos identificadores e comentários são melhores preditores para mudança conjunta do que as métricas de acoplamento estrutural. Enquanto IRC2M obteve entre $8 \%$ a $25 \%$ de medida F, o acoplamento estrutural medido pela métrica ICP variou o valor de medida F entre $4 \%$ a $12 \%$. De forma similar a Poshyvanyk et al. (2009), Torchiano e Ricca (2010) aplicaram processamento de linguagem natural nos comentários dos commits e na descrição das tarefas para recomendar mudanças conjuntas. Os autores investigaram as recomendações em 6 tarefas de cada projeto avaliado (ArgoUML, JEdit, phpMyAdmin, SquirrelMail, ScummVM), e relataram precisão máxima de $13.6 \%$, sensibilidade máxima de $96 \%$ e medida $\mathrm{F}$ média de $25 \%$.

Columbus é uma ferramenta baseada no cálculo de vários tipos de acoplamentos estruturais (Ferenc et al. 2002). Sun et al. (2015) utilizaram a ferramenta Columbus para obter os valores da métrica ICP de uma classe para todas as outras classes do sistema gerando uma lista ordenada das classes que são mais dependentes de acordo com essa métrica de acoplamento estrutural. Essa lista ordenada foi usada para gerar as recomendações de mudanças conjuntas. Sun et al. compararam Columbus com outras duas abordagens frequentemente referenciadas na literatura: ROSE e IRC2M. Os resultados da comparação indicaram que IRC2M e ROSE obtiveram as melhores taxas de sensibilidade, precisão e medida $\mathrm{F}$ quando comparados com a ferramenta Columbus. A combinação de quaisquer duas técnicas melhorou a acurácia em termos gerais. Entretanto, a combinação das três técnicas não produziu melhores resultados. Os melhores valores de sensibilidade foram entre $55 \%$ a $70 \%$ e os valores de precisão ficaram entre $30 \%$ a $45 \%$. Para realizar a comparação, Sun et al. (2015) utilizaram 5 projetos, considerando no maior caso 2 anos de desenvolvimento e no máximo 309 classes. A ferramenta ROSE obteve a medida $\mathrm{F}$ variando de $25 \%$ até $33 \%$, sensibilidade de $50 \%$ a $63 \%$ e precisão de $8 \%$ a $40 \%$.

Petrenko e Rajlich (2009) apresentaram a ferramenta JRipples que utiliza diferentes níveis de granularidade de informações das classes para realizar a análise do impacto da mudança. As recomendações são feitas com base em um grafo de relacionamento entre classes (Class and Member Dependency Graph). Os autores investigaram dois projetos de software livre (Adempiere e Azureus) e relataram precisão média de $18.69 \%$ quando fragmentos do código fonte foram usados para gerar as recomendações. Jashki et al. (2008) propuseram uma forma de calcular o grau de proximidade entre dois artefatos a partir de uma matriz de mudanças conjuntas. Usando algoritmos de agrupamento os autores geraram recomendações para mudanças conjuntas. Os projetos Firefox, FileZilla, Thunderbird, Firebird foram avaliados e a precisão média das recomendações foi de $61.49 \%$.

Mais recentemente, Abdeen et al. (2015) utilizaram modelos bayesianos utilizando acoplamento estrutural, conceitual e a combinação desses dois acoplamentos para prever mudanças conjuntas entre dois artefatos. Os autores reportaram valor de precisão médio de $68 \%$, sensibilidade média de $66 \%$ e medida $\mathrm{F}$ média de $42 \%$. Os autores observaram que o uso de acoplamento estrutural melhora a precisão, enquanto o uso do acoplamento conceitual melhora a sensibilidade dos modelos de predição. Interessante observar que os autores relatam que a combinação do acoplamento estrutural e conceitual não melhoraram a predição em 3 dos 4 projetos avaliados.

\subsubsection{Sumarização dos trabalhos relacionados}

Diversos trabalhos propuseram abordagens para prever mudanças conjuntas em projetos de software. Para facilitar a comparação dos trabalhos relacionados com a abordagem de predição proposta nesta tese, os trabalhos relacionados são sumarizados na Tabela 2-1. A tabela apresenta o tipo de abordagem usada em cada trabalho, os projetos e versões estudados e os resultados obtidos. 
Tabela 2-1 Sumarização dos trabalhos relacionados

\begin{tabular}{|c|c|c|c|}
\hline Autores & Tipo Abordagem & Projetos e Versões & Resultado \\
\hline $\begin{array}{l}\text { Hassan e Holt } \\
(2004)\end{array}$ & Heurísticas & $\begin{array}{l}\text { NetBSD, FreeBSD, OpenBSD, } \\
\text { Postgres, GCC }-40 \text { anos de histórico } \\
\text { analisados no total }\end{array}$ & $\begin{array}{l}\text { Precisão média de } 49 \% \text {. } \\
\text { Sensibilidade média de } 51 \% \text {. } \\
\text { Heurísticas individuais obtêm } 86 \% \\
\text { de sensibilidade e } 6 \% \text { de precisão }\end{array}$ \\
\hline Canfora et al.(2010) & $\begin{array}{l}\text { Regra de } \\
\text { associação }+ \text { séries } \\
\text { temporais }\end{array}$ & $\begin{array}{l}\text { Mylyn, Squid, FreeBsd, Rhino }-8 \\
\text { anos de histórico analisados no total }\end{array}$ & $\begin{array}{l}\text { Medida F média de } 25 \% \text { com as } \\
\text { técnicas combinadas. Maior valor de } \\
\text { medida F reportada foi } 30 \% \text { para o } \\
\text { Rhino }\end{array}$ \\
\hline $\begin{array}{l}\text { Zimmermann et al. } \\
(2005)\end{array}$ & $\begin{array}{l}\text { Regra de } \\
\text { associação }\end{array}$ & $\begin{array}{l}\text { Eclipse, GCC, GIMP, jBoss, jEdit, } \\
\text { KOffice, Postgres, Python }\end{array}$ & $\begin{array}{l}\text { Precisão média de } 29 \% \text {, } \\
\text { Sensibilidade média } 33 \%\end{array}$ \\
\hline Zhou et al. (2008) & $\begin{array}{l}\text { Rede bayesiana } \\
\text { (frequência } \\
\text { mudanças } \\
\text { conjuntas e } \\
\text { dependência } \\
\text { estática) }\end{array}$ & $\begin{array}{l}\text { Azureus2 e ArgoUML ( } 5 \text { versões de } \\
\text { cada projeto) - } 7 \text { anos de histórico } \\
\text { total analisado. }\end{array}$ & $\begin{array}{l}\text { Precisão média de } 70 \% \text {, } \\
\text { Sensibilidade média } 50 \% \text {. Medida F } \\
\text { média em torno de } 70 \% \text {. }\end{array}$ \\
\hline $\begin{array}{l}\text { Kagdi et al. }(2013, \\
2010) \text { e Gethers et } \\
\text { al. (2012) }\end{array}$ & $\begin{array}{l}\text { Acoplamento } \\
\text { evolucionário* }+ \\
\text { conceitual }+ \\
\text { acoplamento } \\
\text { dinâmico }\end{array}$ & $\begin{array}{l}\text { KOffice, iBatis, ArgoUML, Apache } \\
\text { Http e jEdit ( } 30 \text { versões) - } \\
\text { aproximadamente } 26 \text { anos de } \\
\text { histórico dos projetos }\end{array}$ & $\begin{array}{l}\text { Medida } \mathrm{F} \text { média de } 26 \% \text {. Amostras } \\
\text { corretamente preditas variam de } \\
40 \% \text { a } 71 \%\end{array}$ \\
\hline $\begin{array}{l}\text { Abdeen et al. } \\
(2015)\end{array}$ & $\begin{array}{l}\text { Acoplamento } \\
\text { estrutural }+ \\
\text { acoplamento } \\
\text { conceitual }\end{array}$ & $\begin{array}{l}\text { EIRC, FreeMind, LatexDraw, } \\
\text { JFreeChart (46 versões) }\end{array}$ & Medida F Média de $42 \%$ \\
\hline Sun et al. (2015) & $\begin{array}{l}\text { Comparação entre } \\
\text { o acoplamento } \\
\text { evolucionário, } \\
\text { conceitual e } \\
\text { estático }\end{array}$ & $\begin{array}{l}\text { Rhino, Ant, JMeter, XML-Security, } \\
\text { JTopas - } 3 \text { anos de histórico. }\end{array}$ & $\begin{array}{l}\text { Sensibilidade média foram entre } 50 \% \\
\text { a } 63 \% \text { (valor máximo } 69 \% \text { ), e os } \\
\text { valores de precisão média ficaram } \\
\text { entre } 34 \% \text { a } 40 \% \text { (valor máximo } \\
45 \% \text { ) }\end{array}$ \\
\hline $\begin{array}{l}\text { Petrenko e Rajlich } \\
(2009)\end{array}$ & $\begin{array}{l}\text { Grafo de } \\
\text { Dependência e } \\
\text { Fragmentos de } \\
\text { código }\end{array}$ & Adempiere e Azureus & Precisão média de $18.69 \%$ \\
\hline $\begin{array}{l}\text { Torchiano e Ricca } \\
(2010)\end{array}$ & $\begin{array}{l}\text { Processamento de } \\
\text { linguagem natural } \\
\text { nos comentários } \\
\text { dos commits e } \\
\text { descrição das } \\
\text { tarefas }\end{array}$ & $\begin{array}{l}\text { ArgoUML, JEdit, phpMyAdmin, } \\
\text { SquirrelMail, ScummVM }\end{array}$ & $\begin{array}{l}\text { Precisão máxima de } 13.6 \% \text {, } \\
\text { sensibilidade máxima de } 96 \% \text {. } \\
\text { Medida F média de } 25 \% \text {. }\end{array}$ \\
\hline Jashki et al. (2008) & $\begin{array}{l}\text { Matriz de mudança } \\
\text { conjunta, grau de } \\
\text { proximidade e } \\
\text { algoritmo de } \\
\text { agrupamento. }\end{array}$ & $\begin{array}{l}\text { Firefox, FileZilla, Thunderbird, } \\
\text { Firebird }\end{array}$ & Precisão média de $61.49 \%$. \\
\hline
\end{tabular}

*Acoplamento evolucionário é normalmente implementado usando regras de associação para identificar os padrões de mudanças conjuntas entre os arquivos. Acoplamento evolucionário é também conhecido como acoplamento de mudança ou acoplamento lógico (do inglês, change coupling e logical coupling) (Gall et al. 2003; Ying et al. 2004).

Observa-se na sumarização que o método mais usado é o baseado em regras de associação e que a maior parte dos trabalhos utiliza até 5 projetos para avaliar a abordagem proposta. Dentre as principais conclusões indicadas nos trabalhos, é possível perceber que, normalmente, as técnicas possuem alta precisão e baixa sensibilidade, ou o contrário, resultando em um baixo valor de medida F, que é calculado a partir da média harmônica dos valores de precisão e sensibilidade. 


\subsection{Considerações finais}

Neste capítulo, foram apresentados os principais conceitos relacionados a esta tese, como por exemplo, a definição de dependências de software, os tipos de dependência, a definição de contexto, a técnica de predição utilizada e o estado da arte de predição de mudanças conjuntas.

É importante mencionar que cada um dos trabalhos relacionados apresenta particularidades, como, por exemplo, a abordagem de predição realizada e os projetos avaliados. Apesar do amplo esforço realizado pelos pesquisadores, ainda é um desafio reduzir a quantidade de recomendações falsas emitidas por essas abordagens. No próximo capítulo, são descritas as informações contextuais usadas na abordagem de predição proposta nesta tese e a nossa motivação para utilizá-las. 


\section{Capítulo 3 \\ Informações contextuais do desenvolvimento de software}

Este capítulo apresenta o estudo do uso contexto social em modelos de predição aplicados à engenharia de software para verificar quais as métricas foram usadas para construir modelos preditivos e se o seu uso trouxe efeitos positivos nos resultados da predição. Para identificar as métricas sociais foi realizado um mapeamento sistemático da literatura. Após a apresentação do mapeamento sistemático, são apresentadas as informações contextuais escolhidas para construir os modelos de predição de mudanças conjuntas propostos nesta tese.

\subsection{Mapeamento sistemático sobre métricas sociais usadas em modelos de predição aplicados à Engenharia de Software}

Mapeamento sistemático em engenharia de software é definido como um método para construir esquemas de classificação e estruturar áreas de pesquisa de interesse (Petersen et al. 2008). Esse tipo de estudo segue o mesmo método de uma revisão sistemática de literatura, mas os resultados são apresentados para indicar a frequência de publicações por categoria e classificar os estudos para investigar questões de pesquisa específicas.

Para investigar modelos de predição aplicados em engenharia de software, diversos mapeamentos e revisões sistemáticas foram realizadas. A Tabela 3-1 apresenta as revisões sistemáticas encontradas na literatura. Em geral, é possível perceber que esses trabalhos discutem aspectos da construção dos modelos de predição, como por exemplo, quais conjuntos de dados e técnicas foram usados, bem como, apresentam as métricas utilizadas como preditores. A seguir são apresentados cada uma das revisões sistemáticas encontradas na literatura.

Jorgensen e Shepperd (2007) identificaram 304 artigos sobre estimativa de custo. A revisão sistemática não apresenta quais métricas foram mais relevantes nesse contexto, entretanto, os autores indicaram que pesquisadores devem focar na compreensão da relação entre as características do projeto e métodos para estimar custos de software.

Riaz et al. (2009) apresentaram um estudo focado para identificar atributos de qualidade de software. Quinze estudos (15) foram selecionados durante a revisão sistemática. No contexto de manutenibilidade, os autores indicam que os modelos de predição comumente utilizam caraterísticas relacionadas ao tamanho, complexidade e acoplamento do projeto.

Catal e Diri (2009) realizaram uma revisão sistemática para identificar o conjunto de dados e métodos usados para predição de falhas em software. Setenta e quatro (74) artigos foram identificados. Os resultados indicam que o número de modelos de predição de falhas que utilizam técnicas baseadas em algoritmos de aprendizagem de máquina têm aumentado significativamente desde 2005. Catal (2011) atualizou a revisão sistemática descrevendo 90 artigos encontrados na 
literatura. O autor indicou a necessidade de construir ferramentas que possam ser aplicadas em ambientes reais e a falta de estudos que envolvam dados reais obtidos da indústria.

Jureczko e Madeyski (2011) discutiram as diferenças entre métricas de produto e processo a partir da revisão de 44 estudos. Os autores descreveram cinco métricas de processo: número de revisões, número de desenvolvedores únicos que modificaram o arquivo, número de linhas modificadas (code churn), número de linhas adicionadas e número de defeitos encontrados na versão anterior. A métrica número de desenvolvedores únicos que modificaram o arquivo foi a única métrica apresentada como relacionada ao desenvolvedor.

Hall et al. (2012) atualizaram os trabalhos de Catal e Diri $(2009,2011)$ investigando os tipos de modelos criados, as variáveis independentes e as técnicas de modelagem usadas para construir modelos de predição de falhas de software. Como resultado, os autores selecionaram 36 estudos. A análise dos artigos indicou que os modelos utilizaram algoritmos de aprendizagem de máquina (classificadores) tais como Naïve Bayes e Regressão Logística e usaram combinações de métricas (variáveis independentes) para melhorar a acurácia.

Tabela 3-1. Revisões sistemáticas de predição em Engenharia de Software

\begin{tabular}{|c|c|c|}
\hline Autores & Foco & Sumarização \\
\hline $\begin{array}{l}\text { Jorgensen e Shepperd } \\
(2007)\end{array}$ & $\begin{array}{l}\text { Estimar custo de } \\
\text { software }\end{array}$ & $\begin{array}{l}\text { O estudo apresenta uma pesquisa para melhorar a estimativa } \\
\text { do custo do software. Métricas sociais não foram discutidas. }\end{array}$ \\
\hline Riaz et al. (2009) & $\begin{array}{l}\text { Predição de Manutenção } \\
\text { de Software e métricas }\end{array}$ & $\begin{array}{l}\text { Os preditores reportados foram baseados em tamanho, } \\
\text { complexidade e acoplamento de software no nível de código } \\
\text { fonte. Métricas sociais não foram discutidas. }\end{array}$ \\
\hline $\begin{array}{l}\text { Catal e Diri (2009) e } \\
\text { Catal (Catal, 2011) }\end{array}$ & $\begin{array}{l}\text { Modelos de predição de } \\
\text { defeitos }\end{array}$ & $\begin{array}{l}\text { Poucos artigos reportaram o uso de métricas de processo. } \\
\text { Nenhuma métrica social foi discutida. }\end{array}$ \\
\hline $\begin{array}{l}\text { Jureczko e Madeyski } \\
(2011)\end{array}$ & Métricas de processo & $\begin{array}{l}\text { Taxinomia de métricas de processo com cinco métricas. A única } \\
\text { métrica social identificada foi o número de desenvolvedores } \\
\text { distintos que modificaram um arquivo. }\end{array}$ \\
\hline Hall et al. (2012) & $\begin{array}{l}\text { Modelos de predição de } \\
\text { falhas de software }\end{array}$ & $\begin{array}{l}\text { Técnicas de predição que constroem modelos mais simples e } \\
\text { usam combinação de métricas apresentam melhor desempenho } \\
\text { para predizer falhas de software. Poucos trabalhos usaram } \\
\text { alguma métrica social. }\end{array}$ \\
\hline Radjenović et al. (2013) & $\begin{array}{l}\text { Métricas para predição } \\
\text { de falhas de software }\end{array}$ & $\begin{array}{l}\text { Métricas de processo e métricas de orientação à objetos foram } \\
\text { reportados como os melhores preditores de falhas de software } \\
\text { quando comparados com as métricas usadas tradicionalmente, } \\
\text { como por exemplo, métricas de complexidade do código fonte e } \\
\text { do tamanho. Métricas de processo tiveram melhor desempenho } \\
\text { na predição de defeitos pós-versão quando comparadas com } \\
\text { métricas estáticas de código fonte. Hall et al. (2012), } \\
\text { Radjenović et al. (2013) reportaram que informações do } \\
\text { desenvolvedor foram usados para construir modelos de } \\
\text { predição. Entretanto, apenas oito artigos reportaram o uso de } \\
\text { métricas sociais. }\end{array}$ \\
\hline
\end{tabular}

Os autores reportaram diferentes tipos de métricas utilizadas. Considerando as métricas de processo, os autores mencionaram que poucos estudos utilizaram informação dos desenvolvedores e que quando essas métricas foram utilizadas os resultados apresentados eram conflitantes. $\mathrm{O}$ mapeamento sistemático realizado nesta tese complementa o trabalho de Hall et al. (2012), uma vez que as métricas sociais são classificadas e avaliadas, tornando mais clara a contribuição das métricas sociais quando são usadas como preditores.

Radjenovic et al. (2013) apresentaram uma revisão sistemática analisando 106 artigos publicados. Os autores selecionaram artigos de acordo com as métricas e contexto. Os autores encontraram que métricas orientadas a objetos (Chidamber e Kemerer's) foram utilizados em 49 das vezes, enquanto as métricas tradicionais de código fonte (por exemplo, LOC, complexidade ciclomática) foram utilizadas $27 \%$ e métricas de processo $24 \%$ das vezes. Com relação às métricas sociais, Radjenovic et al. (2013) mencionaram que oito artigos usaram informações dos desenvolvedores e indicaram que os aspectos sociais ainda eram pouco explorados em trabalhos de predição no contexto da engenharia de software. 
As revisões sistemáticas apresentadas discutem diferentes aspectos relacionados aos modelos de predição aplicados a engenharia de software. Entretanto, nenhum dos trabalhos discutem a influência das métricas sociais quando essas métricas são consideradas como preditores. O mapeamento sistemático realizado identificou, classificou e discutiu a influência das métricas sociais em relação aos trabalhos encontrados durante a realização do mapeamento sistemático.

\subsubsection{Método do mapeamento sistemático}

Para realização de estudos sistemáticos da literatura, duas abordagens são comumente utilizadas em engenharia de software: a de Kitchenham e Charters (2007), que foca na pesquisa sistemática em bases de dados usando expressões de busca bem definidas e a de Webster e Watson (2002), que faz uso de análise de citação "bola de neve" (snowballing) como um método principal para encontrar artigos relevantes. Jalali e Wohlin (2012) compararam as duas abordagens e não encontraram diferença relevante nos resultados gerados.

Nesta tese, primeiramente foi aplicado o método de Kitchenham e Charters (2007) utilizando uma expressão de busca usada com base nas expressões usadas por Radjenovic et al. (2013) e Hall et al. (2012) para encontrar a nossa lista inicial de artigos candidatos. A expressão adaptada é indicada a seguir:

(software OR "open source" OR repository OR repositories) AND (fault OR effort OR defect OR quality OR error-prone OR error-proneness OR failure OR error OR prone) AND (metric OR metrics OR measurement OR measure OR measuring OR social OR socio-technical OR "communication network" OR "developer network" OR "developer information" OR "developer interaction" OR "human factor") AND (predict* OR estimat* OR classificat* OR regression)

Como os resultados obtidos com a expressão de busca foram genéricos e devolveram muitos artigos fora do escopo desta tese, foi aplicado o método de "bola de neve" recomendado por Jalali e Wohlin (2012), que trata esse tipo de problema dos ruídos que podem ocorrer com o uso de expressões de consulta.

A Figura 3-1 sumariza as etapas para realizar o mapeamento sistemático.

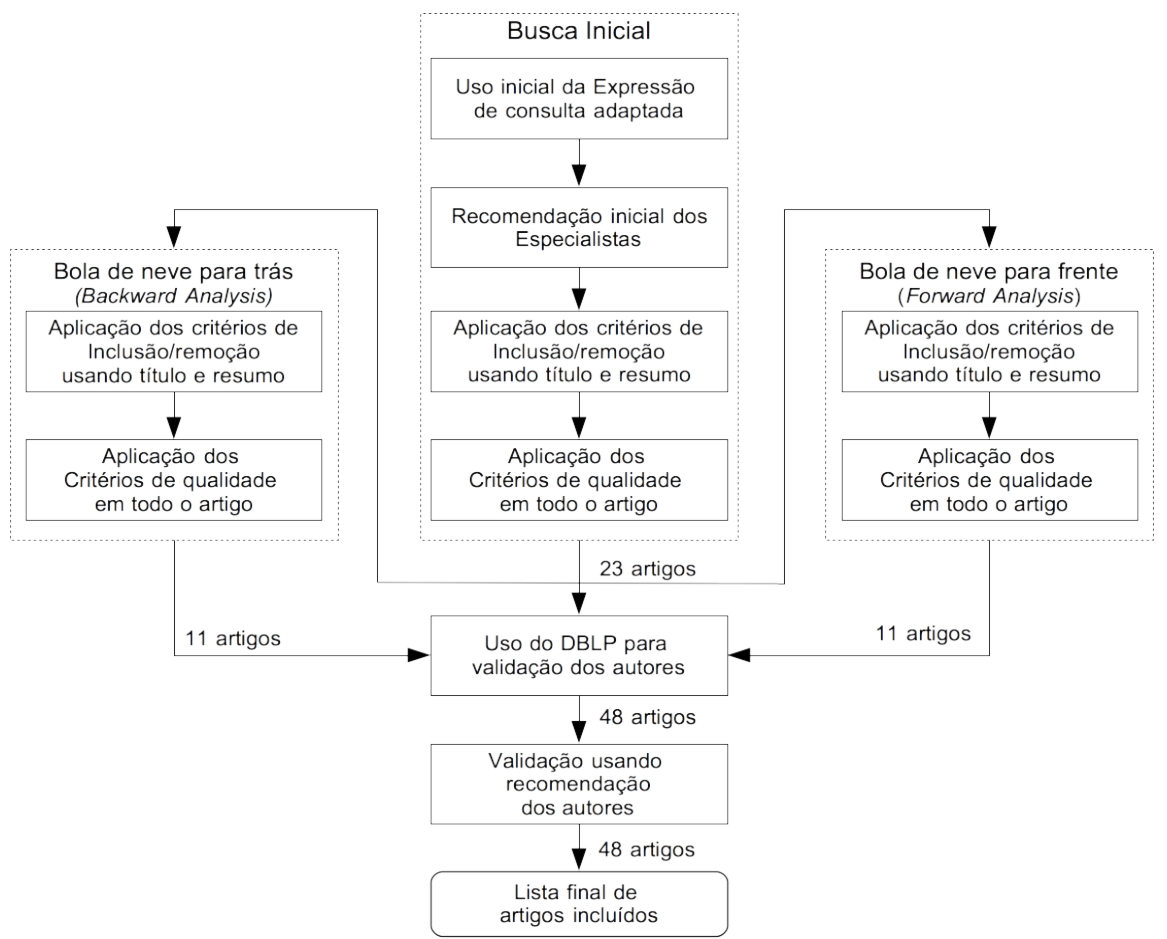

Figura 3-1. Método de Bola de Neve usado para o mapeamento sistemático. 
No primeiro passo, foi utilizada a expressão adaptada de Hall et al. (2012) e Radjenović et al. (2013)(Hall et al. 2012) nas bases de dados da ACM, IEEE e Scopus para criar a lista inicial de artigos candidatos. O título e o resumo dos artigos foram verificados e quando as informações de título e resumo não eram suficientes para julgar os critérios de inclusão e exclusão o texto inteiro foi considerado.

Um artigo foi excluído da lista inicial de artigos candidatos se claramente estava fora de escopo do mapeamento sistemático após verificação dos critérios de inclusão. Todos os estudos primários potenciais foram mantidos para análise, uma vez que as métricas sociais poderiam ser classificadas de maneiras diferentes nos trabalhos. Os critérios de inclusão e exclusão foram usados para guiar a primeira discussão entre dois pesquisadores e definir a concordância ou discordância para cada artigo selecionado. Os artigos eram incluídos se tivessem sido publicados em revistas, conferências e workshops e deveriam ter pelo menos uma métrica que pudesse ser classificada como social. Os artigos foram excluídos se mencionassem somente métricas de código fonte, se o artigo não fosse escrito na língua inglesa, não fossem artigo completo ou se o texto não estivesse acessível.

Após o uso dos critérios de inclusão e exclusão, cada artigo selecionado foi avaliado por dois pesquisadores (o autor desta tese e um segundo pesquisador) que aplicaram os critérios de qualidade na Tabela 3-2. Os critérios de qualidade foram definidos com base no trabalho de Dybå e Dingsoyr's (2008).

A Tabela 3-2 apresenta as questões para avaliar se um artigo seria selecionado. Para serem incluídos na lista de artigos aceitos para o mapeamento, o artigo precisava receber "SIM" pelo menos nas 5 primeiras questões. As questões do critério de análise de dados e conclusão não excluem o artigo da lista de artigos selecionados.

Tabela 3-2 Critério de qualidade para inclusão de artigo no mapeamento sistemático

\begin{tabular}{l|l}
\hline \multicolumn{1}{c|}{ Critério } & \multicolumn{1}{c}{ Questão } \\
\hline Definição do Problema & O objetivo de pesquisa é claro e bem motivado? \\
\hline \multirow{4}{*}{ Coleta de Dados } & $\begin{array}{l}\text { Existe pelo menos uma métrica que usa algum aspecto social? (Desenvolvedor, } \\
\text { comunicação, colaboração, experiência, entre outros) }\end{array}$ \\
\cline { 2 - 2 } & As métricas sociais encontradas estão apropriadamente descritas? \\
\cline { 2 - 2 } & É possível reproduzir a implementação da métrica social? \\
\hline Projeto de Pesquisa & Existe algum modelo de predição utilizado? (Classificação / estatístico) \\
\hline \multirow{2}{*}{ Análise de Dados } & $\begin{array}{l}\text { Existem métricas de avaliação usadas para avaliar o desempenho (acurácia) } \\
\text { dos modelos de predição usados? }\end{array}$ \\
\cline { 2 - 2 } & $\begin{array}{l}\text { Os resultados são explicados usando seleção de atributos ou algum método } \\
\text { que compare o desempenho das métricas? }\end{array}$ \\
\hline Conclusão & O artigo discute limitações ou ameaças à validade? \\
\hline
\end{tabular}

A seleção inicial resultou em 23 artigos. Utilizando esses artigos foi realizada a análise de bola de neve para trás (passo 2) e para frente (passo 3) (backward snowballing e forward snowballing). O método de "bola de neve para trás" analisa as referências dos artigos que são parte da lista inicial de artigos encontrados após a execução do passo 1 para encontrar novos artigos candidatos. No método de "bola de neve para frente", são procurados os artigos que citaram os artigos que eram parte da nossa lista inicial de artigos.

Durante esse procedimento, os critérios de inclusão e exclusão foram utilizados para guiar a discussão entre os dois pesquisadores e definir se o artigo seria incluído na lista final de artigos selecionados. Para incluir o artigo, os dois pesquisadores discutiam com base no critério de qualidade. Onze artigos foram selecionados em cada etapa, resultando em 48 artigos na lista final 
de artigos selecionados. Por fim, o $\mathrm{DBLP}^{2}$, um banco de dados com publicações de cada autor, foi verificado para procurar novos artigos.

Finalmente, para validar nossa lista final de artigos, foi utilizado um passo sugerido por Kitchenham e Brereton (2009). E-mails foram encaminhados para todos os pesquisadores que eram autores de mais de dois estudos primários.

No total, 21 e-mails foram enviados e 10 respostas foram recebidas. Os especialistas recomendaram 26 autores nas respostas, entretanto, somente dois autores não haviam sido identificados após a verificação do DBLP (passo 4). Após a verificação do DBLP desses dois autores, nenhum artigo novo foi adicionado na lista final. Os dois autores indicados tinham trabalhos com aspectos sociais da engenharia de software, mas seus trabalhos não utilizavam modelos de predição.

\subsubsection{Extração de dados}

Esta seção sumariza a quantidade de artigos selecionados na lista final em cada etapa.

A Tabela 3-3 apresenta em qual etapa, cada um dos 48 artigos foram selecionados. A extração de dados foi realizada no mês de janeiro de 2014. São apresentados o número de artigos publicados em conferências e workshops (\#conf), o número de revistas encontradas (\#rev) e o número de artigos que foram excluídos (\#rej). Considerando o número de artigos excluídos durante os passos de bola de neve para trás e para frente, é apresentado o número de artigos distintos que foram excluídos em vez do número de referências que foram encontradas e excluídas.

Para serem incluídos, os artigos tinham que possuir pelo menos uma métrica que pudesse ser classificada como social. Esse critério foi aplicado porque muitas vezes os autores classificaram uma métrica social como uma métrica de processo, do histórico ou de organização.

Tabela 3-3 Sumarização dos estudos primários incluídos e rejeitados

\begin{tabular}{|c|c|c|c|c|c|c|c|c|c|c|c|}
\hline \multicolumn{3}{|c|}{ Lista Inicial } & \multicolumn{3}{|c|}{$\begin{array}{c}\text { Bola de Neve } \\
\text { para trás }\end{array}$} & \multicolumn{3}{|c|}{$\begin{array}{c}\text { Bola de Neve } \\
\text { para frente }\end{array}$} & \multicolumn{3}{|c|}{ DBLP } \\
\hline$\#$ conf & \#rev & \#rej & \# conf & \# rev & \#rej & \# conf & \#rev & \#rej & \# conf & $\#$ rev & $\#$ rej \\
\hline 19 & 4 & 48 & 6 & 5 & 419 & 9 & 2 & 212 & 1 & 2 & 34 \\
\hline
\end{tabular}

Os resultados apresentados na Tabela 3-3 indicam que a maioria dos artigos foi obtida a partir da expressão de busca. Os passos de bola de neve para trás e para frente devolveram 11 artigos em cada passo. A diferença é que o procedimento de bola de neve para trás encontrou 6 artigos de conferência e 5 revistas, enquanto o procedimento baseado em análise das citações (bola de neve para frente) encontrou 9 artigos de conferências. No último passo, somente 3 novos artigos foram adicionados na lista final considerada para a construção do modelo de classificação das métricas sociais.

A maior parte das exclusões ocorreram porque os artigos apresentavam alguma métrica social que não era usada em modelos de predição. Por exemplo, foram encontrados artigos cujo principal objetivo foi investigar a evolução de comunidades de software ou ferramentas de visualização de informações sociais em projetos de software. A maior quantidade de artigos excluídos ocorreu durante a execução do procedimento de bola de neve (para trás e para frente). Seis artigos foram excluídos por critérios de qualidade após a sua seleção inicial.

A lista final de artigos selecionados possui 48 artigos, escritos por 103 autores distintos. Na lista inicial, 55 autores foram encontrados. O passo de bola de neve para trás encontrou 30 autores, mas somente 13 foram distintos em relação ao passo 1. No passo de bola de neve para frente, mais

\footnotetext{
${ }^{2}$ http://www.informatik.uni-trier.de/ ley/db/
} 
38 novos autores foram identificados, e 4 autores estavam na lista inicial de autores. Após a verificação no DBLP, mais 6 autores foram adicionados.

Considerando os veículos de publicação, 35 artigos foram publicados em conferências e 13 artigos foram publicados em revistas importantes da área de engenharia de software. A International Conference on Software Engineering (ICSE) foi a conferência com a maior quantidade de artigos selecionados (10) entre 2008 e 2013. O Foundations of Software Engineering (FSE) com 6 artigos em 2008, 2010, 2011 e 2012 ficou em segundo lugar. A conferência de modelos preditivos em Engenharia de Software (PROMISE) teve 5 artigos publicados em 2007, 2010, 2011 (2) e 2012. Em relação às revistas, os principais veículos foram: Empirical Software Engineering (SPRINGER), Transactions on Software Engineering (IEEE), Information and Software Technology (ELSEVIER) e Journal of Systems and Software (ELSEVIER), sendo a maior parte dos artigos publicados entre 2008 a 2013.

\subsubsection{Resultados e discussão}

Apresenta-se a seguir, os resultados do mapeamento sistemático. Um material complementar sobre as análises e planilhas usadas para condução do mapeamento sistemático é encontrado em https://github.com/igorwiese/promise14.

\subsubsection{Quais as métricas sociais foram usadas em modelos de predição?}

A partir dos 48 estudos preliminares, 51 métricas sociais foram identificadas. A Figura 3-2 apresentam as métricas encontradas na literatura e a referência para cada artigo que utilizou a métrica no modelo de predição. Deste modo é possível rastrear a relação entre métrica e artigo por meio da referência "p[número]".

Observa-se na Figura 3-2 que uma mesma métrica é calculada de diferentes formas e possuí nomes diferentes. Por exemplo, o número de desenvolvedores distintos é obtido com dados de todo o projeto ou de um período específico de tempo (por exemplo, uma versão). A forma de agregação (por exemplo, máximo, mínimo, mediana, etc.) usada para obter o valor da métrica também difere em cada trabalho.

Considerando a quantidade de vezes que cada métrica foi citada, destaca-se que foram frequentemente considerados como preditores a quantidade de desenvolvedores com maior número de modificações para um arquivo específico (5 citações), a experiência dos desenvolvedores (4 citações), a reputação do usuário que relatou a tarefa (4 citações) e a quantidade de palavras em uma discussão (4 citações). 


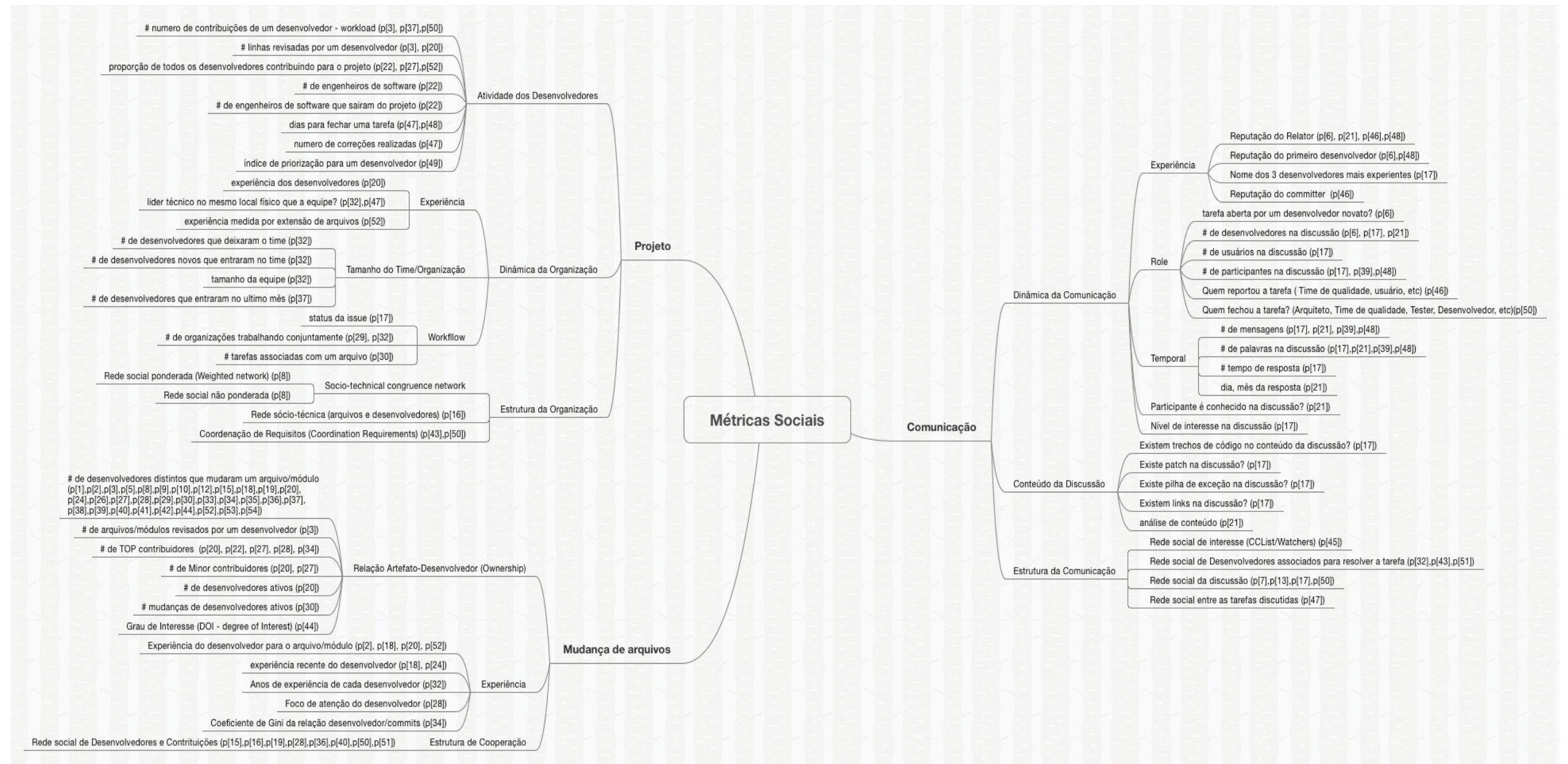

Figura 3-2. Lista das métricas sociais encontradas. 


\subsubsection{Classificação das métricas sociais usadas em modelos de predição em Engenharia de Software de acordo com a literatura.}

Esta subseção apresenta as diferentes definições encontradas na literatura para métricas sociais e exemplos de métricas que foram classificadas por diferentes autores. Posteriormente, é apresentada a classificação proposta para as métricas sociais encontradas no mapeamento sistemático e que foram apresentadas na Figura 3-2.

De acordo com trabalhos encontrados durante o mapeamento sistemático, é difícil distinguir métricas sociais, históricas ou de processo e métricas organizacionais. Por exemplo, o número de desenvolvedores distintos que modificaram um arquivo foi a métrica que apresentou o maior número de diferentes classificações (11 no total) e "processo" foi a classificação mais comum. Essa métrica também foi utilizada com 18 diferentes nomes e apareceu em 32 diferentes artigos. Esse exemplo ilustra que não existe padronização na nomenclatura das métricas e sua classificação.

Para alguns autores (D'Ambros et al. 2012a; Hall et al. 2012; Rahman e Devanbu, 2013) as métricas históricas ou de processo são representadas por medidas obtidas das modificações dos arquivos recuperadas do log do sistema de controle de versão, como por exemplo o Git, Mercurial, CVS e o SVN. Como as métricas de processo podem ser obtidas do histórico e capturam aspectos da evolução do software, o termo "histórico" foi usado para as métricas que refletem as mudanças dos arquivos sobre o tempo, como por exemplo, o número de mudanças no código ao longo de um período de um ano (Jureczko e Madeyski, 2011).

As métricas sociais do desenvolvimento de software capturam diferentes aspectos da relação social entre os desenvolvedores durante a realização de suas tarefas, tais como, a comunicação dos desenvolvedores durante a realização de tarefas que modificam os arquivos (Bird et al. 2008, Bertram et al. 2010, Bettenburg e Hassan 2013, Tsay et al. 2014, Wiese et al. 2014a). O termo "métrica social" refere-se a qualquer métrica que mede aspectos de interação entre os desenvolvedores ou participação humana para realizar alguma tarefa associada ao desenvolvimento de software.

Entretanto, observou-se que como as interações sociais ocorrem no contexto do processo de evolução e manutenção de software, trabalhos anteriores (Illes-Seifert e Paech, 2010) também consideraram que métricas sociais são parte das métricas de processo ou outro contexto do desenvolvimento de software. Por exemplo, Arisholm et al. (2010) indicaram que as métricas de processo necessitam de informações detalhadas sobre o trabalho dos desenvolvedores, como por exemplo, mudanças, correções de falhas, informação sobre os desenvolvedores e momento da mudança. Na definição de Arisholm et al. (2010) é difícil identificar se uma métrica é social ou de processo.

D'Ambros et al. (2012) usaram métricas de processo e de código para construir modelos de predição de defeitos e usaram o termo "outras abordagens" para se referir a aspectos sociais. Três artigos selecionados na nossa lista final de artigos foram classificados por D'Ambros et al. (2012) como "outras abordagens", indicando uma distinção entre o conceito de "processo" adotado na classificação das métricas no artigo e esses artigos que eram associados a aspectos sociais. Dois desses artigos (Bacchelli et al. 2010; Wolf et al. 2009), foram encontrados no mapeamento por se tratar de aspectos sociais. O terceiro artigo trata de métricas sócio-técnicas obtidas de uma rede desenvolvedor-módulo usada para predizer defeitos (Pinzger et al. 2008).

D'Ambros et al. (2012) utilizaram o termo "métricas de processo" do mesmo modo como definido no trabalho de Moser et al. (2008), que usaram um conjunto de métricas de processo centradas nos arquivos, como por exemplo, o número de revisões de um arquivo, o número de vezes que um arquivo foi refatorado, o número de linhas adicionadas e removidas de cada arquivo, o tamanho de uma mudança (em número de arquivos) ou a idade de um arquivo. Todas essas métricas dizem respeito a um arquivo e não têm qualquer associação com pessoas ou interações sociais. Entretanto, na lista de métricas propostas por Moser et al. (2008) há uma métrica definida 
como o número de desenvolvedores distintos que modificaram um arquivo que é um indicativo de quantos desenvolvedores colaboraram modificando aquele arquivo. Essa métrica, no nosso mapeamento foi classificada como uma métrica social e as outras métricas foram descartadas.

Além dos termos "histórico ou de processo", as métricas também foram classificadas como "organizacionais". Essas métricas normalmente eram relacionadas à autoria/responsabilidade de um desenvolvedor para um arquivo ou os papéis dos desenvolvedores durante o desenvolvimento de software. Normalmente, essas métricas foram usadas por estudos que analisaram dados associados à indústria, como pode ser encontrado nos trabalhos de Mockus (2010) e Nagappan et al. (2008). Nessa mesma direção, Rahman e Devanbu (2013) apresentaram métricas de processo mais centradas nos desenvolvedores, que também indicam o entrelaçamento entre aspectos sociais e de processo. Por exemplo, os autores listam 14 métricas de processo e 9 delas têm aspectos sociais relacionados.

Além dos trabalhos que apresentaram as métricas obtidas do histórico, processo e organizacionais, também foram encontrados trabalhos que classificavam suas métricas como sociais. Por exemplo, Shihab et al. (2012) considerou tempo, tamanho, código, arquivo, propósito e aspectos pessoais como dimensões para prever o risco de uma mudança. Nesse trabalho, por exemplo, as métricas da dimensão de aspecto pessoal e a experiência do desenvolvedor foram classificadas como métricas sociais. Ibrahim et al. (2010) usaram propriedades das listas de e-mail para prever a participação dos desenvolvedores em uma discussão, enquanto Bettenburg e Hassan (2012) propuseram o uso de aspectos da interação social, como o conteúdo das discussões das tarefas (issues), a dinâmica da comunicação e a própria organização social para prever defeitos.

Outros artigos consideraram diferentes tipos de redes sociais, como por exemplo, rede social de desenvolvedores que se comunicaram ou que mudaram um mesmo arquivo em um determinado período do desenvolvimento (Bicer et al. 2011; Bird et al. 2009; Meneely et al. 2008; Wolf et al. 2009). Nesses artigos, uma rede social é construída e as propriedades da rede são calculadas com métricas de SNA. Foram identificadas 45 diferentes métricas reportadas por estudos que usaram redes sociais, dentre elas, métricas de centralidade e buracos estruturais (structural holes).

\subsubsection{Proposta de classificação das métricas sociais}

Conforme discutido na seção anterior, as métricas sociais foram classificadas em três categorias: comunicação, mudança de arquivo e projeto. A classificação realizada considerou métricas sociais usadas nos 48 artigos selecionados no mapeamento sistemático. As métricas classificadas correspondem a 21 métricas no grupo de comunicação, 18 métricas no grupo de projetos e 12 métricas relacionadas ao instante em que os arquivos eram modificados. Adicionalmente, 45 métricas de análise de redes sociais foram classificadas em 8 tipos de redes sociais. A Figura 3-2 mostra os grupos (primeiro nível do mapa mental) e categorias (segundo nível do mapa mental) apresentados a seguir. O grupo de comunicação foi subdivido nas categorias dinâmica da comunicação, conteúdo da discussão e estrutura da comunicação. O grupo mudança de arquivo foi subdividido nas categorias relação artefato-desenvolvedor (ownership), experiência e estrutura de cooperação. O grupo projeto foi subdivido em atividade dos desenvolvedores, dinâmica da organização e estrutura da organização.

As métricas de comunicação possuem como principais fontes de informação os gerenciadores de tarefas, como Github, JIRA e Bugzilla, e as listas de discussão de e-mails mantidas pelos projetos. Três categorias foram mapeadas para separar as métricas do grupo de comunicação: dinâmica da comunicação, conteúdo da discussão e a estrutura da comunicação.

Na categoria de dinâmica da comunicação, foram agrupadas as métricas que são relacionadas aos aspectos temporais da comunicação, reputação e experiência dos usuários ou desenvolvedores que participam da comunicação, e a intensidade da troca de mensagens, que é medida pela quantidade de mensagens e quantidade de palavras que são parte da descrição de uma tarefa. Nessa categoria, a quantidade de mensagens (Bacchelli et al. 2010; Bettenburg e Hassan, 2012; Duc 
Anh et al. 2011; Ibrahim et al. 2010), a quantidade de palavras (Bacchelli et al. 2010; Bettenburg e Hassan, 2012; Duc Anh et al. 2011; Ibrahim et al. 2010) e a reputação do usuário/desenvolvedor (Duc Anh et al. 2011; Ibrahim et al. 2010; Zhang et al. 2013; Zimmermann et al. 2012) que relata a tarefa foram as métricas mais selecionadas, com quatro seleções cada uma.

Na categoria de conteúdo de discussão, foram agrupadas as métricas relativas à interação dos desenvolvedores durante a troca de mensagens e o conteúdo de cada discussão. Apenas dois artigos usaram métricas desse grupo (Bettenburg e Hassan, 2012; Ibrahim et al. 2010). Por fim, a terceira categoria agrupou os artigos relacionados à estrutura da comunicação. Nessa categoria foram agrupadas as métricas obtidas a partir de redes sociais geradas com dados da comunicação. Os desenvolvedores são usualmente considerados "nós" e a comunicação arestas ou arcos do grafo (Bettenburg e Hassan, 2012; Bicer et al. 2011; Datta et al. 2012; Wolf et al. 2009).

O segundo grupo de métricas é relativo ao trabalho cooperativo feito pelos desenvolvedores em torno das mudanças dos arquivos. A principal fonte de informação para calcular as métricas sociais desse grupo são os repositórios de código fonte. Novamente as métricas foram divididas em três categorias: relação artefato-desenvolvedor (ownership), experiência e estrutura de cooperação.

A primeira categoria agrupou as métricas relacionadas à contribuição dos desenvolvedores modificando os arquivos no momento em que uma mudança acontecia. Seis diferentes formas de calcular o "proprietário" (ownership) do arquivo foram propostas. O número de desenvolvedores distintos que modificaram um arquivo (D'Ambros et al. 2012a +25 trabalhos) e se o desenvolver é um desenvolvedor que frequentemente modifica o arquivo foram as métricas mais citadas (Bird et al. 2011; Çağlayan et al. 2009; Nagappan et al. 2008; Posnett et al. 2013; Rahman e Devanbu, 2013).

A segunda categoria é relacionada à experiência dos desenvolvedores. Oito artigos e 5 métricas distintas foram identificadas para calcular a experiência de cada desenvolvedor. Por fim, na terceira categoria foram listadas as redes de contribuição/cooperação obtidas do conjunto de desenvolvedores que modificaram os arquivos. Essa rede foi usada por diversos trabalhos com objetivos de predição distintos (Alhassan et al. 2010; Bhattacharya et al. 2012; Bird et al. 2009; Datta et al. 2012; Meneely e Williams, 2009; Meneely et al. 2008; Posnett et al. 2013; Shin et al. 2011).

O último grupo foi chamado de "Projeto". Esse grupo contém 18 métricas separadas em 3 categorias. A primeira categoria é relacionada à atividade dos desenvolvedores no projeto. A proporção de desenvolvedores que contribuíram para o projeto em cada versão foi a métrica mais citada (Bird et al. 2011; Karus e Dumas, 2012; Mockus, 2010). A segunda categoria agrupou as métricas de dinâmica da organização. Nessa categoria, as métricas agrupadas consideram o tamanho do time de desenvolvedores ou da organização e o fluxo de trabalho do projeto. A última categoria representa a estrutura da organização, capturada por meio de métricas obtidas das redes sociais propostas, como por exemplo, o cálculo de congruência sócio-técnica (Cataldo et al. 2009; Datta et al. 2012; Kwan et al. 2011).

\subsubsection{Implicações das métricas sociais nos modelos de predição de Engenharia de Software}

Para mostrar as implicações das métricas sociais, foram procuradas evidências em cada artigo que pudessem revelar se o efeito da métrica social usada no modelo era positivo, negativo ou neutro.

A Tabela 3-4 apresenta os artigos que explicitaram o efeito do uso de métricas sociais em seus modelos. Para sumarizar o efeito das métricas sociais de cada trabalho, usamos os símbolos "+" para efeito positivo, "-" para efeito negativo e "+-" para efeito neutro. Na coluna de indicações são apresentadas conclusões reportadas pelos autores de cada artigo. Os artigos não sumarizados não apresentaram informações suficientes que asseguravam uma classificação. 
Tabela 3-4 Efeito do uso das métricas sociais em modelos de predição

\begin{tabular}{|c|c|c|}
\hline Artigo & Efeito & Indicações \\
\hline $\begin{array}{l}\text { (Shihab et al. } \\
2012 \text { ) }\end{array}$ & + & Experiência do desenvolvedor foi um importante preditor do risco de mudança. \\
\hline $\begin{array}{l}\text { (Matsumoto } \\
\text { et al. 2010) }\end{array}$ & + & $\begin{array}{l}\text { Métricas sociais melhoraram o desempenho do modelo quando combinado com outras } \\
\text { dimensões. Forte correlação entre quantidade de defeitos e quantidade de desenvolvedores. }\end{array}$ \\
\hline $\begin{array}{l}\text { (Bicer et al. } \\
2011)\end{array}$ & + & $\begin{array}{l}\text { Métricas de análise de rede social obtidas da rede social da comunicação dos } \\
\text { desenvolvedores, reduzem o custo associado aos modelos de predição de defeitos }\end{array}$ \\
\hline $\begin{array}{l}\text { (Kwan et al. } \\
\text { 2011) }\end{array}$ & + & $\begin{array}{l}\text { Existem evidências que a quantidade de desenvolvedores reduzem a probabilidade de uma } \\
\text { construção do software ter sucesso, logo essa métrica é um bom preditor para } \\
\text { sucesso/fracasso da construção do software. }\end{array}$ \\
\hline $\begin{array}{l}\text { (Pinzger et al. } \\
2008)\end{array}$ & + & $\begin{array}{l}\text { Os melhores preditores para falhas de software foram número de mudanças e número de } \\
\text { desenvolvedores. }\end{array}$ \\
\hline $\begin{array}{l}\text { (Posnett et al. } \\
\text { 2011) }\end{array}$ & + & $\begin{array}{l}\text { O número de desenvolvedores ativos no projeto adiciona significância no modelo de } \\
\text { predição. }\end{array}$ \\
\hline $\begin{array}{l}\text { (Wolf et al. } \\
2009)\end{array}$ & + & $\begin{array}{l}\text { A comunicação dos desenvolvedores tem papel importante na integração do software e } \\
\text { como preditor do sucesso/fracasso da construção do software. }\end{array}$ \\
\hline $\begin{array}{l}\text { (Bettenburg e } \\
\text { Hassan, 2012) }\end{array}$ & - & $\begin{array}{l}\text { O conteúdo das discussões foi consideravelmente mais relevante que o papel dos } \\
\text { desenvolvedores. A informação social não adicionou explicação no modelo de predição de } \\
\text { defeito, mas complementam a explicação do modelo estatístico. }\end{array}$ \\
\hline $\begin{array}{l}\text { (Mockus e } \\
\text { Weiss, 2000) }\end{array}$ & + & $\begin{array}{l}\text { A experiência do desenvolvedor, expressa como o número de linhas adicionadas e } \\
\text { removidas do desenvolvedor é um bom indicador de qualidade do código e das mudanças. }\end{array}$ \\
\hline $\begin{array}{l}\text { Meneely e } \\
\text { Williams, } \\
\text { 2009) }\end{array}$ & + & $\begin{array}{l}\text { Arquivos são mais propensos a ser vulneráveis quando são modificados por muitos } \\
\text { desenvolvedores. }\end{array}$ \\
\hline $\begin{array}{l}\text { (Ibrahim et } \\
\text { al. 2010) }\end{array}$ & + & $\begin{array}{l}\text { O conteúdo e o tamanho da discussão são métricas importantes para prever a participação } \\
\text { de um desenvolvedor em uma discussão. }\end{array}$ \\
\hline $\begin{array}{l}\text { (Weyuker et } \\
\text { al. 2007) }\end{array}$ & - & $\begin{array}{l}\text { Informações do desenvolvedor adicionam pouca explicação no modelo de predição quando } \\
\text { são adicionados. }\end{array}$ \\
\hline $\begin{array}{l}\text { (Bird et al. } \\
2011)\end{array}$ & + & $\begin{array}{l}\text { Níveis altos de propriedade do desenvolvedor para um arquivo (ownership) são associados } \\
\text { com pouca propensão de inserção de defeitos. }\end{array}$ \\
\hline $\begin{array}{c}\text { (Posnett et al. } \\
2013)\end{array}$ & + & Quando o foco de atenção do desenvolvedor é alto, poucos defeitos são introduzidos. \\
\hline $\begin{array}{c}\text { (Graves et al. } \\
2000)\end{array}$ & - & $\begin{array}{l}\text { O número de desenvolvedores que mudou um módulo não ajuda a prever número de } \\
\text { defeitos. }\end{array}$ \\
\hline $\begin{array}{l}\text { (Weyuker et } \\
\text { al. 2008) }\end{array}$ & - & As informações dos desenvolvedores contribuem pouco para os resultados de predição. \\
\hline $\begin{array}{l}\text { (Çağlayan et } \\
\text { al. 2009) }\end{array}$ & + & $\begin{array}{l}\text { Desenvolvedores que frequentemente modificam os arquivos (ownership) obtiveram baixas } \\
\text { taxas de falso positivos comparado com métricas estáticas do código. }\end{array}$ \\
\hline$\left(\begin{array}{l}\text { Shin et al. } \\
2011)\end{array}\right.$ & +- & $\begin{array}{l}\text { Número de linhas adicionadas e removidas, número de mudanças, e atividade dos } \\
\text { desenvolvedores reduzem a tarefa de inspeção de vulnerabilidade }\end{array}$ \\
\hline $\begin{array}{l}\text { (Ekanayake et } \\
\quad \text { al. 2012) }\end{array}$ & + & $\begin{array}{l}\text { O nome dos autores que fizeram as correções ajuda a melhorar a qualidade dos modelos de } \\
\text { predição de defeitos. }\end{array}$ \\
\hline $\begin{array}{l}\text { (Bacchelli et } \\
\text { al. 2010) }\end{array}$ & - & $\begin{array}{l}\text { Em conjunto com as métricas de código e mudança dos arquivos, as métricas dos } \\
\text { desenvolvedores aumentam o poder de explicação dos modelos de predição de defeitos. }\end{array}$ \\
\hline $\begin{array}{l}\text { (Alhassan et } \\
\text { al. 2010) }\end{array}$ & +- & $\begin{array}{l}\text { Métricas de análise de rede social sozinhas não tem impacto na melhora da predição de } \\
\text { defeitos. Entretanto, essas métricas diminuem a quantidade de falsos alarmes (falso } \\
\text { positivo) quando combinada com outras métricas. }\end{array}$ \\
\hline $\begin{array}{l}\text { (Bell et al. } \\
2011)\end{array}$ & - & As informações dos desenvolvedores não melhoram os resultados de predição. \\
\hline $\begin{array}{c}\text { (Bell et al. } \\
2013)\end{array}$ & - & A informação dos desenvolvedores não melhoram os resultados de predição. \\
\hline
\end{tabular}




\begin{tabular}{c|c|l}
\hline $\begin{array}{c}\text { Cataldo et } \\
\text { al. 2009) }\end{array}$ & + & Métricas obtidas da rede de coordenação de requisitos foram bons preditores para defeito. \\
\hline $\begin{array}{c}\text { Zhang et al. } \\
\text { 2013) }\end{array}$ & + & $\begin{array}{l}\text { O responsável por modificar o arquivo e o desenvolvedor que mais modificou o arquivo no } \\
\text { passado foram os dois melhores preditores. }\end{array}$ \\
\hline $\begin{array}{c}\text { (Duc Anh et } \\
\text { al. 2011) }\end{array}$ & + & $\begin{array}{l}\text { Número de envolvidos em uma tarefa é um bom preditor para o tempo de conclusão da } \\
\text { tarefa. }\end{array}$ \\
\hline $\begin{array}{c}\text { (Datta et al. } \\
2012)\end{array}$ & + & $\begin{array}{l}\text { A relação da comunicação dos desenvolvedores e arquivos é importante em modelos de } \\
\text { predição para projetos de grande porte. }\end{array}$ \\
\hline $\begin{array}{c}\text { Bhattacharya } \\
\text { et al. 2012) }\end{array}$ & + & $\begin{array}{l}\text { Redes construídas com dados de realocação dos desenvolvedores e dos desenvolvedores que } \\
\text { mudaram o mesmo arquivo são importante preditores. }\end{array}$ \\
\hline $\begin{array}{c}\text { (Karus e } \\
\text { Dumas, 2012) }\end{array}$ & + & Métricas organizacionais são melhores que métricas de código. \\
\hline $\begin{array}{c}\text { Illes-Seifert e } \\
\text { Paech, 2010) }\end{array}$ & + & $\begin{array}{l}\text { O número de autores distintos que realizaram mudanças para um arquivo tem forte } \\
\text { correlação com a quantidade de defeitos. }\end{array}$ \\
\hline
\end{tabular}

Observou-se que 21 artigos recomendaram o uso de métricas sociais em modelos de predição com efeito positivo. Seis artigos mencionaram efeitos negativos do uso de métricas sociais. Considerando a aplicabilidade dessas métricas, verificou-se que a maior parte das métricas sociais foram usadas para prever defeito ou falhas de software. Modelos de risco, sucesso da construção do software, vulnerabilidade, tempo de correção de uma tarefa, reabertura de uma tarefa, tipo de severidade do defeito e recomendação de participação em tarefas tiveram entre 1 a 3 artigos mencionados.

É importante destacar que nenhum modelo de predição de mudança conjunta de arquivos foi encontrado durante a realização do mapeamento sistemático.

\subsubsection{Ameaças à validade}

Embora o processo de bola de neve tenha sido utilizado para selecionar estudos primários, sabe-se que as seleções de artigos podem não ter capturado todos os estudos relevantes durante a primeira etapa da definição da lista inicial de artigos. Para tratar esse problema, foram enviados emails para especialistas para avaliar nossa lista inicial. Dez respostas de 10 especialistas foram recebidas e todos os artigos sugeridos já haviam sido encontrados em algum estágio do nosso método de avaliação. Para cada um dos 103 autores distintos identificados durante os três primeiros passos do método de mapeamento, o DBLP foi usado para expandir a busca por artigos que não foram identificados nos três passos que adicionavam artigos. Após essa verificação somente 3 artigos novos foram encontrados e adicionados na lista final de artigos.

Durante os passos de seleção e síntese, algum viés pode ter sido inserido. Para reduzir esse problema, o processo de seleção foi realizado por dois pesquisadores e constantemente verificado por um terceiro pesquisador. Os dois pesquisadores também realizaram conjuntamente a síntese e a criação da classificação. Todos os conflitos foram discutidos até que um consenso fosse alcançado. É importante mencionar que a classificação e a separação das métricas refletem a nossa visão sobre as métricas identificadas.

Com relação ao desempenho das métricas sociais relatadas, há fatores importantes que influenciam o uso de métricas sociais, por exemplo, se o projeto no qual a métrica foi usada é um software livre ou comercial. Outro aspecto importante é que diferentes técnicas de predição foram utilizadas, bem como, a combinação das métricas sociais com outras métricas podem ter influenciado o efeito de cada métrica social reportada. Idealmente as métricas deveriam ser comparadas utilizando um conjunto de dados comum. 


\subsection{Informações contextuais para predição de mudanças conjuntas entre arquivos de software}

De acordo com Dey et al. (Dey et al. 2001), contexto é "qualquer informação que pode ser usada para caracterizar a situação de entidades". Para Brézillon et al. (2004) contexto representa "uma descrição complexa do conhecimento compartilhado sobre algo físico, social, histórico ou qualquer outra circunstância com os quais uma ação ou evento ocorre". Baseado nessas definições de contexto, conjectura-se que as mudanças conjuntas de software são caracterizadas por fontes de informações obtidas quando os arquivos estão mudando durante a resolução de uma tarefa.

Nesta tese, as informações contextuais obtidas das tarefas, da comunicação dos desenvolvedores e das mudanças dos arquivos nessas tarefas representam a nossa definição de contexto para mudanças conjuntas entre artefatos de software. Os modelos de predição propostos consideram como premissa que as informações obtidas em cada mudança identificam quando existe maior propensão de mudança conjunta para um par específico de arquivos.

Essa abordagem difere dos tipos de dependências usados na literatura. Enquanto as dependências tendem a se manter estáveis ao longo do tempo, as informações de contexto são capturadas a cada mudança, e, por essa razão, representam as diferentes tendências de um artefato mudar conjuntamente com outro em um período de tempo e não mudar conjuntamente em outro momento da evolução do software, independentemente se existe ou não uma dependência entre eles.

Muitos autores têm indicado que as mudanças de software são influenciadas por aspectos sóciotécnicos (Bettenburg e Hassan, 2012; De Santana et al. 2013; Kwan et al. 2012; R. Leano, 2014; Schröter et al. 2012; Tsay et al. 2014; Zanetti, 2012), entretanto, as técnicas atuais privilegiam aspectos técnicos relacionados às dependências dos artefatos em detrimento do lado social que é capturado a partir das informações contextuais.

Outro fator importante é que as mudanças de software ocorrem por diferentes razões e que essas razões são difíceis de determinar (Canfora et al. 2014). Por exemplo, um estudo recente mostra que nem sempre a propagação de mudança entre dois artefatos ocorre porque os artefatos mudam frequentemente juntos ou porque há uma dependência estática entre os artefatos (Oliva e Gerosa, 2015a).

Nesta tese, as informações contextuais são usadas como preditores, ou seja, informações úteis para prever a ocorrência e a não ocorrência de uma nova mudança conjunta. Não é objetivo desta tese mostrar que existe uma relação de causa-efeito entre os preditores e as mudanças conjuntas. Logo, conjectura-se que o uso de informações contextuais, não exploradas anteriormente por outros trabalhos de predição de mudanças conjuntas, representam uma importante fonte de informação para melhorar a acurácia da predição de mudanças conjuntas, evitando, por exemplo, a quantidade de recomendações falsas que atualmente dificultam o uso das abordagens atuais na prática.

A Tabela 3-5 apresenta a definição e a justificativa para o uso das informações contextuais selecionadas como preditores de mudanças conjuntas nesta tese. Essas métricas foram selecionadas também com base no mapeamento sistemático (Wiese et al. 2014a) apresentado na seção anterior e com base nos estudos preliminares realizados (Wiese et al. 2014; Wiese et al. 2014b; Wiese et al. 2015)

Tabela 3-5 Informações contextuais usadas como preditores de presença ou ausência de mudanças conjuntas entre dois arquivos

\begin{tabular}{c|l|l|l|l}
\hline $\begin{array}{l}\text { Condição/ } \\
\text { Situação }\end{array}$ & $\begin{array}{l}\text { Nome do } \\
\text { Predito }\end{array}$ & $\begin{array}{l}\text { Tipo do } \\
\text { Dado }\end{array}$ & Definição & Justificativa \\
\hline & $\begin{array}{l}\text { Tipo da } \\
\text { Tarefa }\end{array}$ & String & $\begin{array}{l}\text { O Tipo da solicitação de mudança indicada } \\
\text { quando a tarefa foi descrita. Os valores } \\
\text { podem ser: Bug, Improvement, New Task, } \\
\text { Documentation, Infrastructure, etc. }\end{array}$ & $\begin{array}{l}\text { Mudanças conjuntas ocorrem para resolver } \\
\text { diferentes tipos de solicitação de mudanças. Por algumas modificações são mais } \\
\text { propensas a acontecer para corrigir defeitos e } \\
\text { outras para implementar novos requisitos } \\
\text { (Zimmermann et al. 2012) }\end{array}$ \\
\hline
\end{tabular}




\begin{tabular}{|c|c|c|c|c|}
\hline & $\begin{array}{l}\text { Tarefa foi } \\
\text { reaberta? }\end{array}$ & Booleano & $\begin{array}{l}\text { A partir da coleta do histórico de cada tarefa é } \\
\text { possível descobrir se uma tarefa foi reaberta } \\
\text { analisando as trocas de estado da tarefa. Nós } \\
\text { marcamos se uma tarefa já foi reaberta ou não. }\end{array}$ & $\begin{array}{l}\text { Uma tarefa que modifica mais arquivos é mais } \\
\text { propensa a ser reaberta. Nesse sentido, mais } \\
\text { mudanças conjuntas são necessárias nestas } \\
\text { circunstâncias. Além disso, tarefas reabertas têm sido } \\
\text { associadas a tarefas que tendem a ser mais } \\
\text { complexas. (Shihab et al. 2010) }\end{array}$ \\
\hline & Responsável & String & $\begin{array}{l}\text { Nome do desenvolvedor indicado como } \\
\text { responsável pela resolução da solicitação de } \\
\text { mudança }\end{array}$ & $\begin{array}{l}\text { Um desenvolvedor pode trabalhar em solicitações } \\
\text { de mudança de partes similares do software. Nesse } \\
\text { sentido, eles são propensos a modificar arquivos e } \\
\text { submeter contribuições para um mesmo conjunto } \\
\text { de arquivos (Zhang et al. 2013). }\end{array}$ \\
\hline & Relator & String & $\begin{array}{l}\text { Nome do usuário ou desenvolvedor que } \\
\text { relatou a solicitação de mudança }\end{array}$ & $\begin{array}{l}\text { Usuários podem ser propensos a relatar problemas } \\
\text { para um mesmo componente ou que afetem a } \\
\text { mesma parte do software, uma vez que seus } \\
\text { interesses são para requisitos específicos do } \\
\text { software. Os relatos de um usuário específico } \\
\text { podem ser relacionados a um mesmo conjunto de } \\
\text { arquivos propensos a mudar conjuntamente } \\
\text { (Zimmermann et al. 2012) }\end{array}$ \\
\hline \multirow{4}{*}{ 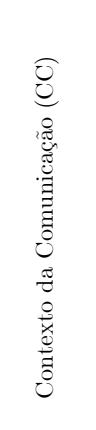 } & $\begin{array}{l}\text { Número de } \\
\text { comentários }\end{array}$ & Numérico & $\begin{array}{l}\text { Número total de comentários feitos na } \\
\text { solicitação de mudança }\end{array}$ & \multirow{4}{*}{$\begin{array}{l}\text { A comunicação envolve aspectos de discussão em } \\
\text { torno das solicitações de mudanças. O número de } \\
\text { comentários, de comentadores, de palavras e de } \\
\text { desenvolvedores que comentaram em uma tarefa } \\
\text { indicam o conjunto de arquivos que mudam } \\
\text { conjuntamente. Por exemplo, algumas mudanças } \\
\text { conjuntas acontecem em tarefas com uma } \\
\text { quantidade de palavras ou comentários porque a } \\
\text { solicitação de mudança é mais difícil de entender, } \\
\text { e nesses casos um conjunto de arquivos mais } \\
\text { propensos de serem modificados juntos mudariam } \\
\text { nessas condições (Bettenburg e Hassan, 2012) }\end{array}$} \\
\hline & $\begin{array}{l}\text { Número de } \\
\text { comentadores }\end{array}$ & Numérico & $\begin{array}{l}\text { O Número de usuários e desenvolvedores } \\
\text { distintos que comentaram na solicitação de } \\
\text { mudança }\end{array}$ & \\
\hline & $\begin{array}{l}\text { Número de } \\
\text { palavras }\end{array}$ & Numérico & $\begin{array}{l}\text { Número total de palavras contidas na } \\
\text { descrição e comentários realizados na } \\
\text { solicitação de mudança. }\end{array}$ & \\
\hline & $\begin{array}{l}\text { Número de } \\
\text { Desenvolvedo } \\
\text { res que } \\
\text { comentaram }\end{array}$ & Numérico & $\begin{array}{l}\text { Número total de desenvolvedores distintos } \\
\text { que previamente modificaram o arquivo e } \\
\text { também escreveram comentários na } \\
\text { solicitação de mudança }\end{array}$ & \\
\hline \multirow{2}{*}{ 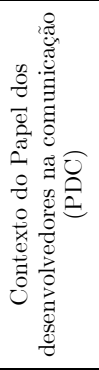 } & $\begin{array}{l}\text { Índice de } \\
\text { intermediação } \\
\text { (Betweenness) }\end{array}$ & Numérico & $\begin{array}{l}\text { Centralidade Betweenness quantifica o número } \\
\text { de vezes que um nó atua como uma ponte para } \\
\text { conectar grupos de nós, considerando sempre o } \\
\text { menor caminho. Nós usamos a mediana do } \\
\text { valor de betweenness entre os desenvolvedores } \\
\text { que comentaram em uma tarefa. }\end{array}$ & \multirow[t]{2}{*}{$\begin{array}{l}\text { Centralidade pode capturar o papel do desenvolvedor } \\
\text { na discussão. Trabalhos em engenharia de software } \\
\text { tem apontado a importância dessa medida para } \\
\text { predizer defeitos ou para organizar a discussão } \\
\text { durante a solução de uma tarefa (Bicer et al. 2011; } \\
\text { Bird et al. 2009; Wolf et al. 2009; Zanetti, 2012). }\end{array}$} \\
\hline & $\begin{array}{l}\text { Indice de } \\
\text { proximidade } \\
\text { (Closeness) }\end{array}$ & Numérico & $\begin{array}{l}\text { Centralidade Closeness é uma medida que } \\
\text { indica quão próximo dos outros } \\
\text { desenvolvedores um desenvolvedor específico } \\
\text { está. Nós usamos a mediana do valor de } \\
\text { closeness dos desenvolvedores que comentaram } \\
\text { em uma tarefa. }\end{array}$ & \\
\hline \multirow{4}{*}{ 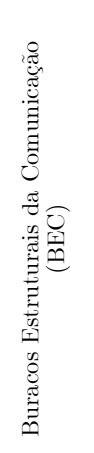 } & $\begin{array}{l}\text { Restrição } \\
\text { (constraint) }\end{array}$ & Numérico & $\begin{array}{l}\text { Mede a falta de buracos entre os vizinhos, } \\
\text { utilizando o grau das conexões exclusivas entre } \\
\text { os nós. Indica a quantidade de alternativas de } \\
\text { conexões que chegam a este nó }\end{array}$ & \multirow{4}{*}{$\begin{array}{l}\text { Possibilita capturar a noção sobre as propriedades } \\
\text { das redes, identificando gaps ou buracos na rede. Os } \\
\text { buracos entre os nós representam que os } \\
\text { desenvolvedores daquela rede social têm acesso a } \\
\text { diferentes informações. É uma medida de diversidade } \\
\text { de caminhos para se obter a informação (Bird et al. } \\
\text { 2009; Igor Scaliante Wiese et al. 2014b; Wolf et al. } \\
\text { 2009). }\end{array}$} \\
\hline & $\begin{array}{l}\text { Hierarquia } \\
\text { (hierarchy) }\end{array}$ & Numérico & $\begin{array}{l}\text { Mede a concentração de restrição de um nó. } \\
\text { Valores altos indicam que a restrição é } \\
\text { concentrada em um único nó vizinho. }\end{array}$ & \\
\hline & $\begin{array}{l}\text { Tamanho } \\
\text { Efetivo } \\
\text { (Effective } \\
\text { Size) }\end{array}$ & Numérico & $\begin{array}{l}\text { Representa a porção de vizinhos não } \\
\text { redundantes de um nó. Altos valores } \\
\text { representam que muitos nós não tem relações } \\
\text { redundantes com os vizinhos }\end{array}$ & \\
\hline & $\begin{array}{l}\text { Eficiência } \\
\text { (Efficiency) }\end{array}$ & Numérico & $\begin{array}{l}\text { Normaliza o tamanho efetivo pela quantidade } \\
\text { de nós vizinhos. }\end{array}$ & \\
\hline \multirow{4}{*}{ 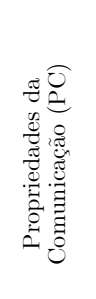 } & Tamanho & Numérico & Número de nós na rede & \multirow{4}{*}{$\begin{array}{l}\text { Propriedades da rede indicam aspectos de como a } \\
\text { rede social está organizada. Redes com mais arcos } \\
\text { indicam maior intensidade de troca de mensagens. } \\
\text { Redes com mais nós indicam uma maior participação } \\
\text { dos desenvolvedores. A propriedade da rede social é } \\
\text { útil para prever defeitos (Bird et al. 2009; Conway, } \\
\text { 1968; Kwan et al. 2012). }\end{array}$} \\
\hline & Laços & Numérico & Número de arcos na rede & \\
\hline & Diâmetro & Numérico & $\begin{array}{l}\text { O diâmetro da rede é determinado pelo valor } \\
\text { máximo sobre todos os pares de vértices }(\mathrm{u}, \mathrm{v}) \\
\text { do tamanho do caminho mais curto de u até v. }\end{array}$ & \\
\hline & Densidade & Numérico & $\begin{array}{l}\text { Densidade é calculado como o percentual das } \\
\text { conexões existentes considerando todas as } \\
\text { possíveis conexões da rede. }\end{array}$ & \\
\hline
\end{tabular}




\begin{tabular}{|c|c|c|c|c|}
\hline \multirow{5}{*}{ 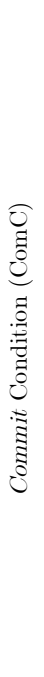 } & $\begin{array}{l}\text { Autor da } \\
\text { Mudança }\end{array}$ & String & $\begin{array}{l}\text { Nome do desenvolvedor que modificou o } \\
\text { arquivo }\end{array}$ & \multirow{2}{*}{$\begin{array}{l}\text { Desenvolvedores podem contribuir para partes } \\
\text { específicas do software. Nesse sentido, eles podem } \\
\text { modificar sempre os mesmos arquivos. Esse indicador } \\
\text { é útil para identificar quando dois arquivos são } \\
\text { modificados conjuntamente se o mesmo conjunto de } \\
\text { desenvolvedores modificam os mesmos arquivos } \\
\text { (Mockus, 2010; Rahman e Devanbu, 2013). }\end{array}$} \\
\hline & $\begin{array}{l}\text { É o mesmo } \\
\text { proprietário? } \\
\text { (Ownership) }\end{array}$ & Booleano & $\begin{array}{l}\text { A medida de quem é o proprietário do arquivo } \\
\text { é calculado sempre na versão anterior, } \\
\text { ordenando os desenvolvedores que mais } \\
\text { modificaram cada arquivo. Os } 10 \% \text { dos } \\
\text { desenvolvedores que mais modificaram o } \\
\text { arquivo são incluídos na lista de proprietários. } \\
\text { Nós marcamos como VERDADEIRO se o } \\
\text { desenvolvedor que fez a mudança atual é parte } \\
\text { da lista de proprietários na versão anterior do } \\
\text { software. }\end{array}$ & \\
\hline & $\begin{array}{l}\text { Número de } \\
\text { linhas de } \\
\text { código } \\
\text { adic./modific. }\end{array}$ & Numérico & $\begin{array}{l}\text { Soma do número de linhas } \\
\text { adicionadas/modificadas em um commit }\end{array}$ & \multirow{3}{*}{$\begin{array}{l}\text { O número de linhas modificadas, excluídas indicam } \\
\text { padrões de propensão de mudança conjunta. Alguns } \\
\text { arquivos podem mudar mais linhas ou excluir mais } \\
\text { linhas de código quando são mudados conjuntamente } \\
\text { com alguns arquivos e apresentar um padrão } \\
\text { diferente quando a quantidade de mudanças } \\
\text { conjuntas é menor. (D'Ambros et al. 2012b; Moser et } \\
\text { al. 2008; Rahman e Devanbu, 2013). }\end{array}$} \\
\hline & $\begin{array}{l}\text { Número de } \\
\text { linhas de } \\
\text { código } \\
\text { excluídas }\end{array}$ & Numérico & $\begin{array}{l}\text { Soma do número de linhas excluídas em um } \\
\text { commit }\end{array}$ & \\
\hline & Code Churn & Numérico & $\begin{array}{l}\text { Soma do número de linhas adicionadas e } \\
\text { excluídas em um commit. }\end{array}$ & \\
\hline
\end{tabular}

\subsection{Considerações finais}

Para selecionar as métricas utilizadas para construir os modelos de predição de mudanças conjuntas entre os pares de arquivos, primeiramente foi realizado um levantamento bibliográfico com base em diversas revisões sistemáticas relativas a modelos de predição usados em engenharia de software. Os estudos obtidos (Jorgensen e Shepperd 2007, Riaz et al. 2009, Arisholm et al. 2010, Hall et al. 2012, Radjenovic et al. 2013) indicaram que diferentes métricas foram amplamente testadas como preditores em diversos modelos com foco na predição de defeito, esforço e custo, entretanto, as mesmas métricas não foram utilizadas em modelos de predição de mudanças conjuntas.

Durante o levantamento, percebeu-se também que nenhum desses trabalhos apresentou com clareza o uso de métricas que representem o contexto social em modelos de predição, muito embora, diversos pesquisadores tenham discutido a importância e a influência dos aspectos sociais no desenvolvimento de software (Betz et al. 2013; Bird et al. 2009; De Souza et al. 2007; Kwan et al. 2011; Zanetti, 2012). As informações contextuais mapeadas são obtidas do desenvolvimento de software e são usadas como características dos modelos de predição construídos para cada par de arquivos. No próximo capítulo, são apresentados os dados e os projetos coletados e o método usado para construção dos modelos de predição. 


\section{Capítulo 4 \\ Modelos de predição de mudanças conjuntas baseados em informações contextuais}

Neste capítulo, as questões de pesquisa investigadas nesta tese, o método usado para construir e avaliar os modelos preditivos e os dados de cada projeto analisado são apresentados.

\subsection{Questões de pesquisa}

Cinco questões de pesquisa foram investigadas nesta tese. A seguir são descritas as justificativas e um resumo da abordagem usada para responder cada questão de pesquisa.

Questão de Pesquisa 1: As informações contextuais possibilitam predizer as mudanças conjuntas entre dois arquivos?

Pesquisas anteriores têm mostrado que é possível prever mudanças conjuntas com base em algum tipo de dependência de software. Entretanto, essas dependências tendem a ficar estáveis ao longo do tempo e não refletem todas as razões pelas quais os artefatos mudam (Canfora et al. 2014; Gethers et al. 2012; Kagdi et al. 2013; Oliva e Gerosa, 2015a; Zimmermann et al. 2005).

A hipótese desta tese é que o uso de informações contextuais das mudanças dos arquivos extraídas das tarefas, comunicação e da própria modificação (commits) dos arquivos combinados com algoritmos de aprendizagem de máquina predizem quando dois arquivos mudam conjuntamente com menor quantidade de falsos alarmes. Evitar recomendações desnecessárias para os desenvolvedores pode ajudar na adoção prática dos modelos de predição.

Abordagem. Para responder a primeira questão de pesquisa, foram construídos modelos de predição para pares de arquivos selecionados dos 10 projetos Apache coletados. Cada modelo utilizou as informações contextuais das mudanças de um artefato para predizer a propensão de mudança conjunta com outro artefato, utilizando conjuntos de treinamento de um período anterior (por exemplo, uma versão) e conjuntos de teste para um período de tempo consecutivo (próxima versão).

Os modelos de predição são específicos para cada par de arquivos e foram construídos com o algoritmo de aprendizagem de máquina random forest em conjunto com o método de seleção de amostragem bootstrap. Os dados de uma versão foram usados para construir o conjunto de treinamento, enquanto os testes foram realizados com os dados da versão consecutiva.

Para avaliar o resultado das predições, foram utilizados os valores da matriz de confusão: verdadeiros positivos (VP) e negativos (VN) e falsos positivos (FP) e negativos (FN), que avaliam a quantidade de testes que foram corretamente preditos. Com o uso desses quatro valores (VP, VN, FP e FN), calcula-se os valores de sensibilidade (recall), precisão (precision), medida $\mathrm{F}$ (f-measure), área sob a curva (AUC) e o coeficiente de correlação de Mathews (MCC). Os valores de 
sensibilidade, precisão e medida $\mathrm{F}$ são importantes para a comparação da abordagem proposta nesta tese com outras abordagens da literatura. O valor de AUC é importante para comparar nossa predição com um classificador aleatório.

Adicionalmente, foi calculada a correlação entre a quantidade de instâncias observadas e preditas a partir do uso do coeficiente de correlação de Mathews (MCC), pois é a única medida que leva em consideração os quatro valores da matriz de confusão. Foram usados testes estatísticos para análise dos resultados, para verificar se existe diferença estatística entre a abordagem proposta nesta tese e o modelo implementado com um classificador aleatório, cujo valor de AUC é igual a 0,50 .

Questão de pesquisa 2: Qual o desempenho da predição de mudanças conjuntas dos modelos de predição baseados em informações contextuais comparado com as regras de associação?

Para comparar o desempenho dos modelos com informações contextuais, foram selecionados os modelos de regras de associação, que realizam a predição com base na inferência das dependências de mudanças.

Essa comparação é importante para posicionar a abordagem proposta em relação ao estado da arte da predição de mudanças, uma vez que as dependências de mudança são frequentemente utilizadas em trabalhos de predição de mudanças conjuntas (Gethers et al. 2012; Kagdi et al. 2013; Sun et al. 2015; Zimmermann et al. 2005) e têm o melhor desempenho quando comparadas com outros tipos de dependências, como por exemplo, a dependência estática e conceitual (Sun et al. 2015).

Abordagem. Para responder a questão de pesquisa 2, diferentes limiares de suporte e confiança foram calculados para obter os arquivos que seriam avaliados. Para cada limiar de suporte e confiança, os resultados obtidos com os modelos baseados em informações contextuais foram comparados com as regras de associação. A comparação das abordagens foi feita com as mesmas medidas usadas na primeira questão de pesquisa: quantidade de predições corretas, os valores da matriz de confusão, precisão, sensibilidade, medida F e MCC.

Questão de pesquisa 3: Qual a influência dos conjuntos de dados usados para construir os modelos de predição de mudanças conjuntas?

O modo de construção do conjunto de dados influencia os resultados obtidos pelos modelos de predição de mudanças conjuntas. Por conjunto de dados, entende-se a forma de agrupamento e coleta dos dados para construir os modelos de predição. Na primeira questão de pesquisa, foram utilizados os dados agrupados por versão, usando as informações contextuais das mudanças entre dois artefatos de uma versão para construir os conjuntos de treinamento e os dados da versão consecutiva para avaliar os modelos de predição. Esse formato é amplamente usado em modelos de predição aplicados à engenharia de software (Hall et al. 2011).

Entretanto, agrupar dados por versões não é a única maneira de construir os conjuntos de treinamento e teste. É importante mencionar que o modo de construção do conjunto de dados influencia os resultados dos modelos preditivos pois podem adicionar uma maior quantidade de desbalanceamento (Khoshgoftaar, 2010; Menzies et al. 2007) na quantidade de amostras de cada uma das classes que compõe o conjunto de dados.

Além do desbalanceamento, é importante avaliar a quantidade de informação contextual necessária para produzir os melhores resultados de predição, uma vez que quanto mais informações forem necessárias, maior é o custo de processamento para o uso da técnica em cenários reais.

Abordagem. Para responder a terceira questão de pesquisa, os dados usados para criar os conjuntos de treinamento e teste foram separados em dois diferentes formatos: por versão e por divisão de tarefas. No primeiro formato, a quantidade de tarefas depende do tamanho de cada versão. Uma versão foi usada para treinamento e a versão consecutiva foi usada para teste. No segundo caso, a quantidade de tarefas de cada projeto foi ordenada e dividida por um denominador comum. Usando essa abordagem as tarefas agrupadas não eram mais equivalentes às versões, uma 
vez que a divisão usando um denominador criaram conjuntos de dados com tamanhos diferentes do conjunto de dados usado em cada versão. Por exemplo, supondo que um projeto tem 1200 tarefas, usando o denominador 3, 4 grupos de 300 tarefas seriam criados e usados para a construção de conjuntos de treino e teste. Os valores 3,4 e 5 foram utilizados como denominadores para dividir o conjunto de tarefas de cada projeto.

Como nas questões de pesquisa anteriores, os valores de predições corretas, valores da matriz de confusão, precisão, sensibilidade, medida F e MCC foram usados para comparar os resultados para cada agrupamento de dados.

Questão de pesquisa 4: Qual o desempenho da predição de mudanças conjuntas para os arquivos que mais mudaram nas últimas 500 tarefas do projeto?

Os resultados das questões de pesquisa anteriores avaliam as predições de mudanças conjuntas em todo o histórico de cada projeto. Nesta questão de pesquisa, o objetivo é avaliar as predições para os arquivos que mudaram mais recentemente no histórico do projeto. Essa análise adiciona uma nova perspectiva investigando a efetividade da abordagem proposta no conjunto de arquivos que demandaram maior quantidade de modificações para corrigir defeitos e adicionar novos requisitos no projeto nas últimas 500 tarefas do projeto. Optou-se por usar 500 tarefas para que projetos com uma menor quantidade de tarefas, e que não foram avaliados nesta tese, possam utilizar a abordagem proposta, já que a maioria dos projetos avaliados tem um histórico de dados superior a esta quantidade de tarefas. Além disso, nas questões de pesquisa anteriores foram avaliados conjuntos de treinamento cujo os tamanhos e quantidade de tarefas poderiam variar de projeto para projeto - versões do software (QP1 e QP2) e quantidade tarefas dividias por um denominador (QP3). Assim, fixar 500 tarefas adiciona uma diferente perspectiva para a avaliação dos resultados.

Abordagem. Para responder a essa questão de pesquisa, foram utilizados dados das últimas 500 tarefas. O método de seleção de amostragem holdout foi utilizado para dividir o conjunto de dados em $70 \%$ para construir o conjunto de treinamento e $30 \%$ para construir o conjunto de teste e avaliar os resultados. De forma similar às questões de pesquisa anteriores, os valores de predições corretas, valores da matriz de confusão, precisão, sensibilidade, medida F e MCC são apresentados.

Questão de pesquisa 5: Quais informações contextuais são mais relevantes para prever mudanças conjuntas?

Identificar as informações contextuais mais relevantes possibilita a construção de modelos de predição com uma menor quantidade de métricas, já que as informações irrelevantes podem ser excluídas do modelo de predição. Desta forma, é possível reduzir o esforço de construção dos modelos de predição, já que o conjunto de informações contextuais que necessitam ser coletadas é menor. Segundo D'Ambros et al. (2006), a identificação de informações contextuais relevantes também possibilita a construção de ferramentas de visualização que auxiliam o acompanhamento das métricas durante a evolução e manutenção do software.

Abordagem. Para responder a essa questão de pesquisa foi utilizada a função que calcula a importância de cada variável (varImp) do pacote Caret (Kuhn, 2008). Essa função devolve a importância de cada informação contextual utilizada para construção do conjunto de treinamento usado para predizer novas amostras de mudanças conjuntas. Os resultados foram reportados comparando os valores de importância obtidos, bem como, por valor de suporte e confiança avaliados nas questões de pesquisa anteriores. Adicionalmente, as informações contextuais frequentemente selecionadas na questão de pesquisa 4 também são reportadas. 


\subsection{Método}

Para responder as questões de pesquisa, o método proposto foi decomposto em 3 passos: coleta de dados, construção do modelo de predição baseada nas informações contextuais e a avaliação dos modelos. A seguir são descritas cada uma das etapas do método, que é sumarizado na Figura 4-1.

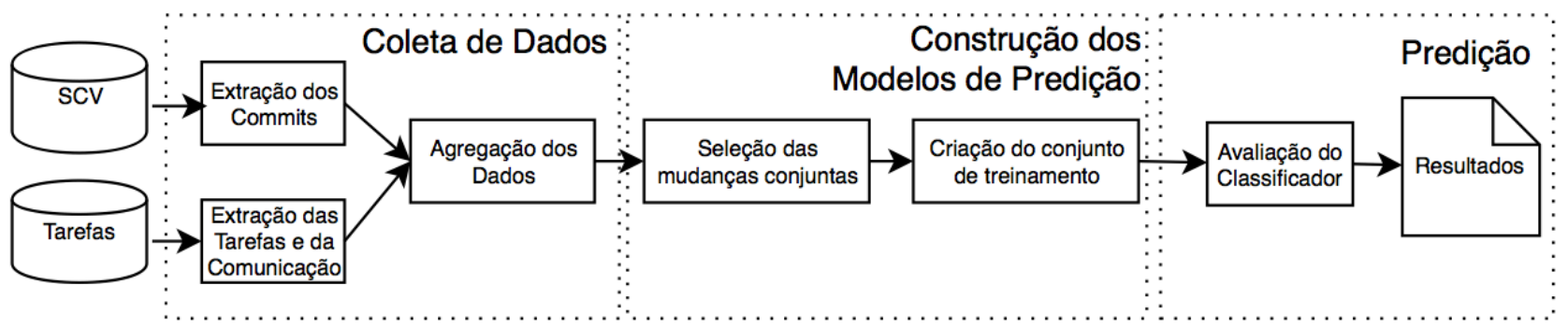

Figura 4-1 Sumarização do método de construção do modelo de predição baseado em informações contextuais.

\subsubsection{Coleta de dados}

Dois repositórios foram utilizados para a coleta de dados: o Sistema de Controle de Versão (SCV) e o Gerenciador de Tarefas (issue tracker system - ITS). Uma tarefa (issue) tipicamente envolve a correção de um defeito ou a implementação de um novo requisito. Para resolver as tarefas, desenvolvedores modificam diferentes arquivos e submetem as modificações para o sistema de controle de versão.

Nos projetos hospedados na Apache Software Foundation, o sistema JIRA é utilizado para armazenar as tarefas e mediar a comunicação dos desenvolvedores. Desse sistema, foram coletadas informações do contexto de cada tarefa e da comunicação entre os desenvolvedores. Como o SCV e o JIRA são ferramentas distintas e não são relacionadas, é necessário usar o identificador único de cada tarefa para encontrar commits realizados para resolver a tarefa.

Depois de obter dados do SCV de cada projeto armazenado, informações dos metadados das modificações realizadas em cada mudança foram coletadas, tais como: autor, data da modificação (commit), mensagem do commit, informações de quantas linhas foram adicionas e removidas de cada arquivo. Do JIRA, foram coletadas informações sobre cada tarefa, tais como: o tipo da solicitação (defeito, melhoria, novo requisito, etc.), estado da solicitação (aberta, fechada, inválida, etc.), desenvolvedor responsável, responsável pela criação da solicitação e descrição. Também foram coletadas as mensagens de comunicação entre os desenvolvedores, tais como: comentários e respectivos autores.

Para realizar a coleta do SCV, uma ferramenta de software livre chamada CVSAnalY ${ }^{3}$ foi usada. Para coletar dados das solicitações de mudança e da comunicação dos desenvolvedores a ferramenta Bicho ${ }^{4}$ foi utilizada.

\subsubsection{Agregação dos dados}

Uma tarefa é resolvida a partir de um ou vários commits. Nos casos em que mais de um commit é usado para resolver uma tarefa, é necessário realizar a associação dos commits. Para agrupar as transações, as mensagens de cada commit foram analisadas procurando por indicativos

\footnotetext{
${ }^{3}$ https://github.com/MetricsGrimoire/CVSAnalY

${ }^{4}$ https://github.com/MetricsGrimoire/Bicho
} 
de um identificador único de uma tarefa. Nos repositórios Apache, esse indicativo é normalmente fo símbolo "\#"+"número da tarefa". A Figura 4-2 apresenta um exemplo de agregação dos commits realizados para resolver a tarefa de número 1000 do projeto Hadoop.

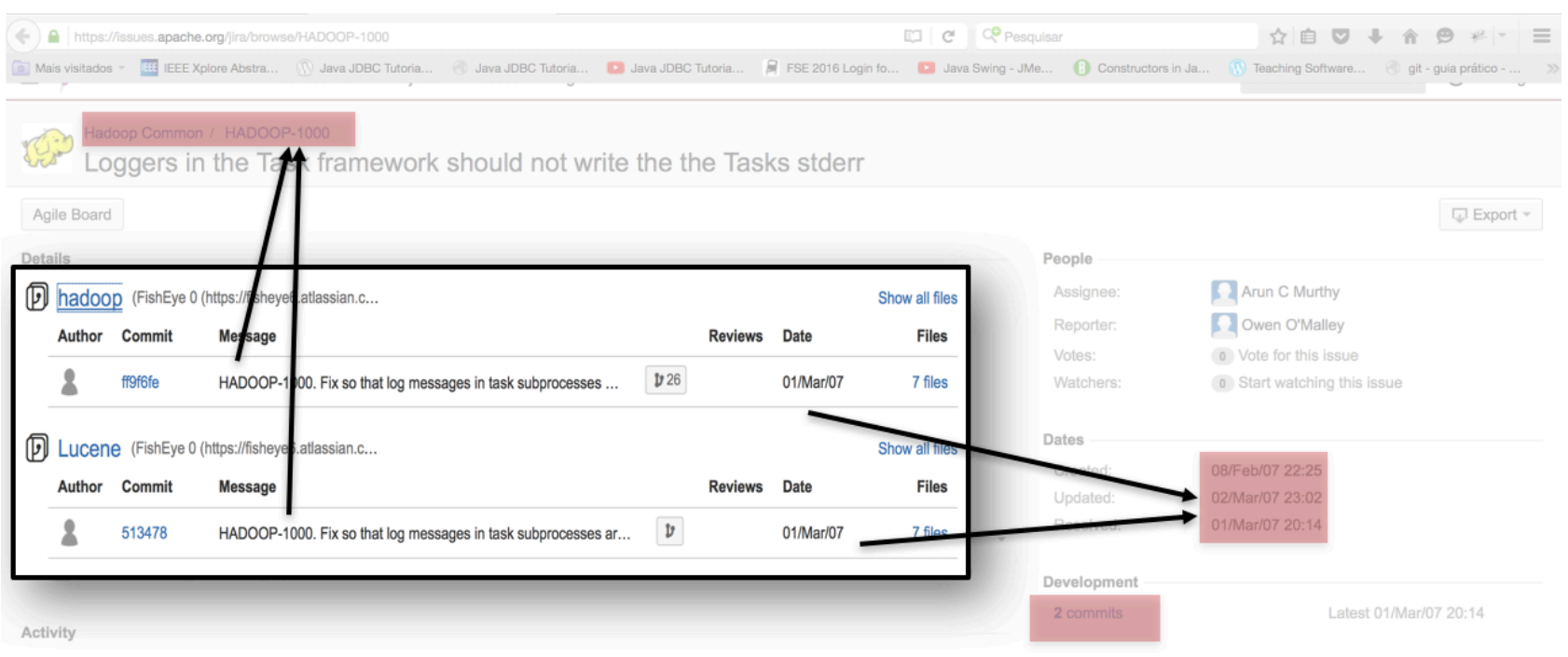

Figura 4-2 Exemplo de agregação de commits e tarefas.

Tarefas sem commit foram descartadas, da mesma forma que foram descartados commits que não estavam associados a nenhuma tarefa. Para garantir que um commit tenha sido feito dentro do período em que a tarefa foi concluída, a data de cada commit foi verificada. Se um commit foi realizado dentro do período em que a tarefa foi aberta e concluída, então esse commit foi associado à tarefa.

Todos os commits com mais de 20 arquivos foram inspecionados para garantir que não se tratavam de operações de mudança de ramo no controle de versão ou alguma refatoração não associada à tarefa.

\subsubsection{Construção do modelo de predição}

Algumas etapas são necessárias para construir os modelos de predição. É preciso obter o conjunto de arquivos para os quais se deseja prever as mudanças conjuntas, construir os conjuntos de treinamento e teste e então construir o modelo de predição com um algoritmo de aprendizagem de máquina. A seguir são descritos os passos de seleção de mudanças conjuntas, construção dos conjuntos de treinamento e teste e a forma de avaliação das predições de mudanças conjuntas realizadas.

\subsubsection{Seleção de mudanças conjuntas}

Para extrair e identificar as mudanças conjuntas, foram consideradas apenas as modificações (commits) feitas em tarefas concluídas e cujo o código fonte foi integrado no projeto. As regras de associação foram usadas para selecionar as mudanças conjuntas mais frequentes e relevantes.

Optou-se pelo uso das regras de associação para selecionar as mudanças conjuntas porque esses modelos são frequentemente utilizados na literatura para prever mudanças conjuntas (Ball et al. 1997; Canfora et al. 2010; Gethers et al. 2012; Kagdi et al. 2013; Ying et al. 2004; Zimmermann et al. 2005). Como visto no Capítulo 2, as regras de associação são importantes para detectar mudanças conjuntas que possuem alta correlação com a ocorrência de defeitos (Cataldo et al. 2009, D'Ambros et al. 2009b), mudanças conjuntas que apontam falhas na arquitetura e oportunidades de refatoração (D'Ambros et al. 2009; Zimmermann et al. 2003); e mudanças conjuntas que 
auxiliam a rastrear requisitos (Ali et al. 2013) e possibilitam avaliar a modularidade do sistema (Silva et al. 2014). Por essas razões, as regras de associação foram usadas como um modelo base para comparar os resultados de predição com os modelos baseados em informações contextuais.

Uma regra de associação é uma relação na forma $\mathrm{I} \Rightarrow \mathrm{J}$, onde I e $\mathrm{J}$ são dois conjuntos disjuntos de itens (itemset). Uma regra $\mathrm{I} \Rightarrow \mathrm{J}$ significa que quando I muda, J é provável de mudar conjuntamente. Em outras palavras, implica que mudanças que contêm I são prováveis de conter J. No escopo desta tese, a regra $\mathrm{I} \Rightarrow \mathrm{J}$ significa que $\mathrm{J}$ mudou conjuntamente com $\mathrm{I}$ em uma tarefa. Também é importante destacar que I e J são conjuntos unitários de arquivos (a), onde $\mathrm{I}=\left\{\mathrm{a}_{\mathrm{i}}\right\}$ e $\mathrm{J}$ $=\left\{a_{j}\right\}$ e $a_{i} \neq a_{j}$.

As regras de associação são medidas por diferentes métricas. Nesta tese, as métricas de suporte e confiança foram usadas, uma vez que têm sido frequentemente utilizadas em estudos anteriores de Engenharia de Software (Ying et al. 2004; Zimmermann et al. 2005). O suporte da regra $\mathrm{r}=$ $\mathrm{I} \Rightarrow \mathrm{J}$ corresponde ao número de mudanças conjuntas de I e J. A confiança se refere à fração de tarefas nas quais ocorrem mudanças contendo I e J, dada uma regra r. Então, uma regra relevante tem altos valores de suporte e confiança. O cálculo do valor de suporte e confiança é obtido da seguinte forma:

$$
\begin{gathered}
\operatorname{suporte}(\boldsymbol{r})=\operatorname{suporte}(I \Rightarrow J)=\operatorname{supporte}(I \cup J)=\operatorname{suporte}\left(\left\{\mathrm{a}_{i}\right\} \cup\left\{\mathrm{a}_{j}\right\}\right)=\text { o número de tarefas que contêm } a_{i} \text { e } a_{j} \\
\qquad \begin{array}{c}
\operatorname{confiança}(\boldsymbol{r})=\operatorname{confiança}(I \Rightarrow J)=\frac{\operatorname{suporte}(I \Rightarrow J)}{\operatorname{suporte}(I)}=\frac{\operatorname{suporte}(I \cup J)}{\operatorname{suporte}(I)}=\frac{\operatorname{suporte}\left(\left\{\mathrm{a}_{i}\right\} \cup\left\{\mathrm{a}_{j}\right\}\right)}{\operatorname{suporte}\left(\left\{a_{i}\right\}\right)} \\
=\text { fração de tarefas contendo } a_{i} \text { onde } a_{j} \text { também aparece. }
\end{array}
\end{gathered}
$$

Para cada período de um projeto para o qual se deseja prever o conjunto de mudanças conjuntas, calculam-se todas as possíveis regras envolvendo os pares de arquivos. As regras encontradas são ordenadas por suporte e desempatadas por confiança. Um dos problemas do uso das regras de associação está associado à definição do limite mínimo aceitável para os valores de suporte e confiança. Nesta tese, os limiares foram definidos para cada questão de pesquisa, uma vez que diferentes intervalos de dados dos projetos foram avaliados em diferentes questões de pesquisa.

\subsubsection{Criação dos conjuntos de treinamento e teste}

Após a seleção das mudanças conjuntas relevantes, para construir os conjuntos de treinamento e teste é necessário recuperar as tarefas e commits para cada par de arquivos de um período específico do projeto.

A título de exemplo, a Tabela 4-1 apresenta um fragmento do conjunto de treinamento para o par de arquivos JMSConduit.java - JMSOldConfigHolder.java construído na versão 2.0 do projeto CXF. Cada linha da tabela representa um commit realizado em uma tarefa para o arquivo JMSConduit.java. A coluna "classe" é marcada com 0 ou 1 dependendo se no commit coletado na versão 2.0 ocorreu uma mudança conjunta entre os dois arquivos. Nesse caso, todas as vezes que a coluna "classe" recebe 0, quer dizer que o arquivo JMSConduit.java mudou sem a presença do arquivo JMSOldConfigHolder.java. Quando o valor é igual a 1, indica que naquele commit específico ocorreu a mudança conjunta entre JMSConduit.java e JMSOldConfigHolder.java.

É importante mencionar que somente as métricas do arquivo JMSConduit.java são usadas para prever as mudanças conjuntas. Isso ocorre porque o arquivo JMSConduit é o antecedente de uma regra de associação identificada na versão 2.0. Um conjunto teste é construído na versão consecutiva com o mesmo formatado da Tabela 4-1. 
Tabela 4-1 Exemplo do conjunto de treinamento.

\begin{tabular}{|c|c|c|c|c|}
\hline $\begin{array}{l}\text { Mudança conjunta } \\
\text { (par de arquivos) }\end{array}$ & Commit & Tarefa & Conjunto de métricas - Tabela 3-5 & Classe \\
\hline $\begin{array}{l}\text { JMSConduit.java - } \\
\text { JMSOldConfigHolder.java }\end{array}$ & 1 & 1760 & $\begin{array}{r}\text { Tipo Tarefa }=\text { Bug, Tarefa Reaberta }=0, \text { Responsável }=\text { ffang, } \\
\text { Relator }=\mathrm{ffang}, \# \text { total de pessoas que comentaram }=3, \# \\
\text { total de devs que comentaram }=2, \text { quantidade de palavras }= \\
438 \ldots\end{array}$ & 0 \\
\hline $\begin{array}{l}\text { JMSConduit.java - } \\
\text { JMSOldConfigHolder.java }\end{array}$ & 13 & 1773 & $\begin{array}{r}\text { Tipo Tarefa }=\text { Improvement, Tarefa Reaberta }=0, \text { Responsável } \\
=\text { njiang, Relator }=\text { chris@die-schneider.net, } \# \text { total de pessoas } \\
\text { que comentaram }=4, \# \text { total de devs que comentaram }=3, \\
\text { quantidade de palavras }=576 \ldots\end{array}$ & 0 \\
\hline $\begin{array}{l}\text { JMSConduit.java - } \\
\text { JMSOldConfigHolder.java }\end{array}$ & 1450 & 1832 & $\begin{array}{r}\text { Tipo Tarefa }=\text { Improvement, Tarefa Reaberta }=0 \text {, responsável } \\
=\text { chris@die-schneider.net, Relator }=\text { chris@die-schneider.net, \# } \\
\text { of } \# \text { total de pessoas que comentaram }=3, \# \text { total de devs que } \\
\text { comentaram }=2, \text { quantidade de palavras }=764 \ldots\end{array}$ & 1 \\
\hline $\begin{array}{l}\text { JMSConduit.java - } \\
\text { JMSOldConfigHolder.java }\end{array}$ & 1700 & 2207 & $\begin{array}{r}\text { Tipo Tarefa }=\text { Bug, Tarefa Reaberta }=0, \text { Responsável }=\text { njiang, } \\
\text { Relator }=\text { liucong, } \# \text { of commenters }=2, \# \text { total de devs que } \\
\text { comentaram }=1, \text { wordiness }=311 \ldots\end{array}$ & 0 \\
\hline $\begin{array}{l}\text { JMSConduit.java - } \\
\text { JMSOldConfigHolder.java }\end{array}$ & 1750 & 2207 & $\begin{array}{r}\text { Tipo Tarefa = Bug, Tarefa Reaberta }=0, \text { Responsável }=\text { njiang, } \\
\text { Relator }=\text { liucong, } \# \text { total de pessoas que comentaram }=2, \# \\
\text { total de devs que comentaram }=1 \text {, quantidade de palavras }= \\
311 \ldots\end{array}$ & 0 \\
\hline $\begin{array}{l}\text { JMSConduit.java - } \\
\text { JMSOldConfigHolder.java }\end{array}$ & 3000 & 2316 & $\begin{array}{r}\text { Issue Type }=\text { Improvement, Tarefa Reaberta } ?=0, \text { Responsável } \\
=\text { dkulp, Relator }=\text { marat, \# total de pessoas que comentaram } \\
=1, \# \text { total de devs que comentaram }=0, \text { quantidade de } \\
\text { palavras }=43 \ldots\end{array}$ & 1 \\
\hline $\begin{array}{r}\text { JMSConduit.java - } \\
\text { JMSOldConfigHolder.java }\end{array}$ & $\cdots$ & & & $\cdots$ \\
\hline
\end{tabular}

No conjunto de treinamento e teste, cada métrica é armazenada em uma coluna específica. É importante perceber que algumas métricas podem ser "texto plano" em vez de número, como por exemplo, o tipo da tarefa, o relator, o responsável por resolver a tarefa e o autor do commit. Uma vez que existem algumas restrições para o uso de texto plano em algoritmos de classificação, por conta da perda de amostras, os modelos construídos são testados com o uso de todas as métricas e também somente com as métricas numéricas.

\subsubsection{Random Forest}

Para implementar os modelos de predição foram utilizados scripts na linguagem $\mathrm{R}$ (versão 3.1.2 - "Pumpkin Helmet") utilizando o pacote Caret (versão 6.0-41), que é amplamente usado, não só para problemas de predição aplicados à engenharia de software, mas também em outras áreas de pesquisa como medicina, ecologia, economia, entre outras (Kuhn, 2008). Para construir o modelo de predição, foi escolhido o algoritmo de aprendizagem random forest.

A decisão de escolha foi tomada com base em experimentos prévios (Wiese et al., 2014b) e na literatura, que indica bons resultados deste algoritmo em problemas aplicados à Engenharia de Software (An et al., 2014; Dias et al., 2015; Lessmann et al., 2008; McIntosh et al., 2014; Robillard et al., 2010; Xia et al., 2015). Além disso, o random forest tende a apresentar bons resultados em conjuntos de dados com diferentes tamanhos e características (Breiman, 2001) quando comparado com outros classificadores.

O Random forest cria um grande número de árvores de decisão para os arquivos de treinamento usando um subconjunto aleatório de todas as métricas calculadas. Esses subconjuntos aleatórios são divididos garantindo que existe baixa correlação entre as métricas, evitando problemas de superajustamento (overfitting) nos modelos (Kuhn, 2008). Usando um método de votação a partir de todas as árvores criadas, o algoritmo realiza uma comparação da pontuação final da votação com o limiar de 0,5 . Caso o valor da pontuação final da votação seja maior que 
0,5, atribui-se a classe "mudança conjunta" para a amostra do conjunto de teste avaliada. Caso contrário, atribui-se a classe "não mudança conjunta".

Para o uso do random forest, dois parâmetros podem ser configurados para ajustar o desempenho do algoritmo: (i) mtry: que indica o número de variáveis aleatoriamente escolhidas em cada árvore aleatória e (ii) ntree: que representa o número de arvores que serão aleatoriamente construídas.

Nesta tese, nenhum parâmetro foi ajustado. A razão para esta decisão está associada a ideia de facilitar o uso do algoritmo. Na prática, a ausência de necessidade de configurações prévias auxilia a adoção de uma técnica, uma vez que os desenvolvedores e gerentes não são especialistas em técnicas de aprendizado de máquina. O uso do pacote Caret facilita o uso do random forest e da avaliação dos resultados criando uma camada de abstração entre o algoritmo de aprendizagem e os parâmetros de configuração. A seguir é apresentada a linha de código necessária para criação do conjunto de treinamento. A função train() é parte do pacote Caret. Nela é possível configurar a variável dependente (train\$isFilePairChanged) e informar quais informações contextuais serão usadas para a criação do modelo de treinamento. O uso do ".", após o " " indica que todos os atributos serão considerados a priori para a geração aleatória das árvores. $O$ parâmetro method="rf" indica que o algoritmo random forest será usado para construção do modelo de aprendizagem.

A função trControl() possibilita usar um dos métodos de amostragem descritos no Capítulo 2. O método bootstrap (trControl=trainControl(method = "boot")) foi escolhido para preservar o aspecto temporal das instâncias. No método de validação cruzada o teste é feito com um percentual de amostras do mesmo conjunto de dados usados para construir o modelo. No método de bootstrap, as amostras do conjunto de dados são aleatoriamente selecionadas para construir o melhor conjunto de treinos possível e um novo conjunto de teste com amostras obtidas em outro momento do tempo é usado para avaliar o modelo construído.

Os dois últimos parâmetros indicam o conjunto de dados usados para construir o conjunto de treinamento (data) e se a importância das informações contextuais será armazenada para posterior inspeção (importance $=$ TRUE).

rf_model <- train(train\$isFilePairChanged ., method="rf", trControl=trainControl(method = "boot"), data=train, importance $=$ TRUE)

\subsubsection{Avaliação dos modelos de predição}

Para realizar a avaliação dos modelos de predição, primeiramente é preciso construir os modelos de predição com o conjunto de treinamento e, posteriormente, avaliar com o conjunto de teste. A seguir são descritas as duas etapas.

\subsubsection{Avaliação dos classificadores}

Para cada par de arquivos, um modelo diferente é construído, conforme apresentado na seção anterior. Para realizar as predições, a função predict() é usada, passando como parâmetro o modelo construído e o conjunto de dados onde os testes serão realizados.

predictions $<-$ predict(rf_model, test)

A função confusionMatrix() é usada passando o resultado das predições obtidas pela função predict() e a variável dependente no conjunto de teste usada como gabarito para conferir os resultados. A função confusionMatrix() retorna as quatro posições da matriz de confusão, que possibilita calcular as métricas de avaliação descritas no Capítulo 2 (MCC, precisão, sensibilidade, medida F, número de verdadeiro positivos e negativos e número de falsos positivos e negativos).

cm $<$-confusionMatrix (predictions,test\$isFilePairChanged) 


\subsubsection{Importância das Informações contextuais}

Identificar a importância de cada informação contextual usada como preditor é importante para entender os modelos criados para prever mudanças conjuntas. Utilizou-se a função $\operatorname{Var} \operatorname{Imp}()$ (variable importance score) (Breiman, 2001) do pacote Caret com normalização por pontuação Z (Z-score). A normalização é atribuída no parâmetro scale.

importance $<$-varImp(rf_model, scale=TRUE)

Para cada informação contextual, a função $\operatorname{var} \operatorname{Imp}()$ retorna uma pontuação é devolvida entre 0 a 100. Quanto maior a pontuação, maior é a importância das informações contextuais para o modelo construído. A normalização garante que os resultados entre os modelos possam ser comparados, uma vez que os valores de importância normalizados sempre variam de 0 a 100 em cada modelo de predição de mudanças conjuntas.

\subsection{Um exemplo da aplicação do método proposto}

Para construir o modelo de treinamento, é necessário selecionar uma janela deslizante no conjunto de dados. Essa janela pode ser construída usando diferentes critérios, como por exemplo, o tempo (usar períodos anuais, mensais, trimestrais), um conjunto de tarefas (uma quantidade de tarefas do projeto), um conjunto de commits ou uma unidade do desenvolvimento do software que divida o projeto (versão ou fase do processo de desenvolvimento).

Nesta tese, foram usadas como janela deslizante o número de tarefas e as versões de cada projeto. $\mathrm{O}$ número de tarefas compreende diferentes informações contextuais, sem levar em considerado o contexto com que essas tarefas ocorreram em relação a uma fase do ciclo de desenvolvimento.

As regras de associação são obtidas a partir das tarefas e commits selecionados na janela deslizante do conjunto de treinamento. Para cada arquivo identificado como antecedente em uma regra de associação identificada, são obtidas as métricas em cada tarefa e cada commit realizado neste arquivo para criar o conjunto de treinamento conforme apresentado na Tabela 4-2. Como é objetivo da tese comparar o desempenho dos modelos baseados em informação contextual com as regras de associação, as tarefas e commits selecionados para o conjunto de teste são escolhidos a partir das regras de associação encontradas no conjunto de treinamento.

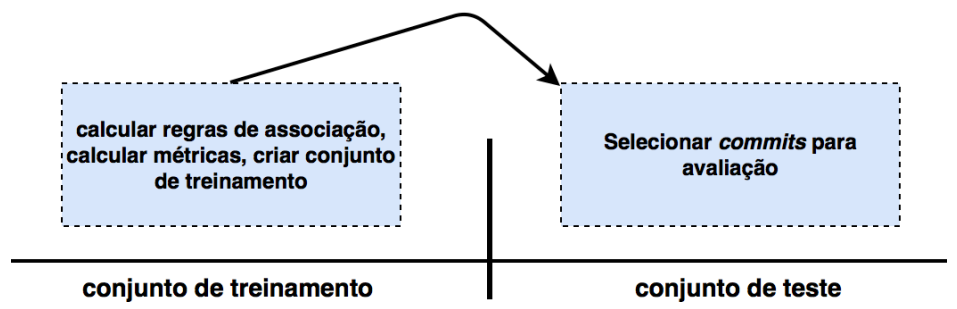

Figura 4-3 Sumarização do método.

Para exemplificar o problema tratado nesta tese é apresentado um caso concreto utilizando a janela deslizante baseada em versão. Na versão 2.1 do projeto Apache CXF, os arquivos JMSConduit.java e JMSOldConfigHolder.java mudaram conjuntamente em 19 commits em 17 tarefas diferentes. Em outros 26 commits, JMSConduit.java não mudou conjuntamente com o JMSOldConfigHolder.java.

As regras de associação indicam que ocorreram 15 mudanças conjuntas (suporte $=15$ ) na versão 2.0. Em $66 \%$ das vezes (confiança = 0,66), JMSOldConfigHolder.java mudou com JMSConduit.java. Os desenvolvedores deveriam decidir com base nos valores de suporte e confiança se essa regra de associação indica uma dependência de mudança "forte". Isso implica que 
os valores de suporte (15) e confiança (66\%) são bons valores para gerar recomendações de mudanças conjuntas entre esses dois arquivos. Usando as regras de associação, para todo commit feito para JMSConduit.java (na versão 2.1) seria possível recomendar corretamente as 19 mudanças conjuntas. Entretanto, como JMSConduit.java mudou sem a presença de JMSOldConfigHolder.java em 26 commits, 26 recomendações falsas seriam emitidas.

A abordagem proposta nesta tese coleta informações contextuais de cada commit feito para o arquivo JMSConduit.java na versão 2.0 e usa essas informações para prever, nas tarefas da versão consecutiva (2.1), se uma mudança conjunta irá ocorrer entre esses dois arquivos. Usando as informações contextuais foi possível prever 17 mudanças conjuntas entre os dois arquivos e 19 mudanças onde JMSConduit.java mudou sem a presença de JMSOldConfigHolder.java. Nove recomendações falsas foram emitidas, sendo 2 quando não ocorreram as mudanças conjuntas (falso negativos) e 7 recomendações falsas (falsos positivos) quando a mudança conjunta ocorreu.

Comparando as duas abordagens, o modelo baseado em regra de associação emitiu 26 recomendações falsas, enquanto os modelos de predição baseados em informações contextuais emitiram 9 recomendações falsas de um total de 45 testes realizados. A diferença entre as abordagens em número de recomendações falsas, nesse exemplo, é de $42 \%$, que representam uma diferença de 19 commits.

\subsection{Projetos estudados}

Para avaliar os modelos de predição de mudanças conjuntas baseados em informações contextuais foram utilizados 10 projetos da Fundação Apache. A Tabela 4-3 apresenta a sumarização dos projetos coletados, realizada a partir de dados do site Open $\mathrm{Hub}^{5}$. O Open Hub compara projetos de software livre apresentando diferentes informações que são coletadas automaticamente de cada projeto.

É possível observar que os projetos diferem em domínio, número de linhas de código (LOC), número de tarefas, número de commits, número de desenvolvedores e nível de atividade. Apesar de todos os projetos estarem hospedados na Fundação Apache, esses projetos são mantidos por diferentes desenvolvedores e apresentam nível de atividade distintos. Por exemplo, o projeto Cassandra tem o menor número de linhas de código, mas não tem a menor quantidade de tarefas e de desenvolvedores que contribuem para o projeto. Já o projeto Derby tem uma maior quantidade de linhas de código quando comparadas com o Cassandra, mas tem uma baixa quantidade de desenvolvedores contribuindo para o projeto. Por outro lado, o projeto HBase tem a maior quantidade de linhas de código, número de tarefas, número de commits, mas não tem a maior quantidade de desenvolvedores contribuindo com o projeto quando comparado com os outros projetos usados nesta tese.

Tabela 4-3 Sumarização dos projetos de acordo com OpenHub.net

\begin{tabular}{|c|c|c|c|c|c|c|}
\hline Projeto & Domínio & $\mathrm{LOC}$ & $\begin{array}{l}\text { \# de } \\
\text { tarefas }\end{array}$ & $\begin{array}{r}\text { \# de } \\
\text { Commits }\end{array}$ & $\begin{array}{r}\# \text { de } \\
\text { Desenvolvedores }\end{array}$ & Nível de Atividade \\
\hline Camel & $\begin{array}{r}\text { Arcabouço para } \\
\text { integração de dados }\end{array}$ & $1000 \mathrm{k}$ & 5864 & 24507 & 200 & Muito Alto \\
\hline Cassandra & $\begin{array}{r}\text { Arcabouço para } \\
\text { computação distribuída }\end{array}$ & $304 \mathrm{k}$ & 3275 & 17622 & 150 & Muito alto \\
\hline Cloudstack & $\begin{array}{l}\text { Plataforma para } \\
\text { computação na Nuvem }\end{array}$ & $1000 \mathrm{k}$ & 1569 & 28737 & 370 & Muito Alto \\
\hline $\mathrm{CXF}$ & $\begin{array}{l}\text { Arcabouço para apoiar } \\
\text { implementação baseada }\end{array}$ & $868 \mathrm{k}$ & 5122 & 11802 & 71 & Não disponível \\
\hline
\end{tabular}

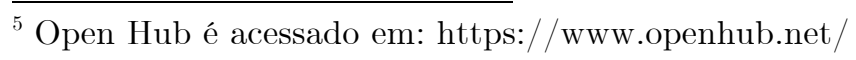




\begin{tabular}{r|r|r|r|r|r|r}
\hline & em serviços & & & & 36 & 137 \\
\hline Derby & Banco de dados relacional & $767 \mathrm{k}$ & 5023 & 7481 & 11628 & Muito Alto \\
\hline Hadoop & $\begin{array}{r}\text { Arcabouço para } \\
\text { computação distribuída }\end{array}$ & $1800 \mathrm{k}$ & 4236 & 52916 & Não disponível \\
\hline Hbase & $\begin{array}{r}\text { Banco de Dados para } \\
\text { Hadoop }\end{array}$ & $4000 \mathrm{k}$ & 9029 & 5213 & Moderado \\
\hline Lucene & $\begin{array}{r}\text { Anfraestrutura de Data } \\
\text { warehouse para Hadoop }\end{array}$ & $1000 \mathrm{k}$ & 3791 & 15970 & Alto \\
\hline Solr & $\begin{array}{r}\text { Servidor de Consulta } \\
\text { baseado no Lucene }\end{array}$ & $438 \mathrm{k}$ & 740 & 10480 & 53 & Muito Alto \\
\hline
\end{tabular}

** o nível de atividade do projeto "não disponível" indica que o repositório de código fonte analisado pelo open hub está inconsistente (http://blog.openhub.net/about-project-activity-icons/)

A Tabela 4-4 apresenta a sumarização dos dados coletados do gerenciador de tarefas (JIRA) e do SCV de cada projeto. O número de versões analisadas difere em cada projeto, consequentemente, o número de tarefas, commits e mudanças conjuntas analisadas também é diferente. As tarefas analisadas compreendem $57.72 \%$ das tarefas resolvidas dos projetos analisados. O número de commits coletados é 186356. Quase um terço dos commits $(29 \%$ - 54k) foram relacionadas às tarefas, representando o conjunto de commits usados para responder as questões de pesquisa.

O número de mudanças conjuntas somente considera as mudanças conjuntas que ocorreram em pelo menos duas tarefas. Optou-se por remover as mudanças conjuntas que ocorreram em uma única tarefa porque esse valor de suporte pode não refletir a razão pela qual duas classes mudam conjuntamente (D. Beyer e Noack, 2005). As mudanças conjuntas foram obtidas em 54388 commits associados a 23802 tarefas. Nesses commits, 7031 mudanças conjuntas distintas foram identificadas, considerando 129 versões dos 10 projetos coletados.

Tabela 4-4 Sumarização dos dados coletados no gerenciador de tarefa e no controle de versão de cada projeto

\begin{tabular}{r|r|r|r|r}
\hline Projeto & $\begin{array}{r}\text { \# de versões } \\
\text { analisadas }\end{array}$ & $\begin{array}{r}\text { Tarefas } \\
\text { analisadas }\end{array}$ & $\begin{array}{r}\text { Total de } \\
\text { Commits } \\
\text { analisados }\end{array}$ & $\begin{array}{r}\text { Pares de arquivos distintos } \\
(>=2 \text { mudanças conjuntas })\end{array}$ \\
\hline Camel & 22 & 3494 & 7765 & 479 \\
\hline Cassandra & 14 & 1597 & 2405 & 519 \\
\hline Cloudstack & 4 & 556 & 1382 & 47 \\
\hline CXF & 9 & 3139 & 8308 & 1464 \\
\hline Derby & 11 & 2605 & 7469 & 363 \\
\hline Hadoop & 22 & 2453 & 4306 & 1954 \\
\hline Hbase & 14 & 5494 & 13372 & 310 \\
\hline Hive & 12 & 2014 & 2393 & 294 \\
\hline Lucene & 17 & 2032 & 6433 & 54 \\
\hline Solr & 4 & 418 & 555 & 7031 \\
\hline Total & 129 & 23802 & 54388 & \\
\hline
\end{tabular}




\subsection{Ameaças à validade}

predição.

Algumas ameaças à validade podem afetar a coleta de dados e a construção dos modelos de

\subsubsection{Validade de construção}

A validade de construção diz respeito à forma com que o estudo mede o que pretende medir.

A primeira ameaça de construção diz respeito a forma que os commits são associados às tarefas (issues) de cada projeto. Essa ameaça é limitada porque os projetos da Fundação Apache utilizam uma forma padrão, conforme descrito na Seção 4.2.1.1, de indicar que um commit resolve uma tarefa. Nos 10 projetos utilizados nesta tese, foi possível verificar que o padrão descrito foi utilizado.

Diversas medidas de avaliação dos modelos de aprendizagem foram usadas para verificar a efetividade dos modelos de predição construídos nesta tese. O MCC foi utilizado para complementar as medidas de avaliação de aprendizagem de máquina normalmente utilizadas por se tratar de uma medida de correlação entre as amostras observadas e preditas, calculada com base nos quatro valores da matriz de confusão é apresentado. Com relação às métricas de avaliação, os resultados apresentados também indicam o número correto de predições e a relação com a quantidade de commits e tarefas. Esses valores podem dar uma maior noção de acerto para os desenvolvedores, que se beneficiariam do uso da abordagem proposta em um cenário real.

Em relação às mudanças conjuntas selecionadas, é importante mencionar que desenvolvedores podem não adequadamente associar commits com tarefas ou fazer commits de formas diferentes. Esse fenômeno é chamado de tangled changes (Herzig e Zeller, 2013). Nesse estudo, essa ameaça é limitada, uma vez que agrupamos e consideramos os commits feitos somente em solicitações de mudança. A abordagem utilizada para relacionar commits a tarefas é amplamente utilizada por outros trabalhos da literatura (D'Ambros et al. 2012a; Silva et al. 2014; Zimmermann et al. 2007).

Por fim, a tese avalia somente arquivos de código fonte (.java e .XML), outras extensões foram removidas. De acordo com o OpenHub, essas duas extensões representam a grande maioria do código fonte dos projetos analisados.

\subsubsection{Validade interna}

A validade interna tem relação com a confiabilidade da pesquisa, evitando que fatores internos possam confundir a interpretação dos resultados ou adicionem viés a interpretação dos resultados

A escolha das amostras para compor o conjunto de treinamento e teste é uma ameaça a validade interna. Para mitigar essa ameaça foram utilizados conjuntos de treinamento com dados obtidos em uma versão e conjunto de testes com dados obtidos na versão consecutiva. Dessa forma, os commits e tarefas que eram usados para compor esses conjuntos eram diferentes. Esse processo foi realizado com dados de 129 versões de 10 projetos diferentes, minimizando o viés que poderia existir de uma versão na qual sempre os mesmos arquivos eram modificados conjuntamente, os mesmos desenvolvedores realizassem as mudanças conjuntas e os projetos tivessem o mesmo domínio de aplicação, que poderia influenciar o modo com que os arquivos eram modificados.

A segunda ameaça interna diz respeito a escolha das informações contextuais usadas para construir os modelos de predição. O conjunto de informações contextuais usados nesta tese pode não ser completo. Para combater essa ameaça, o conjunto de métricas que refletem nosso conceito de informação contextual para as mudanças conjuntas foi definido com base em um mapeamento sistemático realizado durante o desenvolvimento dessa tese, bem como, com testes realizados em estudos preliminares. Esse conjunto representa diferentes fontes de informações, tais como, a tarefa, 
a comunicação e metadados dos commits. A partir da descrição do método utilizado nesta tese, é possível estender e replicar o trabalho com um número maior ou diferente de métricas.

Por fim, para avaliar a efetividade dos modelos baseados em informações contextuais os resultados obtidos foram comparados com modelos de predição de mudanças conjuntas baseados em regras de associação, com modelos aleatórios cujo AUC foi igual a 0,5 e com métricas textuais e numéricas com valores atribuídas aleatoriamente para cada mudança. Essa comparação é apresentada na questão de pesquisa 2 .

\subsubsection{Validade externa}

Ameaças à validade externa dizem respeito a fatores relacionados à capacidade de generalização dos resultados obtidos em outros projetos.

Nesta tese, 10 projetos da Apache Foundation foram analisados. Consequentemente, não é possível generalizar os resultados para diferentes projetos. Para amenizar os efeitos dessa ameaça, os projetos selecionados foram escolhidos por apresentarem características diferentes, tais como: número de tarefas, tamanho em linhas de código, número de mudanças conjuntas encontradas e analisadas, número de commits analisados e número de desenvolvedores que colaboram com o projeto. Além disso, os projetos diferem em domínio e número de versões analisadas.

\subsection{Considerações finais}

Este capítulo apresentou as questões de pesquisa investigadas nesse trabalho com sua justificativa e abordagem. O método de coleta das informações contextuais e a forma de construção dos modelos de predição também foram apresentados.

O próximo capítulo apresenta os resultados de cada uma das questões de pesquisa. 


\section{Capítulo 5 Resultados}

Este capítulo apresenta os resultados obtidos com o uso da abordagem de predição de mudanças conjuntas proposta nesta tese. O intuito foi avaliar se as informações contextuais melhoram a acurácia da predição de mudanças conjuntas reduzindo a quantidade de recomendações falsas. Para esse propósito foram construídos modelos de predição baseados em algoritmos de aprendizagem de máquina para cada par de arquivos.

Diferentemente do estado da arte atual, que se baseia em tipos de dependências entre os arquivos, a abordagem de predição de mudanças conjuntas dessa tese utiliza informações contextuais das tarefas, da comunicação e dos metadados das mudanças de cada arquivo. Para avaliar até que ponto os modelos de predição baseado em informações contextuais melhoram a acurácia da predição de mudanças conjuntas, cinco questões de pesquisa foram investigadas. Os resultados são apresentados a seguir.

\subsection{Questão de pesquisa 1: As informações contextuais possibilitam predizer as mudanças conjuntas entre dois arquivos?}

Para avaliar a acurácia da predição de mudanças conjuntas usando as informações contextuais são obtidos os valores da matriz de confusão (VP, VN, FP e FN), os valores de sensibilidade, precisão e medida $\mathrm{F}$, bem como os valores de AUC e MCC. Todos os resultados apresentados na primeira questão de pesquisa foram obtidos usando dados dos 10 projetos e 129 versões apresentados no capítulo anterior. Os modelos de predição são construídos para cada par de arquivos, utilizando o algoritmo random forest em conjunto com o método de amostragem bootstrap. Nesta questão de pesquisa, o conjunto de treinamento é construído em uma versão e os resultados são obtidos na versão consecutiva usada para construir o conjunto de teste.

A Tabela 5-1 apresenta a visão geral da predição realizada com as informações contextuais considerando todos os projetos e versões analisadas. Os resultados apresentados compreendem dois diferentes conjuntos de modelos: os modelos que utilizam somente as métricas numéricas listadas na Tabela 3-5 e os modelos que utilizam todas as métricas (numéricas e categóricas conjuntamente).

Os resultados são apresentados nesse formato pois observou-se que a quantidade de amostras testadas no modelo com todas as métricas (que incluem as métricas categóricas) é menor. A quantidade menor de amostras existe porque ocorre inconsistência entre as informações categorias presentes nas versões nas quais são construídos o conjunto de treinamento e teste, por exemplo, quando um desenvolvedor faz um commit na versão que é construído o conjunto de teste, mas não faz nenhum commit na versão onde o conjunto de treinamento foi construído.

Observa-se na Tabela 5-1 que os modelos com todas as informações contextuais têm melhor desempenho que os modelos que utilizam as informações contextuais numéricas. A diferença percentual em números de acertos é de 4,90\% (92,90\% - 88,00\%), entretanto, o desempenho melhor é obtido com $85 \%$ menos testes realizados (\# total de mudanças conjuntas + \# total de mudanças 
simples). Considerando somente a predição de mudanças conjuntas (número de VP e o \# total de commits com mudanças conjuntas), é possível observar que os modelos com as métricas numéricas acertam $75 \%$ das predições realizadas (19746 das 26189 mudanças conjuntas testadas) enquanto os modelos com todas as informações contextuais acertam 87\% das predições (5262 das 6029 mudanças conjuntas testadas).

Tabela 5-1 Visão geral da técnica de predição realizada com informações contextuais

\begin{tabular}{r|r|r|r|r|r|r|r|r}
\hline Modelos & $\begin{array}{r}\text { \# total de } \\
\text { mudanças } \\
\text { conjuntas }\end{array}$ & $\begin{array}{r}\text { \# total de } \\
\text { mudanças sem } \\
\text { a mudança } \\
\text { conjunta } \\
\text { esperada }\end{array}$ & VP & FP & FN & VN & $\begin{array}{r}\text { \# } \\
\text { Predições } \\
\text { corretas }\end{array}$ & $\begin{array}{r}\% \text { Predições } \\
\text { corretas }\end{array}$ \\
\hline $\begin{array}{r}\text { Somente métricas } \\
\text { numéricas }\end{array}$ & 26189 & 111174 & 19746 & 10007 & 6443 & 101167 & 120913 & $88,02 \%$ \\
\hline Todas as métricas & 6029 & 13940 & 5264 & 765 & 652 & 13288 & 18552 & $92,94 \%$ \\
\hline
\end{tabular}

A Tabela 5-2, apresenta os valores de precisão, sensibilidade, medida F, percentual (\%) de falsos positivos e negativos para as predições das mudanças conjuntas. O MCC representa a qualidade do modelo de predição por meio da correlação das instâncias observadas e preditas. De acordo com Powers (Powers, 2011), é possível interpretar o valor do MCC de forma similar à correlação de Pearson. A escala dos valores de MCC são as mesmas recomendadas por Evans (Evans, 1996) que considera a correlação como moderada quando o MCC está entre 0,30 e 0,39, correlação forte entre 0,40 a 0,69 e correlação muito forte acima de 0,70 .

Nos testes realizados, verifica-se que existe uma correlação forte $(\mathrm{MCC}=0,63)$ entre as instâncias observadas e preditas pelos modelos com métricas numéricas e uma correlação muito forte $(\mathrm{MCC}=0,83)$ quando os modelos com todas as métricas foram executados. Comparando os dois tipos de modelos é possível perceber que os modelos com todas as métricas obtiveram maiores valores de precisão, sensibilidade e Medida F. Por consequência, os modelos com todas as informações contextuais obtiveram menores percentuais de falsos positivos e negativos.

Tabela 5-2 Medidas de Avaliação da predição de mudanças conjuntas

\begin{tabular}{l|r|r|r|r|r|r}
\hline \multicolumn{1}{l|}{ Modelos } & \multicolumn{1}{l|}{ Precisão } & \multicolumn{1}{l}{ Sensibilidade } & \multicolumn{1}{l|}{ Medida F } & \multicolumn{1}{l|}{ MCC } & \% Falso Positivo & \% Falso Negativo \\
\hline $\begin{array}{r}\text { Somente métricas } \\
\text { numéricas }\end{array}$ & 0,66 & 0,75 & 0,71 & 0,63 & 50,67 & 6,36 \\
\hline Todas as métricas & 0,87 & 0,89 & 0,88 & 0,83 & 14,53 & 4,91 \\
\hline
\end{tabular}

A Figura 5-1 apresenta a distribuição do percentual de acertos na predição considerando todas as amostras, ou seja, quando a mudança conjunta esperada ocorreu (classe $=1$ ) e nas amostras nas quais as mudanças conjuntas não ocorreram (classe $=0$ ). A distribuição da esquerda (cor preta) mostra o desempenho dos modelos construídos com as métricas contextuais numéricas. A distribuição da direita (cor cinza) mostra o desempenho com o uso de todas as métricas.

O gráfico bean, ou beanplot (Kampstra, 2008), é recomendado para visualizar e comparar duas diferentes distribuições visualmente. Um beanplot é similar ao boxplot, entretanto, a representação gráfica foca na densidade das distribuições. As linhas pretas horizontais indicam os valores medianos de cada distribuição. A linha pontilhada indica a média entre as duas distribuições. 


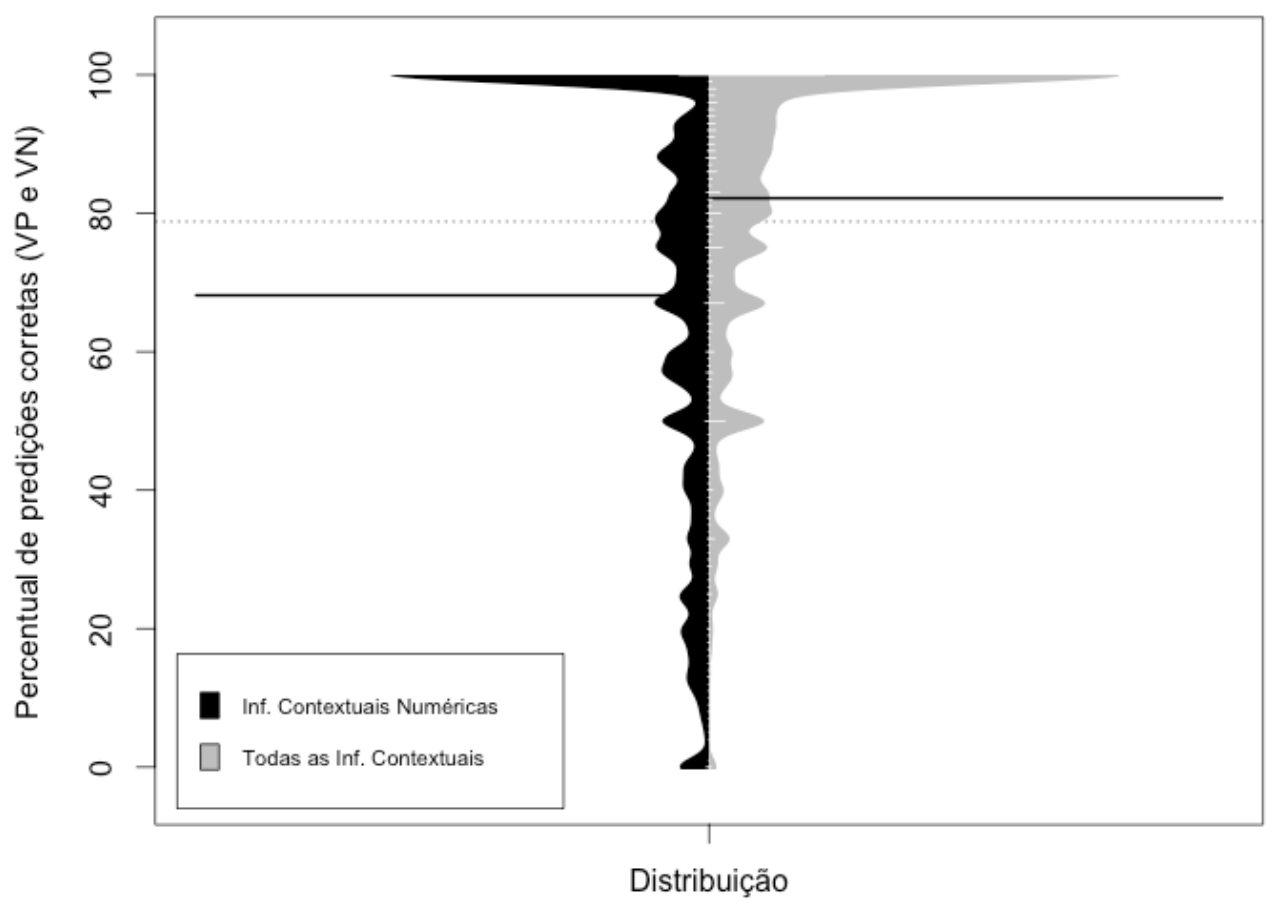

Figura 5-1. Distribuição do percentual de acertos dos modelos testados.

A análise da distribuição indica que a mediana dos modelos que utilizam somente métricas numéricas têm aproximadamente $70 \%$ de acurácia, enquanto os modelos com todas as métricas ultrapassam $80 \%$ de acurácia. Os modelos com todas as métricas têm a densidade das distribuições mais concentrada acima dos 50\%, indicando que a maioria dos modelos construídos acertam pelo menos $50 \%$ das amostras que são testadas. Os modelos com métricas numéricas também apresentam uma maior concentração acima de $50 \%$, entretanto, é possível perceber uma maior densidade abaixo dos 50\% quando comparada com os modelos que utilizam todas as informações contextuais.

A Figura 5-2 apresenta a distribuição do percentual de acertos somente considerando as amostras que indicam a ocorrência de mudanças conjuntas (valores de VP da Tabela 5-1, classe = 1). Observa-se que a mediana das distribuições é menor nos modelos que utilizam somente as informações contextuais numéricas indicando que os modelos de predição baseados em todas as informações contextuais têm um desempenho melhor para prever somente as ocorrências de mudanças conjuntas. Entretanto, a diferença entre as medianas da distribuição dos modelos baseados em todas as informações contextuais e dos modelos baseados em informações contextuais numéricas é menor na Figura 5-2 quando comparados com a diferença entre as medianas dos dois tipos de modelos na Figura 5-1. A diminuição da distância entre as medianas indica que o percentual de modelos que acertam as amostras com mudanças conjuntas é similar nos dois tipos de modelos.

Também é interessante observar que existe um percentual de modelos - independente do conjunto de informações contextuais usadas - que é capaz de acertar todas as amostras de mudanças conjuntas avaliadas. Também é possível perceber que existe um conjunto de modelos incapaz de acertar uma única amostra na qual tenha ocorrido uma mudança conjunta. Nesses casos a densidade do percentual de acertos dos modelos tem um pico nos valores de 0 e 100 . 


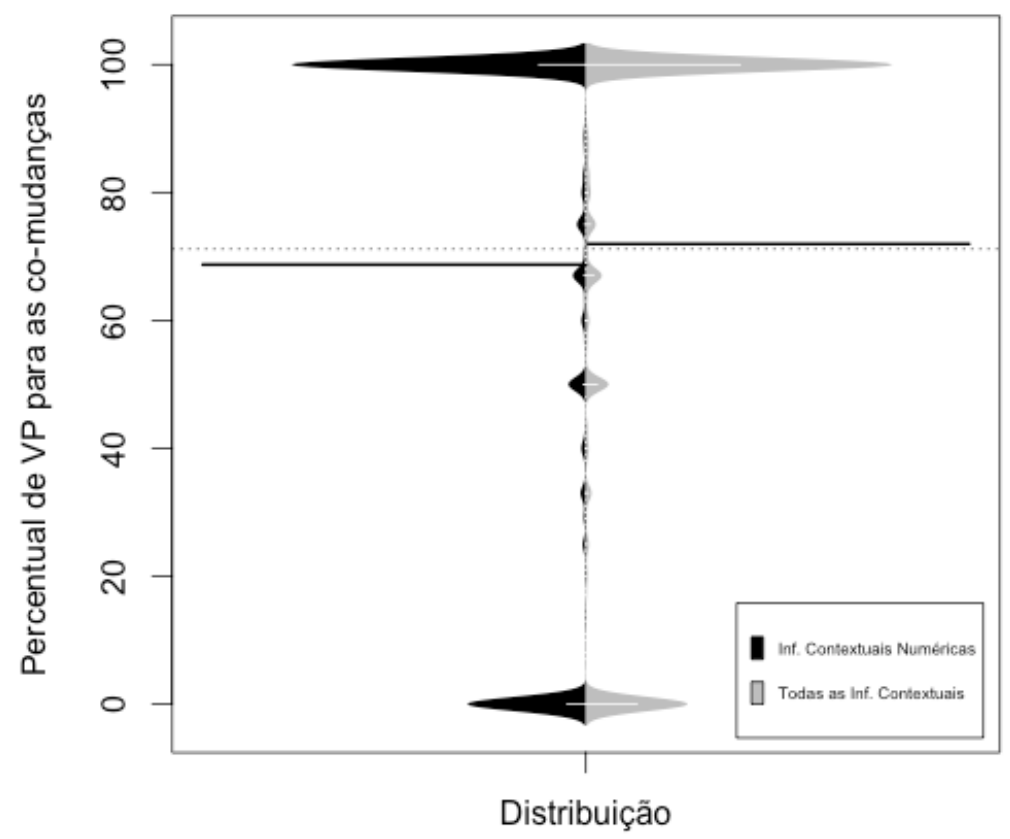

Figura 5-2. Distribuição do percentual de verdadeiro positivos (acertos) somente para as mudanças conjuntas

A Figura 5-3 apresenta a distribuição dos valores da medida $\mathrm{F}$ quando foram realizadas as predições das mudanças conjuntas. Novamente é possível verificar que os modelos apresentam mediana acima de 0,60 independente do conjunto de informações contextuais usados e que dois grupos de modelos concentram valores de medida $\mathrm{F}$ iguais a 1 e iguais a 0.

Quantitativamente, verificou-se que 1360 modelos construídos somente com métricas numéricas erraram todas as suas predições, enquanto 4366 modelos acertaram todas as predições de mudanças conjuntas. Considerando os modelos com todas as métricas, 451 modelos erraram todas as predições de mudanças conjuntas, enquanto 1200 modelos acertaram todas.

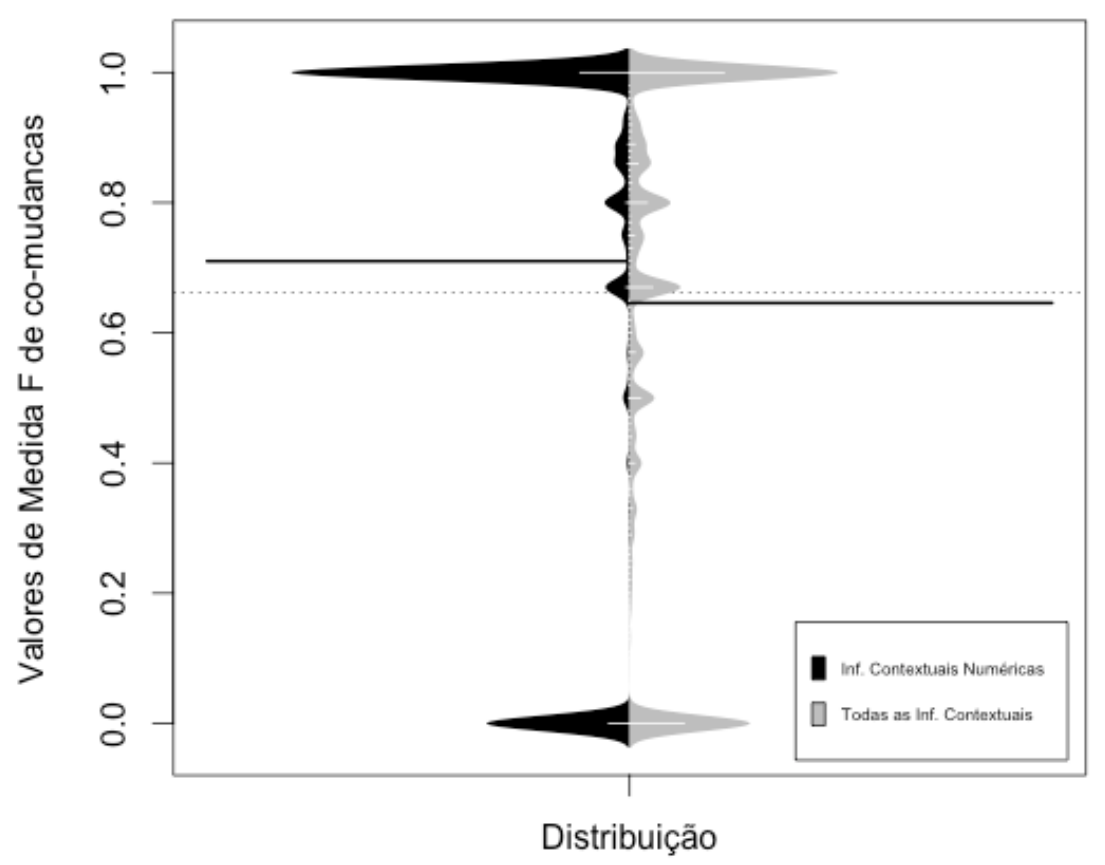

Figura 5-3. Distribuição dos valores de Medida F dos modelos para prever mudança conjunta. 
A Figura 5-4 apresenta a distribuição dos valores de AUC para os modelos com métricas numéricas e com todas as métricas. Observando a distribuição verifica-se que os modelos construídos com métricas numéricas têm a mediana dos valores de AUC acima de 0,8. Os modelos com todas as métricas têm a mediana próxima de um modelo aleatório ( $\mathrm{AUC}=0,5)$, entretanto, nota-se que a grande parte desses modelos tem AUC igual a 1 ou igual a 0.

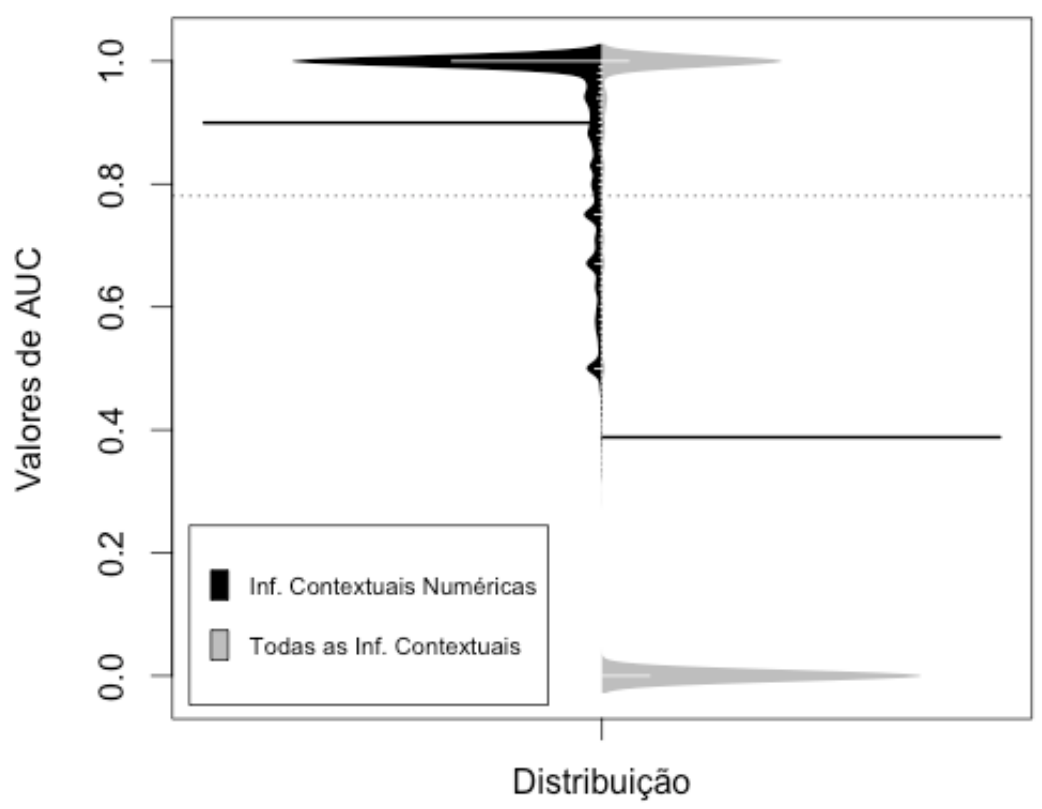

Figura 5-4. Distribuição dos valores de AUC para os modelos construídos com todas as métricas e somente as métricas numéricas.

Para Powers (2012), analisar somente o AUC enviesa a análise da acurácia dos modelos já que essa medida não utiliza as informações de falsos positivos e negativos. Apesar desse viés, o AUC é comumente reportado quando algoritmos de aprendizagem de máquina são utilizados. Para complementar a análise, a partir da recomendação de Powers (2012), também são apresentados os valores da correlação de Mathews (MCC) que levam em consideração os valores de falsos positivos e negativos (Powers, 2011).

A Tabela 5-3 apresenta os resultados dos modelos de predição usando as métricas numéricas e todas as métricas por projeto. Os valores de precisão, sensibilidade, Medida F correspondem às predições de mudanças conjuntas.

A análise das predições corretas mostra que os modelos com pior desempenho acertam pelo menos $74 \%$ das amostras avaliadas. Entretanto, quando o percentual de falsos positivos (\%FP) é observado, a metade dos projetos apresenta altos valores de falsos positivos. Os valores de Medida F variam de 0,44 e 0,80 para os modelos com métricas numéricas e entre 0,33 a 1,00 para os modelos com todas as métricas.

Com relação ao MCC observa-se que 6 projetos apresentaram correlação forte e muito forte entre as instâncias observadas e preditas nos modelos com métricas numéricas. Já nos modelos com todas as informações contextuais, 8 projetos apresentaram MCC com correlação entre forte e muito forte. Os altos valores de MCC indicam que os modelos são capazes de distinguir amostras que contêm uma mudanças conjunta e amostras que não contêm uma mudança conjunta. 
Tabela 5-3 Comparação da Precisão, Sensibilidade e Medida F para a predição de mudanças conjuntas por projeto

\begin{tabular}{|c|c|c|c|c|c|c|c|c|}
\hline Projeto & Métricas** & Precisão & Sensibilidade & Medida F & $\mathrm{MCC}$ & $\begin{array}{r}\% \text { Predições } \\
\text { Corretas }\end{array}$ & $\% \mathrm{FP}$ & $\% \mathrm{FN}$ \\
\hline \multirow{2}{*}{ Camel } & Numéricas & 0,71 & 0,79 & 0,75 & 0,65 & 85,49 & 41,75 & 8,70 \\
\hline & Todas & 0,85 & 0,90 & 0,87 & 0,81 & 91,63 & 18,12 & 5,09 \\
\hline \multirow{2}{*}{ Cassandra } & Numéricas & 0,43 & 0,48 & 0,45 & 0,34 & 80,36 & 133,68 & 12,08 \\
\hline & Todas & 0,32 & 0,55 & 0,41 & 0,30 & 78,69 & 210,00 & 8,47 \\
\hline \multirow{2}{*}{ Cloudstack } & Numéricas & 0,61 & 0,60 & 0,60 & 0,50 & 83,08 & 64,71 & 12,17 \\
\hline & Todas* & 1,00 & 1,00 & 1,00 & 1,00 & 100,00 & 0,00 & 0,00 \\
\hline \multirow{2}{*}{$\mathrm{CXF}$} & Numéricas & 0,75 & 0,86 & 0,80 & 0,72 & 87,86 & 34,15 & 6,06 \\
\hline & Todas & 0,90 & 0,92 & 0,91 & 0,88 & 94,91 & 10,69 & 3,29 \\
\hline \multirow{2}{*}{ Derby } & Numéricas & 0,70 & 0,86 & 0,77 & 0,71 & 88,56 & 42,04 & 4,62 \\
\hline & Todas & 0,88 & 0,95 & 0,91 & 0,87 & 94,03 & 13,00 & 2,93 \\
\hline \multirow{2}{*}{ Hadoop } & Numéricas & 0,46 & 0,47 & 0,47 & 0,30 & 74,44 & 116,59 & 19,87 \\
\hline & Todas & 0,72 & 0,66 & 0,69 & 0,61 & 87,29 & 38,81 & 9,86 \\
\hline \multirow{2}{*}{ HBase } & Numéricas & 0,68 & 0,71 & 0,69 & 0,68 & 91,40 & 47,81 & 4,85 \\
\hline & Todas & 0,94 & 0,93 & 0,93 & 0,90 & 95,32 & 6,64 & 3,98 \\
\hline \multirow{2}{*}{ Hive } & Numéricas & 0,44 & 0,53 & 0,48 & 0,35 & 78,83 & 128,98 & 12,49 \\
\hline & Todas & 0,68 & 0,64 & 0,66 & 0,59 & 87,94 & 46,43 & 8,72 \\
\hline \multirow[t]{2}{*}{ Lucene } & Numéricas & 0,50 & 0,66 & 0,57 & 0,46 & 81,32 & 101,21 & 9,19 \\
\hline & Todas & 0,72 & 0,69 & 0,70 & 0,62 & 87,40 & 39,38 & 9,33 \\
\hline \multirow{2}{*}{ Solr } & Numéricas & 0,44 & 0,47 & 0,44 & 0,33 & 78,01 & 125,00 & 15,21 \\
\hline & Todas & 0,70 & 0,70 & 0,70 & 0,58 & 82,35 & 42,85 & 14,28 \\
\hline
\end{tabular}

* Cloudstack foi testado somente uma versão com todas as métricas.

** Na coluna métricas o texto "numéricas" corresponde aos modelos que utilizam somente as métricas numéricas. O valor "todas" corresponde aos modelos que utilizam todas as métricas.

A Figura 5-5 apresenta os resultados das predições corretas realizadas em cada projeto. Notase que a mediana das predições corretas é superior a 75\%. Nos projetos Cloudstack, CXF, Derby, Hbase, Hive e Lucene os modelos com informações contextuais numéricas e os modelos com todas as informações contextuais obtêm taxas de acerto acima de $75 \%$. Percebe-se também grande variabilidade no tamanho de cada boxplot. Apesar da variabilidade observada, todos os projetos obtiveram pelo menos $50 \%$ de acertos. Em todos os projetos avaliados, as maiores medianas são sempre dos modelos com todas as métricas. Entretanto, também é possível verificar que a maior quantidade de outliers pertencem a esses modelos.

Para comparar o desempenho dos modelos foi utilizado o teste de tamanho do efeito nãoparamétrico Delta de Cliff (descrito no Capítulo 2, seção 2.5.3). Após a execução do teste, constatou-se que o tamanho do efeito entre os dois modelos, considerando o número de predições corretas (ver coluna 7 - Tabela 5-3) dos projetos analisados foi grande (valor de $|\mathrm{d}|=0,58$ ). O intervalo de confiança de $95 \%$ indica que o valor de $|\mathrm{d}|$ está entre 0,05 e 0,85 , demonstrando que estatisticamente é possível afirmar que os modelos com todas as métricas têm melhor desempenho considerando o número total de predições realizadas. Entretanto, em alguns projetos o valor de $|\mathrm{d}|$ indica que o tamanho do efeito é insignificante. 


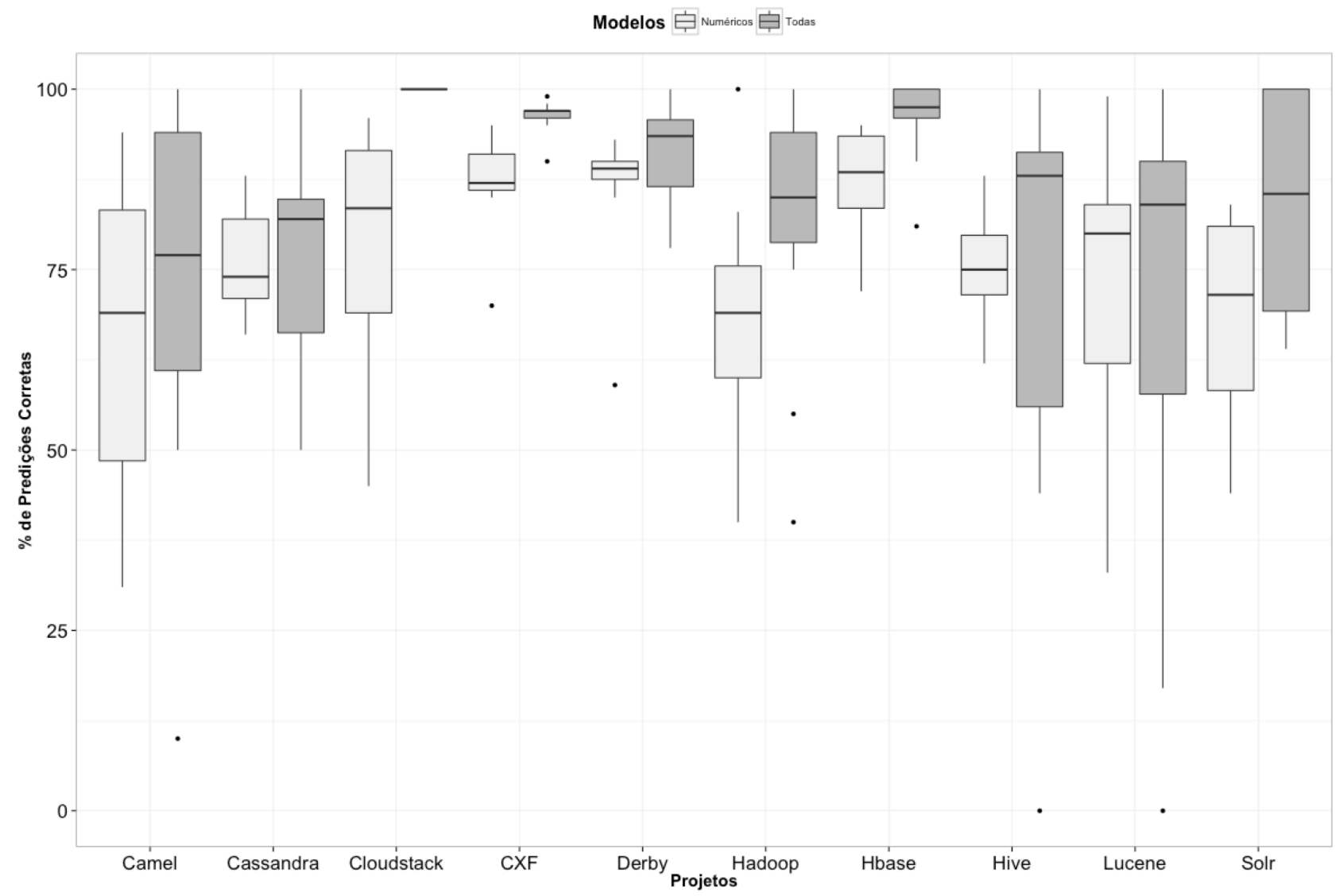

Figura 5-5. Boxplot com os valores das predições corretas por projeto.

A Figura 5-6 apresenta os resultados dos valores da medida $\mathrm{F}$ para predição das mudanças conjuntas. Os projetos CXF e Derby apresentam a mediana dos valores de medida F superiores a 0,75 , independente do tipo de métrica utilizada. O projeto Hbase tem a mediana da medida $\mathrm{F}$ superior a 0,75 somente para os modelos com métricas numéricas. O contrário foi observado no projeto Cloudstack, os modelos com todas as métricas possuem a mediana superior a 0,75. Também, é possível perceber que nesses dois projetos mesmo que as métricas numéricas tenham os maiores valores de medida $\mathrm{F}$, os resultados com todas as métricas são ainda melhores.

Os projetos Cloudstack e Hbase obtêm a mediana superior a 0,75 nos modelos que utilizam todas as métricas, mostrando influências das métricas categóricas nesses dois projetos. Os projetos Hive, Lucene, Hadoop e Cassandra têm a mediana próxima a 0,50. Os demais projetos têm medianas inferiores a esse valor. Nos projetos em que a mediana é inferior, casos do projeto Camel e Solr, os modelos com informações contextuais numéricas são melhores. Nos projetos Hive, Cassandra e Lucene, as medianas são praticamente iguais, entretanto, nos projetos Cloudstack, CXF, Derby, Hbase e Hadoop, os modelos com todas as informações contextuais são superiores.

De um modo geral, os boxplots dos modelos construídos com informações contextuais numéricas tendem a ser mais estáveis, uma vez que distância entre o primeiro quartil e o terceiro quartil são menores. Observa-se também que em 6 dos 10 projetos, a variabilidade dos modelos com todas as informações contextuais apresenta modelos com valor de Medida $F$ que variam de 0 até 1,0. Nota-se que os modelos de predição que utilizam todas as informações contextuais são muito precisos (valores próximos de um) ou muito imprecisos (valores próximos a 0 ).

Para verificar se existe diferença no desempenho da predição de amostras com mudanças conjuntas, o tamanho do efeito de Cliff foi novamente calculado a partir dos valores da medida $\mathrm{F}$ (coluna 7 - Tabela 5-3). Após a execução do teste, verificou-se que existe grande diferença $(|\mathrm{d}|=$ 0,53) no desempenho dos modelos. Entretanto, verificou-se que em alguns projetos a diferença do 
tamanho do efeito foi insignificante, uma vez que o valor de delta com $95 \%$ de confiança ficou entre -0,03 e 0,83. Essa diferença de desempenho é observada nos projetos Cassandra, Hive e Lucene em que as medianas da medida $\mathrm{F}$ foram muito próximas.

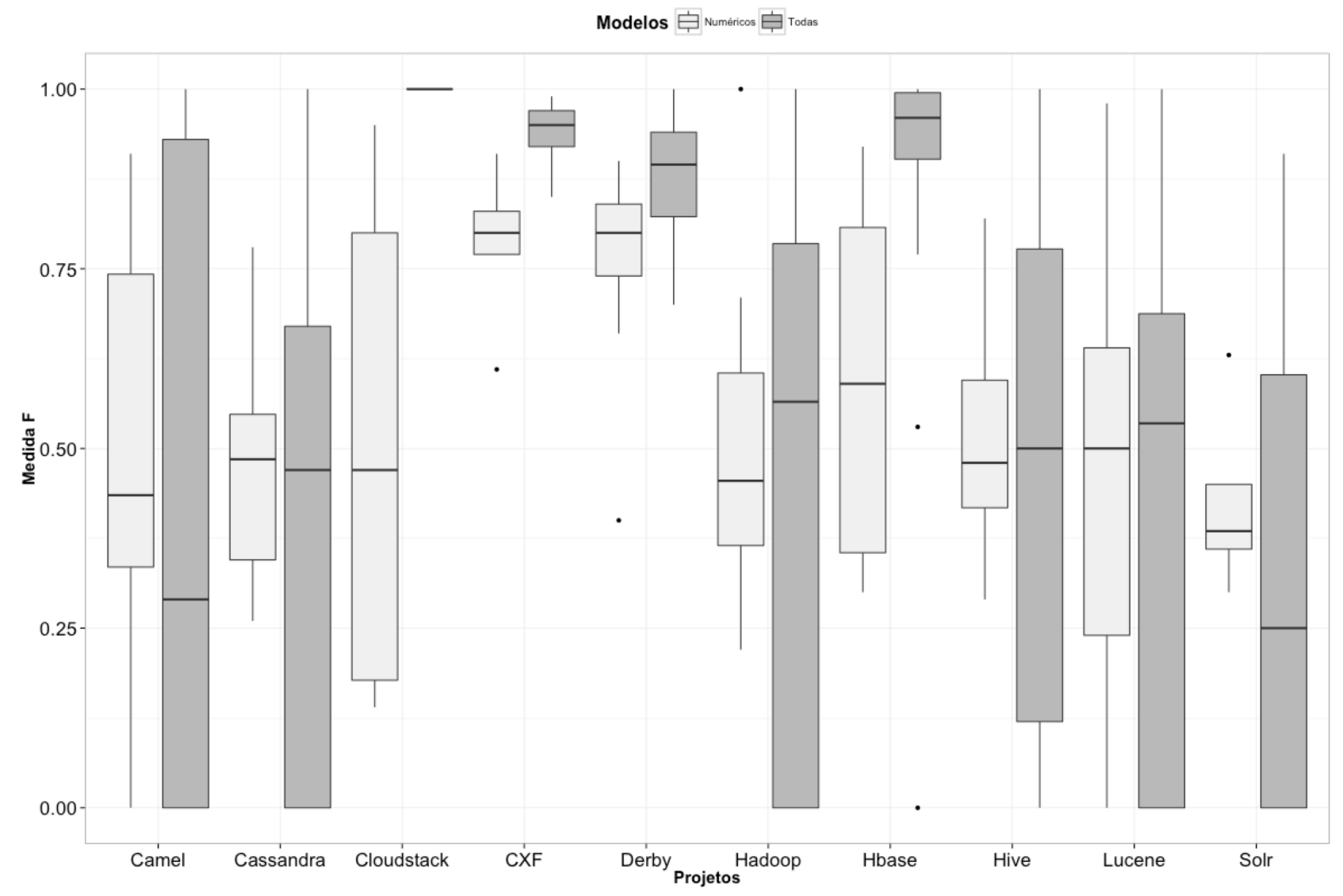

Figura 5-6. Boxplot com os valores da medida F da predição das mudanças conjuntas por projeto.

A Tabela 5-4 mostra a quantidade de versões em que os modelos obtiveram predições de mudanças conjuntas com valor de medida $\mathrm{F}$ igual ou maior que 0,75 . A terceira coluna apresenta a quantidade de versões encontradas para cada tipo de modelo testado. A quarta coluna apresenta a quantidade de versões coletadas de cada projeto. A última coluna indica o percentual de versões em que a predição de mudanças conjuntas teve medida $\mathrm{F}$ igual ou maior que 0,75 .

A quantidade de versões avaliadas é diferente quando os tipos de modelos são comparados. Anteriormente, verificou-se que $85 \%$ a menos de amostras foram avaliadas por modelos que usaram todas as informações contextuais. Dentro desse percentual, observou-se que os modelos com todas as informações contextuais testaram 24 versões a menos. Os modelos com informações contextuais obtiveram um terço das versões avaliadas com valor de medida $\mathrm{F}$ igual ou maior que 0,75 , enquanto os modelos com todas as informações contextuais obtiveram $60 \%$ das versões com esse mesmo desempenho.

Tabela 5-4 Quantidade de versões com Medida F igual ou maior que 0,75

\begin{tabular}{r|r|r|r|r}
\hline Projeto & Métricas & $\begin{array}{r}\text { Versões com } \\
\text { Medida F }>=0,75\end{array}$ & Total de Versões & $\begin{array}{r}\text { \% de versões com } \\
\text { Medida F }>=0,75\end{array}$ \\
\hline \multirow{2}{*}{ Camel } & Numéricas & 6 & 22 & $27 \%$ \\
\cline { 2 - 5 } & Todas & 1 & 19 & $42 \%$ \\
\hline \multirow{2}{*}{ Cassandra } & Numéricas & 2 & 14 & $7 \%$ \\
\cline { 2 - 5 } & Todas & 12 & $17 \%$ \\
\hline
\end{tabular}




\begin{tabular}{|c|c|c|c|c|}
\hline \multirow{2}{*}{ Cloudstack } & Numéricas & 1 & 4 & $25 \%$ \\
\hline & Todas* & 1 & 1 & $100 \%$ \\
\hline \multirow{2}{*}{ CXF } & Numéricas & 8 & 9 & $89 \%$ \\
\hline & Todas & 9 & 9 & $100 \%$ \\
\hline \multirow{2}{*}{ Derby } & Numéricas & 7 & 11 & $63 \%$ \\
\hline & Todas & 9 & 10 & $90 \%$ \\
\hline \multirow{2}{*}{ Hadoop } & Numéricas & 1 & 22 & $5 \%$ \\
\hline & Todas & 2 & 12 & $17 \%$ \\
\hline \multirow{2}{*}{ HBase } & Numéricas & 4 & 14 & $29 \%$ \\
\hline & Todas & 12 & 14 & $86 \%$ \\
\hline \multirow{2}{*}{ Hive } & Numéricas & 1 & 12 & $8.3 \%$ \\
\hline & Todas & 4 & 12 & $33 \%$ \\
\hline \multirow[t]{2}{*}{ Lucene } & Numéricas & 2 & 17 & $12 \%$ \\
\hline & Todas & 2 & 12 & $17 \%$ \\
\hline \multirow{2}{*}{ Solr } & Numéricas & 0 & 4 & $0 \%$ \\
\hline & Todas & 4 & 4 & $100 \%$ \\
\hline
\end{tabular}

\subsubsection{Sumarização dos resultados}

A seguir são sumarizados os resultados obtidos para responder a questão de pesquisa 1:

- Os conjuntos de treinamento e testes foram construídos com dados coletados em cada versão.

- Foram consideradas mudanças conjuntas que ocorreram em pelo menos duas tarefas (suporte igual a 2).

- Os modelos construídos usaram o algoritmo de aprendizagem de máquina random forest com a configuração padrão.

- Foram comparados os modelos com informações contextuais numéricas e com todas as informações contextuais (que incluem as métricas representadas como String e Booleana)

- Modelos com informações contextuais numéricas foram testados em 129 versões. Modelos com todas as informações contextuais foram avaliados em 105 versões.

- Métricas categóricas diminuem a quantidade de falso positivos nos modelos para menos de $15 \%$ (de média).

- Independente do conjunto de informações contextuais (numéricas ou todas as métricas) menos de $7 \%$ de falsos negativos foram obtidos considerando todos os projetos avaliados.

- A diferença de desempenho para prever somente as mudanças conjuntas é grande $(|d|$ $=0,53)$ de acordo com o teste de Cliff. Entretanto, em alguns projetos essa diferença é insignificante.

- Modelos com todas as informações contextuais foram melhores, entretanto os modelos tendem a apresentar maior variabilidade (ou acertam muito ou erram muito), e testam 
$85 \%$ menos commits (24 versões a menos) que os modelos que utilizaram somente as informações contextuais numéricas.

QP1: Sim, as informações contextuais melhoram a acurácia da predição de mudança conjunta entre dois arquivos. De maneira geral, os resultados obtidos indicam que é possível usar informações contextuais para prever a ocorrência de mudanças conjuntas entre pares de arquivos. Pelo menos $88 \%$ de amostras foram corretamente preditas (120193 commits dos 137363 commits testados). Do ponto de vista das mudanças conjuntas, 19746 das 26189 mudanças conjuntas foram preditas corretamente, o que equivale a $75 \%$ de predições corretas. Esses resultados são similares ou superiores aos resultados encontrados nos trabalhos relacionados.

\subsection{Questão de pesquisa 2: Qual o desempenho da predição de mudanças conjuntas dos modelos de predição baseados em informações contextuais comparado com as regras de associação?}

Nessa questão de pesquisa, o objetivo é comparar os modelos construídos com informações contextuais com um modelo base que utiliza regras de associação. As regras de associação utilizam a frequência de mudanças conjuntas entre dois arquivos no passado para criar regras de associação que possibilitam inferir quão relevante é o acoplamento entre dois arquivos. Para realizar a comparação com os modelos de predição de mudanças conjuntas baseados em informações contextuais, as regras de associação foram identificadas em uma versão e usadas para prever mudanças conjuntas da próxima versão. As regras de associação foram obtidas de acordo com a descrição feita no Capítulo 4, Seção 4.2.2.1, que descreve a forma de cálculo do suporte e confiança usada nesta tese.

Conforme descrito no Capítulo 2, as regras de associação possuem diferentes limiares de suporte e confiança. Quanto maior o valor de suporte e confiança, maior a relevância e força de uma regra de associação. Espera-se que uma regra de associação com maior valor de suporte a confiança inferida em uma versão de um projeto possa recomendar várias mudanças conjuntas na próxima versão. Baseado nos limiares apresentados nos trabalhos relacionados (Ball et al. 1997; Canfora e Cerulo, 2005; Canfora et al. 2010; Ying et al. 2004; Zimmermann et al. 2012) foram coletadas diferentes regras de associação entre os pares de arquivos e os resultados são comparados em relação à força e relevância de cada regra.

A Tabela 5-5 apresenta a quantidade de pares de arquivos encontrados por limiar de suporte e confiança. As colunas de 1 a 14 representam, respectivamente, a quantidade de pares em cada regra de associação: suporte igual a 2 e confiança entre 50 e 70 (1), suporte igual a 2 e confiança entre 90 e 100 (2), suporte $=3$ e confiança entre 50 e 70 (3), suporte $=3$ e confiança entre 70 e 90 (4), suporte $=3$ e confiança entre 90 e $100(5)$, suporte $=4$ e 5 e confiança entre 50 e 70 (6), suporte $=$ 4 e 5 e confiança entre 70 e $90(7)$, suporte $=4$ e 5 e confiança entre 90 e 100 (8), suporte $=6$ e 7 e confiança entre 50 e 70 (9), suporte $=6$ e 7 e confiança entre 70 e 90 (10), suporte $=6$ e 7 e confiança entre 90 e 100 (11), suporte maior ou igual a 8 e confiança entre 50 e 70 (12), suporte maior ou igual a 8 e confiança entre 70 e 90 (13), suporte igual ou maior a 8 e confiança entre 90 e 100 (14). A última coluna apresenta a soma total de pares de arquivos usados no estudo porque estão entre os limiares de 1 a 14 . A coluna total apresenta o total de pares de arquivos avaliados em cada projeto.

Observa-se na Tabela 5-5 que a quantidade de pares de arquivos tende a diminuir à medida que os valores de suporte e confiança aumentam. Por exemplo, no projeto Camel a soma da quantidade de pares das colunas 1 e 2 é superior à soma das demais colunas, o que indica que a maioria dos pares analisados mudaram conjuntamente em duas tarefas. Esse comportamento é comum nos demais projetos analisados. Conforme apresentado no Capítulo 4, o suporte mínimo 2 
foi utilizado porque uma única mudança conjunta não reflete porque duas classes frequentemente mudam conjuntamente (Beyer e Noack, 2005). O projeto com o maior número de pares de arquivos analisados foi o projeto Hbase, o menor foi o projeto Solr.

Tabela 5-5 Quantidade de pares de arquivos por limiar de suporte e confiança

\begin{tabular}{r|r|r|r|r|r|r|r|r|r|r|r|r|r|r|r}
\hline Projeto & 1 & 2 & 3 & 4 & 5 & 6 & 7 & 8 & 9 & 10 & 11 & 12 & 13 & 14 & Total \\
\hline Camel & 193 & 158 & 21 & 12 & 30 & 9 & 19 & 20 & 1 & 0 & 0 & 3 & 5 & 8 & 479 \\
\hline Cassandra & 168 & 88 & 53 & 36 & 40 & 55 & 30 & 15 & 16 & 0 & 3 & 3 & 4 & 8 & 519 \\
\hline Cloudstack & 16 & 20 & 1 & 1 & 3 & 0 & 1 & 4 & 0 & 0 & 0 & 0 & 1 & 0 & 47 \\
\hline CXF & 449 & 577 & 54 & 54 & 125 & 44 & 60 & 68 & 8 & 5 & 5 & 2 & 5 & 8 & 1464 \\
\hline Derby & 476 & 525 & 137 & 99 & 122 & 44 & 53 & 40 & 9 & 17 & 14 & 5 & 1 & 5 & 1547 \\
\hline Hadoop & 133 & 123 & 35 & 20 & 13 & 15 & 9 & 10 & 2 & 1 & 0 & 1 & 1 & 0 & 363 \\
\hline Hbase & 703 & 472 & 159 & 132 & 99 & 113 & 82 & 39 & 40 & 36 & 6 & 39 & 29 & 5 & 1954 \\
\hline Hive & 129 & 94 & 19 & 17 & 23 & 11 & 4 & 12 & 0 & 0 & 0 & 0 & 1 & 0 & 310 \\
\hline Lucene & 80 & 166 & 7 & 11 & 17 & 2 & 5 & 2 & 0 & 3 & 0 & 1 & 0 & 0 & 294 \\
\hline Solr & 25 & 9 & 1 & 2 & 5 & 6 & 2 & 2 & 2 & 0 & 0 & 0 & 0 & 0 & 54 \\
\hline
\end{tabular}

A Tabela 5-6 mostra a visão geral dos resultados de predições realizadas. Essa tabela compara os modelos com informações contextuais numéricas, os modelos com informações contextuais que utilizam todas as métricas e as regras de associação. As regras de associação foram executadas em dois conjuntos de dados diferentes porque verificou-se na questão de pesquisa 1 que os modelos de predição de mudanças conjuntas com todas as informações contextuais testam menos amostras (veja Tabela 5-1).

É possível observar que a quantidade de predições corretas dos modelos baseados em regras de associação é de 19,06\% considerando todas as amostras obtidas nas 129 versões dos 10 projetos e $30,19 \%$ com as mesmas amostras usadas nos modelos com todas as informações contextuais. Esse valor é bem inferior aos modelos baseados em informações contextuais. É possível observar que os modelos de regras de associação recomendam uma mudança conjunta quando na verdade a mudança conjunta não ocorre (conforme exemplo da Seção 4.4.). Assim, é possível observar que os modelos de regras de associação apresentam alto valor de falsos positivos e nenhum verdadeiro ou falso negativo.

Tabela 5-6 Visão geral dos modelos de predição baseados em informações contextuais comparados com os modelos de regras de associação.

\begin{tabular}{r|r|r|r|r|r|r|r|r}
\hline Modelos & $\begin{array}{r}\text { \# total de } \\
\text { mudanças } \\
\text { conjuntas }\end{array}$ & $\begin{array}{r}\text { \# total de } \\
\text { mudanças sem } \\
\text { a mudança } \\
\text { conjunta } \\
\text { esperada }\end{array}$ & VP & FP & FN & VN & $\begin{array}{r}\text { \# } \\
\text { Predições } \\
\text { corretas }\end{array}$ & $\begin{array}{r}\text { Predições } \\
\text { corretas }\end{array}$ \\
\hline $\begin{array}{r}\text { Somente } \\
\text { métricas } \\
\text { numéricas }\end{array}$ & 26189 & 111174 & 19746 & 10007 & 6443 & 101167 & 120913 & $88,02 \%$ \\
\hline $\begin{array}{r}\text { Regras de } \\
\text { Associação } \\
\text { (numéricas) }\end{array}$ & 26189 & 111174 & 26189 & 111174 & 0 & 0 & 26189 & $19,06 \%$ \\
\hline $\begin{array}{r}\text { Todas as } \\
\text { métricas }\end{array}$ & 6029 & 13940 & 5264 & 765 & 652 & 13288 & 18552 & $92,90 \%$ \\
\hline $\begin{array}{r}\text { Regras de } \\
\text { Associação } \\
\text { (todas as } \\
\text { métricas) }\end{array}$ & 6029 & 13940 & 6029 & 13940 & 0 & & \\
\hline
\end{tabular}


A Tabela 5-7 mostra os valores de precisão, sensibilidade e medida F somente para a predição de mudanças conjuntas. Observa-se que os modelos com regras de associação têm sensibilidade de $100 \%(1,00)$, porque capturam todas as mudanças conjuntas que ocorreram. Entretanto, como existe uma grande quantidade de falsos positivos, a precisão é baixa. Isso está associada à quantidade de vezes que uma amostra não corresponde a uma mudança conjunta e que as regras de associação recomendam a ocorrência de uma mudança conjunta. Também é possível observar que essa quantidade de amostras na qual a mudança conjunta não acontece (classe $=0$ ) é muito maior que a quantidade de amostras com mudanças conjuntas (classe $=1$ ), e, por conta disso, o desempenho das regras de associação foi baixo.

O teste de Cliff foi utilizado para comparar os modelos baseados em informações contextuais com os modelos baseados em regras de associação. A comparação dos modelos que utilizam as informações contextuais numéricas com as regras de associação no mesmo conjunto de dados apresenta tamanho do efeito grande $(|\mathrm{d}|=1)$. A média do valor da medida $\mathrm{F}$ nas regras de associação é 0,32 . Os modelos com informações contextuais numéricas obtiveram valor médio de medida $\mathrm{F}$ de 0,71 , maior que o dobro do valor de medida $\mathrm{F}$ obtido pelos modelos baseados em regras de associação.

O teste de Cliff também encontrou uma diferença grande $(|d|=0,90)$ quando são comparados os modelos com todas as informações contextuais e as regras de associação. Com $95 \%$ de confiança pode-se dizer que o valor do delta de Cliff da comparação da medida $\mathrm{F}$ dos modelos pode variar entre $|\mathrm{d}|=0,67$ a $|\mathrm{d}|=0,97$. Mesmo com o valor mínimo $(|\mathrm{d}|=0,67)$ pode-se afirmar que os modelos baseados em informações contextuais são superiores aos modelos baseados em regras de associação. Nesse caso, a diferença média do valor da medida $\mathrm{F}$ entre os modelos é quase o dobro (0,46 para regras de associação e 0,88 para os modelos com todas as informações contextuais).

Tabela 5-7 Medidas de Avaliação da predição de mudanças conjuntas

\begin{tabular}{r|r|r|r}
\hline \multicolumn{1}{l|}{} & Precisão & Sensibilidade & \multicolumn{1}{l}{ Medida F } \\
\hline Somente métricas numéricas & 0,66 & 0,75 & 0,71 \\
\hline Regras de Associação (numéricas) & 0,19 & 1,00 & 0,32 \\
\hline Todas as métricas & 0,87 & 0,89 & 0,88 \\
\hline Regras de Associação (todas as métricas) & 0,30 & 1,00 & 0,46 \\
\hline
\end{tabular}

Após a visão geral dos modelos são apresentados os valores de predição para cada um dos limiares de suporte e confiança usados. Essa análise é necessária para comparar a variabilidade do desempenho de predições em diferentes limiares de suporte e confiança, já que se espera, que as regras de associação maiores apresentem melhores resultados na predição de mudanças conjuntas (Zimmermann et al. 2005).

A Figura 5-7 apresenta os resultados por limiares de suporte e confiança e compara os resultados de precisão, sensibilidade e medida $F$ entre os modelos baseados em informações contextuais que utilizam as métricas numéricas e as regras de associação. Cada linha no gráfico indica a combinação de um modelo - seja o modelo baseado em regra de associação ou baseado em informações contextuais - com uma medida de avaliação. Por exemplo, as linhas que têm círculos, quadrados e triângulos indicam os modelos baseados em informações contextuais numéricas, com as métricas de medida $\mathrm{F}$, precisão e sensibilidade, respectivamente. Os outros três símbolos representam os modelos baseados em regras de associação. 


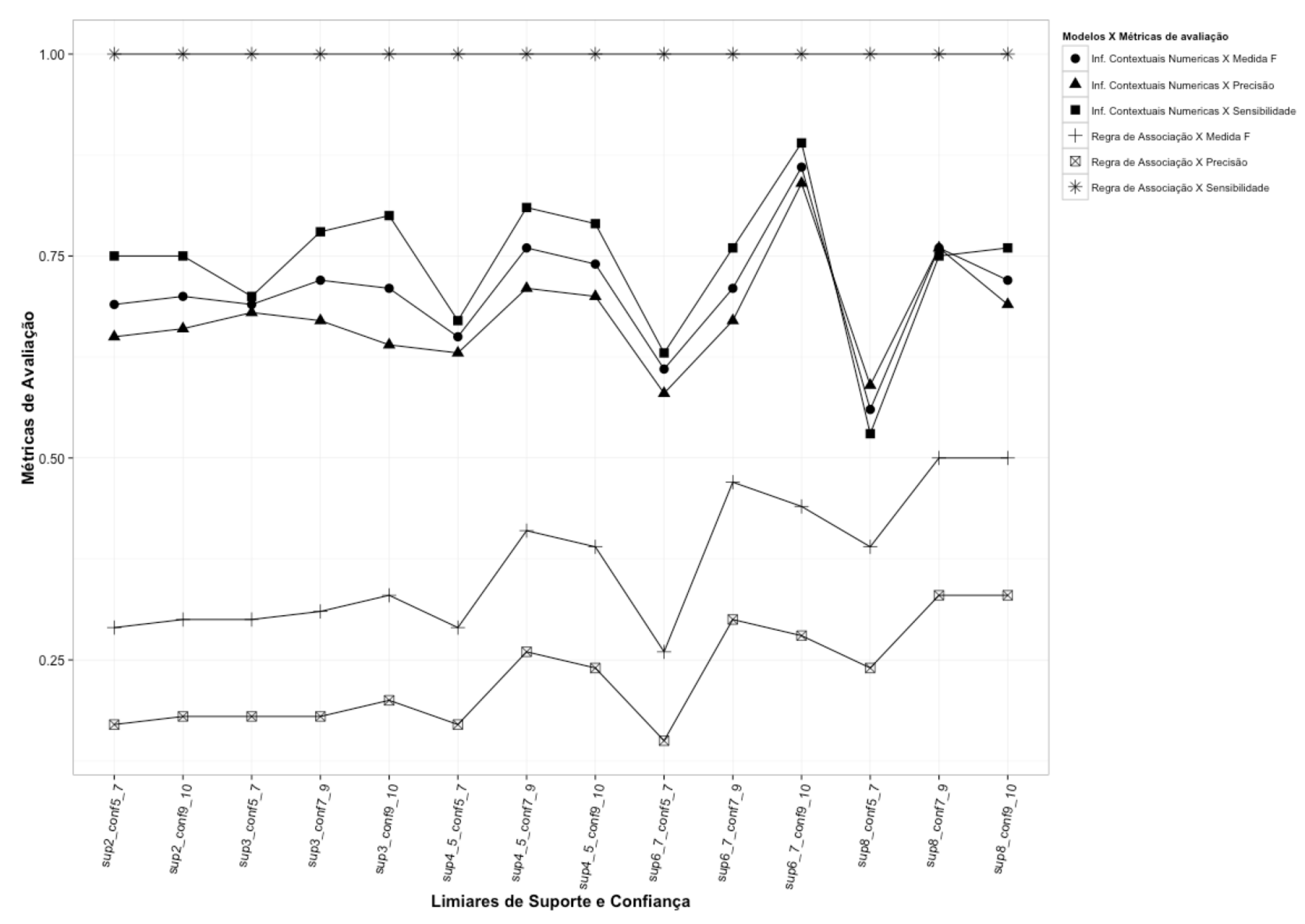

Figura 5-7. Comparação dos valores de Precisão, Sensibilidade e Medida F entre os modelos construídos com informações contextuais numéricas e regras de associação.

Percebe-se no gráfico que os modelos baseados em regras de associação apresentam uma tendência de aumentar a precisão e a medida $\mathrm{F}$ conforme os valores de suporte e confiança aumentam. Esse comportamento é esperado, uma vez que os trabalhos relacionados relatam que quanto maiores os valores de suporte e confiança mais "acoplados" dois arquivos deveriam estar sob ponto de vista da dependência de mudança (Ball et al. 1997; Ying et al. 2004; Zimmermann et al. 2005).

Nesta tese, as regras de associação mais relevantes testadas têm suporte igual ou maior que 8 e confiança entre 90 e 100\%. Já a regra de associação menos relevante tem suporte igual a 2 e confiança entre 50 e 70\%. Nota-se que o valor de precisão começa em 0,17 com o limiar menos relevante (suporte $=2 \mid$ confiança entre 50-70\%) até alcançar 0,33 com o limiar mais relevante (suporte $>=8 \mid$ confiança entre $90-100 \%$ ). O mesmo acontece com o valor da medida $\mathrm{F}$ que varia de 0,29 a 0,50. Apesar do desempenho das regras de associação melhorarem à medida que os valores de suporte e confiança aumentam, os valores de falsos positivos ainda influenciam o desempenho dos modelos baseados em regra de associação, uma vez que o valor de medida $\mathrm{F}$ máximo obtido foi 0,50 .

Para os modelos baseados em informações contextuais numéricas, observa-se que as três medidas se mantêm muito próximas ao longo de cada limiar. Essa característica indica que existe uma estabilidade nos valores da predição de mudanças conjuntas independentemente da quantidade de vezes que os artefatos mudaram juntos no passado. Na maioria dos limiares quando a precisão aumenta, existe um aumento na sensibilidade e, por consequência, do valor da medida $F$. Em alguns limiares, esse comportamento não ocorre, como por exemplo, no limiar de suporte $=3$ | confiança entre 50-70\%, no qual observa-se que a sensibilidade diminuiu, enquanto a precisão tem um pequeno aumento. Além disso, verifica-se que ocorre uma inversão de comportamento dos 
valores de precisão e sensibilidade quando o limiar atinge o valor de suporte igual a 8 ou maior. Nos dois primeiros limiares onde o suporte é 8 ou maior e a confiança está entre 50-90\%, a precisão tem valor um pouco maior que a sensibilidade.

É importante observar que o valores das medidas de avaliação para os modelos baseados em informações contextuais numéricas são superiores a 0,50 . Na maioria dos limiares de suporte e confiança, esse valor ultrapassa 0,65 podendo chegar a 0,90 como é o caso das mudanças conjuntas que têm suporte igual a 5 ou 6 e confiança entre 90 e $100 \%$.

A Figura 5-8 mostra a comparação dos modelos com todas as métricas contextuais e os modelos baseados em regras de associação. Diferentemente do comportamento visto no gráfico anterior, o comportamento dos modelos tem um pico nos valores das métricas para as regras de associação com limiar de suporte entre 6 e 7 quando a confiança varia entre 70 a 100\%. Nesse mesmo limiar, os modelos baseados em informações contextuais também melhoram seu desempenho para a predição de mudanças conjuntas. A medida $\mathrm{F}$ dos modelos se aproxima muito nesses limiares, mas tendem a se manter distantes nos outros limiares de suporte e confiança.

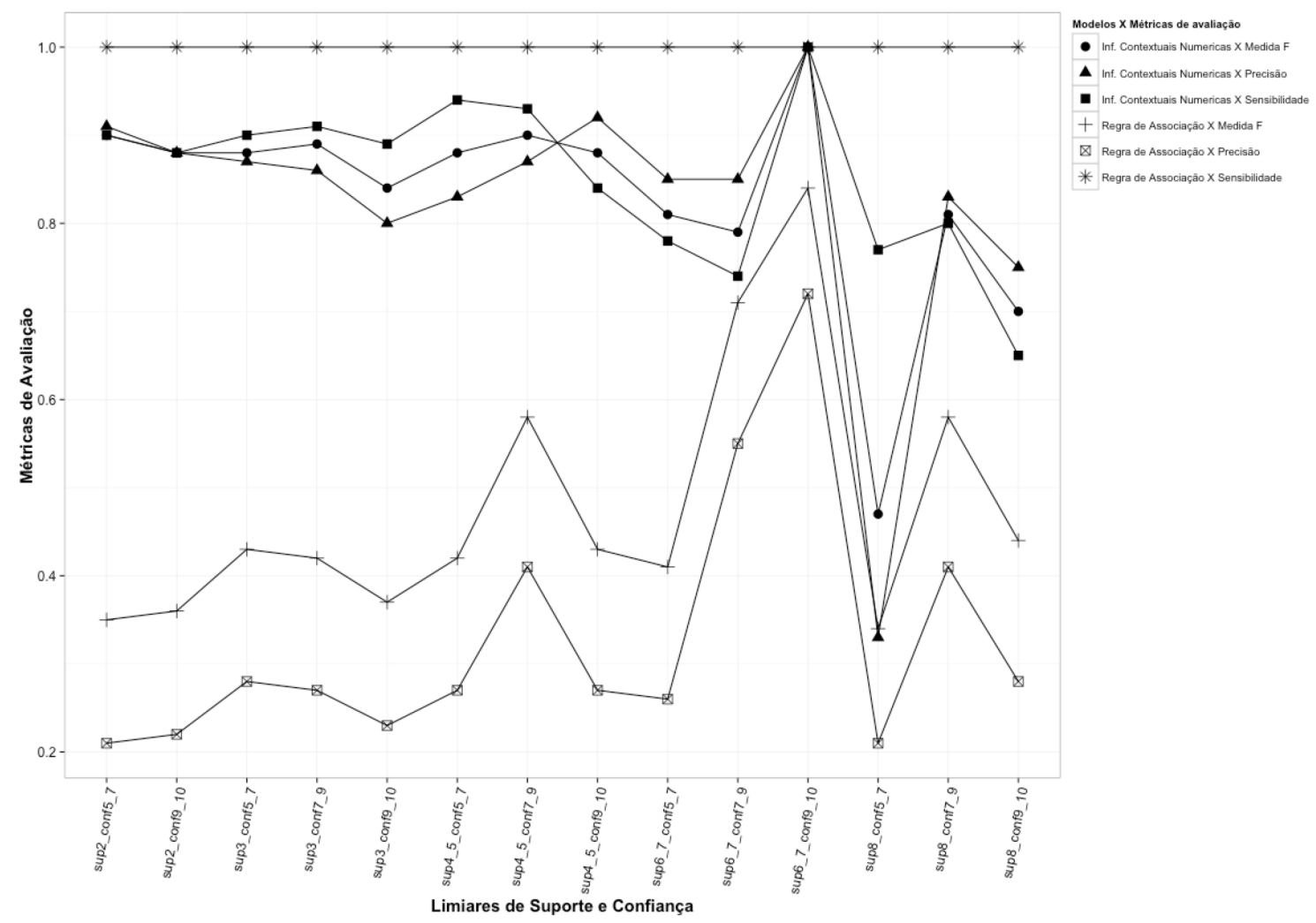

Figura 5-8. Comparação dos valores de Precisão, Sensibilidade e Medida F entre os modelos construídos com todas as informações contextuais e regras de associação.

Outra tendência observada indica que os modelos baseados em informações contextuais têm valores mais estáveis de precisão, sensibilidade e medida $\mathrm{F}$ para as mudanças conjuntas que ocorreram menos vezes juntas (menores valores de suporte e confiança). Dos valores de suporte 2 até 5, independente do valor de confiança, os modelos baseados em informações contextuais mostraram progressiva melhora de desempenho em todas as métricas de avaliação. Entretanto, nos últimos limiares percebe-se maior variabilidade no desempenho das predições. Os modelos baseados em regras de associação variam a precisão de 0,2 a 0,7 e variam a medida $\mathrm{F}$ de 0,35 a 0,84 . Os modelos baseados em informações contextuais variam a precisão de 0,33 a 1,00, a sensibilidade de 0,7 a 1,00 e a medida $\mathrm{F}$ de 0,47 a 1,00 .

A Figura 5-9 apresenta o valor da Medida F obtido para cada projeto. Três tipos de modelos são apresentados: os modelos baseados em todas as informações contextuais (cinza claro), os 
modelos baseados em informações contextuais numéricas (cinza escuro) e os modelos baseados em regras de associação (cinza) executados no mesmo conjunto de dados usados pelos modelos baseados em informações contextuais numéricas. Percebe-se que os modelos que utilizam todas as informações contextuais variam os valores de medida $\mathrm{F}$ de 0 até 1,0 em seis projetos (Camel, Cassandra, Hadoop, Hive, Lucene e Solr). Esse comportamento indica conformidade com a densidade das distribuições apresentadas na questão de pesquisa 1.

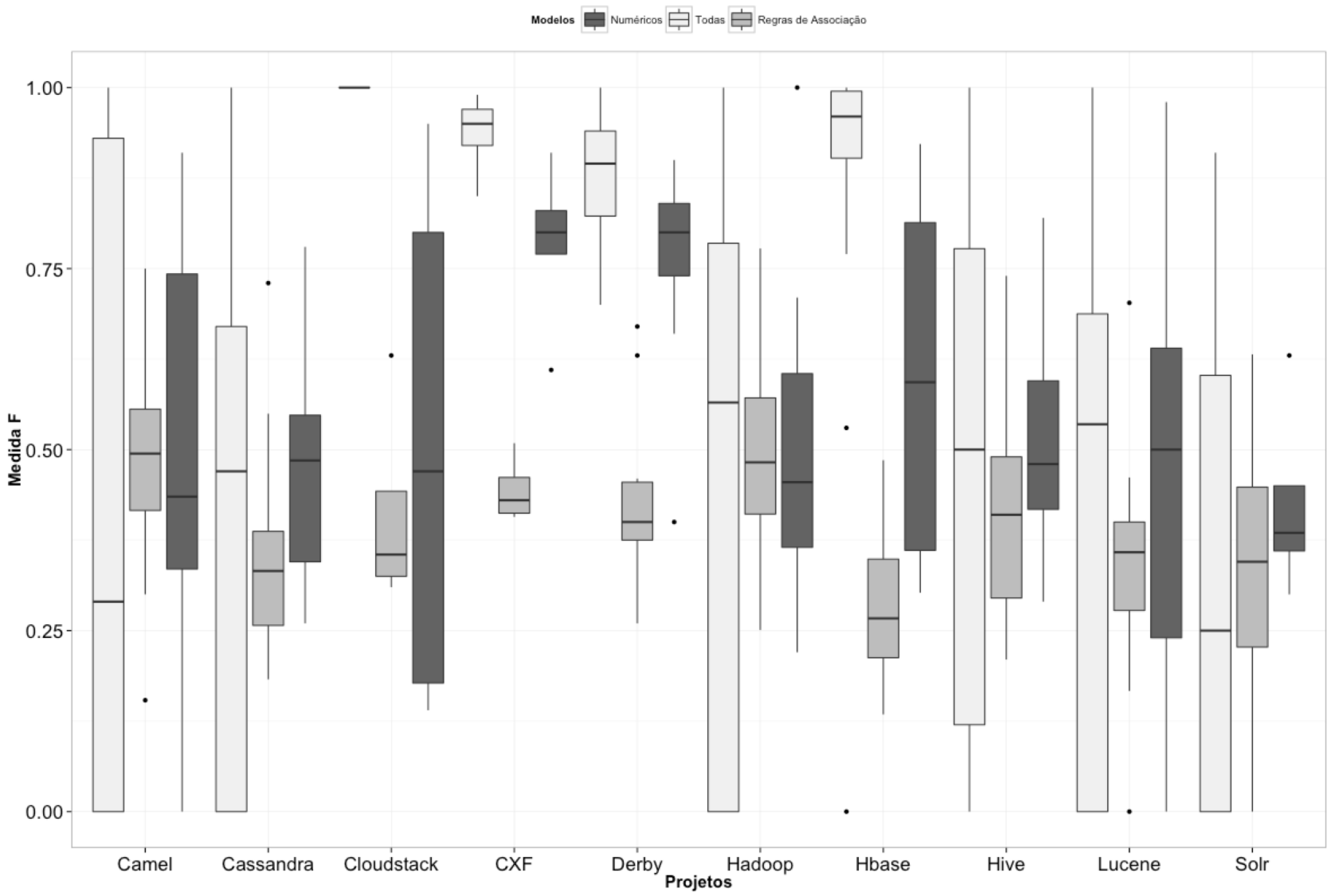

Figura 5-9. Valor da Medida F dos modelos construídos com informações contextuais (métricas numéricas e todas as métricas) comparado com o modelo baseado em regras de associação

É possível verificar que os modelos baseados em todas as informações contextuais são muito mais instáveis (boxplot maior) que os que são baseados em informações contextuais numéricas e em regras de associação.

Quando a mediana é observada, os modelos com todas as informações contextuais são superiores em 8 dos 10 projetos analisados. Os que são baseados em regras de associação só são melhores que os baseados em informações contextuais no projeto Camel. Já os que são baseados em informações contextuais numéricas são melhores que os baseados em regras de associação nos projetos Cassandra, Solr, CXF e Derby.

Os modelos baseados em regras de associação não apresentaram mediana do valor da medida $\mathrm{F}$ acima de 0,50 , enquanto os baseados em informações contextuais numéricas apresentaram mediana da medida F acima de 0,50 nos projetos CXF, Derby e Hbase. Entretanto, é possível observar que vários "whiskers superiores" (linhas acima do terceiro quartil) tendem a ser maiores nos modelos com informações contextuais numéricas que nos baseados em regras de associação. As regras de associação têm os whiskers superiores maiores somente em 2 (Hadoop e Solr) dos 10 projetos. 


\subsubsection{Sumarização dos resultados}

Os resultados apresentados foram utilizados para os modelos com informações contextuais que foram comparados com os modelos baseados em regras de associação que são frequentemente utilizados na literatura. Abaixo são sumarizados os resultados da segunda questão de pesquisa:

- Os conjuntos de treinamento e testes foram construídos com dados coletados em cada versão.

- Foram consideradas mudanças conjuntas que ocorreram em pelo menos duas tarefas (suporte igual a 2).

- Os resultados foram comparados para cada limiar de suporte e confiança. Ao todo, 14 limiares diferentes foram comparados. Os valores variaram de suporte $=2 \mid$ confiança entre 50 e $70 \%$ até suporte maior ou igual a 8 | confiança entre 90 e $100 \%$.

- O teste de Cliff indicou uma grande diferença de desempenho $(\mathrm{d}=|1,0|)$ entre os modelos baseados em todas informações contextuais e as regras de associação quando o valor da medida $\mathrm{F}$ foi comparado.

- O teste de Cliff indicou uma grande diferença de desempenho $(\mathrm{d}=|0,94|)$ entre os modelos baseados em informações contextuais numéricas e as regras de associação quando o valor da medida $\mathrm{F}$ foi comparado.

- Os modelos baseados em informações contextuais numéricas têm valores maiores de sensibilidade, precisão e medida $\mathrm{F}$ em qualquer valor de suporte e confiança, quando comparados com as regras de associação.

- Os modelos que utilizam as informações contextuais numéricas obtiveram melhor desempenho em três dos 10 projetos (Camel, Hive e Solr). Nos outros 7 projetos os modelos com todas as informações contextuais são melhores.

- Os modelos baseados em regras de associação variam a medida F de 0,35 a 0,84 , entretanto a mediana é inferior a 0,50 .

- Os modelos de predição com todas as informações contextuais variaram a medida $\mathrm{F}$ de 0,47 a 1,00. A mediana foi superior a 0,50 em 5 dos 10 projetos avaliados.

- Os modelos de predição baseados em informações contextuais numéricas variaram de 0,55 a 0,90. A mediana do valor de Medida F é superior a 0,50 em 3 dos 10 projetos avaliados.

- Os modelos de regras de associação foram os piores modelos em 8 dos 10 projetos. Nos projetos Camel e Solr, os modelos de regras de associação obtiveram melhor desempenho que os modelos construídos com todas as informações contextuais.

QP2: Os modelos baseados em informações contextuais apresentaram melhores resultados na predição de mudanças conjuntas quando comparados com regras de associação. Independentemente dos projetos testados e dos limiares de suporte e confiança avaliados, os modelos baseados em informações contextuais apresentam melhores valores de Medida F. As regras de associação apresentaram altos índices de falsos positivos por não detectar as amostras no qual a mudança conjunta não ocorre. Essa característica torna os modelos baseados em regras de associação imprecisos e com uma maior quantidade de recomendações falsas. 


\subsection{Questão de pesquisa 3: Qual a influência dos conjuntos de dados usados para construir os modelos de predição de mudanças conjuntas?}

Durante a construção de modelos de predição baseados em algoritmos de aprendizagem de máquina é importante considerar o efeito do desbalanceamento das classes no conjunto de dados coletados. A distribuição da quantidade de amostras em cada classe - nesta tese representada pela quantidade de ocorrências de mudanças conjuntas e da não ocorrência de mudanças conjuntas entre dois arquivos - é um dos principais fatores de baixo desempenho na predição das amostras que representam a classe em menor quantidade (He e Garcia, 2009; Khoshgoftaar et al., 2010).

Em modelos de predição construídos para tratar problemas relacionados à engenharia de software (sucesso ou fracasso na construção do software, propensão de defeitos, vulnerabilidades etc.), é normal ocorrer o desbalanceamento entre as classes (McIntosh et al. 2014; Menzies et al. 2008, 2007). Nesta tese, esse problema é evidenciado pela comparação da quantidade de amostras com mudanças conjuntas e não mudanças conjuntas no conjunto de dados.

A Tabela 5-1 (questão de pesquisa 1) apresentou que 24832 amostras pertenciam à classe de mudança conjunta. Entretanto, 107083 amostras representavam situações na qual uma mudança conjunta entre dois artefatos não acontecia. Nesse caso, verifica-se que a quantidade de mudanças conjuntas representa $18,82 \%$ do total de amostras investigadas, valor que evidencia $\mathrm{o}$ desbalanceamento entre a quantidade de amostras de cada classe.

Quando os testes foram realizados com os modelos de predição de mudanças conjuntas baseados em todas as informações contextuais, a diminuição na quantidade total de amostras reduziu o desbalanceamento. Aqui se percebe que, 6029 amostras representam as mudanças conjuntas e 13940 amostras representam a não ocorrência de uma mudança conjunta. Para esse cenário o percentual de desbalanceamento foi menor, já que a quantidade de amostras com mudanças conjuntas representa $30,19 \%$ do total das amostras.

Para avaliar o impacto do modo de agrupamento dos dados e do desbalanceamento nos resultados da predição de mudanças conjuntas, foram comparadas a formação de conjuntos de treinamento construídos em cada versão com a construção de conjunto de treinamento que ordenava as tarefas e dividia a quantidade total de tarefas de cada projeto por um denominador. Três formas de divisão foram usadas: o número total de tarefas de um projeto dividido por três (denominador $=3$ ) que é indicado nesta questão de pesquisa como grupo 3 , o grupo 4 que dividiu a quantidade total de tarefas pelo denominador 4 e o grupo 5 que dividiu as tarefas pelo denominador 5. Os denominadores foram escolhidos considerando que o aumento de 1 unidade no denominador causasse impacto na divisão da quantidade de amostras de cada classe.

A Tabela 5-8 apresenta a comparação do tamanho dos conjuntos de dados por número de tarefas, commits e mudanças conjuntas selecionadas em cada projeto. Além do total, as medianas são apresentadas e comparadas com o agrupamento de dados por versões.

Percebe-se que a divisão por quantidade de tarefas, divididas em grupos de 3 , 4 e 5 partes, tem aproximadamente a metade de tarefas em relação ao agrupamento por versão. Essa diferença ocorre porque a quantidade total de tarefas nos projetos é dividida por um valor fixo e a última divisão é usada somente para teste. Por exemplo, a divisão com o denominador 3 tem dois conjuntos de treinamentos e testes, as divisões por quatro têm três conjuntos de treinamentos e testes, e a divisão por cinco têm quatro conjuntos de treinamentos e testes. Nesse caso, quanto maior a quantidade de divisões efetuadas no total de tarefas, menor será a quantidade de tarefas que será desconsiderada por não existir tarefas futuras para construir o conjunto de testes.

Ainda é possível observar, na Tabela 5-8, que a divisão por denominadores possui uma menor quantidade de commits e mudanças conjuntas para a construção dos conjuntos de treinamento e teste. É importante ressaltar que as mudanças conjuntas de cada conjunto de testes são diferentes, 
uma vez que o critério usado para seleção dos pares de arquivos foi baseado nos valores de suporte e confiança aplicados na segunda questão de pesquisa (QP2). Logo, quando a divisão por tarefa muda, as tarefas usadas para selecionar as mudanças conjuntas também mudam, e consequentemente, as amostras avaliadas são outras.

Tabela 5-8 Sumarização dos intervalos de dados usados para construir conjuntos de treinamento e teste.

\begin{tabular}{r|r|r|r|r|r|r}
\hline $\begin{array}{r}\text { Intervalo de } \\
\text { Dados }\end{array}$ & $\begin{array}{r}\text { \# de } \\
\text { tarefas }\end{array}$ & $\begin{array}{r}\text { Mediana de } \\
\text { tarefas por } \\
\text { projeto }\end{array}$ & $\begin{array}{r}\text { \# de } \\
\text { commits }\end{array}$ & $\begin{array}{r}\text { Mediana de } \\
\text { commits por } \\
\text { projeto }\end{array}$ & $\begin{array}{r}\text { \# mudanças } \\
\text { conjuntas } \\
\text { tarefas }>=2)\end{array}$ & $\begin{array}{r}\text { Mediana de mudanças } \\
\text { conjuntas por projeto }\end{array}$ \\
\hline Por versão & 23802 & 2242,5 & 54388 & 5369,5 & 40068 & 3250,5 \\
\hline Grupo 3 & 13523 & 1223 & 25121 & 2624,5 & 17677 & 1674 \\
\hline Grupo 4 & 15168 & 1367 & 28571 & 3027 & 19603 & 1847 \\
\hline Grupo 5 & 16117 & 1447,5 & 30632 & 3236 & 20992 & 1997,5 \\
\hline
\end{tabular}

A Tabela 5-9 apresenta a visão geral da predição comparando as predições realizadas entre as versões com as predições realizadas entre cada intervalo de dados. Da mesma forma que a primeira questão de pesquisa, foram testados os modelos contendo todas as informações contextuais e somente os modelos com as informações contextuais numéricas.

Tabela 5-9 Visão geral da predição realizada em cada intervalo de dados.

\begin{tabular}{|c|c|c|c|c|c|c|c|}
\hline $\begin{array}{r}\text { Intervalo de } \\
\text { Dados }\end{array}$ & Modelos & $\begin{array}{c}\# \text { total de } \\
\text { mudanças } \\
\text { conjuntas }\end{array}$ & $\begin{array}{r}\text { \# total de } \\
\text { mudanças sem a } \\
\text { mudança } \\
\text { conjunta } \\
\text { esperada }\end{array}$ & $\mathrm{VP}$ & $\mathrm{FP}$ & $\mathrm{FN}$ & $\mathrm{VN}$ \\
\hline Por versão & $\begin{array}{r}\text { Somente métricas } \\
\text { numéricas }\end{array}$ & 26189 & 111174 & 19746 & 10007 & 6443 & 101167 \\
\hline Por Versão & Todas as métricas & 6029 & 13940 & 5264 & 765 & 652 & 13288 \\
\hline 3 Períodos & $\begin{array}{r}\text { Somente métricas } \\
\text { numéricas }\end{array}$ & 10250 & 76345 & 3642 & 7363 & 6608 & 68982 \\
\hline 3 Períodos & Todas as métricas & 1478 & 22008 & 398 & 1080 & 1451 & 20557 \\
\hline 4 Períodos & $\begin{array}{r}\text { Somente métricas } \\
\text { numéricas }\end{array}$ & 12853 & 96565 & 4387 & 8937 & 8466 & 87628 \\
\hline 4 Períodos & Todas as métricas & 1697 & 25984 & 490 & 1207 & 1775 & 24209 \\
\hline 5 Períodos & $\begin{array}{r}\text { Somente métricas } \\
\text { numéricas }\end{array}$ & 12304 & 86267 & 4262 & 9140 & 8042 & 77127 \\
\hline 5 Períodos & Todas as métricas & 1684 & 24146 & 395 & 1289 & 1778 & 22368 \\
\hline
\end{tabular}

Verifica-se nos resultados que as divisões por quantidade de tarefas geraram menor número de amostras para o conjunto de treinamento e teste, entretanto, o desbalanceamento aumentou, reduzindo a quantidade de mudanças conjuntas em relação ao total de amostras. É possível perceber que na divisão por tarefas, as amostras de mudanças conjuntas no máximo representam $7 \%$ do total de amostras. Observando os valores da matriz de confusão (VP, FP, FN e VN), a quantidade de falsos positivos nos modelos construídos com as divisões por denominadores é sempre maior que a quantidade de verdadeiros positivos.

A Tabela 5-10 apresenta os valores de sensibilidade, precisão, medida F e MCC, além dos percentuais de acertos e o percentual de amostras de mudanças conjuntas avaliadas. É possível observar que o desempenho dos modelos que utilizam os conjuntos de dados agrupados por versões é melhor que os modelos construídos com agrupamento de dados baseado na divisão de tarefas. 
Tabela 5-10 Visão geral da técnica de predição realizada com informações contextuais em cada conjunto de dados testado

\begin{tabular}{r|r|r|r|r|r|r}
\hline $\begin{array}{r}\text { Intervalo de } \\
\text { Dados }\end{array}$ & Modelos & Sensibilidade & Precisão & Medida F & MCC & $\begin{array}{r}\text { \% de amostras com } \\
\text { mudanças conjuntas }\end{array}$ \\
\hline Por versão & $\begin{array}{r}\text { Somente métricas } \\
\text { numéricas }\end{array}$ & 0,74 & 0,66 & 0,70 & 0,63 & 18,82 \\
\hline Por Versão & Todas as métricas & 0,89 & 0,87 & 0,88 & 0,83 & 30,19 \\
\hline 3 Períodos & $\begin{array}{r}\text { Somente métricas } \\
\text { numéricas }\end{array}$ & 0,36 & 0,33 & 0,34 & 0,25 & 11,83 \\
\hline 3 Períodos & Todas as métricas & 0,22 & 0,27 & 0,24 & 0,18 & 6,29 \\
\hline 4 Períodos & $\begin{array}{r}\text { Somente métricas } \\
\text { numéricas }\end{array}$ & 0,34 & 0,33 & 0,34 & 0,24 & 11,74 \\
\hline 4 Períodos & Todas as métricas & 0,22 & 0,29 & 0,25 & 0,19 & 6,13 \\
\hline 5 Períodos & $\begin{array}{r}\text { Somente métricas } \\
\text { numéricas }\end{array}$ & 0,35 & 0,32 & 0,33 & 0,23 & 12,48 \\
\hline 5 Períodos & Todas as métricas & 0,18 & 0,23 & 0,20 & 0,14 & 6,51 \\
\hline
\end{tabular}

Observa-se que os valores de sensibilidade são muito parecidos nos três grupos, variando de 0,34 a 0,36 . O mesmo acontece com o valor da precisão que varia entre 0,32 e 0,33 quando os modelos utilizam somente as métricas numéricas. Com todas as métricas, os modelos apresentam um pior desempenho.

Apesar do percentual de acerto ser alto (acima de 80\%), a predição das mudanças conjuntas apresenta baixos valores de precisão, sensibilidade e Medida F, influenciada pelo aumento do desbalanceamento das classes, que inclui mais amostras no qual a mudança conjunta não ocorria. Desta forma, os modelos de predição baseados em informações contextuais tendem a sempre prever as amostras como sendo da classe com maior quantidade de amostras, ou seja, quando não ocorria uma mudança conjunta.

A Figura 5-10 apresenta a variação da Medida F para cada projeto. Cada uma das linhas representa um tipo de agrupamento de dados utilizado. Os agrupamentos indicados com formas geométricas (círculo, triângulo e quadrado) indicam os testes feitos com divisões de tarefas em vez de versões, respectivamente, as divisões do total de tarefas de cada projeto por um denominador (3, 4, 5). No agrupamento de dados por divisão de tarefas, são avaliados os modelos baseados em informações contextuais numéricas, uma vez que esses modelos testam uma quantidade maior de amostras. Para o agrupamento de versões são apresentados os modelos de predição baseados em todas as informações contextuais, usando somente as informações contextuais numéricas e os modelos baseados em regras de associação.

Uma vez que o gráfico de linhas representa o desempenho para cada modelo, é possível observar qual combinação de agrupamento de dados e tipo de modelo é melhor para prever mudanças conjuntas em cada projeto. Pode-se perceber que os resultados corroboram com as questões de pesquisas anteriores. Nota-se que os modelos com todas as informações contextuais têm melhores resultados em quase todos os projetos, com exceção dos projetos Hive, Solr e Camel. Nesses três projetos é recomendado usar modelos com as informações contextuais numéricas, pois os mesmos têm o menor desbalanceamento verificado entre os conjuntos de dados avaliados. Para o projeto Cassandra, é preferível usar somente os modelos de predição de mudanças conjuntas baseados em informações contextuais numéricas, visto que o esforço de coleta é menor comparado com os modelos que utilizam todas as métricas. 


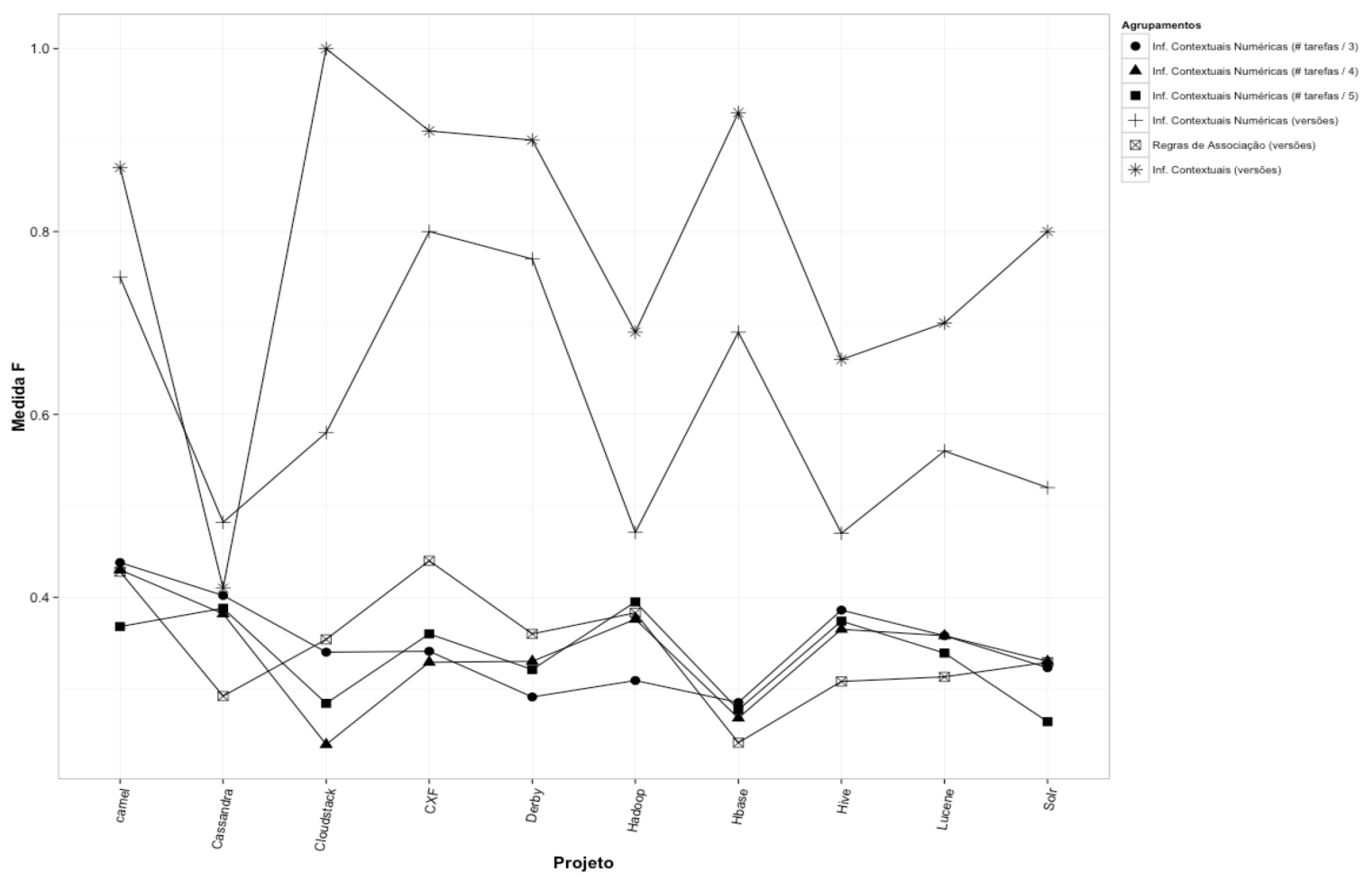

Figura 5-10. Comparação do valor da Medida F dos modelos construídos com cada agrupamento de dados por projeto.

A Figura 5-11 mostra a comparação da quantidade de mudanças conjuntas por limiar de suporte e confiança em cada agrupamento de dados. Por motivos de escala do gráfico e para ressaltar as diferenças entre os valores de suporte e confiança dos intervalos de dados, são apresentados somente os limiares de suporte igual ou acima de 3 e todos os intervalos de confiança avaliados. Percebe-se no gráfico que independentemente do modo de agrupamento - se por versão ou divisão de tarefas (grupo 3, 4 e 5) - a quantidade de amostras por limiar de suporte e confiança são proporcionais. O mesmo padrão também ocorre com o suporte igual a dois, que não é apresentado no gráfico.

Todos os modos de agrupamento apresentam uma maior quantidade de mudanças conjuntas quando o suporte é igual a três e a confiança entre $90 \%$ e $100 \%$. Nota-se, que o suporte igual a três e a confiança entre 50 e $70 \%$ e $70 \%$ e $90 \%$ obtiveram a segunda e terceira maior quantidade de mudanças conjuntas. A medida que o valor de suporte aumenta, existe uma tendência de redução da quantidade de amostras com mudanças conjuntas, conforme visto anteriormente. 


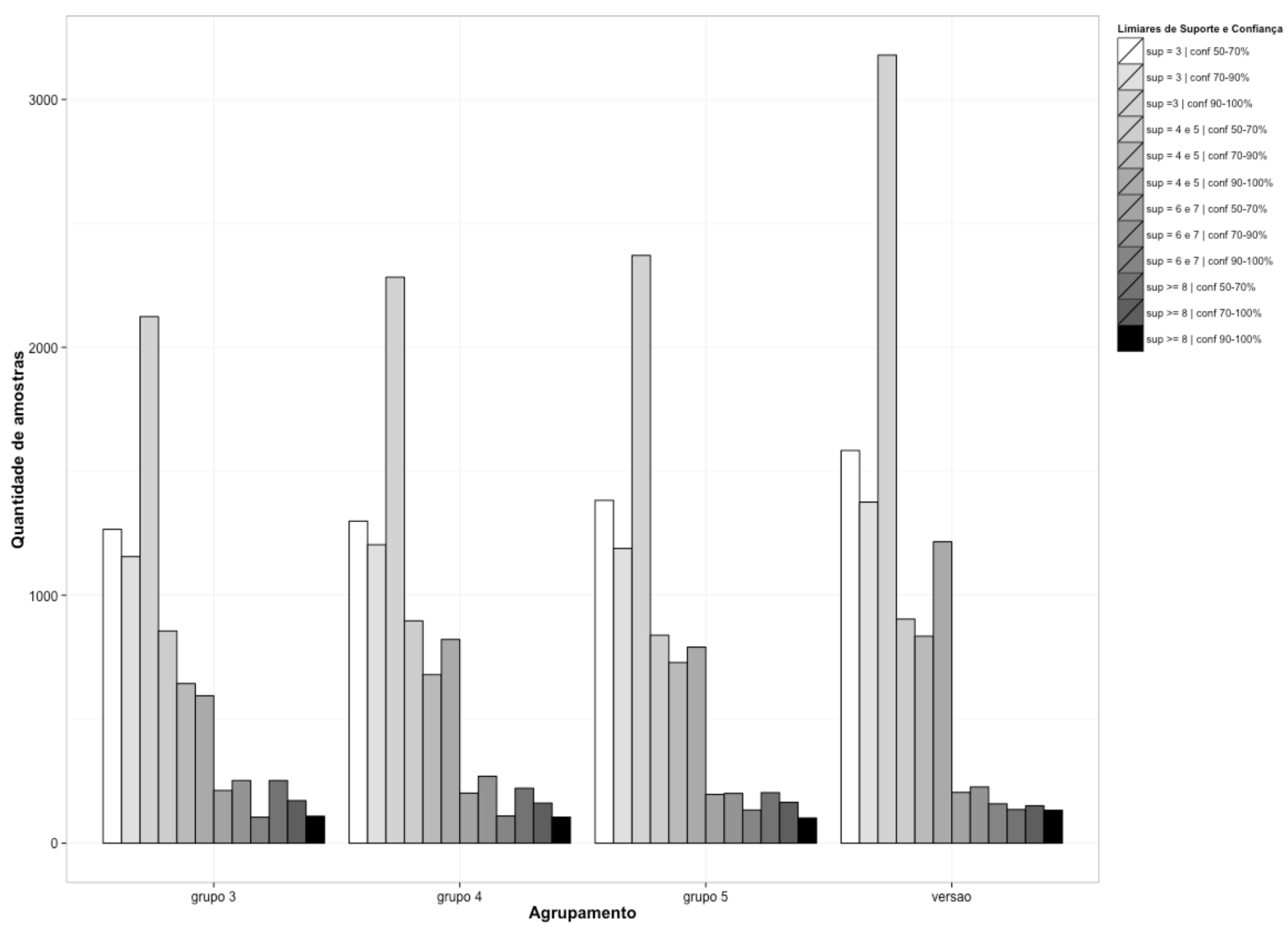

Figura 5-11. Comparação da quantidade de mudanças conjuntas por limiar de suporte e confiança em cada agrupamento de dados

Analisando os valores de mudanças conjuntas em cada limiar, nota-se que o agrupamento por versões obteve a maior quantidade de mudanças conjuntas entre os limiares. Entretanto, com suporte igual a seis com a confiança entre 70 e $90 \%$, o grupo 3 obteve 26 mudanças conjuntas a mais que as versões. Nesse mesmo limiar, o grupo 4 obteve 43 mudanças conjuntas a mais que as versões.

O agrupamento por divisão de tarefas possui uma maior quantidade de mudanças conjuntas quando o limiar do suporte foi igual a oito e a confiança entre $50 \%$ e $70 \%$. Nesse caso, os grupos 3 , 4 e 5 obtiveram respectivamente 117, 86 e 68 mudanças conjuntas a mais que as versões. Com o suporte igual a oito e a confiança entre $70 \%$ e $90 \%$, a diferença para os grupos 3, 4 e 5 foram respectivamente de 21,11 e 14 .

A Figura 5-12 mostra o desempenho da predição das mudanças conjuntas a partir dos valores da medida F para cada limiar de suporte e confiança em cada um dos agrupamentos de dados. É possível observar que os modelos baseados em informações contextuais construídos usando dados agrupados por tarefas apresentam desempenho similar ao modelo de regras de associação construídos usando dados por versões. Em qualquer limiar de suporte e confiança, os modelos baseados em informações contextuais usando os dados agrupados por versões apresentam os melhores resultados considerando os valores da medida F. 


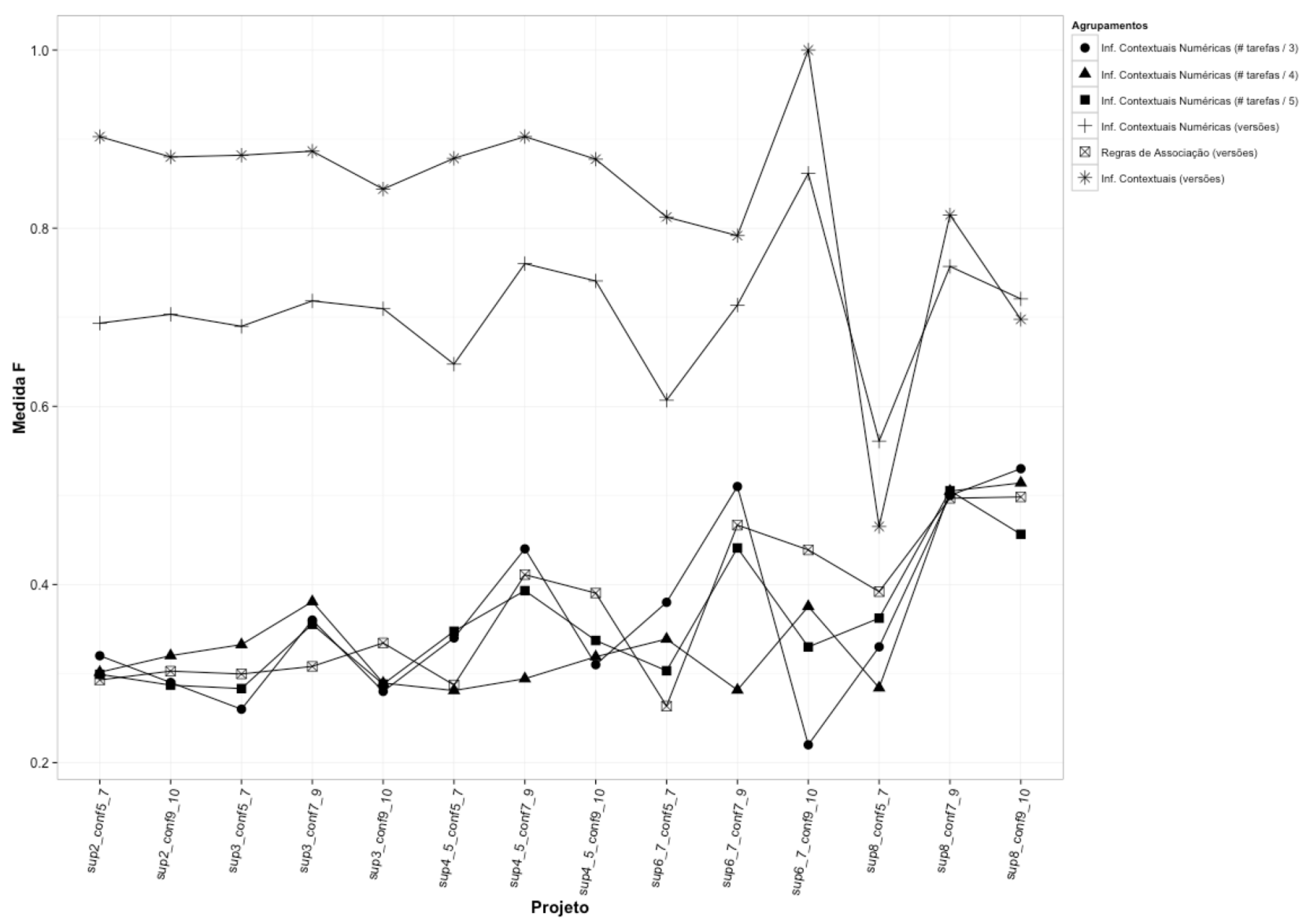

Figura 5-12. Comparação do valor da Medida F dos modelos construídos com cada agrupamento de dados por limiar de suporte e confiança.

Utilizando o teste de Cliff, observou-se um tamanho do efeito grande $(\mathrm{d}=|1,00|)$ na comparação do uso das informações contextuais agrupadas por versão com o agrupamento realizado por tarefa. Esse tamanho do efeito é observado na Figura 5-12, que mostra os valores de medida $\mathrm{F}$ do agrupamento de dados por versão. Na maioria dos valores de suporte e confiança são acima de 0,6 (linhas com pontos de ${ }^{*} \mathrm{e}+$ ), enquanto os modelos agrupados por tarefas (círculo, triângulo e quadrado) possuem valores de medida $\mathrm{F}$ na maioria das vezes inferiores ou próximos de 0,3.

Quando a comparação do tamanho do efeito é feita em relação às diferentes formas de divisão de tarefas, a única comparação significativa envolveu o grupo 5 e grupo 4. Nessa comparação, o tamanho do efeito é pequeno $(\mathrm{d}=|0,17|)$, indicando que a divisão da quantidade de tarefas em 5 grupos produz melhor desempenho. As outras comparações mostraram que não existe diferença no desempenho dos modelos.

Por fim, a comparação entre os modelos de predição baseados em informações contextuais que usam os agrupamentos de dados por tarefas com as regras de associação, indica que o tamanho do efeito do desempenho das regras de associação é pequeno $(\mathrm{d}=|0,19|)$ quando comparados com o grupo 4. A comparação das regras de associação com os grupos 3 e 5 não encontrou diferença no tamanho do efeito entre os modelos, indicando que o desempenho da predição de mudanças conjuntas é semelhante. Essa diferença menor em relação aos grupos de divisão por tarefa com as regras de associação é observada nos valores de suporte $=6$ e confiança acima de $70 \%$ e no suporte $>=8$ com confiança entre $50 \%$ e $70 \%$.

Após a análise dos resultados, os modelos baseados em versões mostraram-se melhores quando comparados com os agrupamentos por tarefas. As evidências indicam que o melhor desempenho está associado a ideia de que o contexto de uma versão é mais bem definido que o contexto capturado a partir da divisão por tarefas a partir de um denominador. 


\subsubsection{Sumarização dos resultados}

A seguir são sumarizados os resultados da terceira questão de pesquisa:

- Foram consideradas mudanças conjuntas que ocorreram em pelo menos duas tarefas (suporte igual a 2).

- Os resultados foram comparados para cada limiar de suporte e confiança. Ao todo, 14 limiares diferentes foram comparados. Os valores variaram de suporte $=2 \mid$ confiança entre 50 e $70 \%$ até suporte maior ou igual a 8 | confiança entre 90 e $100 \%$.

- A construção dos conjuntos de treinamento por versões apresenta menos desbalanceamento entre a quantidade de amostras em cada uma das classes avaliadas quando ocorre a mudança conjunta e quando não ocorre a mudança conjunta esperada. A divisão por tarefas aumentou o desbalanceamento entre as classes em $10 \%$ na média.

- O desbalanceamento afetou os resultados da predição de mudanças conjuntas. Isso pôde ser percebido a partir da comparação do desempenho (valor de Medida F) dos modelos de predição de mudanças conjuntas baseados em informações contextuais quando estes usam dados agrupados por versão ou por quantidade de tarefas.

- Os modelos com informações contextuais construídos com base nas divisões por quantidade de tarefa apresentaram desempenho similar as regras de associação executadas com dados das versões.

- Os modelos com informações contextuais construídos com dados das versões têm melhor desempenho (valores de medida F) em todos os projetos e em todos os limiares de suporte e confiança testados quando são comparados com as regras de associação e os modelos com informações contextuais com dados baseados nas divisões por quantidade de tarefas. O tamanho do efeito medido do desempenho da predição de mudanças conjuntas é grande $(\mathrm{d}=|1,00|)$.

QP3: O resultado da predição de mudanças conjuntas é melhor com o uso de versões para capturar as informações contextuais. O resultado indica que mesmo com a heterogeneidade de números de tarefas, commits e mudanças conjuntas, é melhor usar o contexto obtido nas versões em vez do contexto obtido a partir da divisão por tarefas. A divisão por tarefas aumenta o desbalanceamento entre as classes, piorando o desempenho da predição de mudanças conjuntas.

\subsection{Questão de pesquisa 4: Qual o desempenho da predição de mudanças conjuntas para os arquivos que mais mudaram nas últimas 500 tarefas do projeto?}

Para investigar a viabilidade do uso das informações contextuais na prática, avaliamos o desempenho dos modelos de predição nos arquivos que mais recentemente mudaram no histórico de cada projeto. Foram selecionados os $10 \%$ de arquivos que mais mudaram em cada projeto, por se tratar dos arquivos que mais têm sido utilizados pelos desenvolvedores para completar as tarefas recentemente em cada projeto.

O período utilizado para selecionar esses arquivos compreende as últimas 500 tarefas de cada projeto. Utilizando essas tarefas, foram construídos os conjuntos de treinamento e teste para avaliação do desempenho da predição. Os modelos foram construídos para cada par de arquivos, usando o algoritmo de aprendizagem de máquina random forest. A única diferença é que nessa questão de pesquisa, os commits coletados nas 500 tarefas foram divididos na proporção de 
$70 \% / 30 \%$ utilizando o método de seleção de amostragem holdout, sendo a maior parte e mais antiga dos commits usada para construir o conjunto de treinamento.

A Tabela 5-11 mostra a quantidade de arquivos distintos e quantos pares de arquivos foram testados em cada projeto, o total de commits que continham a mudança conjunta esperada e a quantidade de commits na qual a mudança conjunta esperada não ocorreu. No total, 213 arquivos foram avaliados em 466 mudanças conjuntas. O projeto Lucene teve a maior quantidade de arquivos distintos e pares de arquivos avaliados. O projeto Hive foi o menor projeto. A matriz de confusão apresenta o desempenho de acertos e erros obtidos durante a realização das predições.

Os resultados foram obtidos com modelos que utilizam somente as informações contextuais numéricas, uma vez que nas questões de pesquisas anteriores verificou-se que uma maior quantidade de instâncias é avaliada quando as informações contextuais numéricas são usadas. Em relação ao desempenho, é possível verificar que os testes realizados apresentam baixo valor de falso positivo (FP) e falso negativo (FN), indicando que nesses casos, poucos falsos positivos são emitidos durante a predição.

A relação entre a quantidade de pares de arquivos e a quantidade de arquivos distintos indica que alguns dos arquivos tiveram mais de uma mudança conjunta avaliada. Por exemplo, no projeto Camel, um dos arquivos avaliados mudou conjuntamente com 6 arquivos, logo 6 dos 31 pares avaliados dizem respeito a esse arquivo. Também é possível perceber que o conjunto de treinamento e teste gerados apresentam uma menor diferença entre a quantidade de commits com mudanças conjuntas esperadas e com commits no qual a mudança conjunta esperada aconteceu, diminuindo o desbalanceamento entre as classes. Nos casos do CXF e Hive, a quantidade de mudanças conjuntas e não mudanças conjuntas é muito similar, chegando a ser de somente 4 e 2 commits, respectivamente.

Tabela 5-11 Comparação da Precisão, Sensibilidade e Medida F para a predição de mudanças conjuntas (top $10 \%)$ por projeto

\begin{tabular}{|c|c|c|c|c|c|c|c|c|}
\hline Projeto & $\begin{array}{l}\text { Arquivos } \\
\text { distintos }\end{array}$ & $\begin{array}{l}\text { Quantidade } \\
\text { de Pares de } \\
\text { Arquivos }\end{array}$ & $\begin{array}{c}\text { \# total de } \\
\text { mudanças } \\
\text { conjuntas }\end{array}$ & $\begin{array}{r}\text { \# total de } \\
\text { mudanças sem } \\
\text { a mudança } \\
\text { conjunta } \\
\text { esperada }\end{array}$ & $\mathrm{TP}$ & FP & FN & $\mathrm{TN}$ \\
\hline Camel & 19 & 31 & 81 & 179 & 70 & 2 & 11 & 177 \\
\hline Cassandra & 10 & 15 & 36 & 92 & 32 & 0 & 4 & 92 \\
\hline Cloudstack & 15 & 28 & 62 & 143 & 60 & 0 & 2 & 143 \\
\hline $\mathrm{CXF}$ & 14 & 28 & 65 & 69 & 62 & 0 & 3 & 69 \\
\hline Derby & 29 & 60 & 135 & 270 & 134 & 0 & 1 & 270 \\
\hline Hadoop & 28 & 57 & 129 & 158 & 129 & 0 & 0 & 158 \\
\hline HBase & 33 & 94 & 216 & 584 & 212 & 1 & 4 & 583 \\
\hline Hive & 7 & 10 & 22 & 24 & 22 & 0 & 0 & 24 \\
\hline Lucene & 44 & 111 & 254 & 541 & 251 & 3 & 3 & 538 \\
\hline Solr & 14 & 32 & 68 & 98 & 65 & 0 & 3 & 98 \\
\hline
\end{tabular}

A Tabela 5-12 apresenta os resultados da predição de mudanças conjuntas. É possível perceber que em todos os projetos, considerando somente os $10 \%$ dos arquivos que mais mudaram, os resultados da predição superam os resultados até então apresentados nas questões de pesquisa anteriores. $O$ valor de Medida $F$ varia de 0,92 a 1,00 , indicando que os modelos nesses casos capturam a ocorrência das mudanças conjuntas com alto percentual de acerto.

É importante mencionar que esses resultados são importantes porque representam as predições realizadas nos arquivos que mais sofreram mudanças recentemente em cada projeto. Entretanto, 
esses arquivos representam uma pequena quantidade (TOP $10 \%$ dos projetos) de arquivos testados em relação às outras questões de pesquisa.

Tabela 5-12 Comparação da Precisão, Sensibilidade e Medida F para a predição de mudanças conjuntas (top $10 \%)$ por projeto

\begin{tabular}{r|r|r|r|r|r}
\hline Projeto & Precisão & Sensibilidade & Medida F & MCC & $\begin{array}{r}\text { \% Predições } \\
\text { Corretas }\end{array}$ \\
\hline Camel & 0,97 & 0,86 & 0,92 & 0,88 & 95,00 \\
\hline Cassandra & 1,00 & 0,89 & 0,94 & 0,92 & 96,88 \\
\hline Cloudstack & 1,00 & 0,97 & 0,98 & 0,98 & 99,02 \\
\hline CXF & 1,00 & 0,95 & 0,98 & 0,96 & 97,76 \\
\hline Derby & 1,00 & 0,99 & 1,00 & 0,99 & 99,75 \\
\hline Hadoop & 1,00 & 1,00 & 1,00 & 1,00 & 100,00 \\
\hline HBase & 1,00 & 0,98 & 0,99 & 0,98 & 99,38 \\
\hline Hive & 1,00 & 1,00 & 1,00 & 1,00 & 100,00 \\
\hline Lucene & 0,99 & 0,99 & 0,99 & 0,98 & 99,25 \\
\hline Solr & 1,00 & 0,96 & 0,98 & 0,96 & 98,19 \\
\hline
\end{tabular}

A Tabela 5-13 apresenta a quantidade de amostras no conjunto de treinamento usadas para construir os modelos de predição para prever mudanças conjuntas nos TOP $10 \%$ de arquivos que mudaram recentemente em cada projeto.

Observa-se que a mediana das amostras sem a mudança conjunta esperada é pelo menos o dobro do valor da mediana das amostras com a mudança conjunta esperada. Enquanto a mediana das mudanças conjuntas esperadas (primeira coluna) fica entre 4 e 5 amostras podendo alcançar no máximo 40 commits, a mediana das amostras no qual a mudança conjunta esperada não acontece (quinta coluna) fica entre 8 e 24 commits, podendo atingir no máximo 77 commits.

Os valores da distribuição das amostras indicam que não é necessária uma grande quantidade histórica de dados para predizer mudanças conjuntas para os arquivos que mais mudaram em cada projeto. Essa característica é importante pois diminui o esforço de coleta e processamento necessário para obter os dados e calcular as métricas para construir os modelos de predição baseados em informações contextuais.

Tabela 5-13 Comparação da quantidade de amostras no conjunto de treinamento em cada classe.

\begin{tabular}{|c|c|c|c|c|c|c|c|c|}
\hline \multirow[b]{2}{*}{ Projeto } & \multicolumn{4}{|c|}{ Amostras com a mudança conjunta esperada } & \multicolumn{4}{|c|}{ Amostras sem a mudança conjunta esperada } \\
\hline & Mediana & Média & Mínimo & Máximo & Mediana & Média & Mínimo & Máximo \\
\hline Camel & 5 & 7 & 2 & 21 & 12 & 21 & 2 & 77 \\
\hline Cassandra & 5 & 5 & 2 & 11 & 13 & 23 & 2 & 47 \\
\hline Cloudstack & 4 & 5 & 2 & 11 & 21 & 21 & 6 & 39 \\
\hline $\mathrm{CXF}$ & 5 & 5 & 3 & 11 & 10 & 12 & 2 & 26 \\
\hline Derby & 4 & 5 & 2 & 40 & 11 & 18 & 2 & 64 \\
\hline Hadoop & 5 & 5 & 2 & 19 & 11 & 13 & 2 & 33 \\
\hline HBase & 5 & 6 & 2 & 22 & 24 & 24 & 3 & 56 \\
\hline Hive & 3 & 4 & 2 & 8 & 8 & 11 & 5 & 23 \\
\hline Lucene & 4 & 4 & 2 & 13 & 10 & 21 & 2 & 77 \\
\hline Solr & 4 & 4 & 2 & 12 & 15 & 14 & 2 & 31 \\
\hline
\end{tabular}


QP4: Foram avaliados 1068 commits na qual a mudança conjunta ocorreu. Detectaram-se somente 37 predições erradas (6 falsos positivos e 31 falsos negativos). Na média, os modelos obtiveram medida $\mathrm{F}$ de 0,98 usando as últimas 500 tarefas de cada projeto para construir os modelos de predição baseados em informações contextuais.

\subsection{Questão de pesquisa 5: Quais informações contextuais são mais relevantes para prever mudanças conjuntas?}

Para investigar as informações contextuais mais relevantes para prever as mudanças conjuntas, dois cenários foram considerados. Primeiro, foi utilizado a função VarImp descrita no Capítulo 4 para obter o valor normalizado da importância de cada preditor para cada modelo construído durante a realização da questão de pesquisa 1 . Nesse cenário, os conjuntos de treinamentos eram construídos em uma versão, e o conjunto de teste correspondiam às mudanças ocorridas na versão consecutiva. No segundo cenário, o conjunto de dados levou em consideração somente os arquivos que mais mudaram nas últimas 500 tarefas de cada projeto (questão de pesquisa 4).

A Tabela 5-14 apresenta a importância de cada informação contextual utilizada pelos modelos de predição de mudanças conjuntas durante a avaliação de todas as versões e projetos. As cinco informações contextuais mais importantes de cada projeto são destacadas com as células com fundo escuro. Todas as informações contextuais numéricas apresentadas no Capítulo 3 foram utilizadas. As informações contextuais textuais e booleanas não foram utilizadas porque os modelos com informações contextuais numéricas testaram $85 \%$ mais amostras que os modelos baseados em todas as informações contextuais.

Tabela 5-14 Importância de cada informação contextual para prever mudanças conjuntas em cada projeto

\begin{tabular}{|c|c|c|c|c|c|c|c|c|c|c|c|c|c|c|c|c|c|}
\hline Projeto & 1 & 2 & 3 & 4 & 5 & 6 & 7 & 8 & 9 & 10 & 11 & 12 & 13 & 14 & 15 & 16 & 17 \\
\hline Camel & 24,7 & 21,5 & 41,8 & 59,5 & 3,9 & 32,0 & 22,1 & 27,0 & 23,3 & 22,2 & 24,5 & 27,2 & 22,5 & 15,1 & 50,7 & 49,9 & 63,1 \\
\hline Cassandra & 23,4 & 22,5 & 48,2 & 56,5 & 13,8 & 51,4 & 45,7 & 43,0 & 46,6 & 45,5 & 23,9 & 35,4 & 33,2 & 8,8 & 51,0 & 51,6 & 65,8 \\
\hline Cloudstack & 19,1 & 19,5 & 54,3 & 52,2 & 22,1 & 48,6 & 41,2 & 35,8 & 46,4 & 40,7 & 19,6 & 27,0 & 39,0 & 15,5 & 37,8 & 32,4 & 57,2 \\
\hline CXF & 22,5 & 21,4 & 32,8 & 58,0 & 1,5 & 21,8 & 15,7 & 17,7 & 13,6 & 16,4 & 22,9 & 17,7 & 10,6 & 13,2 & 53,3 & 52,1 & 62,2 \\
\hline Derby & 25,5 & 17,8 & 37,1 & 40,8 & 13,6 & 38,7 & 34,8 & 32,8 & 30,8 & 33,1 & 25,6 & 32,6 & 26,3 & 13,0 & 53,9 & 53,4 & 64,1 \\
\hline Hadoop & 27,8 & 23,8 & 45,5 & 50,5 & 25,0 & 50,5 & 45,4 & 44,5 & 45,9 & 45,9 & 28,7 & 40,7 & 41,4 & 11,7 & 39,9 & 39,0 & 53,5 \\
\hline Hbase & 26,5 & 24,5 & 43,7 & 49,5 & 26,7 & 47,8 & 41,7 & 43,9 & 43,0 & 44,2 & 26,6 & 39,9 & 37,6 & 12,5 & 40,2 & 39,5 & 53,6 \\
\hline Hive & 27,9 & 20,5 & 49,3 & 55,4 & 21,0 & 49,3 & 44,2 & 46,3 & 44,5 & 46,0 & 28,1 & 39,1 & 35,5 & 12,0 & 38,6 & 38,9 & 52,9 \\
\hline Lucene & 23,5 & 13,0 & 34,3 & 38,9 & 17,6 & 37,3 & 32,0 & 32,0 & 31,0 & 33,3 & 25,2 & 29,4 & 26,4 & 14,4 & 56,4 & 54,6 & 65,7 \\
\hline Solr & 21,3 & 16,4 & 48,3 & 52,9 & 15,7 & 45,2 & 34,4 & 37,7 & 41,5 & 37,2 & 23,7 & 32,5 & 27,8 & 14,2 & 51,7 & 55,2 & 76,0 \\
\hline Total & 24,2 & 20,1 & 43,5 & 51,4 & 16,1 & 42,3 & 35,7 & 36,1 & 36,7 & 36,4 & 24,9 & 32,1 & 30,0 & 13,1 & 47,3 & 46,7 & 61,4 \\
\hline
\end{tabular}

1- Número de Desenvolvedores que comentaram, 2- Número de comentadores, 3- Número de palavras, 4- Número de comentários, 5- Índice de proximidade (Closeness), 6- Índice de intermediação (Betweenness), 7- Tamanho, 8- Laços, 9- Densidade, 10 - Diâmetro, 11Eficiência, 12- Tamanho Efetivo, 13- Restrição, 14- Hierarquia, 15- Número de linhas de código excluídas, 16- Número de linhas de código adicionadas e modificadas, 17- Code Churn

Observa-se que é muito difícil definir o melhor subconjunto de informações contextuais, uma vez que a maior parte das informações contextuais tem o valor da importância entre 20 e 40 . As cinco informações contextuais mais importantes, na média, têm valores de importância superiores a 43. Nota-se também, que o número de palavras (coluna 3), número de comentários (coluna 4), número de linhas de código excluídas (coluna 15), número de linhas de código adicionadas e modificadas (coluna 16) e o Code Churn (coluna 17) foram mais importantes, juntas, em 4 dos 10 projetos.

Os resultados obtidos sugerem que para prever mudanças conjuntas é importante analisar o número de linhas de código adicionados, modificados, removidos e o code churn. Essas informações 
contextuais foram selecionadas em 7 de 10 projetos. Também é importante observar que o tamanho da discussão, capturada pela quantidade de palavras coletadas de cada tarefa e o code churn foram as únicas informações contextuais selecionadas em todos os 10 projetos analisados.

A Tabela 5-15 apresenta a importância de cada informação contextual em cada limiar de suporte e confiança. Nota-se que os valores de importância encontrados são semelhantes aos valores encontrados nos projetos. Assim como na análise de cada projeto, a quantidade de palavras (4) e o code churn (17) foram selecionadas em todos os limiares de suporte e confiança. Em 13 dos 14 limiares, as métricas de linhas de código $(15,16$ e 17) foram as mais importantes. Também observa-se que em 8 dos 14 limiares, as informações contextuais 4, 6, 15, 16 e 17 foram as mais importantes, apresentando novamente um padrão de importância similar aos projetos.

Tabela 5-15 Importância de cada informação contextual para prever mudanças conjuntas em cada limiar de suporte e confiança

\begin{tabular}{|c|c|c|c|c|c|c|c|c|c|c|c|c|c|c|c|c|c|}
\hline $\begin{array}{l}\text { Suporte e } \\
\text { Confiança }\end{array}$ & 1 & 2 & 3 & 4 & 5 & 6 & 7 & 8 & 9 & 10 & 11 & 12 & 13 & 14 & 15 & 16 & 17 \\
\hline $\begin{array}{r}\sup 2 \\
\text { conf5_7 }\end{array}$ & 28,8 & 24,8 & 44,4 & 53,2 & 17,4 & 42,6 & 37,4 & 38,0 & 36,0 & 37,5 & 29,2 & 35,4 & 31,1 & 15,0 & 47,0 & 47,1 & 56,2 \\
\hline $\begin{array}{r}\text { sup2 } \\
\text { conf9_10 }\end{array}$ & 24,9 & 20,1 & 36,5 & 47,5 & 14,1 & 35,3 & 30,7 & 32,1 & 29,9 & 31,1 & 25,4 & 30,0 & 25,7 & 14,3 & 51,3 & 49,8 & 61,5 \\
\hline $\begin{array}{r}\text { sup3 } \\
\text { conf5_7 }\end{array}$ & 22,9 & 18,9 & 40,5 & 46,9 & 17,8 & 40,2 & 31,2 & 33,6 & 32,9 & 33,4 & 22,5 & 30,1 & 26,1 & 8,8 & 45,2 & 43,9 & 57,5 \\
\hline $\begin{array}{r}\text { sup3 } \\
\text { conf7_9 }\end{array}$ & 24,8 & 22,1 & 43,9 & 53,8 & 14,6 & 45,2 & 36,0 & 37,3 & 34,8 & 38,6 & 24,9 & 33,7 & 28,6 & 13,0 & 45,2 & 44,4 & 63,4 \\
\hline $\begin{array}{r}\text { sup3 } \\
\text { conf9_10 }\end{array}$ & 22,9 & 18,6 & 37,0 & 50,2 & 12,0 & 32,6 & 30,1 & 29,6 & 28,3 & 30,4 & 22,9 & 28,9 & 23,9 & 10,4 & 48,4 & 47,2 & 67,1 \\
\hline $\begin{array}{c}\text { sup4 } \\
\text { conf5_ }\end{array}$ & 19,7 & 17,8 & 41,3 & 53,0 & 14,9 & 41,5 & 35,0 & 36,1 & 36,5 & 34,7 & 20,5 & 32,2 & 29,4 & 5,4 & 46,0 & 43,3 & 57,5 \\
\hline $\begin{array}{c}\text { sup4 } 4-5 \\
\text { conf7_-9 }\end{array}$ & 20,5 & 20,0 & 38,2 & 49,9 & 13,5 & 39,1 & 31,0 & 31,4 & 32,0 & 33,4 & 20,1 & 29,0 & 24,3 & 9,1 & 44,4 & 46,2 & 61,9 \\
\hline $\begin{array}{c}\text { sup4_5 } \\
\text { conf9_10 }\end{array}$ & 15,6 & 17,2 & 32,4 & 45,3 & 8,9 & 37,1 & 24,7 & 23,4 & 22,9 & 24,7 & 15,6 & 21,6 & 21,1 & 7,9 & 47,3 & 50,3 & 65,3 \\
\hline $\begin{array}{c}\text { sup6_7 } \\
\text { conf5_ } 7\end{array}$ & 22,1 & 19,8 & 44,7 & 57,4 & 14,1 & 46,1 & 39,2 & 40,1 & 42,2 & 42,0 & 21,4 & 37,7 & 26,8 & 5,4 & 46,4 & 48,6 & 61,6 \\
\hline $\begin{array}{c}\text { sup6 } \\
\text { conf7_ } \\
\end{array}$ & 25,2 & 15,0 & 33,5 & 42,2 & 10,4 & 34,9 & 34,4 & 31,4 & 37,4 & 39,3 & 23,1 & 34,2 & 32,1 & 11,3 & 41,4 & 40,5 & 62,2 \\
\hline $\begin{array}{c}\text { sup6_7 } \\
\text { conf9_10 }\end{array}$ & 17,3 & 14,8 & 32,4 & 38,6 & 9,1 & 35,0 & 23,8 & 21,7 & 26,0 & 28,6 & 18,9 & 26,2 & 19,7 & 6,2 & 62,1 & 57,7 & 69,7 \\
\hline $\begin{array}{r}\sup 8 \\
\text { conf5_ } 7\end{array}$ & 15,3 & 18,3 & 44,4 & 61,0 & 22,9 & 47,7 & 41,2 & 38,2 & 42,9 & 46,8 & 15,2 & 31,9 & 35,5 & 4,1 & 49,1 & 46,7 & 65,6 \\
\hline $\begin{array}{r}\sup 8 \\
\text { conf7_ } 9\end{array}$ & 15,4 & 15,5 & 43,8 & 60,4 & 17,8 & 55,1 & 43,4 & 40,6 & 37,4 & 36,1 & 15,1 & 25,6 & 29,9 & 6,4 & 36,1 & 36,0 & 59,3 \\
\hline $\begin{array}{r}\sup 8 \\
\text { conf9_10 }\end{array}$ & 17,6 & 12,7 & 41,4 & 65,9 & 10,0 & 49,3 & 31,0 & 30,8 & 38,4 & 33,8 & 16,6 & 29,1 & 25,5 & 9,0 & 58,6 & 50,9 & 60,7 \\
\hline Total & 20,9 & 18,3 & 39,6 & 51,8 & 14,1 & 41,5 & 33,5 & 33,2 & 34,1 & 35,0 & 20,8 & 30,4 & 27,1 & 9,0 & 47,7 & 46,6 & 62,1 \\
\hline
\end{tabular}

1- Número de Desenvolvedores que comentaram, 2- Número de comentadores, 3- Número de palavras, 4- Número de comentários, 5- Índice de proximidade (Closeness), 6- Índice de intermediação (Betweenness), 7- Tamanho, 8- Laços, 9- Densidade, 10 - Diâmetro, 11 Eficiência, 12- Tamanho Efetivo, 13- Restrição, 14- Hierarquia, 15- Número de linhas de código excluídas, 16- Número de linhas de código adicionadas e modificadas, 17- Code Churn

A Tabela 5-16 apresenta a quantidade de arquivos encontrados no percentual dos $10 \%$ arquivos que mais mudaram nas últimas 500 tarefas de cada projeto, o total de informações contextuais selecionadas pelos modelos de predição construídos para prever mudanças conjuntas para esses arquivos e a média de informações usadas em cada modelo de predição.

É possível observar que essa quantidade de arquivos variou entre 10 arquivos no projeto Hive e 111 arquivos no projeto Lucene. Verifica-se também, que ao longo das execuções, os modelos 
utilizaram entre 6 e 9 informações contextuais para cada projeto. Os projetos Cassandra, CXF, Hadoop utilizaram a menor quantidade de média. Já o projeto Solr retornou a maior quantidade.

Tabela 5-16 Quantidade e Média de informações contextuais selecionadas por projeto

\begin{tabular}{r|r|r|r}
\hline Projeto & $\begin{array}{r}\text { Quantidade de } \\
\text { Arquivos (top 10\%) }\end{array}$ & $\begin{array}{r}\text { Total de informações } \\
\text { Contextuais Selecionadas }\end{array}$ & $\begin{array}{r}\text { Média de informações } \\
\text { Contextuais Selecionadas }\end{array}$ \\
\hline Camel & 31 & 223 & 7 \\
\hline Cassandra & 15 & 91 & 6 \\
\hline Cloudstack & 28 & 228 & 8 \\
\hline CXF & 28 & 157 & 6 \\
\hline Derby & 60 & 448 & 7 \\
\hline Hadoop & 57 & 353 & 7 \\
\hline HBase & 94 & 626 & 7 \\
\hline Hive & 10 & 73 & 7 \\
\hline Lucene & 111 & 744 & 9 \\
\hline Solr & 32 & 277 & 6 \\
\hline
\end{tabular}

A Tabela 5-17 apresenta o percentual de seleção em cada projeto. Para cada projeto, o maior percentual foi destacado na tabela na cor "laranja". Os demais percentuais em ordem decrescente são destacados até atingir a média de informações contextuais. Por exemplo, para o projeto Camel, a Tabela 5-16 indica que na média 7 informações contextuais foram usadas pelos modelos, portanto, na Tabela 5-17, 7 informações contextuais são destacadas. Em casos de empate, as informações contextuais com o mesmo percentual também são destacadas.

Observa-se na Tabela 5-17 que a maior concentração de seleção encontra-se nas informações contextuais 3, 4 e 5, que são referentes aos aspectos sociais de comunicação e as informações contextuais 15, 16 e 17 que dizem respeito às linhas adicionadas ou modificadas, removidas e o code churn (linhas adicionadas + linhas modificadas + linhas removidas) dos artefatos. Inclusive, o code churn, individualmente representa a maior quantidade de seleções individuais (Cassandra, CXF, Derby, Hadoop, Hbase e Lucene). Além do code churn, a informações contextual 3, com três seleções, e 4 com duas seleções foram as 3 informações contextuais mais frequentemente selecionadas nos projetos.

Nota-se que na maioria dos projetos, existe uma grande tendência de distribuição das informações contextuais, o que indica que não existe um padrão na importância e seleção das informações contextuais. Esse padrão corrobora com pesquisas anteriores que indicam que os artefatos mudam por razões diferentes (Canfora et al. 2014; Oliva e Gerosa, 2015a; Oliva et al. 2013). A única exceção observada é o projeto CXF para o qual foram usadas 4 informações contextuais (3, 15, 16 e 17) para capturar mais de $50 \%$ dos casos da ocorrência de mudanças conjuntas.

De um modo geral, com $8 \%$ de seleções dos testes executados, o code churn (17) e a quantidade de palavras (3) foram as duas informações contextuais mais selecionadas. A quantidade de linhas adicionadas (16) e índice de intermediação (Betweenness) (6) foram selecionadas em 7\% de todos os testes executados. A quantidade de desenvolvedores que modificaram os artefatos e também participaram da discussão nas tarefas (1) foi menos selecionada, com $5 \%$ das seleções. O número de usuários que comentaram (2) e o tamanho da rede social (7) também foram selecionados somente em $5 \%$ dos testes executados.

As informações contextuais de 1 a 4 representam os metadados da comunicação (MC). As métricas 5 e 6 representam o papel dos desenvolvedores na comunicação (PC). As informações contextuais 7, 8, 9 e 10 representam propriedades básicas da rede social de comunicação dos desenvolvedores (PB), enquanto as informações contextuais 11, 12, 13 e 14 representam aspectos 
estruturais da rede sociais (AE). Finalmente, 15, 16 e 17 representam os metadados das mudanças dos artefatos obtidos a partir dos commits (MM).

Tabela 5-17 Percentual de seleção de cada informação contextual em cada projeto

\begin{tabular}{r|r|r|r|r|r|r|r|r|r|r|r|r|r|r|r|r|r}
\hline Projeto & 1 & 2 & 3 & 4 & 5 & 6 & 7 & 8 & 9 & 10 & 11 & 12 & 13 & 14 & 15 & 16 & 17 \\
\hline Camel & $4 \%$ & $5 \%$ & $10 \%$ & $8 \%$ & $7 \%$ & $6 \%$ & $4 \%$ & $5 \%$ & $3 \%$ & $4 \%$ & $4 \%$ & $6 \%$ & $7 \%$ & $4 \%$ & $8 \%$ & $8 \%$ & $9 \%$ \\
\hline Cassandra & $3 \%$ & $5 \%$ & $3 \%$ & $8 \%$ & $7 \%$ & $3 \%$ & $5 \%$ & $8 \%$ & $3 \%$ & $3 \%$ & $4 \%$ & $8 \%$ & $8 \%$ & $8 \%$ & $8 \%$ & $7 \%$ & $9 \%$ \\
\hline Cloudstack & $4 \%$ & $5 \%$ & $8 \%$ & $8 \%$ & $7 \%$ & $4 \%$ & $7 \%$ & $5 \%$ & $7 \%$ & $4 \%$ & $5 \%$ & $5 \%$ & $4 \%$ & $5 \%$ & $7 \%$ & $7 \%$ & $7 \%$ \\
\hline CXF & $6 \%$ & $7 \%$ & $13 \%$ & $8 \%$ & $4 \%$ & $2 \%$ & $6 \%$ & $2 \%$ & $2 \%$ & $2 \%$ & $3 \%$ & $1 \%$ & $1 \%$ & $3 \%$ & $13 \%$ & $13 \%$ & $14 \%$ \\
\hline Derby & $5 \%$ & $5 \%$ & $6 \%$ & $7 \%$ & $7 \%$ & $6 \%$ & $5 \%$ & $6 \%$ & $6 \%$ & $2 \%$ & $5 \%$ & $6 \%$ & $7 \%$ & $6 \%$ & $7 \%$ & $7 \%$ & $9 \%$ \\
\hline Hadoop & $5 \%$ & $3 \%$ & $9 \%$ & $5 \%$ & $7 \%$ & $5 \%$ & $3 \%$ & $4 \%$ & $6 \%$ & $3 \%$ & $7 \%$ & $5 \%$ & $6 \%$ & $7 \%$ & $7 \%$ & $8 \%$ & $9 \%$ \\
\hline Hbase & $5 \%$ & $4 \%$ & $7 \%$ & $7 \%$ & $8 \%$ & $4 \%$ & $4 \%$ & $6 \%$ & $8 \%$ & $3 \%$ & $7 \%$ & $6 \%$ & $7 \%$ & $7 \%$ & $5 \%$ & $5 \%$ & $8 \%$ \\
\hline Hive & $1 \%$ & $4 \%$ & $4 \%$ & $11 \%$ & $4 \%$ & $11 \%$ & $4 \%$ & $4 \%$ & $4 \%$ & $7 \%$ & $5 \%$ & $7 \%$ & $4 \%$ & $7 \%$ & $8 \%$ & $10 \%$ & $4 \%$ \\
\hline Lucene & $4 \%$ & $4 \%$ & $7 \%$ & $5 \%$ & $7 \%$ & $3 \%$ & $4 \%$ & $7 \%$ & $5 \%$ & $4 \%$ & $8 \%$ & $8 \%$ & $6 \%$ & $8 \%$ & $5 \%$ & $5 \%$ & $9 \%$ \\
\hline Solr & $4 \%$ & $6 \%$ & $7 \%$ & $5 \%$ & $5 \%$ & $4 \%$ & $6 \%$ & $6 \%$ & $6 \%$ & $4 \%$ & $8 \%$ & $5 \%$ & $7 \%$ & $6 \%$ & $6 \%$ & $6 \%$ & $6 \%$ \\
\hline
\end{tabular}

1- Número de Desenvolvedores que comentaram, 2- Número de comentadores, 3- Número de palavras, 4- Número de comentários, 5- índice de proximidade (closeness), 6- Índice de intermediação (Betweenness), 7- Tamanho, 8- Laços, 9- Densidade, 10 - Diâmetro, 11 Eficiência, 12- Tamanho Efetivo, 13- Restrição, 14- Hierarquia, 15- Número de linhas de código excluídas, 16- Número de linhas de código adicionadas e modificadas, 17- Code Churn.

Levando em consideração esses agrupamentos de informações contextuais, os metadados da comunicação (MC), e os metadados das mudanças (MM) representam as duas principais fontes de dados. Juntas, essas informações contextuais representam $45 \%$ das seleções. No projeto CXF, esse percentual foi de $75 \%$, no projeto Lucene essas informações contextuais foram selecionadas em $40 \%$ dos pares de arquivos avaliados. Em projetos novos, essas informações contextuais seriam recomendadas como prioritárias para construir os modelos de predição de mudanças conjuntas.

\subsubsection{Comparando as melhores métricas sociais e de mudanças}

Levando em consideração os resultados apresentados na seção anterior, comparamos as três melhores métricas sociais (número de palavras, número de comentários e índice de intermediação (betweenness)) com as métricas obtidas de cada mudança (número de linhas de código excluídas, adicionadas e o code churn).

A Tabela 5-18 apresenta a comparação entre as melhores métricas sociais e de mudanças. Na média as métricas sociais obtiveram 0,56 de MCC, 0,72 de sensibilidade e 0,59 de precisão. Já as métricas calculadas a partir das mudanças obtiveram 0,60 de MCC, 0,74 de sensibilidade e 0,63 de precisão. O teste Mann-Whitney-U não mostrou diferença estatística entre os dois subconjuntos de métricas quando foram comparados os valores da Medida F. Entretanto, é possível observar um efeito de tamanho pequeno $(|\mathrm{d}|=0,19)$ nos valores de MCC a favor das métricas calculadas a partir das mudanças.

Verificou-se também que existe um tamanho de efeito pequeno $(|\mathrm{d}|=0,28$ e $|\mathrm{d}|=0,17)$ quando são comparados os valores de Medida F obtidos com os modelos de predição de mudanças conjuntas com todas as métricas numéricas com os modelos obtidos usando as métricas sociais e as métricas das mudanças. Quando o MCC é comparado verificou-se um tamanho de efeito médio (|d| $=0,33)$ na comparação de todas as métricas numéricas com as métricas sociais e efeito de tamanho pequeno $(|\mathrm{d}|=0,21)$ na comparação com as métricas calculadas a partir das mudanças. 
Tabela 5-18 Comparação da Precisão, Sensibilidade, Medida F, MCC e \% de Predições corretas para o subconjunto de métricas sociais e de mudança para a predição de mudanças conjuntas por projeto

\begin{tabular}{|c|c|c|c|c|c|c|}
\hline Projeto & Métricas & Precisão & Sensibilidade & Medida F & $\mathrm{MCC}$ & $\begin{array}{r}\% \text { Predições } \\
\text { Corretas }\end{array}$ \\
\hline Camel & Sociais & 0,67 & 0,75 & 0,70 & 0,59 & 74,72 \\
\hline Camel & Mudanças & 0,73 & 0,76 & 0,74 & 0,65 & 75,86 \\
\hline Cassandra & Sociais & 0,38 & 0,48 & 0,42 & 0,30 & 47,84 \\
\hline Cassandra & Mudanças & 0,36 & 0,46 & 0,41 & 0,27 & 46,37 \\
\hline Cloudstack & Sociais & 0,44 & 0,64 & 0,52 & 0,37 & 63,83 \\
\hline Cloudstack & Mudanças & 0,55 & 0,62 & 0,58 & 0,46 & 61,70 \\
\hline CXF & Sociais & 0,69 & 0,85 & 0,76 & 0,66 & 84,93 \\
\hline $\mathrm{CXF}$ & Mudanças & 0,74 & 0,83 & 0,78 & 0,69 & 82,74 \\
\hline Derby & Sociais & 0,63 & 0,79 & 0,70 & 0,61 & 79,17 \\
\hline Derby & Mudanças & 0,68 & 0,87 & 0,76 & 0,69 & 86,68 \\
\hline Hadoop & Sociais & 0,41 & 0,47 & 0,44 & 0,25 & 46,83 \\
\hline Hadoop & Mudanças & 0,37 & 0,44 & 0,40 & 0,19 & 44,13 \\
\hline Hbase & Sociais & 0,59 & 0,70 & 0,64 & 0,58 & 70,31 \\
\hline Hbase & Mudanças & 0,61 & 0,70 & 0,65 & 0,59 & 69,77 \\
\hline Hive & Sociais & 0,35 & 0,47 & 0,47 & 0,25 & 47,43 \\
\hline Hive & Mudanças & 0,41 & 0,55 & 0,47 & 0,34 & 54,81 \\
\hline Lucene & Sociais & 0,41 & 0,58 & 0,48 & 0,36 & 58,17 \\
\hline Lucene & Mudanças & 0,49 & 0,63 & 0,55 & 0,45 & 62,50 \\
\hline Solr & Sociais & 0,30 & 0,39 & 0,34 & 0,17 & 39,18 \\
\hline Solr & Mudanças & 0,39 & 0,44 & 0,41 & 0,26 & 43,56 \\
\hline
\end{tabular}

QP5: Os resultados apontam que o número de palavras, número de comentários, número de linhas de código excluídas, número de linhas de código adicionadas e modificadas e o Code Churn foram as informações contextuais mais importantes para prever mudanças conjuntas.

\subsection{Considerações finais}

Neste capítulo, foram apresentados os resultados obtidos com os modelos de predição construídos com base nas informações contextuais das mudanças de software. Cinco questões de pesquisa investigaram o desempenho dos modelos para prever a ocorrência de mudança conjunta para diferentes pares de arquivos.

Os resultados apresentados indicam que as informações contextuais usadas em conjunto com algoritmos de aprendizagem de máquina preveem pelo menos $75 \%$ da ocorrência das mudanças conjuntas dos 10 projetos e 129 versões avaliadas. Considerando somente os arquivos que mais frequentemente mudaram nas últimas 500 tarefas de cada projeto, foram avaliados 213 arquivos em 466 mudanças conjuntas distintas, sendo que se verificou que o desempenho dos modelos baseados em informações contextuais foi ainda melhor.

Comparados com as regras de associação, o desempenho dos modelos baseados em informações contextuais foi superior para qualquer valor de suporte e confiança. Em relação à comparação, também se observou que as regras de associação têm melhor desempenho quando os valores de 
suporte e confiança aumentam. Entretanto, esses valores são diferentes entre os projetos o que dificulta a escolha desses limiares em um cenário prático. O correto uso do limiar das regras de associação pode reduzir a quantidade de alarmes falsos emitidos por essa abordagem. É importante mencionar, que mesmo com os valores mais altos de suporte e confiança, a abordagem proposta nesta tese obteve desempenho superior de acordo com o teste estatístico de Cliff que mede o efeito de tamanho do desempenho entre as abordagens.

Os modelos de predição propostos nesta tese não dependem de limiares ou configuração prévia, uma vez que o algoritmo random forest foi utilizado com a configuração padrão. No próximo capítulo, são discutidos os resultados obtidos em relação ao estado da arte e também as possíveis implicações no aspecto prático. 


\section{Capítulo 6 Discussão}

No capítulo anterior foram apresentados os resultados de cada uma das cinco questões de pesquisa. Neste capítulo, os resultados são discutidos em relação ao estado da arte e às implicações no cenário prático.

\subsection{Como é relacionada a pesquisa no estado da arte?}

Para relacionar o estado da arte com os resultados obtidos nesta tese é apresentada uma comparação dos resultados de cada trabalho relacionado listado no Capítulo $2 \mathrm{com}$ os resultados apresentados no capítulo anterior. Cada linha da Tabela 6-1 corresponde a um trabalho relacionado. A terceira coluna apresenta os resultados obtidos pelos trabalhos relacionados. A quarta coluna apresenta os resultados obtidos nesta tese.

É possível observar que os resultados obtidos pelos modelos baseados em informações contextuais são semelhantes à literatura quando são comparados os valores da precisão, sensibilidade e medida F. É importante mencionar que a comparação foi realizada para posicionar os resultados obtidos com os resultados da literatura, uma vez que uma comparação direta sem a replicação de cada abordagem no mesmo conjunto de dados não foi realizada.

Tabela 6-1 Comparação dos trabalhos relacionados com os resultados obtidos na questão de pesquisa 1

\begin{tabular}{|c|c|c|c|}
\hline Autores & Tipo Abordagem & Resultado & $\begin{array}{l}\text { Modelos com Informações } \\
\text { contextuais }\end{array}$ \\
\hline $\begin{array}{l}\text { Hassan e Holt } \\
(2004)\end{array}$ & Heurísticas & $\begin{array}{l}\text { Precisão média de } 49 \% \text {. Sensibilidade } \\
\text { média de } 51 \% \text {. Heurísticas individuais } \\
\text { apresentaram } 86 \% \text { de sensibilidade e } \\
6 \% \text { de precisão. }\end{array}$ & $\begin{array}{l}\text { Precisão média de } 66 \% \text {. } \\
\text { Sensibilidade média de } 75 \% \text {. } \\
\text { Modelos de algumas versões. Medida } \\
\text { F de } 71 \% \text { mostra estabilidade nos } \\
\text { valores de sensibilidade e precisão. } \\
\text { Comparado com o trabalho de } \\
\text { Hassan e Holt, a medida F seria de } \\
11.22 \%\end{array}$ \\
\hline $\begin{array}{l}\text { Canfora et al. } \\
(2010)\end{array}$ & $\begin{array}{l}\text { Regra de } \\
\text { associação }+ \text { séries } \\
\text { temporais }\end{array}$ & $\begin{array}{l}\text { Medida } \mathrm{F} \text { média de } 25 \% \text { com as } \\
\text { técnicas combinadas. Maior valor de } \\
\text { medida F reportada foi } 30 \% \text { para o } \\
\text { Rhino. }\end{array}$ & A média da Medida $\mathrm{F}$ foi de $71 \%$. \\
\hline $\begin{array}{l}\text { Zimmermann et al. } \\
(2005)\end{array}$ & $\begin{array}{l}\text { Regra de } \\
\text { associação }\end{array}$ & $\begin{array}{l}\text { Precisão média de } 29 \% \text {, Sensibilidade } \\
\text { média } 33 \%\end{array}$ & $\begin{array}{l}\text { Precisão média de } \\
\text { Sensibilidade média de } 75 \% .\end{array}$ \\
\hline $\begin{array}{l}\text { Zhou et al. (Zhou et } \\
\text { al. 2008) }\end{array}$ & $\begin{array}{l}\text { Rede bayesiana } \\
\text { (frequência } \\
\text { mudanças } \\
\text { conjuntas e } \\
\text { dependência } \\
\text { estática) }\end{array}$ & $\begin{array}{l}\text { Precisão média de } 70 \% \text {, Sensibilidade } \\
\text { média } 50 \% \text {. Medida F média em } \\
\text { torno de } 58 \% \text {. }\end{array}$ & $\begin{array}{l}\text { Precisão média de } 66 \% \text {. } \\
\text { Sensibilidade média de } 75 \% \text {. A } \\
\text { média da Medida F foi de } 71 \% \text {. }\end{array}$ \\
\hline $\begin{array}{l}\text { Kagdi et al. }(2013 \text {, } \\
\text { 2010) e Gethers et } \\
\text { al. (2012) }\end{array}$ & $\begin{array}{l}\text { Acoplamento } \\
\text { evolucionário* }+ \\
\text { conceitual }+ \\
\text { acoplamento } \\
\text { dinâmico }\end{array}$ & $\begin{array}{l}\text { Medida } \mathrm{F} \text { média de } 26 \% \text {. Instâncias } \\
\text { corretamente preditas variaram de } \\
40 \% \text { a } 71 \%\end{array}$ & A média da Medida $\mathrm{F}$ foi de $71 \%$. \\
\hline
\end{tabular}




\begin{tabular}{|c|c|c|c|}
\hline $\begin{array}{l}\text { Abdeen et al. } \\
(2015)\end{array}$ & $\begin{array}{l}\text { Acoplamento } \\
\text { estrutural }+ \\
\text { acoplamento } \\
\text { conceitual }\end{array}$ & Medida F média de $42 \%$ & Medida F média de $71 \%$. \\
\hline $\begin{array}{l}\text { Sun et al. } \\
(2015)\end{array}$ & $\begin{array}{l}\text { Comparação entre } \\
\text { o acoplamento } \\
\text { evolucionário, } \\
\text { conceitual e } \\
\text { estático }\end{array}$ & $\begin{array}{l}\text { Sensibilidade média foram entre } 50 \% \\
\text { a } 63 \% \text { (valor máximo } 69 \% \text { ), e os } \\
\text { valores de precisão média ficaram } \\
\text { entre } 34 \% \text { a } 40 \% \text { (valor máximo } 45 \% \text { ) }\end{array}$ & $\begin{array}{l}\text { Precisão média de } 66 \% \text {. } \\
\text { Sensibilidade média de } 74 \% \text {. }\end{array}$ \\
\hline $\begin{array}{l}\text { Petrenko e Rajlich } \\
(2009)\end{array}$ & $\begin{array}{l}\text { Grafo de } \\
\text { Dependência e } \\
\text { Fragmentos de } \\
\text { código }\end{array}$ & Precisão média de $18.69 \%$ & Precisão média de $66 \%$. \\
\hline $\begin{array}{l}\text { Torchiano e Ricca } \\
(2010)\end{array}$ & $\begin{array}{l}\text { Processamento de } \\
\text { linguagem natural } \\
\text { nos comentários } \\
\text { dos commits e } \\
\text { descrição das } \\
\text { tarefas }\end{array}$ & $\begin{array}{l}\text { Precisão máxima de } 13.6 \% \text {, } \\
\text { sensibilidade máxima de } 96 \% \text {. Medida } \\
\text { F média de } 25 \% \text {. }\end{array}$ & Medida F média de $71 \%$. \\
\hline Jashki et al. (2008) & $\begin{array}{l}\text { Matriz de mudança } \\
\text { conjunta, grau de } \\
\text { proximidade e } \\
\text { algoritmo de } \\
\text { agrupamento. }\end{array}$ & Precisão média de $61.49 \%$. & Precisão média de $66 \%$. \\
\hline
\end{tabular}

Em relação à abordagem de construção dos modelos é importante mencionar as principais diferenças. Por exemplo, Zhou et al. (2008) utilizam um único modelo de predição para todos os arquivos. Em vez de usar as informações de cada commit, os autores sumarizam as informações coletadas em categorias (baixo, médio e grande) perdendo o contexto específico de cada commit. Nenhum outro trabalho relacionado propõe a construção de modelos de predição específicos para cada par de arquivos, como foi realizado nesta tese. Na predição de defeitos e esforço, modelos "locais" ou específicos para um conjunto de amostras já foi utilizado e apresentou resultados melhores quando comparados com modelos "globais" (Bettenburg et al., 2012; Menzies et al., 2013). Assim, nossa hipótese é que a construção de modelos específicos captura aspectos que são relevantes para cada par de arquivos, já que os arquivos não mudam conjuntamente da mesma forma com todos os arquivos do sistema durante a evolução do software.

Além da diferença na abordagem da construção dos modelos, é possível observar diferenças em termos de características coletadas (variáveis independentes) usadas pelos modelos de predição de mudanças conjuntas. A maior parte dos trabalhos relacionados (Canfora et al. 2010; Gethers et al. 2012; Kagdi et al. 2013; Zimmermann et al. 2005) baseia-se no uso de algum tipo de dependência de software para realizar as predições de mudanças conjuntas. A hipótese desses trabalhos considera que se existe alguma dependência entre dois artefatos, então os artefatos devem mudar conjuntamente. Entretanto, pesquisas recentes indicam que relação entre as mudanças conjuntas e a dependência estrutural não é tão forte quanto o esperado (Oliva e Gerosa, 2015a). Por esse fato, também optamos pela construção de modelos específicos para cada par de arquivos em vez de modelos globais.

Para realizar uma comparação dos resultados desta tese com uma abordagem usada pelos trabalhos relacionados, optou-se pelo uso de modelos baseados em regras de associação. Esse modelo foi escolhido porque a maioria dos trabalhos relacionados usaram as regras de associação para inferir a dependência de mudança com base na frequência de mudanças conjuntas obtidas a partir do histórico de commits. Comparado com as regras de associação, os modelos baseados em informações contextuais conseguiram reduzir a quantidade de falsos positivos, aumentando a precisão do modelo. Após o teste do tamanho do efeito de Cliff é possível verificar que existe grande diferença do desempenho entre os modelos baseados em informações contextuais e o modelo baseado em regras de associação.

Considerando a forma de implementação e uso dos modelos, pode-se dizer que as regras de associação utilizam uma quantidade menor de informações para realizar as predições, uma vez que é necessário coletar somente informações do histórico das modificações. Nesse aspecto, os modelos baseados em informações contextuais são mais complexos porque necessitam da coleta de múltiplas 
fontes de dados, o que demandam esforço extra de coleta e pré-processamento para associar commits às tarefas. Entretanto, esse fator pode ser mitigado se somente as informações contextuais mais importantes forem utilizadas.

Finalmente, ressalta-se que os resultados apresentados nesta tese foram obtidos após a análise de 10 projetos e 129 versões. Nenhum dos trabalhos usou uma quantidade maior de projetos e versões avaliadas nesta tese.

\subsubsection{Importância das informações contextuais}

Nesta tese, diferentemente do estado da arte, aspectos sócio-técnicos foram considerados para a construção dos modelos de predição. As informações contextuais coletadas não foram consideradas como preditores de mudanças conjuntas. A hipótese é que o contexto específico de uma mudança é importante para prever a ocorrência das mudanças conjuntas, já que os artefatos podem mudar por razões diferentes, como por exemplo, uma necessidade de refatoração, por aspectos arquiteturais, necessidades do cliente, entre outros (Dirk Beyer e Noack, 2005; Canfora et al. 2014; Oliva e Gerosa, 2015a, 2015b; Oliva et al. 2013; Shihab et al. 2012; Silva et al. 2014).

Diante do cenário complexo que envolvem as mudanças conjuntas dos artefatos, é importante considerar aspectos sociais do desenvolvimento do software, bem como hipotetizar que as mudanças conjuntas podem ocorrer por diversas razões e não só porque existem dependências entre os artefatos. Nesse sentido, é difícil afirmar as causas ou razões do porquê dois artefatos mudam. A quinta questão de pesquisa verificou a importância de cada informação contextual capturada nas mudanças conjuntas entre os artefatos.

Os resultados evidenciam que as mudanças conjuntas são associadas a diferentes dimensões do desenvolvimento de software, uma vez que não é possível determinar um único conjunto de informações contextuais relevantes, conforme pôde ser observado (Tabelas 5-15, 5-16 e 5-17). Podese dizer então que a abordagem de construção dos modelos específicos para cada par de arquivos associados às informações contextuais usadas e ao algoritmo de aprendizagem random forest produziram os resultados obtidos. Desse modo, qualquer uma dessas três características, se modificadas, podem produzir resultados diferentes dos resultados obtidos nesta tese.

Entretanto, destaca-se que diversos cenários foram avaliados nas quatro primeiras questões de pesquisa. A partir deste resultado é possível afirmar que a predição de mudanças conjuntas pode se beneficiar das informações contextuais, caracterizando esse fenômeno como multidimensional, o que adiciona uma nova perspectiva ao estado da arte que realiza a recomendação de mudanças conjuntas baseada somente na premissa que dois artefatos mudam conjuntamente porque possuem uma relação de dependência - seja ela de qualquer tipo (estática/estrutural, dinâmica, conceitual/semântica ou por mudança).

A característica multidimensional das mudanças conjuntas é, portanto, uma possível explicação para a diferença de desempenho entre os modelos baseados em informações contextuais e as regras de associação, que utilizam somente a frequência de mudança dos artefatos para identificar padrões (regras). É importante enfatizar que não foram investigadas relações de causalidade entre as mudanças conjuntas e as informações contextuais coletadas. Essa relação ou explicação do porquê dois artefatos mudam frequentemente é difícil de ser realizada, já que não é trivial obter essas informações dos desenvolvedores que realizaram as mudanças. Além disso, isso foge ao escopo desta tese, que objetivou encontrar bons preditores de mudanças conjuntas, objetivando embasar a construção de ferramentas.

Com relação às métricas mais frequentemente selecionadas é possível conjecturar sobre sua importância. O número de linhas modificadas, excluídas e o code churn são classificadas como métricas relativas ao processo de mudança (Moser et al., 2008). Durante a evolução do software, diferentes quantidades de linhas de código são adicionadas, removidas e modificadas para realizar as mudanças necessárias para completar uma tarefa. Nós conjecturamos que em cada mudança 
conjunta, o contexto que representa a mudança das linhas de código difere, ajudando a descrever o contexto de uma mudança conjunta. O uso dessas métricas foram também inspiradas na literatura. Por exemplo, essas métricas apresentaram desempenho superior às métricas de código (Rahman e Devanbu, 2013) para a predição de defeitos. Esse subconjunto de métricas é o único que pode ser usado independente da existência das tarefas, o que torna esse conjunto de métricas similar às regras de associação dado que podem ser coletados da mesma fonte de informação (controle de versão).

Em relação aos aspectos sociais, nesta tese, foram utilizadas métricas que pudessem ser coletadas da comunicação que envolve a discussão em torno das solicitações de mudanças. A escolha dessas métricas tem relação com a lei de Conway (1968) que indica relação da estrutura de comunicação com o projeto do software, e também com estudos anteriores em engenharia de software que mostram que a comunicação tem um papel chave para os modelos de predição, conforme apresentado no Capítulo 3.

O número de comentários e de palavras no relato da tarefa foram as métricas mais selecionadas e importantes dessa dimensão. Nós conjecturamos que o número de comentários e a quantidade de palavras relacionam-se com as mudanças e descrevem o contexto em que cada mudança conjunta ocorre. Por exemplo, desenvolvedores tendem a comentar e discutir em tarefas ou mudanças das quais eles podem contribuir. Neste sentido, o número de comentários é um proxy para o interesse dos desenvolvedores (Bettenburg e Hassan, 2012) ou um indicador para a dificuldade da tarefa, já que tarefas mais complexas podem demandar maior quantidade de comentários. Outro aspecto importante é que em projetos de software livre, a comunicação - neste caso representada pelo número de comentários em cada tarefa - pode ser usada para ajudar na coordenação da realização das tarefas. Assim, artefatos podem ser propensos a mudar conjuntamente com diferentes padrões na quantidade de interações entre os desenvolvedores.

O número de palavras é usado como um proxy para a complexidade da tarefa (Bettenburg e Hassan, 2012). Quanto maior a quantidade de palavras usadas para descrever cada solicitação de mudança, mais difícil pode ser a interpretação do que deve ser realizado, logo, mais difícil será para o desenvolvedor realizar as mudanças conjuntas. Assim, nós também conjecturamos que essa informação contextual é importante para identificar quando dois artefatos são mais propensos a mudar conjuntamente. Diferente do número de linhas de código adicionado, removido e do code churn, o número de comentários e o número de palavras no relato da tarefa são obtido do gerenciador de tarefa.

\subsection{Implicações práticas}

A abordagem apresentada nesta tese apresenta implicações no cenário prático que são discutidos a seguir. Várias abordagens foram propostas para prever mudanças conjuntas, entretanto, não foram encontrados estudos que avaliam ou indicam a adoção das abordagens em cenário prático (Li et al. 2012).

Dentre as possíveis razões para a não adoção no cenário prático estão a dificuldade/necessidade de parametrizar limiares, como por exemplo, determinar o que é uma dependência forte ou fraca, ou até mesmo a diferença na interpretação das dependências (Bavota et al. 2013) e a facilidade/dificuldade de replicação dessas abordagens.

Nesse sentido, os dois modelos apresentam diferentes características. Os modelos baseados em regras de associação exigem uma pré-configuração dos valores de suporte e confiança para serem utilizados o que é uma desvantagem, mas é mais simples porque necessita somente dos dados obtidos do histórico de mudanças. Os modelos baseados em informações contextuais demandam a criação de um modelo para cada par de arquivos e várias informações contextuais, um esforço que pode ser grande se considerarmos o tamanho dos projetos de software o que pode exigir inúmeras combinações de pares de arquivos. 
No que diz respeito aos limiares, pouca discussão é feita sobre a melhor forma de definir os valores de suporte e confiança. A maioria dos autores determina seus limiares com base no conjunto de dados que possui. Assim, determinar esses limiares não é uma tarefa trivial, já que que os limiares variam de projeto para projeto, e até mesmo dentro de diferentes versões de um único projeto. Por isso, Zimmermann et al. (Zimmermann et al. 2005) recomendam testar vários limiares de suporte e confiança. Muitas das ferramentas propostas na literatura, como por exemplo o ImpactMiner (Dit et al. 2014), demandam a configuração desses parâmetros ou a interpretação de parâmetros de similaridade entre classes, por exemplo.

Nesta tese, o uso de limiares não é necessário, uma vez que as informações contextuais são obtidas de cada commit e tarefa. Na questão de pesquisa 2, os resultados dos modelos construídos com informações contextuais foram sempre superiores às regras de associação em qualquer limiar de suporte e confiança. Desse modo, a abordagem proposta, sem a necessidade de configuração de qualquer parâmetro ou limiar de suporte e confiança, obteve resultados positivos em quase todos os projetos e versões avaliadas.

Outra importante preocupação em relação ao uso das abordagens de predição no cenário prático diz respeito à quantidade de recomendações falsas que levam os desenvolvedores a revisar arquivos que não são relacionados àquela mudança conjunta. A abordagem proposta nesta tese mostrou que é possível reduzir a quantidade de falso positivos e negativos. Especialmente os falsos positivos puderam ser reduzidos pela combinação das informações contextuais em conjunto com o algoritmo de aprendizagem de máquina. A grande quantidade de vezes que a ocorrência de mudanças conjuntas esperada não ocorre representa uma maior quantidade de amostras dos conjuntos de dados avaliados. Em alguns projetos, esse percentual representa $80 \%$ dos commits, e possivelmente essa é a razão que gera a quantidade de recomendações falsas das abordagens baseadas em dependências, uma vez que elas não capturam ou se preocupam em identificar quando uma mudança conjunta não ocorre.

Para as comunidades de software livre, que tendem a ser dinâmicas e aceitam contribuições esporádicas de novos desenvolvedores, os modelos de predição são construídos para ajudar desenvolvedores que têm pouca experiência e conhecimento sobre a arquitetura do software, e, consequentemente, têm mais dificuldade de saber quais artefatos mudam juntos em uma tarefa. Nesse cenário, as informações contextuais numéricas mostraram-se mais recomendadas já que elas foram usadas em uma maior quantidade de commits, o que garante uma avaliação mais ampla do uso das informações contextuais numéricas.

No ambiente empresarial, os desenvolvedores tendem a ser os mesmos por um maior período de tempo e a rotatividade da equipe de desenvolvimento é menor, as informações contextuais textuais são recomendadas, já que não haveria inconsistência no nome dos desenvolvedores que modificaram os artefatos entre as versões. Essas métricas reduziram a quantidade de falsos positivos para taxas de 15\%, enquanto as informações contextuais numéricas obtiveram falsos positivos próximos de $40 \%$. Entretanto, é importante mencionar que nos projetos testados, pela inconsistência das informações contextuais textuais diferentes nos conjuntos de treinamento e teste, muitas instâncias não foram testadas, reduzindo em $8 \%$ a quantidade de commits avaliados.

O uso de informações contextuais usadas nesta tese foi avaliado em 10 projetos de software livre hospedados na Fundação Apache. As informações contextuais foram avaliadas também separadamente, logo, é possível usar um subconjunto das informações contextuais para predizer as mudanças conjuntas. Assim, as métricas utilizadas nesta tese podem ser adicionadas ou removidas de acordo com a necessidade específica de cada empresa ou projeto de software livre. Entretanto, é possível recomendar a construção dos modelos de predição utilizando somente o número de linhas adicionadas, removidas e também calcular o code churn. Essas métricas podem ser obtidas do controle de versão, que armazena as mudanças realizadas. De acordo com a disponibilidade, o número de palavras dos requisitos/tarefas e o número de comentários podem ser adicionados nos modelos de recomendação. 


\subsubsection{Tempo de Execução}

Foi avaliado o tempo de execução das duas abordagens em dois projetos: Hbase e CXF. O Hbase foi escolhido porque tem a maior quantidade de pares de arquivos analisados entre todos os projetos. O CXF foi escolhido por ser considerado um caso médio entre os projetos quando são comparados o número de tarefas, commits e pares de arquivos analisados. A Tabela 6-2 apresenta a estatística descritiva do tempo de execução para a construção do conjunto de treinamento. O teste de desempenho de tempo foi executado 5 vezes. O valor mínimo, máximo, média e mediana foram calculados usando as 5 execuções em todas as versões de cada projeto. O valor da soma $(*)$ apresenta o tempo gasto para construir todos os conjuntos de treinamento. Foi utilizado o maior valor da soma obtido durante as 5 execuções.

Tabela 6-2 Comparação do tempo de execução dos modelos baseados em regras de associação e dos modelos baseados em informações contextuais.

\begin{tabular}{|c|c|c|c|c|c|c|c|c|c|c|c|}
\hline \multirow{3}{*}{ Projeto } & \multirow{3}{*}{$\begin{array}{l}\text { Quantidade } \\
\text { de versões }\end{array}$} & \multicolumn{10}{|c|}{ Estatística descritiva do tempo de execução medido em segundos (após 5 execuções)** } \\
\hline & & \multicolumn{5}{|c|}{$\begin{array}{c}\text { Modelos baseados } \\
\text { em informações contextuais }\end{array}$} & \multicolumn{5}{|c|}{ Modelos baseados em regras de associação } \\
\hline & & Min. & Max. & Média & Mediana & Soma* & Min. & Max. & Média & Mediana & Soma* \\
\hline Hbase & 14 & 1,59 & 355,23 & 87,27 & 23,27 & 1266,29 & 0,24 & 6,72 & 2,18 & 1,26 & 31,48 \\
\hline $\mathrm{CXF}$ & 9 & 4,18 & 15,86 & 8,72 & 8,19 & 82,24 & 0,66 & 4,28 & 2,02 & 1,82 & 18,70 \\
\hline
\end{tabular}

É possível perceber que no pior caso o tempo máximo para se obter o conjunto de treinamento é de 6 segundos no projeto Hbase e 4 segundos no projeto CXF quando as regras de associação são utilizadas. Na média, são necessários 2 segundos nos projetos Hbase e CXF. O tempo é maior nos modelos baseados em informações contextuais que demoram no máximo 355 segundos (aproximadamente 6 minutos) para construir o conjunto de treinamento em uma versão do projeto Hbase e 15 segundos no projeto CXF. Na média, são necessários 87 segundos para construir um conjunto de treinamento no projeto Hbase e 8 segundos no projeto CXF. Como discutido anteriormente, as regras de associação são mais rápidas porque o algoritmo apriori utiliza somente o histórico de commits para construir o conjunto de treinamento. Para os modelos baseados em informações contextuais as métricas da Tabela 3-5 precisam ser calculadas, logo, o tempo de processamento é maior.

O tempo para carregar o conjunto de treinamento e executar a predição para uma amostra é de 2,97 segundos nos modelos baseados em informações contextuais. Esse tempo foi calculado a partir da média dos testes executados nos projetos Hbase e CXF. Para as regras de associação o tempo é de 1,73 segundos. Nos dois modelos, é possível perceber que o tempo de resposta é inferior a 3 segundos. Esse seria o tempo de espera que um desenvolvedor deveria esperar para receber uma recomendação. A análise do tempo de execução para realizar uma predição não é uma limitação para nenhuma abordagem.

\subsection{Interação com os desenvolvedores dos projetos avaliados}

Para obter feedback dos desenvolvedores de cada comunidade de software utilizada como estudo de caso foram enviadas mensagens para a lista de discussão de cada projeto apresentando informações sobre os resultados obtidos nesta tese. O objetivo da interação foi fomentar a discussão sobre os resultados obtidos para verificar se a abordagem poderia ser útil no dia a dia dos desenvolvedores e se os resultados surpreenderam os desenvolvedores de alguma forma.

O e-mail enviado continha a quantidade geral de acertos nas predições de mudanças conjuntas, bem como, apresentava um exemplo prático da predição realizada para um par de arquivos 
específico de cada projeto. Também foram apresentadas as informações contextuais relevantes para a predição de mudanças conjuntas em cada projeto e uma página web que possibilitava a inspeção dos resultados.

A Tabela 6-3 apresenta um resumo da quantidade de acessos, a quantidade de desenvolvedores que responderam a mensagem enviada e a quantidade de trocas de mensagens realizadas com os desenvolvedores. Quinhentos e dois (502) acessos foram realizados nas páginas disponibilizadas com os resultados apresentados nesta tese. Cinquenta e nove (59) trocas de mensagens foram feitas. Vinte desenvolvedores distintos trocaram mensagens com o autor da tese. Somente dois (Camel e Hive) dos 10 projetos avaliados não responderam a mensagem encaminhada.

Tabela 6-3 Comparação dos trabalhos relacionados com os resultados obtidos na questão de pesquisa 1

\begin{tabular}{|c|c|c|c|}
\hline Projeto & Página web com os resultados & $\begin{array}{r}\text { \# de } \\
\text { Desenvolvedores }\end{array}$ & $\begin{array}{l}\text { \# troca de } \\
\text { mensagens }\end{array}$ \\
\hline Camel & http://flosscoach.com/index.php/17-cochanges/65-camel & 0 & 0 \\
\hline Cassandra & http://flosscoach.com/index.php/17-cochanges/66-cassandra & 1 & 3 \\
\hline Cloudstack & http://flosscoach.com/index.php/17-cochanges/67-cloudstack & 5 & 25 \\
\hline $\mathrm{CXF}$ & http://flosscoach.com/index.php/17-cochanges/68-cxf & 2 & 9 \\
\hline Derby & http://flosscoach.com/index.php/17-cochanges/69-derby & 6 & 2 \\
\hline Hadoop & http://flosscoach.com/index.php/17-cochanges/70-hadoop & 1 & 4 \\
\hline HBase & http://flosscoach.com/index.php/17-cochanges/71-hbase & 1 & 2 \\
\hline Hive & http://flosscoach.com/index.php/17-cochanges/72-hive & 0 & 0 \\
\hline Lucene ${ }^{*}$ & http://flosscoach.com/index.php/17-cochanges/73-lucene & 2 & 7 \\
\hline Solr $*$ & http://flosscoach.com/index.php/17-cochanges/74-solr & 2 & 7 \\
\hline
\end{tabular}

De acordo com os desenvolvedores, os modelos de predição construídos nesta tese são interessantes e podem ser úteis para os projetos, especialmente para apoiar os desenvolvedores novatos a navegar no código para completar as mudanças. Verificou-se que os desenvolvedores discordam quando foi dito que a abordagem poderia auxiliar durante a revisão de código, já que desenvolvedores experientes sabem quais arquivos mudam juntos em uma tarefa. Essa afirmação pode ser percebida por uma mensagem recebida do projeto CXF “...Bem, desenvolvedores antigos usualmente sabem quais arquivos são relacionados, mas eu concordo com Chris [nome fictício] que pode ser útil para ajudar novatos a navegar [nas classes] no projeto".

Além de ajudar os novatos, os desenvolvedores do Cloudstack sugeriram o uso da abordagem durante a fase de construção de testes de unidade ou integração. Projetos novos como o Cloudstack têm utilizado a prática de TDD - Test Driven Development no qual os desenvolvedores primeiro implementam os casos de teste e depois escrevem o código para completar a mudança de modo que os testes sejam também aceitos. Nesse caso, os modelos de predição podem ser utilizados para encontrar os objetos para serem utilizados na construção dos casos de teste. Interessante observar também, que recentemente fatores humanos têm sido associados à construção de casos de testes, o que também indica que os fatores sociais são importantes no contexto de testes de software (Prado et al. 2015).

Com relação às informações contextuais, os desenvolvedores ficaram surpresos com os resultados, já que é comum mudar artefatos que têm dependências entre arquivos ou que pelo menos estejam no mesmo pacote. Desse modo, o fato da tese não usar essas informações causou surpresa aos desenvolvedores.

Quando questionados se é comum os desenvolvedores recorrerem à documentação, depuração e às dependências estruturais entre os artefatos para realizar as mudanças, um desenvolvedor do projeto Derby afirmou “...sim, eu concordo que é o jeito normal. Também pode ser por meio da revisão do código, testes e mensagens do compilador. Se sua ideia é usar as mudanças do histórico 
como você descreveu, e alguma ferramenta avisar os desenvolvedores quando eles estão fazendo um certo tipo de mudança, e então sugerir outras relacionadas... Eu penso que é uma ideia interessante". Um outro desenvolvedor do Derby completou dizendo "Em geral, esta ferramenta poderia ser muito útil para capturar casos nos quais você não tem dependências explícitas entre arquivos e componentes".

Além de questionar as aplicações práticas da pesquisa nas suas comunidades e dar sugestões de uso, os desenvolvedores também discutiram os exemplos de mudanças conjuntas apresentados na mensagem enviada para cada projeto. Isso ocorreu nos projetos Lucene, Solr, Derby, CXF e Cassandra. O exemplo mais interessante é relacionado ao projeto Lucene/Solr no qual dois desenvolvedores discutiram as eventuais razões associadas às mudanças conjuntas entre "lucene/index/IndexWriter.java" e "lucene/index/StandardDirectoryReader.java".

Outro fato interessante é que um desenvolvedor dos projetos Lucene/Solr inspecionou os resultados apresentados identificando casos que os modelos de predição capturaram commits envolvendo mudanças nos dois projetos ao mesmo tempo. Nesses casos, o desenvolvedor sugeriu que é interessante fazer a predição "entre projetos", especialmente verificando quando commits em um projeto podem "causar ou demandar" mudanças em um subprojeto associado, como é o caso do Lucene, que depende do Solr.

Os desenvolvedores do projeto Lucene/Solr também alertaram para efeitos de "heavy commits", que contêm muitos arquivos e que são feitos de uma única vez. Essa ameaça à validade é também discutida na literatura como "tangled commits" (já discutida no Cap. 4) e tem relação com os hábitos de commit praticados por uma comunidade ou desenvolvedor. Para reduzir esse efeito os commits com mais de 20 arquivos foram removidos, bem como, só foram considerados commits associados a uma tarefa (issue), que normalmente é descrito a partir de um problema (defeito) ou necessidade de um novo requisito.

Além das sugestões, os desenvolvedores discutiram e apontaram uma limitação da abordagem construída nesta tese. Existem casos em que um novo arquivo pode ser criado e a ausência de histórico inviabilizaria a construção dos modelos de predição. Durante a discussão do problema um desenvolvedor do Cloudstack sugeriu usar o histórico dos arquivos do mesmo pacote para construir modelos de predição para novos arquivos. Segundo esse desenvolvedor, arquivos de um mesmo pacote podem ter "um contexto semelhante" e ser útil para ajudar nos casos que não existe histórico suficiente para construir o modelo de aprendizagem.

Para finalizar, os desenvolvedores sugeriram formas de implementar uma ferramenta para os desenvolvedores, por exemplo, como um plug-in integrado ao ambiente de desenvolvimento de software ou uma ferramenta similar ao Maven que em tempo de compilação pode realizar as predições e alertar os desenvolvedores sobre os artefatos propensos a mudar conjuntamente. 


\section{Capítulo 7 Conclusão}

A predição de mudanças conjuntas tem sido utilizada para apoiar os desenvolvedores enquanto trabalham para concluir uma determinada tarefa (Bohner e Arnold, 1996; Zimmermann et al. 2005) notificando os desenvolveres sobre arquivos que são mais propensos a mudar conjuntamente, já que desenvolvedores precisam mudar os artefatos para evoluir ou manter o software (D'Ambros et al. 2006; Hassan e Holt, 2004; Kagdi et al. 2013; Shihab et al. 2013).

A maioria dessas propostas é baseada no uso de algum tipo de dependência de software inferida pela análise estática (Briand et al. 1999) ou dinâmica do código (Orso et al. 2004), dependência de mudanças (Canfora et al. 2010; Gall et al. 1998; Ying et al. 2004; Zimmermann et al. 2005), e análise semântica/conceitual do código fonte (Kagdi et al. 2010; Revelle et al. 2011). Além disso, algumas abordagens híbridas foram propostas (Gethers et al. 2012; Hassan e Holt, 2004; Kagdi et al. 2013; Zhou et al. 2008). Entretanto, as abordagens atuais ainda sofrem com problemas relacionados a baixa acurácia, especialmente no que diz respeito à quantidade de recomendações falsas que dificultam o uso dessas abordagens na prática.

Diante do desafio de melhorar a acurácia da predição de mudança conjunta e diminuir a quantidade de recomendações falsas, esta tese investigou o uso de informações contextuais das tarefas, da comunicação e dos metadados de cada mudança para criar modelos de predição específicos para cada par de arquivos. Cinco questões de pesquisa foram investigadas para avaliar empiricamente os resultados dos modelos propostos. Primeiro foram construídos conjuntos de treinamentos e testes com base em 10 projetos hospedados na fundação Apache. Os resultados foram obtidos em 129 versões e indicaram que as informações contextuais podem prever pelo menos $88 \%$ dos commits avaliados corretamente. Isso implica que 120913 commits dos 137363 commits testados foram corretamente preditos. Do ponto de vista das mudanças conjuntas, 19746 dos 26189 commits que continham a mudança conjunta esperada foram preditas corretamente, o que equivale a $75 \%$ de predições corretas.

A segunda questão de pesquisa comparou os resultados das regras de associação com os modelos de predição baseados em informações contextuais. As regras de associação foram frequentemente usadas em técnicas de predição de mudança conjunta. Os resultados indicaram que os modelos baseados em informações contextuais têm melhor desempenho quando o valor da medida $\mathrm{F}$ é utilizado para comparar os modelos, independentemente do limiar de suporte e confiança.

A terceira questão de pesquisa investigou o impacto no modo de agrupamento dos dados para criar os conjuntos de treinamento. Como a abordagem proposta nesta tese utiliza um algoritmo de aprendizagem de máquina foi investigado o efeito do desbalanceamento nos resultados. Os resultados indicaram que separando os dados por versões, $18 \%$ das amostras representaram amostras de mudanças conjuntas, enquanto o agrupamento por quantidade de tarefas divididas por um denominador (3, 4 ou 5) aumentou o desbalanceamento das amostras, no qual as amostras com mudanças conjuntas representaram somente $6 \%$ do total de amostras avaliadas. Usando o agrupamento por versão os valores de Medida $\mathrm{F}$ para prever a ocorrência de mudanças conjuntas que foi de aproximadamente 0,70 na média, foram reduzidos a 0,35 quando os dados são agrupados por divisão na quantidade de tarefas. 
As questões 4 e 5 mostraram o esforço para o uso da abordagem em um cenário prático, avaliando a viabilidade dos modelos nos arquivos que mais mudaram nas últimas 500 tarefas de cada projeto e as informações contextuais mais relevantes para a construção dos modelos. Os modelos construídos utilizaram entre 6 e 9 informações contextuais. As principais métricas selecionadas foram o número de palavras, número de comentários e números de usuários que comentaram nas tarefas, além das métricas dos metadados das mudanças, como as linhas de código adicionadas, linhas de código removidas e o code churn. Realizando a predição de mudanças conjuntas para os $10 \%$ de arquivos que mais mudaram nas últimas 500 tarefas de cada projeto, os modelos construídos obtiveram alto valor de medida $\mathrm{F}(0,98)$, usando $70 \%$ dos dados coletados para construir o conjunto de treinamento e testando nos $30 \%$ de dados restantes.

Os modelos de predição de mudanças conjuntas baseados nas informações contextuais melhoraram a acurácia nos 10 projetos e 129 versões avaliadas quando comparados com as regras de associação. Combinar um algoritmo de aprendizagem (nesta tese o random forest) com informações contextuais coletadas das tarefas, comunicação e metadados das mudanças dos arquivos para construir modelos de predição para cada par de arquivos reduz o número de falsas redomendações (\% falsos positivos) em relação ao estado da arte. Os modelos são mais simples de serem usados, pois não demandam a configuração de limiares para a sua aplicação, entretanto demandam um maior esforço de coleta de dados em relação às regras de associação. Também foi possível perceber que os modelos podem obter valores de medida $\mathrm{F}$ maiores que as regras de associação mesmo nos casos de valores pequenos de suporte e confiança. Justamente nesses casos, as regras de associação emitem maior quantidade de falsas recomendações.

A partir desses resultados, espera-se que os modelos possam ser usados em cenários práticos e possam ajudar os desenvolvedores na realização de suas tarefas diárias, especialmente em projetos de software livre, que atraem a atenção de usuários e desenvolvedores no mundo todo (Santos et al. 2013), mas que em contrapartida ainda oferecem um conjunto de barreiras para novas contribuições (Steinmacher et al. 2014), como por exemplo, a dificuldade de encontrar artefatos para serem modificados e concluir as tarefas de evolução e manutenção do software.

\subsection{Trabalhos futuros}

Durante a realização dessa tese, uma série de questões, ainda em aberto, emergiram e devem ser investigadas em trabalhos futuros.

Com relação à generalização dos resultados, é possível investigar o uso da abordagem em outras linguagens de programação. Por exemplo, em linguagens de programação que são difíceis de se obter os valores de dependências estruturais (por exemplo, linguagens de scripts). Os projetos utilizados envolveram arquivos. JAVA e XML, entretanto, a técnica proposta não é dependente de uma linguagem de programação. Nesse sentido, ela pode ser utilizada para prever mudanças conjuntas entre diferentes tipos de artefatos, e não somente código fonte. Por exemplo, como sugerido pelos desenvolvedores, a abordagem poderia ser usada para guiar os desenvolvedores durante a construção de casos de teste, no qual é necessário instanciar objetos para completar um requisito/tarefa.

O conjunto de métricas que capturaram o contexto de mudanças conjuntas foram obtidos a partir do mapeamento sistemático descrito no Capítulo 3. Entretanto, é possível estender o conjunto de informações contextuais e investigar se elas podem melhorar os resultados obtidos. Também é possível investigar a relação das informações contextuais com outros tipos de dependências, tais como estrutural, dinâmica e conceitual.

Esta tese investigou aspectos quantitativos na predição de mudanças conjuntas. Uma investigação qualitativa complementaria o entendimento do comportamento dos modelos em determinadas situações. Entender melhor as razões pelos quais alguns pares de arquivos são melhores preditos que outros ainda é uma questão em aberto e evitaria que os desenvolvedores utilizem o modelo em situações no qual alarme falsos já são esperados. 
Por fim, é necessário avaliar a abordagem em vários cenários práticos, como por exemplo, tarefas que são reabertas nos projetos. O modelo é capaz de ajudar a encontrar arquivos que poderiam mudar conjuntamente em tarefas que foram reabertas? Seria possível usar o modelo para ajudar novatos em suas primeiras tarefas? Como os modelos se comportariam em um cenário empresarial/comercial? Um estudo dessas práticas associados ao custo e esforço que podem ser reduzidos com a adoção da abordagem também é importante. 


\section{Referências Bibliográficas}

Abdeen, H., Bali, K., Sahraoui, H., Dufour, B., 2015. Learning dependency-based change impact predictors using independent change histories. Inf. Softw. Technol. 67, 220-235.

Abebe, S.L., Haiduc, S., Marcus, A., Tonella, P., Antoniol, G., 2009. Analyzing the evolution of the source code vocabulary. Proc. Eur. Conf. Softw. Maint. Reengineering, CSMR 189-198.

Alali, A., 2014. Improved Methods for Mining Software Repositories to Detect Evolutionary Couplings. Kent State University.

Alhassan, S., Çağlayan, B., Bener, A., 2010. Do more people make the code more defect prone?: Social network analysis in OSS projects. In: SEKE 2010 - Proceedings of the 22nd International Conference on Software Engineering and Knowledge Engineering. pp. 93-98.

An, L., Khomh, F., Adams, B., 2014. Supplementary bug fixes vs. re-opened bugs. In: Proceedings - 2014 14th IEEE International Working Conference on Source Code Analysis and Manipulation, SCAM 2014. pp. 205-214.

Apiwattanapong, T., Orso, A., Harrold, M.J., 2005. Efficient and precise dynamic impact analysis using execute-after sequences. In: Proc. ICSE. p. 432.

Arisholm, E., 2002. Dynamic coupling measures for object-oriented software. Proc. Eighth IEEE Symp. Softw. Metrics 33-42.

Arisholm, E., Briand, L.C., Johannessen, E.B., 2010. A systematic and comprehensive investigation of methods to build and evaluate fault prediction models. J. Syst. Softw. 83, 2-17.

Arnaoudova, V., Eshkevari, L., Oliveto, R., Gueheneuc, Y.-G., Antoniol, G., 2010. Physical and conceptual identifier dispersion: Measures and relation to fault proneness. In: 2010 IEEE International Conference on Software Maintenance. pp. 1-5.

Arnold, R.S., Bohner, S.A., 1993. Impact analysis-Towards a framework for comparison. 1993 Conf. Softw. Maint.

Bacchelli, A., D\&apos;Ambros, M., Lanza, M., 2010. Are popular classes more defect prone? In: Lecture Notes in Computer Science (Including Subseries Lecture Notes in Artificial Intelligence and Lecture Notes in Bioinformatics). pp. 59-73.

Ball, T., Kim, J., Siy, H.P., 1997. If your version control system could talk. ICSE Work. Process Model. Empir. Stud. Softw. Eng.

Bavota, G., Dit, B., Oliveto, R., Di Penta, M., Poshyvanyk, D., De Lucia, A., 2013. An empirical study on the developers' perception of software coupling. Proc. - Int. Conf. Softw. Eng. 692701.

Bell, R.M., Ostrand, T.J., Weyuker, E.J., 2011. Does Measuring Code Change Improve Fault Prediction? In: Proceedings of the 7th International Conference on Predictive Models in Software Engineering, Promise '11. ACM, New York, NY, USA, pp. 2:1-2:8.

Bell, R.M., Ostrand, T.J., Weyuker, E.J., 2013. The limited impact of individual developer data on software defect prediction. Empir. Softw. Eng. 18, 478-505.

Bennett, K.H., Rajlich, V.T.V.T., 2000. Software maintenance and evolution: a roadmap. In: 
Proceedings of the Conference on The Future of Software Engineering. pp. 73-87.

Bettenburg, N., Hassan, A.E., 2012. Studying the impact of social interactions on software quality. Empir. Softw. Eng.

Bettenburg, N., Nagappan, M., Hassan, A.E., 2012. Think locally, act globally: Improving defect and effort prediction models. In: IEEE International Working Conference on Mining Software Repositories. pp. 60-69.

Betz, S., Šmite, D., Fricker, S., Moss, A., Afzal, W., Svahnberg, M., Wohlin, C., Börstler, J., Gorschek, T., 2013. An evolutionary perspective on socio-technical congruence: The rubber band effect. In: Proceedings - 2013 3rd International Workshop on Replication in Empirical Software Engineering Research, RESER 2013. pp. 15-24.

Beyer, D., Noack, A., 2005. Clustering Software Artifacts Based on Frequent Common Changes. In: 13th International Workshop on Program Comprehension (IWPC'05). pp. 259-268.

Beyer, D., Noack, A., 2005. Clustering software artifacts based on frequent common changes. In: Proceedings - IEEE Workshop on Program Comprehension. pp. 259-268.

Bhattacharya, P., Iliofotou, M., Neamtiu, I., Faloutsos, M., 2012. Graph-based analysis and prediction for software evolution. 2012 34th Int. Conf. Softw. Eng. 419-429.

Bicer, S., Bener, A.B., Caglayan, B., 2011. Defect prediction using social network analysis on issue repositories. In: 2011 International Conference on Software and Systems Process, ICSSP 2011, Co-Located with ICSE 2011, May 21, 2011 - May 22, 2011. pp. 63-71.

Bird, C., Nagappan, N., Murphy, B., Gall, H., Devanbu, P., 2009. Putting it all together: Using socio-technical networks to predict failures. In: Proceedings - International Symposium on Software Reliability Engineering, ISSRE. pp. 109-119.

Bird, C., Nagappan, N., Murphy, B., Gall, H., Devanbu, P., 2011. Don’T Touch My Code!: Examining the Effects of Ownership on Software Quality. In: Proceedings of the 19th ACM SIGSOFT Symposium and the 13th European Conference on Foundations of Software Engineering. pp. $4-14$.

Bohner, S.A., Arnold, R.S., 1996. Software Change Impact Analysis, Aviation.

Breiman, L., 2001. Random forests. Mach. Learn. 45, 5-32.

Brézillon, P., Borges, M.R., Pino, J.A., Pomerol, J., 2004. Context-awareness in group work: Three case studies. In: International Conference on Decision Support Systems. pp. 115-124.

Briand, L.C., Labiche, Y., O’Sullivan, L., Sówka, M.M., 2006. Automated impact analysis of UML models. J. Syst. Softw. 79, 339-352.

Briand, L.C., Wust, J., Lounis, H., 1999. Using coupling measurement for impact analysis in object-orientedsystems. Proc. IEEE Int. Conf. Softw. Maint. - 1999 (ICSM'99). 'Software Maint. Bus. Chang. (Cat. No.99CB36360).

Brooks, F.P., 1975. The Mythical Man-Month. ACM SIGPLAN Not.

Çağlayan, B., Bener, A., Koch, S., 2009. Merits of using repository metrics in defect prediction for open source projects. In: Proceedings of the 2009 ICSE Workshop on Emerging Trends in Free/Libre/Open Source Software Research and Development, FLOSS 2009. pp. 31-36.

Canfora, G., Ceccarelli, M., Cerulo, L., Di Penta, M., 2010. Using multivariate time series and association rules to detect logical change coupling: An empirical study. In: IEEE International Conference on Software Maintenance, ICSM.

Canfora, G., Cerulo, L., 2005. Impact analysis by mining software and change request repositories. In: Proceedings - International Software Metrics Symposium. pp. 261-269. 
Canfora, G., Cerulo, L., Cimitile, M., Di Penta, M., 2014. How changes affect software entropy: An empirical study. Empir. Softw. Eng. 19, 1-38.

Catal, C., 2011. Software fault prediction: A literature review and current trends. Expert Syst. Appl.

Catal, C., Diri, B., 2009. A systematic review of software fault prediction studies. Expert Syst. Appl.

Cataldo, M., Mockus, A., Roberts, J.A., Herbsleb, J.D., 2009. Software dependencies, work dependencies, and their impact on failures. IEEE Trans. Softw. Eng. 35, 864-878.

Conway, M.E., 1968. How do committees invent. Datamation 14, 28-31.

D’Ambros, M., Lanza, M., Lungu, M., 2006. The evolution radar: visualizing integrated logical coupling information. In: MSR '06: Proceedings of the 2006 International Workshop on Mining Software Repositories. pp. 26-32.

D'Ambros, M., Lanza, M., Lungu, M., 2009. Visualizing co-change information with the evolution radar. IEEE Trans. Softw. Eng. 35, 720-735.

D'Ambros, M., Lanza, M., Robbes, R., 2012a. Evaluating defect prediction approaches: a benchmark and an extensive comparison. Empir. Softw. Eng. 17, 531-577.

D'Ambros, M., Lanza, M., Robbes, R., 2012b. Evaluating defect prediction approaches: A benchmark and an extensive comparison. In: Empirical Software Engineering. pp. 531-577.

Datta, S., Sindhgatta, R., Sengupta, B., 2012. Talk Versus Work: Characteristics of Developer Collaboration on the Jazz Platform. SIGPLAN Not. 47, 655-668.

De Santana, A.M., Da Silva, F.Q.B., De Miranda, R.C.G., Mascaro, A.A., Gouveia, T.B., Monteiro, C.V.F., Santos, A.L.M., 2013. Relationships between communication structure and software architecture: An empirical investigation of the Conway's Law at the Federal University of Pernambuco. In: Proceedings - 2013 3rd International Workshop on Replication in Empirical Software Engineering Research, RESER 2013. pp. 34-42.

De Souza, C.R., Quirk, S., Trainer, E., Redmiles, D.F., 2007. Supporting collaborative software development through the visualization of socio-technical dependencies. In: 2007 International ACM Conference on Supporting Group Work, GROUP'07, November 4, 2007 - November 7, 2007. pp. 147-156.

Dey, A.K., Abowd, G.D., Salber, D., 2001. A Conceptual Framework and a Toolkit for Supporting the Rapid Prototyping of Context- Aware Applications. Hum. - Comput. Interact. 16, 97-166.

Dias, M., Bacchelli, A., Gousios, G., Cassou, D., Ducasse, S., 2015. Untangling fine-grained code changes. In: 2015 IEEE 22nd International Conference on Software Analysis, Evolution, and Reengineering, SANER 2015 - Proceedings. pp. 341-350.

Dit, B.., Wagner, M.., Wen, S.., Wang, W.., Linares-Vásquez, M.., Poshyvanyk, D.., Kagdi, H.., 2014. ImpactMiner: A tool for change impact analysis. In: 36th International Conference on Software Engineering, ICSE Companion 2014 - Proceedings. pp. 540-543.

Duc Anh, N., Cruzes, D.S., Conradi, R., Ayala, C., 2011. Empirical validation of human factors in predicting issue lead time in open source projects. In: Proceedings of the 7th International Conference on Predictive Models in Software Engineering. pp. 13:1-13:10.

Dybå, T., Dybå, T., Dingsøyr, T., Dingsøyr, T., 2008. Strength of evidence in systematic reviews in software engineering. In: Proceedings of the Second ACM-IEEE International Symposium on Empirical Software Engineering and Measurement T. pp. 178-187.

Ekanayake, J., Tappolet, J., Gall, H.C., Bernstein, A., 2012. Time variance and defect prediction in software projects: Towards an exploitation of periods of stability and change as well as a 
notion of concept drift in software projects. In: Empirical Software Engineering. pp. 348-389.

Evans, J.D., 1996. Straightforward Statistics for the Behavioral Sciences. Brooks/Cole Publishing Company.

Faceli, K., Lorena, A.C., Gama, J., Carvalho, A., 2011. Intelig\{ê\}ncia Artificial: Uma Abordagem

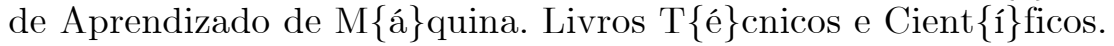

Ferenc, R., Beszedes, A., Tarkiainen, M., Gyimothy, T., 2002. Columbus - reverse engineering tool and schema for $\mathrm{C}++$. Int. Conf. Softw. Maintenance, 2002. Proceedings.

Fuks, H., Raposo, A.B., Gerosa, M.A., Lucena, C.J.P., 2005. Applying the 3C model to groupware development. Int. J. Coop. Inf. Syst. 14, 299-328.

Gall, H., Hajek, K., Jazayeri, M., 1998. Detection of logical coupling based on product release history. Proceedings. Int. Conf. Softw. Maint. (Cat. No. 98CB36272).

Gall, H., Jazayeri, M., Krajewski, J., 2003. CVS release history data for detecting logical couplings. Sixth Int. Work. Princ. Softw. Evol. 2003. Proceedings.

Gethers, M., Dit, B., Kagdi, H., Poshyvanyk, D., 2012. Integrated impact analysis for managing software changes. In: Proceedings - International Conference on Software Engineering. pp. 430-440.

Graves, T.L., Karr, A.F., Marron, U.S., Siy, H., 2000. Predicting fault incidence using software change history. IEEE Trans. Softw. Eng. 26, 653-661.

Hall, T., Beecham, S., Bowes, D., Gray, D., Counsell, S., 2011. A Systematic Review of Fault Prediction Performance in Software Engineering. IEEE Trans. Softw. Eng.

Hall, T., Beecham, S., Bowes, D., Gray, D., Counsell, S., 2012. A systematic literature review on fault prediction performance in software engineering. IEEE Trans. Softw. Eng.

Hassan, A.E., 2009. Predicting faults using the complexity of code changes. In: Proceedings International Conference on Software Engineering. pp. 78-88.

Hassan, A.E., Holt, R.C., 2004. Predicting change propagation in software systems. In: IEEE International Conference on Software Maintenance, ICSM. pp. 284-293.

He, H., Garcia, E. a., 2009. Learning from imbalanced data. IEEE Trans. Knowl. Data Eng. 21, 1263-1284.

Herzig, K., Zeller, A., 2013. The impact of tangled code changes. In: IEEE International Working Conference on Mining Software Repositories. pp. 121-130.

Horwitz, S., Reps, T., Binkley, D., 2004. Interprocedural slicing using dependence graphs. ACM SIGPLAN Not. 39, 229.

Ibrahim, W.M., Bettenburg, N., Shihab, E., Adams, B., Hassan, A.E., 2010. Should I contribute to this discussion? In: Proceedings - International Conference on Software Engineering. pp. 181190 .

Illes-Seifert, T., Paech, B., 2010. Exploring the relationship of a file's history and its faultproneness: An empirical method and its application to open source programs. Inf. Softw. Technol. 52, 539-558.

Jain, a K., Dubes, R.C., Chen, C.C., 1987. Bootstrap techniques for error estimation. IEEE Trans. Pattern Anal. Mach. Intell. 9, 628-633.

Jalali, S., Wohlin, C., 2012. Systematic literature studies: database searches vs. backward snowballing. In: Proceedings of the 2012 6th ACM_IEEE International Symposium on Empirical Software Engineering and Measurement (ESEM̄). pp. 29-38. 
Jashki, M.-A., Zafarani, R., Bagheri, E., 2008. Towards a more efficient static software change impact analysis method. ACM SIGPLANSIGSOFT Work. Progr. Anal. Softw. tools Eng. PASTE 84-90.

Jorgensen, M., Shepperd, M., 2007. A Systematic Review of Software Development Cost Estimation Studies. IEEE Trans. Softw. Eng.

Jureczko, M., Madeyski, L., 2011. A review of process metrics in defect prediction studies. Methods Appl. Comput. Sci. 1, 133-145.

Kagdi, H., Gethers, M., Poshyvanyk, D., 2013. Integrating conceptual and logical couplings for change impact analysis in software. Empir. Softw. Eng. 18, 933-969.

Kagdi, H., Gethers, M., Poshyvanyk, D., Collard, M.L., 2010. Blending conceptual and evolutionary couplings to support change impact analysis in source code. In: Proceedings Working Conference on Reverse Engineering, WCRE. pp. 119-128.

Kampstra, P., 2008. Beanplot: A Boxplot Alternative for Visual Comparison of Distributions. J. Stat. Softw. 28, 1-9.

Karus, S., Dumas, M., 2012. Code churn estimation using organisational and code metrics: An experimental comparison. Inf. Softw. Technol. 54, 203-211.

Khoshgoftaar T.M., Seliya, N.. D.D.J.., 2010. Evolutionary data analysis for the class imbalance problem. Intell. Data Anal. 14, 69-88.

Kitchenham, B., Charters, S., 2007. Guidelines for performing Systematic Literature reviews in Software Engineering Version 2.3, Keele University EBSE Technical Report EBSE200701.

Kitchenham, B., Pearl Brereton, O., Budgen, D., Turner, M., Bailey, J., Linkman, S., 2009. Systematic literature reviews in software engineering - A systematic literature review. Inf. Softw. Technol.

Kuhn, M., 2008. Building Predictive Models in R Using the caret Package. J. Stat. Softw. 28, 1-26.

Kwan, I., Cataldo, M., Damian, D., 2012. Conway's Law Revisited: The Evidence for a Task-Based Perspective. IEEE Softw.

Kwan, I., Schröter, A., Damian, D., 2011. Does socio-technical congruence have an effect on software build success? A study of coordination in a software project. IEEE Trans. Softw. Eng. 37, 307-324.

Lanza, M., Marinescu, R., Practice, O.M., 2006. Object-Oriented Metrics in Practice, Design.

Lessmann, S., Baesens, B., Mues, C., Pietsch, S., 2008. Benchmarking Classification Models for Software Defect Prediction: A Proposed Framework and Novel Findings. IEEE Trans. Softw. Eng. 34, 485-496.

Li, B., Sun, X., Leung, H., Zhang, S., 2012. A survey of code-based change impact analysis techniques. Softw. Testing, Verif. Reliab. n/a-n/a.

M M Lehman, L.A.B., 1985. Program Evolution: Processes of Software Change. Academic Press Professional, Inc., San Diego, CA, USA.

Mamone, S., 1998. The IEEE standard for software maintenance. ACM SIGSOFT Softw. Eng. Notes $19,75-76$.

Matsumoto, S., Kamei, Y., Monden, A., Matsumoto, K., Nakamura, M., 2010. An Analysis of Developer Metrics for Fault Prediction. In: Proceedings of the 6th International Conference on Predictive Models in Software Engineering, PROMISE '10. ACM, New York, NY, USA, pp. 18:1-18:9. 
McIntosh, S., Adams, B., Nagappan, M., Hassan, A.E., 2014. Mining Co-Change Information to Understand when Build Changes are Necessary. In: Proc. of the 30th Int'l Conf. on Software Maintenance and Evolution (ICSME). pp. 241-250.

Meneely, A., Williams, L., 2009. Secure open source collaboration: An empirical study of Linus' law. In: 16th ACM Conference on Computer and Communications Security, CCS'09, November 9, 2009 - November 13, 2009. pp. 453-462.

Meneely, A., Williams, L., Snipes, W., Osborne, J., 2008. Predicting failures with developer networks and social network analysis. In: Proceedings of the 16th ACM SIGSOFT International Symposium on Foundations of Software Engineering - SIGSOFT '08/FSE-16. p. 13.

Menzies, T., Butcher, A., Cok, D., Marcus, A., Layman, L., Shull, F., Turhan, B., Zimmermann, T., 2013. Local versus global lessons for defect prediction and effort estimation. IEEE Trans. Softw. Eng. 39, 822-834.

Menzies, T., Greenwald, J., Frank, A., 2007. Data Mining Static Code Attributes to Learn Defect Predictors. IEEE Trans. Softw. Eng. 33, 2-13.

Menzies, T., Kocagüneli, E., Minku, L., Peters, F., Turhan, B., 2015. Chapter 8 - Defect Prediction. In: Turhan, T.M.K.M.P. (Ed.), Sharing Data and Models in Software Engineering. Morgan Kaufmann, Boston, pp. 43-46.

Menzies, T., Turhan, B., Bener, A., Gay, G., Cukic, B., Jiang, Y., 2008. Implications of ceiling effects in defect predictors. Proc. 4th Int. Work. Predict. Model. Softw. Eng. - PROMISE ’08 47.

Michie, E.D., Spiegelhalter, D.J., Taylor, C.C., 1994. Machine Learning, Neural and Statistical Classification. Technometrics 37, 459.

Mockus, A., 2010. Organizational Volatility and its Effects on Software. In: Proceedings of the 2010 Foundations of Software Engineering Conference. pp. 117-126.

Mockus, A., Weiss, D.M., 2000. Predicting risk of software changes. Bell Labs Tech. J. 5, 169-180.

Moser, R., Pedrycz, W., Succi, G., 2008. A comparative analysis of the efficiency of change metrics and static code attributes for defect prediction. 2008 ACM/IEEE 30th Int. Conf. Softw. Eng.

Nagappan, N., Murphy, B., Basili, V.R., 2008. The Influence of Organizational Structure on Software Quality: An Empirical Case Study. Organization 521-530.

Oliva, G.A., Gerosa, M.A., 2015a. Experience Report: How do Structural Dependencies Influence Change Propagation? An Empirical Study. In: Proceedings of the 26th IEEE International Symposium on Software Reliability Engineering, ISSRE 2015.

Oliva, G.A., Gerosa, M.A., 2015b. Change Coupling Between Software Artifacts: Learning from Past Changes. In: Bird, C., Menzies, T., Zimmermann, T. (Eds.), The Art and Science of Analyzing Software Data. Morgan Kaufmann, pp. 285-324.

Oliva, G.A., Steinmacher, I., Wiese, I., Gerosa, M.A., 2013. What can commit metadata tell us about design degradation? In: Proceedings of the 2013 International Workshop on Principles of Software Evolution - IWPSE 2013. ACM Press, p. 18.

Orso, A., Apiwattanapong, T., Law, J., Rothermel, G., Harrold, M.J., 2004. An empirical comparison of dynamic impact analysis algorithms. Proceedings. 26th Int. Conf. Softw. Eng.

Page-Jones, M., 1992. Comparing Techniques by Means of Encapsulation and Connascence. Commun. ACM 35, 147-151.

Page-Jones, M., 2000. Fundamentals of Object-Oriented Design in UML, The Addison-Wesley 
Object Technology Series.

Parnas, D.L., 1994. Software aging. Proc. 16th Int. Conf. Softw. Eng.

Petersen, K., Feldt, R., Mujtaba, S., Mattsson, M., 2008. Systematic mapping studies in software engineering. In: EASE'08 Proceedings of the 12th International Conference on Evaluation and Assessment in Software Engineering. pp. 68-77.

Petrenko, M., Rajlich, V., 2009. Variable granularity for improving precision of impact analysis. IEEE Int. Conf. Progr. Compr. 10-19.

Pinzger, M., Nagappan, N., Murphy, B., 2008. Can developer-module networks predict failures? In: 16th ACM SIGSOFT International Symposium on the Foundations of Software Engineering, SIGSOFT 2008/FSE-16, November 9, 2008 - November 14, 2008. pp. 2-12.

Poshyvanyk, D., Marcus, A., 2006. The conceptual coupling metrics for object-oriented systems. In: IEEE International Conference on Software Maintenance, ICSM. pp. 469-478.

Poshyvanyk, D., Marcus, A., Ferenc, R., Gyimóthy, T., 2009. Using information retrieval based coupling measures for impact analysis. Empir. Softw. Eng. 14, 5-32.

Posnett, D., D'Souza, R., Devanbu, P., Filkov, V., 2013. Dual ecological measures of focus in software development. In: Proceedings - International Conference on Software Engineering. pp. $452-461$.

Posnett, D., Filkov, V., Devanbu, P., 2011. Ecological inference in empirical software engineering. In: 2011 26th IEEE/ACM International Conference on Automated Software Engineering, ASE 2011, Proceedings. pp. 362-371.

Powers, D.M., 2011. Evaluation: from Precision, Recall and F-measure to ROC, Informedness, Markedness and Correlation. J. Mach. Learn. Technol. 2, 37-63.

Powers, D.M.W., 2012. The problem of area under the curve. In: Proceedings of 2012 IEEE International Conference on Information Science and Technology, ICIST 2012. pp. 567-573.

Prado, M.P., Verbeek, E., Storey, M.-A., Vincenzi, A.M.R., 2015. WAP: Cognitive aspects in unit testing: The hunting game and the hunter's perspective. In: Software Reliability Engineering (ISSRE), 2015 IEEE 26th International Symposium on. pp. 387-392.

R. Leano, B.K.K. and A.S., 2014. Recommending Task Context: Automation Meets Crowd. In: International Workshop on Context in Software Development (FSE Companion). Hong Kong.

Radjenović, D., Heričko, M., Torkar, R., Živkovič, A., 2013. Software fault prediction metrics: A systematic literature review. Inf. Softw. Technol.

Rahman, F., Devanbu, P., 2013. How, and why, process metrics are better. In: Proceedings International Conference on Software Engineering. pp. 432-441.

Revelle, M., Gethers, M., Poshyvanyk, D., 2011. Using structural and textual information to capture feature coupling in object-oriented software. Empir. Softw. Eng. 16, 773-811.

Riaz, M., Mendes, E., Tempero, E., 2009. A systematic review of software maintainability prediction and metrics. In: 2009 3rd International Symposium on Empirical Software Engineering and Measurement, ESEM 2009. pp. 367-377.

Robillard, M., Walker, R., Zimmermann, T., 2010. Recommendation systems for software engineering. IEEE Softw. 27, 80-86.

Santos, C., Kuk, G., Kon, F., Pearson, J., 2013. The attraction of contributors in free and open source software projects. J. Strateg. Inf. Syst. 22, 26-45.

Schneidewind, N.F., 1987. The State of Software Maintenance. IEEE Trans. Softw. Eng. SE-13. 
Schröter, A., Aranda, J., Damian, D., 2012. To Talk or Not to Talk: Factors that Influence Communication around Changesets. Proc. ACM 2012 Conf. Comput. Support. Coop. Work CSCW '12 1317-1326.

Shihab, E., Hassan, A.E., Adams, B., Jiang, Z.M., 2012. An Industrial Study on the Risk of Software Changes. In: Proceedings of the ACM SIGSOFT 20th International Symposium on the Foundations of Software Engineering. pp. 62:1-62:11.

Shihab, E., Ihara, A., Kamei, Y., Ibrahim, W.M., Ohira, M., Adams, B., Hassan, A.E., Matsumoto, K.I., 2010. Predicting re-opened bugs: A case study on the Eclipse project. In: Proceedings Working Conference on Reverse Engineering, WCRE. pp. 249-258.

Shihab, E., Ihara, A., Kamei, Y., Ibrahim, W.M., Ohira, M., Adams, B., Hassan, A.E., Matsumoto, K.I., 2013. Studying re-opened bugs in open source software. Empir. Softw. Eng. 18, 10051042 .

Shin, Y., Meneely, A., Williams, L., Osborne, J.A., 2011. Evaluating complexity, code churn, and developer activity metrics as indicators of software vulnerabilities. IEEE Trans. Softw. Eng. $37,772-787$.

Silva, L.L., Valente, M.T., Maia, M.D. a., 2014. Assessing modularity using co-change clusters. Proc. 13th Int. Conf. Modul. - Modul. '14 49-60.

Steinmacher, I., Chaves, A.P., Conte, T.U., Gerosa, M.A., 2014. Preliminary empirical identification of barriers faced by newcomers to Open Source Software projects. In: Software Engineering (SBES), 2014 Brazilian Symposium on. pp. 51-60.

Stevens, W.P., Myers, G.J., Constantine, L.L., 1974. Structured design. IBM Syst. J. 13, 115-139.

Sun, X., Li, B., Leung, H., Li, B., Zhu, J., 2015. Static change impact analysis techniques: A comparative study. J. Syst. Softw. 109, 137-149.

Torchiano, M., Ricca, F., 2010. Impact Analysis by Means of Unstructured Knowledge in the Context of Bug Repositories. In: Proceedings of the 2010 ACM-IEEE International Symposium on Empirical Software Engineering and Measurement. pp. 47:1-47:4.

Tsay, J., Dabbish, L., Herbsleb, J., 2014. Influence of Social and Technical Factors for Evaluating Contribution in GitHub. In: Proceedings of the 36th International Conference on Software Engineering. pp. 356-366.

Webster, J., Watson, R.T., 2002. Analyzing the Past to Prepare for the Future: Writing a Literature Review. MIS Q. 26, xiii - xxiii.

Weyuker, E.J., Ostrand, T.J., Bell, R.M., 2007. Using developer information as a factor for fault prediction. In: Proceedings - ICSE 2007 Workshops: Third International Workshop on Predictor Models in Software Engineering, PROMISE'07.

Weyuker, E.J., Ostrand, T.J., Bell, R.M., 2008. Do too many cooks spoil the broth? Using the number of developers to enhance defect prediction models. Empir. Softw. Eng. 13, 539-559.

Wiese, I.S., Côgo, F.R., Ré, R., Steinmacher, I., Gerosa, M.A., 2014a. Social metrics included in prediction models on software engineering: a mapping study. In: Wagner, S., Penta, M. Di (Eds.), The 10th International Conference on Predictive Models in Software Engineering, \{PROMISE\} '14, Torino, Italy, September 17, 2014. ACM, pp. 72-81.

Wiese, I.S., Kuroda, R.T., Junior, D.N.R., Ré, R., Oliva, G.A., Gerosa, M.A., 2014b. Using Structural Holes Metrics from Communication Networks to Predict Change Dependencies. In: Baloian, N., Burstein, F., Ogata, H., Santoro, F.M., Zurita, G. (Eds.), Collaboration and Technology - 20th International Conference, \{CRIWG 2014, Santiago, Chile, September 710, 2014. Proceedings, Lecture Notes in Computer Science. Springer, pp. 294-310. 
Wiese, I.S., Kuroda, R.T., Re, R., Oliva, G.A., Gerosa, M.A., 2015. An Empirical Study of the Relation Between Strong Change Coupling and Defects Using History and Social Metrics in the Apache Aries Project. In: Open Source Systems: Adoption and Impact. Springer International Publishing, pp. 3-12.

Wiese, I.S., Kuroda, R.T., Ré, R., Oliva, G.A., Gerosa, M.A., 2014. Um estudo empírico do uso da comunicação para caracterizar a ocorrência de dependências de mudança no projeto Ruby on Rails 2nd Worksh.

Wolf, T., Schröter, A., Damian, D., Nguyen, T., 2009. Predicting build failures using social network analysis on developer communication. In: Proceedings - International Conference on Software Engineering. pp. 1-11.

Xia, X., Lo, D., Mcintosh, S., Shihab, E., Hassan, A.E., 2015. Cross-project build co-change prediction. In: 2015 IEEE 22nd International Conference on Software Analysis, Evolution, and Reengineering, SANER 2015 - Proceedings. pp. 311-320.

Ying, A.T.T., Murphy, G.C., Ng, R., Chu-Carroll, M.C., 2004. Predicting source code changes by mining change history. IEEE Trans. Softw. Eng. 30, 574-586.

Zanetti, M.S., 2012. The co-evolution of socio-technical structures in sustainable software development: Lessons from the open source software communities. In: Proceedings International Conference on Software Engineering. pp. 1587-1590.

Zhang, H., Gong, L., Versteeg, S., 2013. Predicting bug-fixing time: An empirical study of commercial software projects. In: Software Engineering (ICSE), 2013 35th International Conference on. pp. 1042-1051.

Zhou, Y., Wursch, M., Giger, E., Gall, H., Lu, J., 2008. A Bayesian Network Based Approach for Change Coupling Prediction. Fifteenth Work. Conf. Reverse Eng. Proc. 27-36 \r348.

Zimmermann, T., Diehl, S., Zeller, A., 2003. How history justifies system architecture (or not). Sixth Int. Work. Princ. Softw. Evol. 2003. Proceedings.

Zimmermann, T., Nagappan, N., Guo, P.J., Murphy, B., 2012. Characterizing and predicting which bugs get reopened. In: Proceedings - International Conference on Software Engineering. pp. $1074-1083$.

Zimmermann, T., Premraj, R., Zeller, A., 2007. Predicting Defects for Eclipse. In: Third International Workshop on Predictor Models in Software Engineering (PROMISE'07: ICSE Workshops 2007). pp. 9-9.

Zimmermann, T., Weißgerber, P., Diehl, S., Zeller, A., 2005. Mining version histories to guide software changes. IEEE Trans. Softw. Eng. 31, 429-445. 